SAND97-2396 • UC-704

Unlimited Release

Printed October 1997

\title{
Biomimetic Processing of Oriented Crystalline Ceramic Layers
}

\section{DEc o 1987 \\ OSTI}

J. Cesarano, J. A. Shelnutt

Prepared by

Sandia National Laboratories

Albuquerque, New Mexico $\$ 7185$ and Livermore, California 94550

Sandia is a multiprogramilaboratory operated by Sandia

Corporation, a Lockheed Martin Company, for the United States

Department of Energy under Contract DE-AC04-94AL85000.

Approved for public release; furtherdissemination unimited.

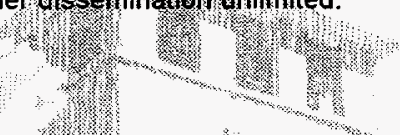

G. Sandia National Laboratories
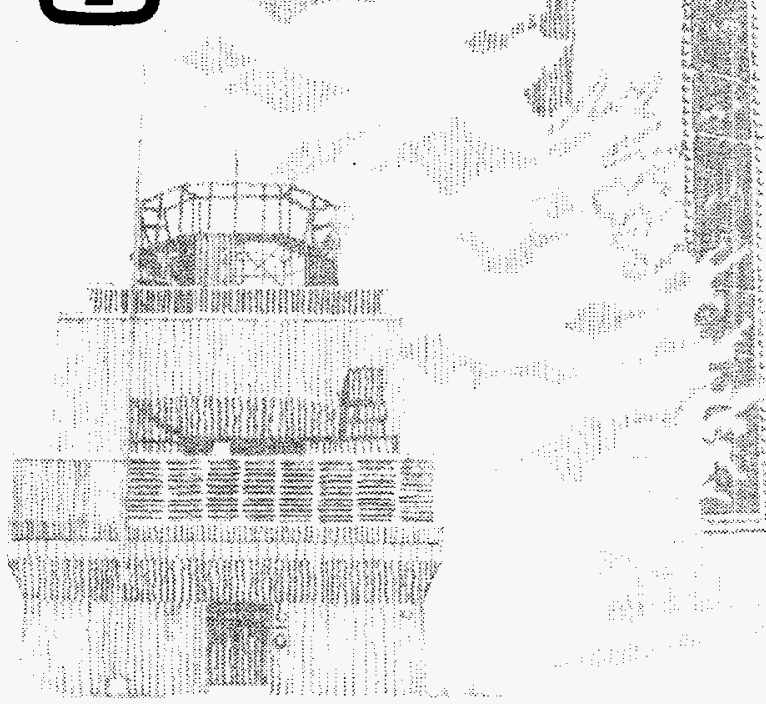
Issued by Sandia National Laboratories, operated for the United States Department of Energy by Sandia Corporation.

NOTICE: This report was prepared as an account of work sponsored by an agency of the United States Government. Neither the United States Government nor any agency thereof, nor any of their employees, nor any of their contractors, subcontractors, or their employees, makes any warranty, express or implied, or assumes any legal liability or responsibility for the accuracy, completeness, or usefulness of any information, apparatus, product, or process disclosed, or represents that its use would not infringe privately owned rights. Reference herein to any specific commercial product, process, or service by trade name, trademark, manufacturer, or otherwise, does not necessarily constitute or imply its endorsement, recommendation, or favoring by the United States Government, any agency thereof, or any of their contractors or subcontractors. The views and opinions expressed herein do not necessarily state or reflect those of the United States Government, any agency thereof, or any of their contractors.

Printed in the United States of America. This report has been reproduced directly from the best available copy.

Available to DOE and DOE contractors from

Office of Scientific and Technical Information

P.O. Box 62

Oak Ridge, TN 3783:1

Prices available from (615) 576-8401, FTS 626-8401

Available to the public from

National Technical Information Service

U.S. Department of Commerce

5285 Port Royal Rd

Springfield, VA 22161

NTIS price codes

Printed copy: A08

Microfiche copy: A01 


\section{DISCLAmizR}

Portions of this docoment mey be illegibie in electronic image prodnets. Images are produced from the best available ariginal docomenter 


\title{
Biomimetic Processing of Oriented Crystalline Ceramic Layers
}

\author{
J. Cesarano, J. A. Shelnutt \\ Materials and Process Sciences Center \\ Sandia National Laboratories \\ P. O. Box 5800 \\ Albuquerque, NM 87185-1349
}

\begin{abstract}
The aim of this project was to develop the capabilities for Sandia to fabricate self assembled Langmuir-Blodgett (LB) films of various materials and to exploit their twodimensional crystalline structure to promote the growth of oriented thin films of inorganic materials at room temperature. This includes the design and synthesis of Langmuir-active (amphiphilic) organic molecules with end groups offering high nucleation potential for various ceramics. A longer range goal is that the understanding of the underlying principles, make it feasible to use the techniques presented in this report to fabricate unique oriented films of various materials for electronic, sensor, and membrane applications. Therefore, whenever possible, work completed in this report was completed with the intention of addressing the fundamental phenomena underlying the growth of crystalline, inorganic films on template layers of highly organized organic molecules. This problem was inspired by biological processes, which often produce exquisitely engineered structures via templated growth on polymeric layers. Seashells, for example, exhibit great toughness owing to their fine brick-and-mortar structure that results from templated growth of calcium carbonate on top of layers of ordered organic proteins. A key goal in our work, therefore, is to demonstrate a positive correlation between the order and orientation of the template layer and that of the crystalline ceramic material grown upon it.

The work completed was comprised of several parallel efforts that encompassed the entire spectrum of biomimetic growth from solution. Studies were completed on seashells and the mechanisms of growth for calcium carbonate. Studies were completed on the characterization of LB films and the capability developed for the in-house fabrication of these films. Standard films of fatty acids were studied as well as novel polypeptides and porphyrins that we synthesized. Finally, studies were completed for the biomimetic growth of $\mathrm{ZnS}$ and $\mathrm{CdS}$ on LB film templates.

In summary, a new capability for facilitation of LB technology for materials development of thin film structures has been created for Sandia and it has been demonstrated that organic templates may be used for the controlled growth of inorganic sulfide films under ambient conditions. Also, the design and usefulness of synthetic polypeptides and porphyrins for LB technology has been demonstrated.
\end{abstract}




\section{SUMMARY}

Biomimetic growth of ceramic materials is a phrase that is utilized to convey the concept of utilizing functionalized organic molecular structure to facilitate and control the growth of a ceramic material within the environment of living organisms. The often used analogies are the growth of seashells or bones. The growth of these materials is directed by protein molecules that induce the precipitation of these ceramics from solutions of ions in their immediate environment. Our research attempts to simulate these growth conditions for materials potentially useful for Sandia's mission and to learn more about the underlying principles for this type of biomimetic growth.

The unique approach taken in this research involves the use of the LangmuirBlodgett method to form highly ordered template films. This technique begins with the spreading of a monomolecular film on the surface of a quiescent liquid, an example of which is a colored oil film on a water puddle. Upon adjusting the area occupied by the film using multiple barriers, such films can be forced into two-dimensional phases analogous to gas, liquid, or solid. (A fourth state of matter possessing a long-range orientational order but short-range translational order, the "hexatic" phase, is also possible.) The Langmuir film is then transferred from the liquid surface to a solid substrate by dipping a wetting substrate into the liquid through the film.

The template thus prepared is then immersed in a saturated solution of the desired ceramic material; the template it is hoped will provide a low energy nucleation site for the desired ceramic phase. If properly done, the result should be a continuous polycrystalline film whose grains are oriented in some way with the ordered substrate. Also, the growth is confined to the substrate and does not occur throughout the solution.

We were successful in demonstrating this biomimetic technique for the growth of $\mathrm{ZnS}$ and CdS on LB films. We believe that the CdS grown on films of Cd-arachidate (fatty acid) is an oriented structure. We also learned that in addition to templating provided by an organized organic layer, enzymes may be useful in controlling the local chemistry and facilitating growth where it would otherwise not occur. A detailed analysis of these results and related work is presented below in a series of papers and presentations.

The topics covered are in several chapters and include:

1. An introduction to biomirnetic processing;

2. The preparation of Langmuir-Blodgett films for biomimetic processing;

3. The chemical precipitation of metal sulfides from solution;

4. The biomimetic deposition of metal sulfide thin films;

5. A summary of our Russian collaboration for the fabrication and characterization of biomimetic films;

6. Custom-synthesized oligopeptides for biomimetic mineralization;

7. The fabrication of ordered Langmuir monolayers of acetyl-phenylalanine6aspartic acid;

8. The design and synthesis of an amphiphilic porphyrin; and,

9. A review of seashell structure and precipitation of calcium carbonate. 


\section{ACKNOWLEDGMENTS}

This work was the result of collaborations with Alan Hurd at Sandia National Laboratories, Prof. Lev Feigin and his staff at the Institute of Crystallography, Russian Academy of Science, Moscow; Prof. Gabriel Lopez at the University of New Mexico; and Prof. Gillian Bond at New Mexico Tech. Several other students and technicians are also acknowledged for their dedicated work: Ron Baker, Suzanne Paradis, Xiang Xu, Xingzhi Song, Jenifer Dean, Rachel Segalman, Eileen Burch, Hogan Martin, Luda Yanusova, Nina Stiopina, Vera Klechkovskaya, Elena Rakova.

Sandia is a multi-program laboratory operated by Sandia Corporation, a Lockheed Martin Company, for the United States Department of Energy under Contract DE-AC0494AL85000.

\section{Table of Contents}

Title

Abstract

Summary

Acknowledgments

Chapter 1: Introduction to Biomimetic Processing

Chapter 2: Preparation of Langmuir-Blodgett Films for Biomimetic Processing

Chapter 3: Chemical Precipitation of Metal Sulfides From Solution

Chapter 4: Biomimetic Deposition of Metal Sulfide Thin Films

Chapter 5: Summary of Russian Collaboration

5.1 Report on Fabrication of Langmuir-Blodgett Films on Silicon and Preliminary Characterization of the Films

5.2 Preparation and Electron Diffraction Study of PbS Films on Langmuir Layers of Fatty Acids Lead Salts

5.3 Electron Diffraction Study of CdS Films Grown on Langmuir Layers of Fatty Acid Salts: Structure and Orientation

5.4 Electron and X-ray Characterization of Langmuir-Blodgett Films and the Fabrication of Inorganic Ceramic Films on the LB Structures

5.5 Characterization of Ceramic Films Grown on Langmuir-Blodgett Films on Silicon

Chapter 6: Custom-Synthesized Oligopeptides for Biomimetic Mineralized Studies

99

Chapter 7: Fabrication of Ordered Langmuir Monolayers of Acetyl-Phenylalanine6-Aspartic Acid

Chapter 8: Design and Synthesis of an Amphiphilic Porphyrin

Chapter 9: Review of Seashell Structure and Precipitation of Calcium Carbonate

9.1 Review and Examination of Naturally Occurring and Biomimetically Prepared Ceramic Thin Films 


\section{Chapter 1}

\section{Introduction to Biomimetic Processing}

The complex composite architecture often observed in naturally biomineralized structures are generally thought to be made because of the ability of the systems to direct the nucleation and growth of the mineral crystals. An example is shown below for the layered structure of an abalone shell. Acidic proteins interact with ions from sea water to direct the growth of oriented calcium carbonate crystals. It is believed that the spatial periodicity of functional groups on the protein scaffold provide a templating mechanism for growth of the inorganic material.

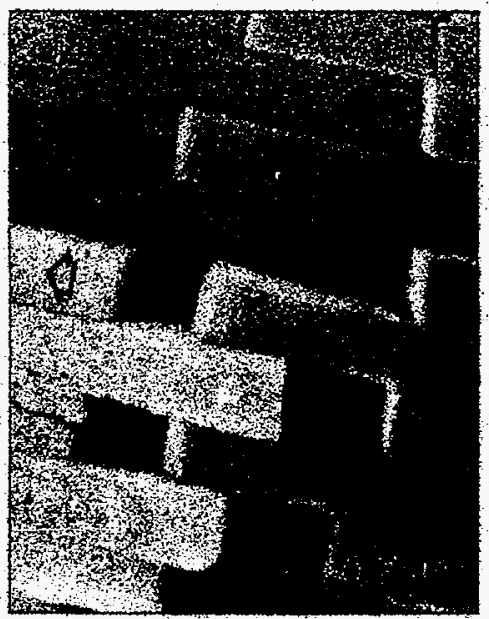

\section{Biomineralization}

- acidic proteins assembled on the hydrophobic scaffold

- nucleation and growth of inorganic crystals on organic scaffold

We are proposing that by applying Langmuir-Blodgett films of biochemicals and synthesized bio-like chemicals to substrates we will have the necessary control of chemical functionality and spatial periodicity to develop a biomimetic process to grow oriented crystalline ceramic films. LB films can have controlled spatiality at the molecule level. Precipitation of $\mathrm{CaCO}_{3}$ has already been shown to be controllable under Langmuir monolayers at the air water interface by Mann et al. However, the methodology of using the precision of LB film technology for biomimetic processing is unexplored territory. A schematic of the idea is represented below; showing ions from an aqueous solution nucleating on the functional head groups of an LB film attached to a solid substrate.

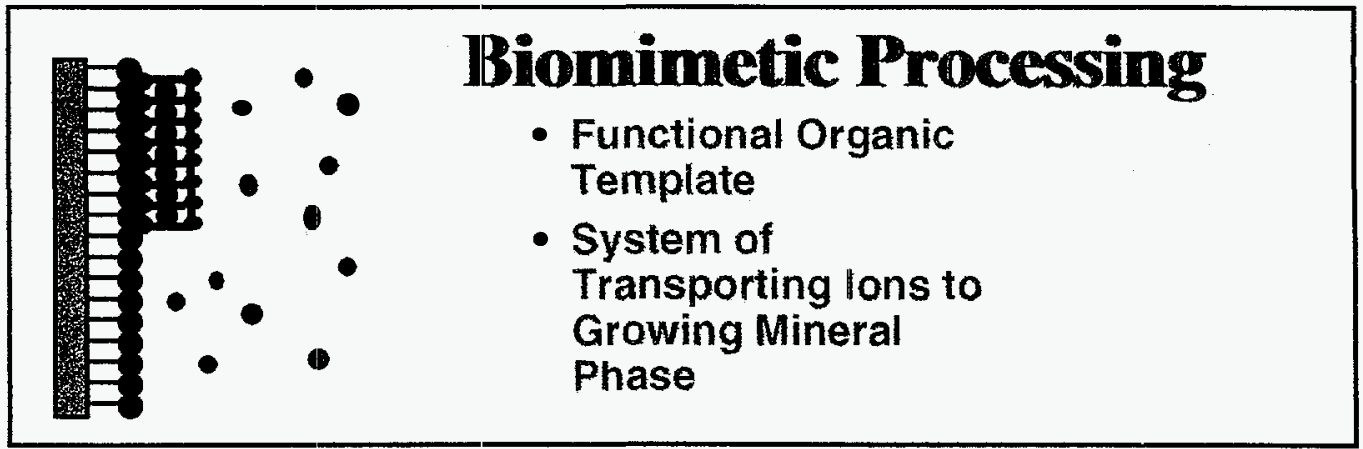

For success, expertise must first be developed for the fabrication and characterization of LB films. The following 13 pages are a summary of the techniques we used to fabricate LB films to be used to facilitate the growth of CdS. 


\title{
Chapter 2
}

\section{Preparation of Langmuir-Blodgett Films for Biomimetic Processing}

\author{
Jennifer M. Dean and Joe Cesarano
}

Langmuir-Blodgett (LB) Films Made of Surface Active Molecules

- Molecules are amphiphilic

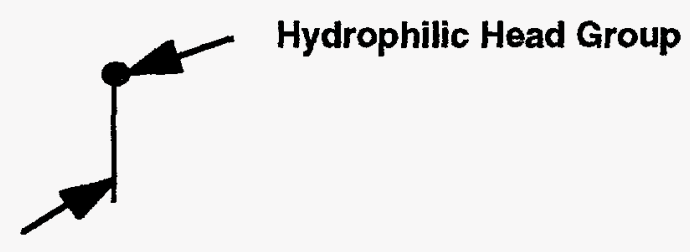

Hydrophobic Tail Group

- Molecules with correct amphiphatic balance are trapped at interface

- Molecules act to reduce surface tension of subphase

- Molecules can be compressed to form oriented monolayer 
- Sequential buildup of monolayers as substrate crosses airwater interface

- Produces a controlled, highly structured thin film

- Applications include step gauges, anti-reflection coatings, and template for dieposition of inorganics

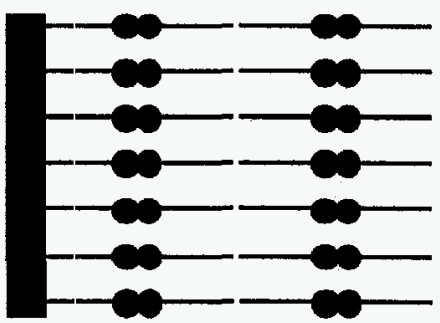

\section{Langmuir Films}

Pressure sensor

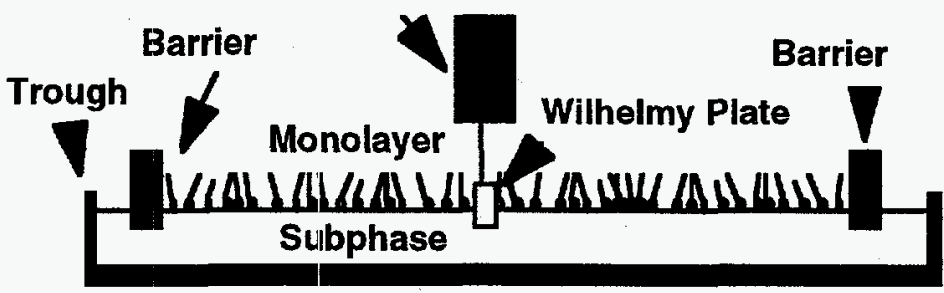

Monolayer

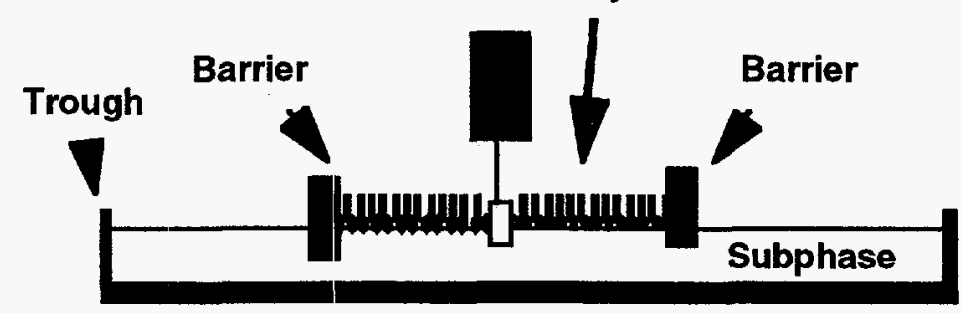


LB Films Deposited as Substrate Passes Air-water Interface

- Hydrophobic substrates start deposition on first downward pass

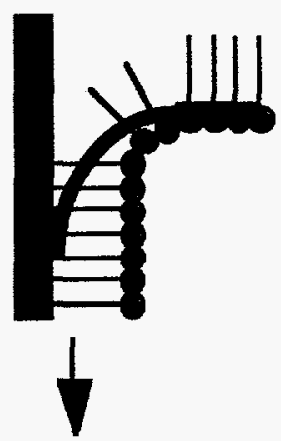

- Meniscus of subphase dips below level of surface and wets substrate at an angle of $\mathbf{1 8 0}$ degrees

- Hydrophobic tail groups contact substrate and are deposited

- Multilayers are built up 'head-to-head and tail-to-tail'
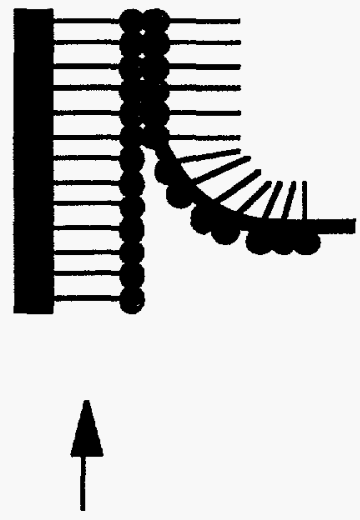

Buildup of multilayers on hydrophobic substrate

- Process repeatable until desired thickness formed 


\section{Factors Affecting LB Film Quality}

- Cleanliness of equipment, chemicals, and substrates

- Choice of deposition material

- $\mathrm{pH}$ of subphase

- Concentration of Cadmium ions in subphase

- Highly hydrophobic substrate

- Deposition speed and "pressure"

\section{Project Objectives}

- Produce high quality Langmuir-Blodgett films

- Modify process to provide template for metal sulfide deposition

- Preliminary characterization of 4-layer Langmuir-Blodgett films 
Chemical Functionality of Three- and Four-Layer LB Films

- Three-layer films show carboxylic acid group outward

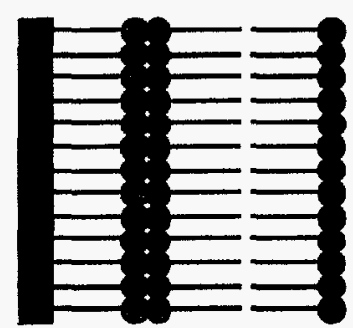

$$
=-\mathrm{COO}^{-}
$$

- Four-layer films show methyl group outward

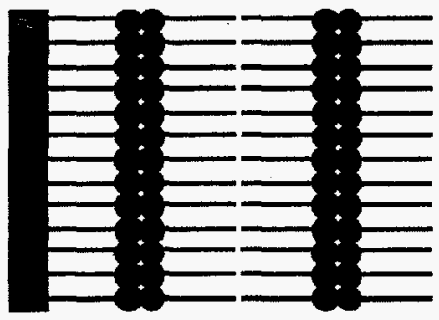

$-=-\mathrm{CH}_{3}$

Cleanliness Critical in Formation of High Quality LB Films

- Substrates plasma cleaned before treatment

- Glassware "piranha cleaned"

- LB films processed in Class 100 cleanroom

- Equipment thoroughly cleaned before each use

- Ultra-pure water used as subphase

- Subphase surface contamination removed 


\section{Silicon wafers are plasma cleaned to}

remove all organic contaminates

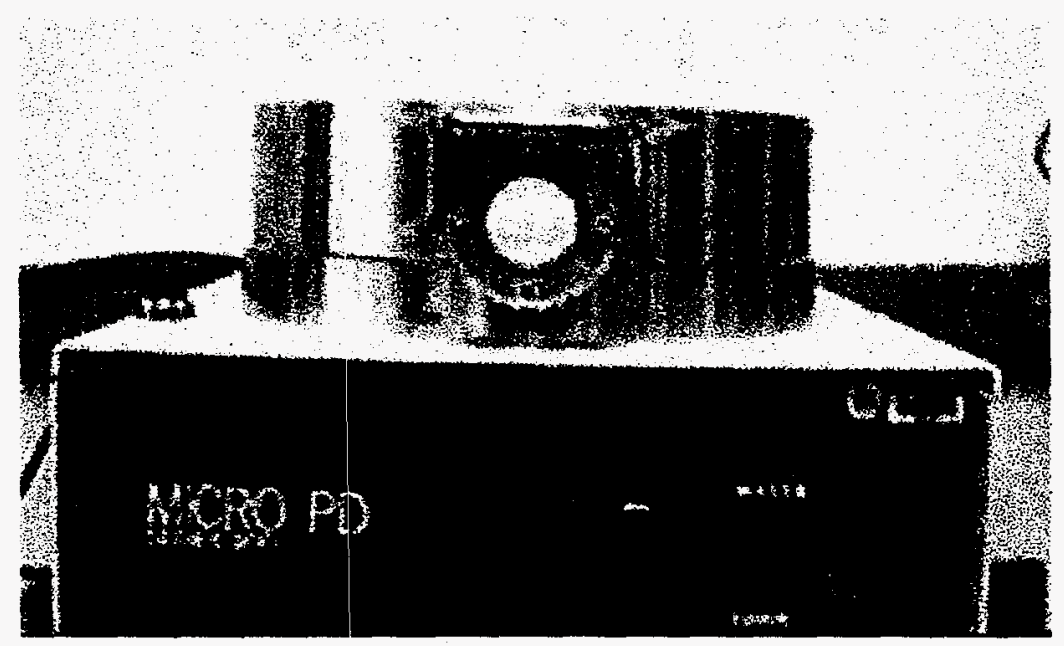

Arachidic Acid Selected as Deposition Material

- Has correct amphiphatic balance

- Has been extensively characterized

- Easily forms LB films

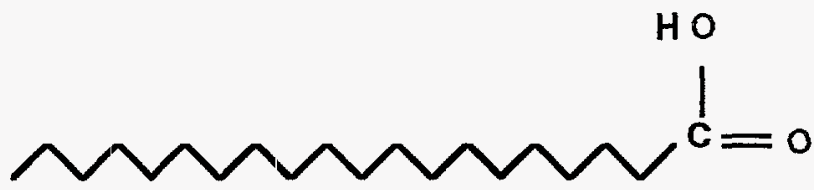

Arachidic Acid - a Fatty Acid

$\mathrm{CH}_{3}-\left(\mathrm{CH}_{2}\right){ }_{18-} \mathrm{COOH}$ 
Subphase $\mathrm{pH}$ and Cadmium Concentration Control Rigidity of LB Film

- Higher pH and concentration of $\mathbf{C d}^{+2}$ ions in subphase form more rigid monolayers

- Less acidic pH promotes dissociation of carboxylic group

- $\mathrm{Cd}^{+2}$ ions complex arachidic acid molecules<smiles>[R]C(=O)C(=O)[O-]</smiles>

Cadmium Arachidate

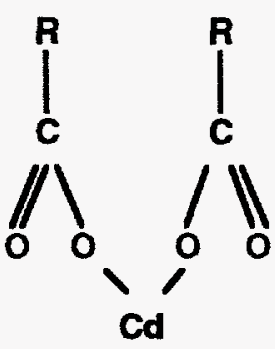

Intermediate $\mathrm{pH}$ and Cadmium Concentration is More Suitable for Biomimetic Processing

- Rigid monolayers produce rigid films

- Rigid monolayers are hard to dip and LB films produced are often blotchy

- Acceptable balance between rigidity and film quality leads to following subphase conditions:

$\mathrm{pH}: 5.3$

$\left[\mathrm{Cd}^{+2}\right]: 2.5 \times 10-4 \mathrm{M}$

- Isotherms (surface pressure vs. area) show rigidity of monolayer 
Substrates Treated to Form Highly Hydrophobic Surface Prior to Deposition of LB Fllm

- Silicon wafers treated with Octadecyltrichlorosilane (OTS)

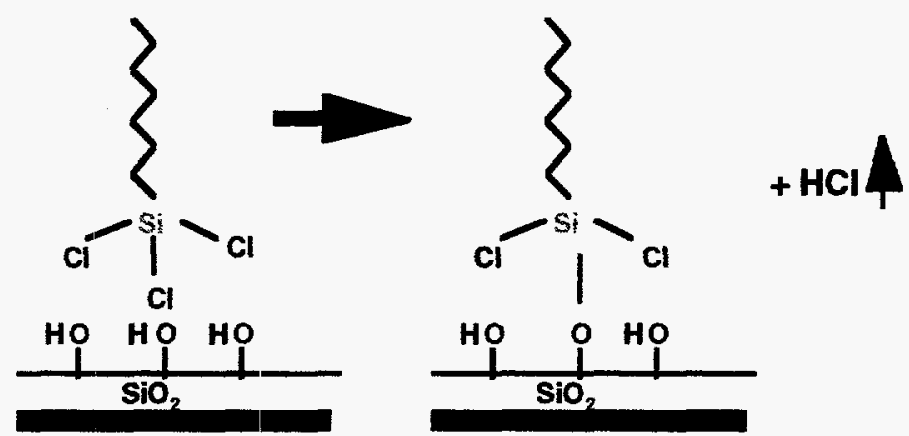

- Methyl terminated chain makes substrate surface hydrophobic

- Hexadecyl Mercaptan, $\mathrm{HS}-\left(\mathrm{CH}_{2}\right)_{15}-\mathrm{CH}_{3}$, reacts in similar way with gold coated wafers to produce hydrophobic surface

- Contact angles on substrates measured before and after treatment

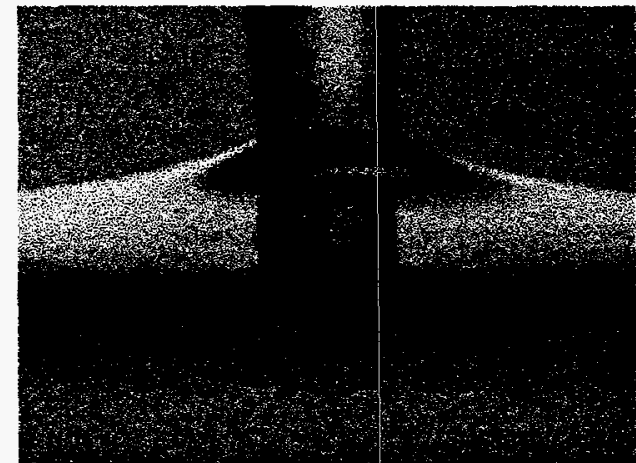

Water wets an untreated silicon wafer.

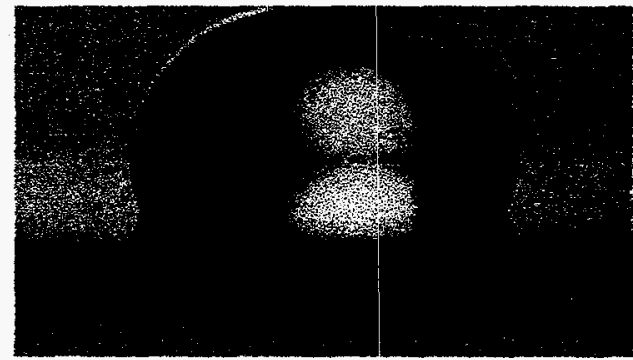

After treatment with OTS, wafer is hydrophobic and prepared for LB film deposition. 


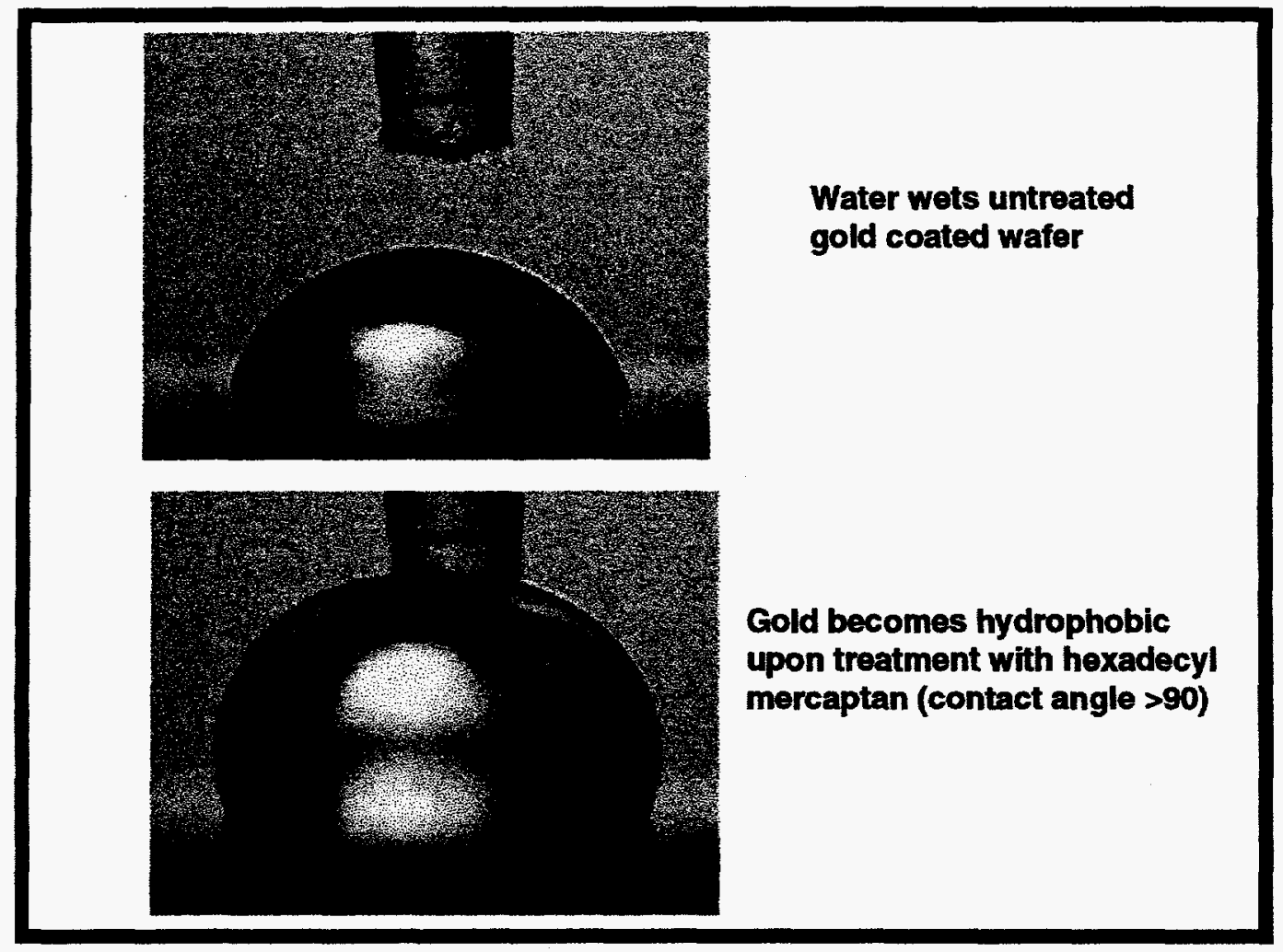

Deposition of LB Film Must Occur at Slow Rate and Constant Pressure

- Dipping speed of $1.6 \mathrm{~mm} / \mathrm{min}$

- Deposition "pressure" must be within "solid" phase, but well below critical pressure

- Acceptable deposition "pressures" for Arachidic Acid are in the range of $25-30 \mathrm{mN} / \mathrm{m}$

- Selected deposition "pressure" for this project is $28 \mathrm{mN} / \mathrm{m}$ 


\section{Experimental Procedure for 4-Layer LB Films Used in Eliomimetic Processing}

- Substrate, either silicon wafer or gold coated silicon wafer, treated to produce highly hydrophobic surface

- Subphase (ultra-pure water with Cd+2) prepared, pH measured

- Clean trough and barriers thoroughly with chloroform

- Set up barriers, pressure sensor, Wilhemy plate

- Spread subphase in trough

- Clean subphase of surface contamination to within $0.5 \mathrm{mN} / \mathrm{m}$

- Set up substrate in dipping mechanism

- Spread deposition material (arachidic acid) on subphase surface and allow solvent to evaporate and monolayer to come into equilibrium

- Run isotherm on monolayer

- Set "pressure" control

- Dip substrate, watching meniscus for indication of film quality

- Remove substrate after deposition of four layers and clean trough

Ability to Form Stable Three-Layer LB Films Necessary for Biomimetic Processing

- Stable LB films of arachidic acid have methyl group outward

- Three-layer LB films have carboxylic group outward

- Three-layer LB films are stable in water, but will rearrange upon exposure to air

- Able to modify procedure for four layer films to produce stable three-layer films

- Necessary to provide reactive-COO-site in template for metal sulfide deposition 
Experimental Procedure for 3-Layer LB Films Used in Biomimetic Processing

- Substrate, either silicon wafer or gold coated silicon wafer, treated to produce highly hydrophobic surface

- Subphase (ultra-pure water with $\mathrm{Cd}+2$ ) prepared, pH measured

- Clean trough and barriers thoroughly with chloroform

- Set up barriers, pressure sensor, Wilhemy plate

- Place sealable "piranha" cleaned jar in bottom of trough

- Spread subphase in trough

- Clean subphase of surface contamination to within $0.5 \mathrm{mN} / \mathrm{m}$

- Set up substrate in dipping mechanism

- Spread deposition material (arachidic acid) on subphase surface and allow solvent to evaporate and monolayer to come into equilibrium

- Run isotherm on monolayer

- Set "pressure" control

- Dip substrate, watching meniscus for indication of film quality

- After deposition of three layers, open barriers and clean arachidic acid from area surrounding substrate

- Carefully and quickly lower substrate into jar placed in bottom of trough

- Seal jar under water

- Sample should be used quickly following deposition of film

- Clean trough

\section{Conditions Used for Biomimetic Processing}

- Biomimetic processing imitates the deposition of inorganics on an organic layer

- Previous trials led to the following conditions:

- pH : 6.5

$-\left[C d^{+2}\right]: 5 \times 10^{-4 M}$

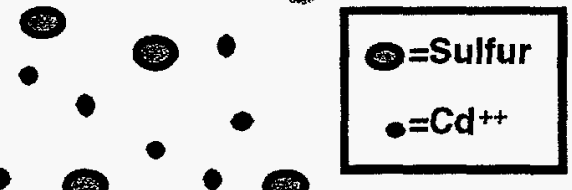

Langmuir Blodgett film
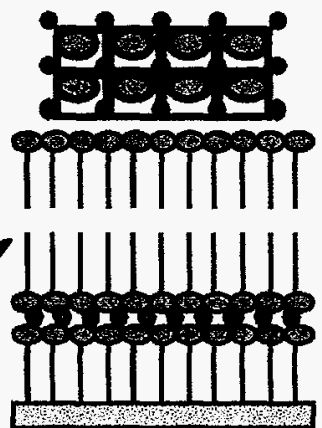


\section{Ellipsometry Used as Preliminary Characterization of Four-Layer LB Films}

- Ellipsometry on LB films on OTS treated silicon wafers show average thickness per layer consistent with length of one molecule of arachidic acid ( 28 angstroms)

\begin{tabular}{lcll} 
Trial & Thickness per laver & & Standard Deviation \\
\cline { 2 - 3 } & (angstroms) & & (angstroms) \\
$6-28-4$ & 24.5 & 2.7 \\
$6-28-8$ & 27 & 0.5 \\
$6-28-12$ & 27.8 & 0.4 \\
$6-30-4$ & 29.2 & 0.3 \\
$6-30-8$ & 29.9 & 0.8 \\
$6-30-10$ & 31.8 & 1.36
\end{tabular}

- Profilometry confirmed ellipsometry reading on silicon substrates

Ellipsometry on Gold Substrates Gives Variable Results

- For ellipsometry, gold film must be thick enough to be considered a substrate

- Gold film not single crystal, made from evaporative process

$\begin{array}{lcl}\text { Run } & \text { Thicleness per laver } & \begin{array}{l}\text { Standard Deviation } \\ \text { (angstroms) }\end{array} \\ \text { (ang:stroms) } & 0.4 \\ 7-29 \# 3 & 41.9 & 1.2 \\ 7-25 & 35.1 & 0.8 \\ 7-26 & 29.4 & 0.1 \\ 7-29 \# 2 & 25.4 & 0.6 \\ 8-2 \text { \#2 } & 27.4 & 1 \\ 8-1 \text { \#1 } & 46.2 & 0.3 \\ 8-1 \text { \#2 } & 45 & \end{array}$

- However, profilometry readings indicate thickness per layer values close to theoretical value of 28 angstroms 


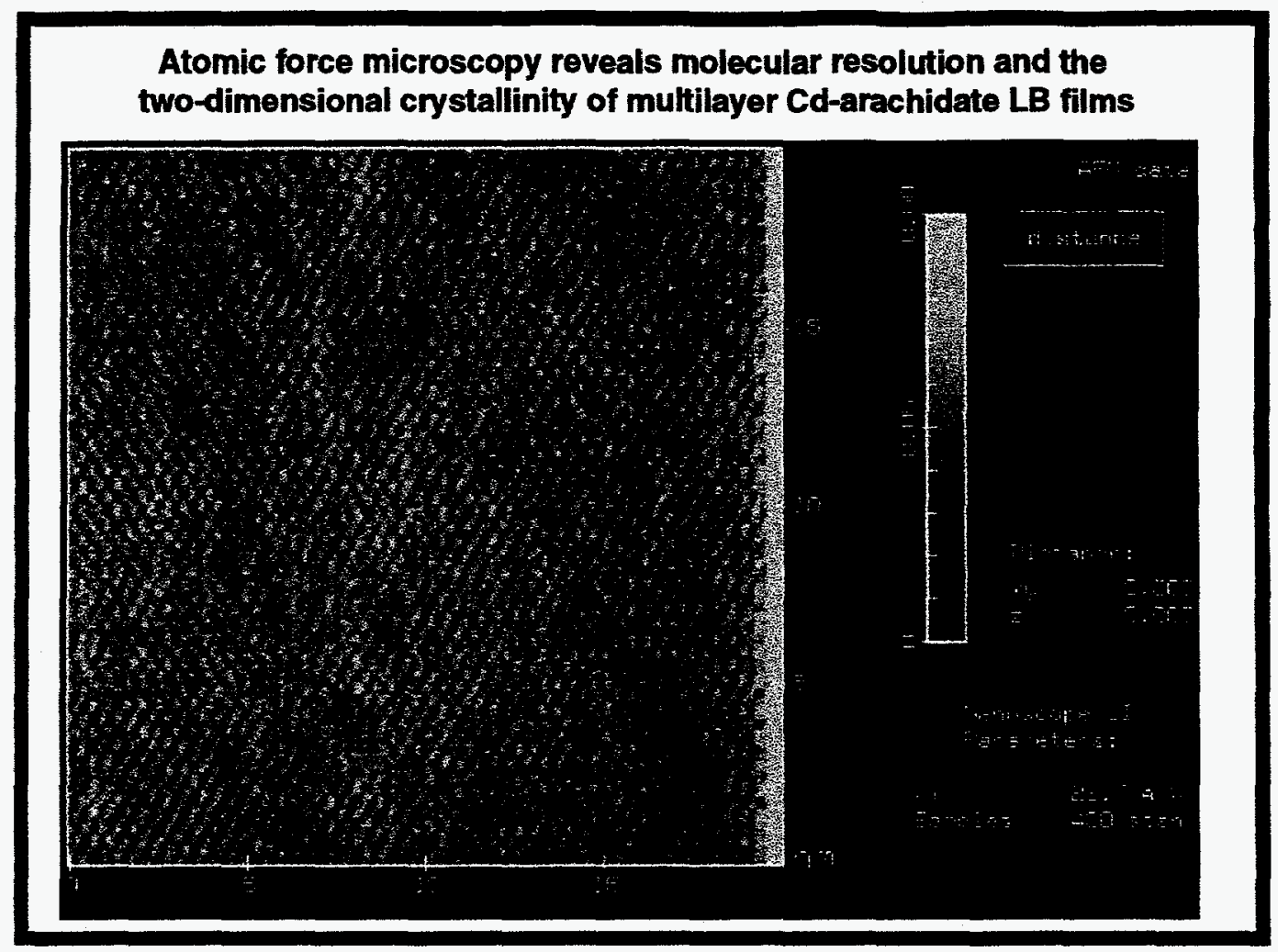

Conclusions

- Able to make consistently high quality LB films on silicon substrates and on gold coated silicon substrates

- Able to control chemical functionality of LB film with modifications to four-layer process to produce stable threelayer films

- Ellipsometry and profilometry of LB films on silicon substrates indicate uniform film with thickness consistent to four monolayers

- Ellipsometry of LB films on gold coated silicon wafers is variable due to difficulties associated with ellipsometry on gold and surface roughness-of gold after evaporation

- Ellipsometry of LB films on gold coated silicon wafers shows sample with uniform film 


\title{
Chapter 3
}

\section{Chemical Precipitation of Metal Sulfides From Solution}

\begin{abstract}
Summary
Prior to attempting the biomimetic growth of metal sulfides on LB film templates, two techniques were studied for the controlled precipitation of $\mathrm{CdS}$ and $\mathrm{ZnS}$ in aqueous solutions without any substrate present. Precipitation induced by either thiourea or thioacetamide decomposition reactions were studied. It was determined that using thiourea for the precipitation of $\mathrm{CdS}$ ended up producing $\mathrm{CdS}$ that was relatively amorphous and contaminated with $\mathrm{CdCO}_{3}$ and $\mathrm{CdCN}_{2}$. This occurred even if very extreme purification steps were taken. Alternatively, a thioacetamide decomposition technique produced very crystalline forms of both $\mathrm{CdS}$ and $\mathrm{ZnS}$. Some more detail of this work is presented in the following 14 diagrams on the next three pages.
\end{abstract}

\section{Contents}

- Metallic Sulfides in the Biomimetic Project

- The Thiourea and Cadmium Nitrate Reaction-Rieke's method

- The Thioacetomide and Zinc Reaction--Akinc's method

- $\mathrm{ZnS}$ and CdS Acetate Thioacetomide Reactions

- Conclusions 


\section{Goals}

- optimize the chemical precipitation of Cadmium and Zinc Sulfide for biomimetic deposition on LB films.

- both mildly acidic and mildly basic conditions

- ambient temperatures

-well crystalline, pure precipitates

2

\section{Approach}

- Thiourea Decomposition in basic conditions with both Cadmium and Zinc Nitrate

- Thioacetomide decomposition in acidic conditions with various precursor salts 


\section{Rieke's Thiourea Reaction}

Rieke, P., Chem. Mater. 1993, 43-53

- CdS deposited from basic solutions $(\mathrm{pH} \geq 9)$

a $0.5 \mathrm{M}$ Thiourea -sulfur source

m $0.1 \mathrm{M} \mathrm{Cd}\left(\mathrm{NO}_{3}\right)_{2}$ - metal source

- 1.0 $\mathrm{M} \mathrm{NH}_{4} \mathrm{NO}_{3}$ - to complex $\mathrm{Cd}^{++}$

a ambient temperatures

\section{$\mathrm{Cd}\left(\mathrm{NO}_{3}\right)_{2} \rightarrow \mathrm{Cd}\left(\mathrm{NH}_{3}\right)_{\mathrm{x}^{2+}} \rightarrow \mathrm{Cd}^{2+}$}

$\mathrm{Cd} 2++\mathrm{NH}_{2}-\mathrm{CS}-\mathrm{NH}_{2}$ $+2 \mathrm{OH}$ -

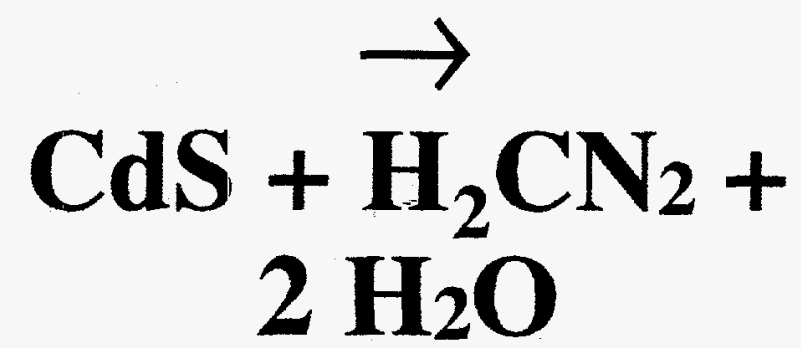

5 


\section{Results Using Rieke's Method $\mathrm{Cd}_{2}+\mathrm{NH}_{2}-\mathrm{CS}_{-} \mathrm{NH}_{2}+2 \mathrm{OH}^{-} \rightarrow \mathrm{CdS}+\mathrm{H}_{2} \mathrm{CN}_{2}$ $+2 \mathrm{H}_{2} \mathrm{O}$}

- formation of $\mathrm{CdOH}$ when $\left(\mathrm{NH}_{4} \mathrm{NO}\right)<$ $1.0 \mathrm{M}$

- precipitate contained $\mathrm{CdS}, \mathrm{CdCO}_{3}$, and $\mathrm{CdCN}_{2}$

- precipitate was highly amorphous indicating very poor crystal formation

\section{Results under Optimal Conditions}

- conducted most reactions at pH 8.5

- Isolated reaction in a Nitrogen box and boiled the water under Nitrogen to reduce contamination by $\mathrm{CO}_{2}$

- eliminated $\mathrm{CdCO}_{3}$

- recrystalized the Thiourea from hot methanol

- precipitate stil highly amorphous and contained both $\mathrm{CdS}$ and $\mathrm{CdCN}_{2}$ 


\section{Akinc's Method}

Akinc, M. and Celikkaya, A., J.Am. Ceram. Soc., 73 [2], 240-50

Akinc, $M$ and Celikkaya, A., J. Am. Ceram. Soc., 73 [8], 2360-65

-Precipitation of zinc sulfide by thermal decomposition of Thioacetomide in acidic solutions

- [Thioacetomide] / $\left[\mathrm{Zn}\left(\mathrm{NO}_{3}\right)_{2}\right]=4,8,16$

$\mathrm{aH}<3$, temperature $60^{\circ} \mathrm{C}$

\section{$\mathbf{H}_{3} \mathbf{0}^{+}$}

$\mathrm{CH}_{3} \mathrm{C}(\mathrm{S}) \mathrm{NH}_{2} \rightarrow$

$\mathrm{CH}_{3} \mathrm{C}(\mathrm{O}) \mathrm{HN}_{2}+\mathrm{H}_{2} \mathrm{~S}$

$\mathrm{H}_{2} \mathrm{~S} \Rightarrow \mathrm{HS}^{-+\mathbf{H}_{30}} \mathbf{0}^{+}$

$\mathrm{HS}^{-} \Rightarrow \mathrm{S}_{2-}+\mathrm{H}_{3} \mathbf{0}^{+}$

$\mathrm{Zn} 2+(a q)+\mathrm{S}^{2-(a q)} \Rightarrow \mathrm{ZnS}(s)$

9 


\section{Results Using Akinc's Procedure}

a chemical reaction described for $\mathrm{pH}<3$ only

- reactions at $\mathrm{pH} 4$ and ambient temperatures produced $\mathrm{ZnS}$ very slowly

$\square \mathrm{pH}$ dropped from 4.0 to 2.5 as Thioacetomide formed acetic acid

10

\section{Thioacetomide with other Zinc Salts}

- Zinc Acetate, $\mathrm{pH}<3$

- acetate ion buffers $\mathrm{pH}$ to 1.9

- acetate catalyzes the decomposition of Thioacetomide

- Zinc Acetate at $\mathrm{pH} 4$

$-\mathrm{pH}$ buffered at 4.0

- pure, well crystaline Zinc Sulfide formed

- reaction complete within 5 days 


\section{Thioacetomide Method with Cadmium}

- Followed Akinc's method substituting Cadmium Acetate

- precipitate evident in half an hour

- reaction complete within 3 days

- $\mathrm{pH}$ stable at 4.01

- Formed well crystalline Cadmium Sulfide

\section{Conclusion}

aFormation of Cadmium Sulfide using Thioacetomide reactions may improve reaction rates and purity of thin films with relative ease. Thiourea decomposition reactions yield unpure $\mathrm{CdS}$ deposites. 


\section{Future Research}

- Thioacetomide precipitation $4<\mathrm{pH}<7$

- different chemical reaction

a Chemical Deposition of $\mathrm{ZnS}$ and CdS on Langmuir-Blodgett Films

14 


\section{Chapter 4}

\section{Biomimetic Deposition of Metal Sulfide Thin Films}

\section{Summary}

The next step in this project was to explore various methods to achieve the biomimetic formation of metal sulfides on a Langmuir-Blodgett film template. The basic methodology is to expose a substrate with an LB film to an aqueous solution containing either $\mathrm{Cd}^{++}$or $\mathrm{Zn}^{++}$ions. Then a source of $\mathrm{S}^{-2}$ must be introduced so that the solubility limit of the metal sulfide is approached in the vicinity of the LB film. It is then hoped that the LB will provide periodic heterogeneous nucleation sites for the growth of a crystalline metal sulfide film. This chapter will present results for our work on precipitation induced by thioacetamide decomposition, alternate dipping in separate thioacetamide and $\mathrm{Cd}$-nitrate solutions, and electro-assisted deposition in $\mathrm{Cd}^{++} /$ thioacetate solutions. In following chapters, work completed by our Russian contractors is presented showing results for using gaseous $\mathrm{H}_{2} \mathrm{~S}$ and thiourea as sources of $\mathrm{S}^{-2}$.

Another objective of this work was to attempt to assess the effects of chemical functionality and crystallinity for the organic template. Therefore, LB films were fabricated with acid groups extending into solution and others with non-polar groups extending into solution. Deposition on these films were compared to substrates with adsorbed polyallyamine templates and others with adsorbed polyacrylic acid templates.

Results from this work showed that trying to complete biomimetic growth by thioacetamide decomposition in a single solution (that also contains a source of $\mathrm{Cd}^{++}$) was not very successful. In addition to difficulty in controlling the $\mathrm{pH}$, precipitation could not be limited to just the surface of the template. Powder precipitated throughout the solution. Biomimetic polycrystalline films of CdS were successfully prepared with both the alternate dipping technique and the electro-deposition technique. The films were approximately $50 \AA$ thick. The electro-deposition technique proved to provide much faster fabrication times (completion in about five minutes) and lead to the development of an ionic electro-deposition technique discussed in "Modeling and Characterization of Molecular Structures in Self Assembled and Langmuir-Blodgett Films for Controlled Fabrication" (SAND 97-2395).

It was also shown that methyl terminated LB films inhibited CdS growth however the effect of template crystallinity was not so clear. Atomic force microscopy (AFM) seemed to show that the crystalline LB films promoted larger more distinct crystalline regions than the polymer templates. Molecular level AFM was unsuccessful in determining if the crystalline regions were oriented with respect to the substrate.

\section{Procedures:}

\section{Preparation of Metal Sulfides in Solution:}

The decomposition of Thioacetamide in the presence of metal salts to form metal sulfides is well documented. In the $\mathrm{pH}$ range between 1 and 4 , thioacetamide slowly decomposes to form sulfur ions which then react with metal ions to form metal sulfides. In $\mathrm{pH}>4$, a direct reaction between the metal ions and thioacetamide predominates. The charged Langmuir-Blodgett films are very $\mathrm{pH}$ sensitive and are most ordered at $\mathrm{pH}>4$. A solution of $0.2 \mathrm{M}$ Thioacetamide and $0.05 \mathrm{M} \mathrm{Cd}\left(\mathrm{NO}_{3}\right)_{2} * 4 \mathrm{H}_{2} \mathrm{O}$ has an ambient $\mathrm{pH}$ of $5, \mathrm{NaOH}$ was used to bring the $\mathrm{pH}$ to 6.0. During a direct reaction however, the byproducts of the cadmium sulfide solution include an acidic thioacetate group. This 
tends to lower the $\mathrm{pH}$ from the stable range as the reaction progresses. At the end of a typical reaction the $\mathrm{pH}$ would be on the order of 2.0 . In order to stabilize the $\mathrm{pH}$ in the "direct reaction range," a Mettler DV11 titration device was used to control the pH. According to M.S. Akinc, at $\mathrm{pH}>4$, a direct reaction predominates in the production of the precipitate.

\section{Organic Template Preparation}

As demonstrated in the accompanying diagram, Langmuir Blodgett films are constructed of ordered amphiphilic molecules which are deposited layer by layer along an air water interface. The polymer layers used in this project consisted of polyallyamine adsorbed on the surface of a silicon wafer for 1 hour in an ultrasonic bath at pH 6 . Polyacrylic acid layers were similarly adsorbed so the resulting film was sufficiently disordered but contained $\mathrm{COO}^{-}$groups similar to those present on the LB films.

\section{Ceramic Thin Film Deposition. by Alternate Dipping}

The alternate dipping method of film deposition was attempted in lieu of direct deposition from a CdS solution. An organic template was dipped alternately into a $0.1 \mathrm{M}$ Thioacetamide and $0.1 \mathrm{M} \mathrm{Cd}\left(\mathrm{NO}_{3}\right)_{2}$ solutions hoping to attract $\mathrm{Cd}^{2+}$ to the film substrate where they would bind to the charged hydrocarbon chains on the organic template. The organic template, now coated with cadmium, was exposed to a solution of thioacetamide so that the two ions could react on the surface of the substrate, not in solution. This process proceeds a layer at a time, so the process was repeated 50 times in the hopes that a fifty layer film would result.

\section{Ceramic Thin Film Deposition. by Electro-Deposition}

Biomimetic deposition in the presence of an electric field was completed in solutions of Cd-nitrate and thioacetate. Cycles consisting of alternating positive and negative voltages were used alternately to attract cadmium and thioacetate ions towards the electrodes where the ions react to form cadmium sulfide. 


\section{Biomimetic Processing}

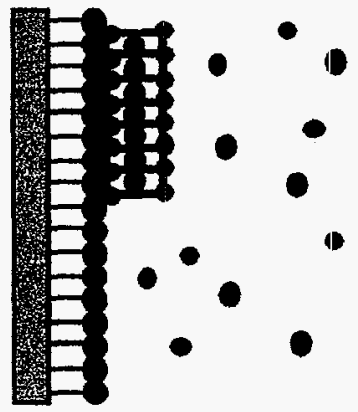

- Functional Organic Template

- System of Transporting lons to Growing Mineral Phase

\section{Objective}

Deposition of Cadmium Sulfide in the Presence of Organic Thin Film Templates

- Effect of Deposition Techniques

- Examination of Effectiveness of Chemical Functionality of Organic Template

- Effect of Crystallinity of Organic Template on Crystall Growth 


\section{Organic Templates}

- LB film with organized amphiphilic molecules

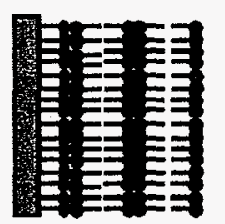

- Polymer templates with random orientation of functional groups

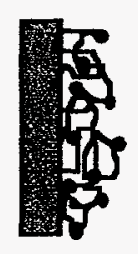

\section{Functionality Groups}

4 Layer LB Film

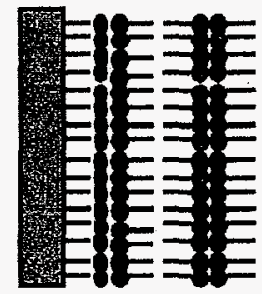

5 Layer LB Fillm

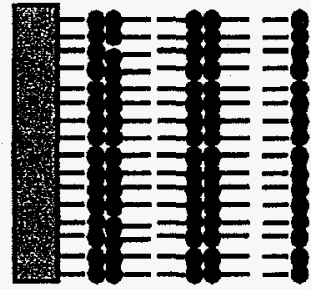

Polyallylamine

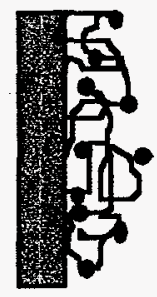

$\bullet=\mathrm{NH}_{2}{ }^{+}$

$-=\mathrm{CH}_{3}$

- $=$ COO

Polyacrylic acid

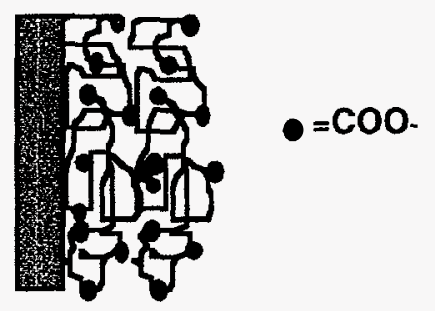




\section{Approach}

- Exposure to Cadmium Source

- Exposure to Sulfur Source

- Reaction to form Cadmium Sulfide
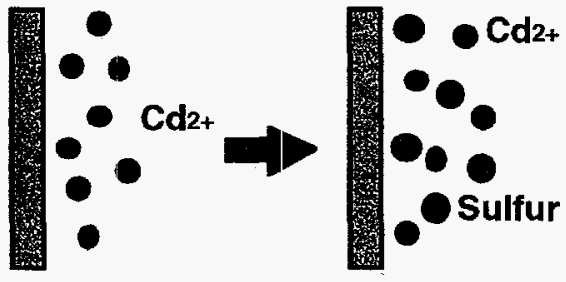

\section{Methods of Deposition}

- Thioacetomide Decomposition

- Alternate Dipping Chemical Deposition

- direct reaction between $\mathrm{Cd}{ }^{2+}$ and Thioacetomide on surface of substrate

- Electrodeposition

- attraction of $\mathrm{Cd}_{2+}$ and Thioacetic Acid ions 


\section{Production of CdS from Thioacetamide}<smiles>CC(N)=S</smiles>

- Musaf Akinc* describes decomposition of Thioacetamide to form $\mathrm{CdS}$ at $\mathrm{pH}<4$

- When $\mathrm{pH}>4$, fast direct reaction to form CdS

${ }^{\star}$ M. Akinc and A. Celikkaya, J. American Ceramic Societ , 73 [2] 2450 [1990]

\section{Chemical Deposition Setup}

- Substrates prepared with charged organic films

- Substrates dipped alternately in Sulfur and Cadmium solutions
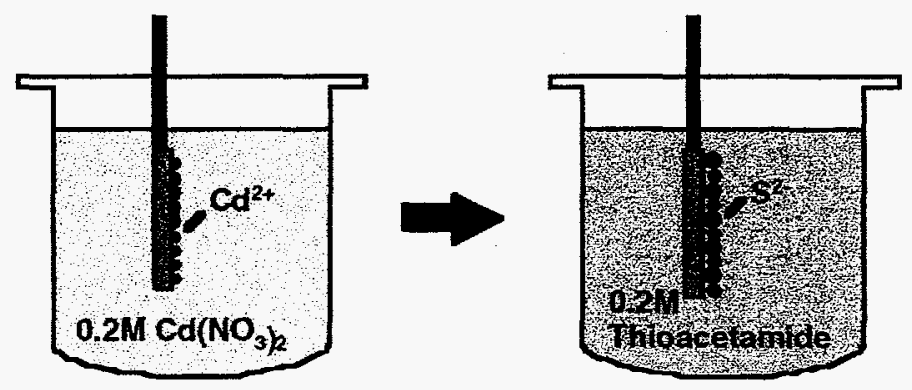


\section{Electrodeposition}

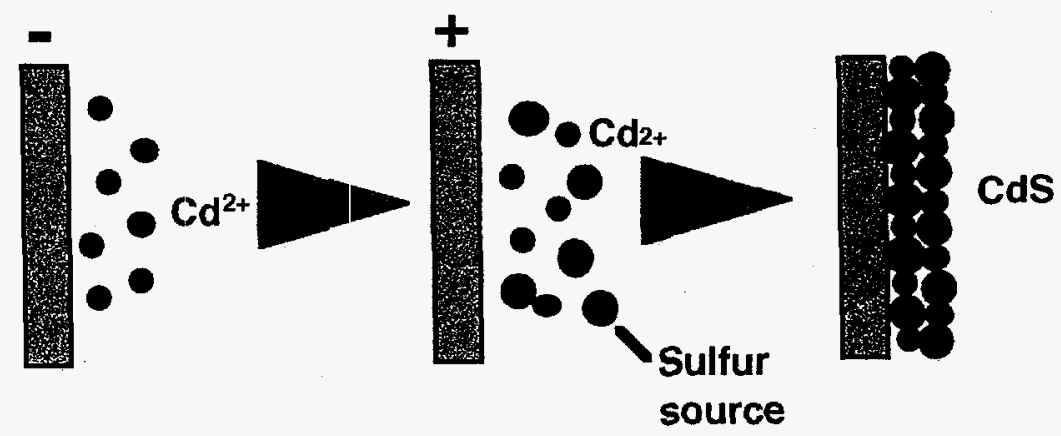

\section{Experimental Setup}

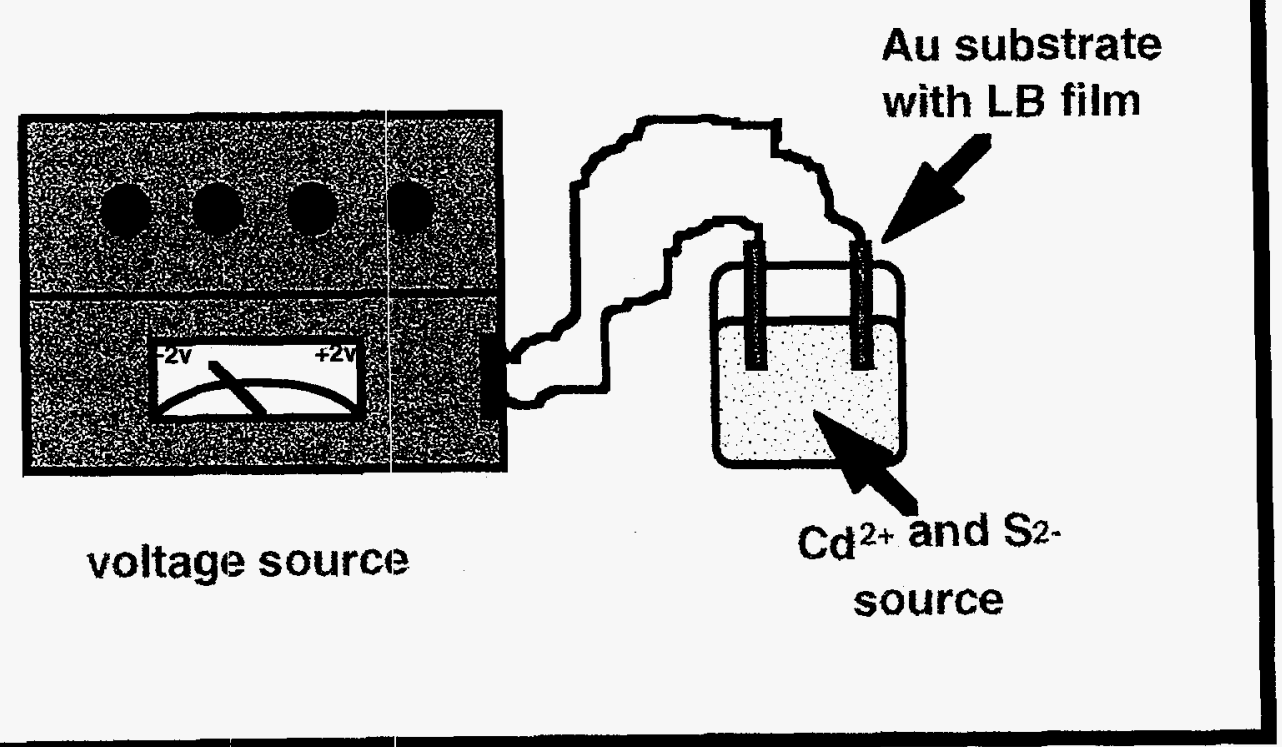




\section{Electrodeposition by Organic Sulfur Sources}

- Using methodology explored in Chemical Deposition<smiles>CC([O-])=S</smiles>

- Cd source: $\mathrm{Cd}\left(\mathrm{NO}_{3}\right)_{2}$

- Cycle: $-2 v, 2 s ;+2 v, 4 s$

- Approximately 50 cycles (5 minutes)

\section{Conclusions}

- Effect of Deposition Techniques

- Electrodeposition

* Dense films

» Thicker films

»Ease of fabrication

- Effect of Chemical Functionality of Organic Template

- Nucleation and growth of inorganic crystaline film aftected by chemical functionality of the organic thin film templates

"Carboxyl group

- Effect of Crystallinity of Organic Template on Crystal Growth

- indirect evidence-crystallinity of organic thin fitm improves orientation 


\section{Chapter 5}

\section{SUMMARY OF RUSSIAN COLLABORATION}

\section{Growth and Structure of Ceramic Films on Langmuir-Blodgett Films}

The aim of work presented was to establish conditions of ceramic film growth on the organic sublayer and following fixing of such a complex system on the solid substrate. Pbs and CdS were selected as ceramics, Langmuir-Blodgett films of fatty acids salts were choosen as organic sublayers, and monocrystallyne Si wafers were choosen as solid substrates. The most significant requirement imposed on the techniques developed was that the ceramics films must be oriented. By other woras, films should be grown by epitaxial growth.

The main factor of epitaxial growth is mesting some requirements on relationship between crystallographic orientations of the substrate (matrix) and the grown film. So the main attention at the beginning of the work was paid to the following problems: - appropriate selection of struccure investigation techniques; - preparation of highly ordered Langmuir-Blodget films of fatty acids salts; - structure study of si substrace treated by various techniques and investigation of influence of the substrate structure on the structure of LB film deposited on the substrate.

Three techniques were used for study the structure of lB layers deposited on the solid substrate:

- small-angle $X$-ray scattering (SAXS) which provides information or spacing in the film and electron density distribution across the Eilm:

Feflection High Energy Electron Diffraction (RLEED) which gives information on electron density ciscribution at the film layers near the surface of the film;

Transmission Electron Diffraction. The use of this technicue required special sample preparation. Langmuir - Elodgete films were deposited onto celluloid subatrates which were preliminary attachej onto special grids transparent for electron beam. The us of the electron diffraction camera of the special geometry made possible to obtain transmission diffraction pattenns of high resolution at normal incidence of the electron beam to the sample as well as at oblique incidence at tilt angles up to 70 degress. patterns of normal incidence provide information only or. reflexions of indices hko while patterns of oblique texture type show practically whole thresdimensional set of reflexes arailable. Such information provides not only analysis of the repetion lnit but also complete structure investigation of the sample under study including analysis of such cefects $O_{1}$ the lattice as disruption of the molecular lattice, inclinations and bends of molecules $E t c$.

Structure of crystallyne silicon substrate surface was studied by RHEED. Substrates treated through various preparation procedures were studiej. Techniques of polising, surface cleaning and hydrophibization were varied. It was established that orientation of the crystal sustrate surface (1100) or (111)) does not affect the structure of the Langmuir-elodgett film deposited while the value of surface roughness and the techriqueof cleaning are of significance.

Langmuir-Blodgett films were prepared with the use of "Langmuir Trough 4" (Joyce Loeble. England).

Easic stages of investigation of LE films were the following:

- preparation of the subphase;

- spreading the layer of amphiphilic molecules over the subphase; 
- analysis of the monolayer structure on the subphase by $p-A$ isotherm;

- deposition of the monolayer onto the solid substrate;

- possible repetition of the preceding stage;

- analysis of the film obtained.

Reports on Task 2 and Task 3 include the detailed description of the techniques mentioned above and results on investigation of LB films of fatty acids salts of bivalent metals, length of hydrocarbon tail being varied. Stearic ( $C(18)$ ), arachidic( $C(20))$, behenic( $C(22)$, acids were used.

Conditions of deposition of ordered LB films were established for PbSt2, CaSt2, PbBeh2. Organic matrixes for growing ceramic films of PbS and CdS were prepared under these conditions.

For the growth of ceramic crystals, the following three methods of crystallization from solution were applied:

- layer-by-layer chemosorbtion of metal and sulphur ions from water solutions of the corresponding salts;

- growth from solution as a result of reaction with hydrogen sulphide provided from gaseous phase;

- the same as above but hydrogen sulphide is provided by thiourea reaction.

Orientation and structure of the grown ceramic films were studied by electron diffraction. The time of ceramic film growth, method of picking up of the samples from subphase and thiourea concentration were varied in the course of experiments.

Section 4 of the Report on task 3 includes preliminary results of growth studies of PbS and Cas crystals by layer-by-layer chemosorbtion. Only polycrystalline ceramic films were obtained in this case because used were hydrophobic surfaces of LB bilayers.

In the second and the third methods (see Report on task 4) special attention has been paid to the experiment arrangement in the manner when ceramic film is deposited onto the hydrophilic surface of LB film.

The most successful was the method of the growth from solution by reaction with hydrogen sulphide. As it was established by means of electron diffraction, in this case the oriented growth of pbS (111), (001), (011) and CdS (111), (0001) crystaliites and non-oriented polycrystals took place. Orientation of (111) and (001) faces in the first approximation correspond to the symmetry of molecular arrangement in the packed LB layer. At the mostly ordered sites of LB layer at $28 \mathrm{mN} / \mathrm{m}$ it was possible to grow PbS (111) and CdS (1II), (0001) crystallites with low misorientation (2-5 degrees).

Further research in the line of the optimization of growth parameters may be prospective for fabrication of continuous oriented films.

The difference of the space groups of stmmetry and the types of chemical bonding of sulphides of the elements of 2 rd and 4 th groups of the periodic table may allow to compare the processes of the nucleation and growth of different ceramic compounds at LB matrixes (if systematic experimental data become available). 


\section{Chapter 5.1}

\section{Report on Fabrication of Langmuir - Blodgett Films on Silicon and Preliminary Characterization of the Films}

The aim of the current work - to investigate a possibility of formation of oriented non-organic semiconductor CdS and PbS layers on Langmuir-Blodgett thin film organic dielectrics.

It may be suggested that the formation of oriented layers monocrystal domains or polycrystal textures - may be carried out by means of film growth from electrolyte solution at room temperature using layer-by-layer chemosorbtion of potential-defining ions on the surface of a growing film.

As an organic base for IB film, lead and cadmium salts of stearic acid have been chosen. These metals are involved in formation of the required semiconductor layers.

1. The first stage of the research includes the following tasks:

- to develop and describe the method of cadmium and lead stearate LB film preparation;

- to estimate the role of substrate treatment quality in LB film formation;

- to obtain preliminary results of structure studies of the LB films using $\mathrm{X}$-ray and electron diffraction.

1.1. The method of cadmium and lead stearate LB film fabrication

1.1.1. Equipment for Langmuir-Blodgett (LB) film fabrication and stages of the process.

For LB film fabrication the Langmuir trough is used. Its main elements are: trough, movable barrier, sensitive electronic balance for surface pressure measurement and feedback system maintaining surface pressure at the required value during LB film deposition.

In this work, commercially available "Langmuir Trough 4" (Joyce Loeble, England) was used. It is equipped with Whilgelmy balance providing surface pressure measurement sensitivity of $0.1 \mathrm{mN} / \mathrm{m}$.

The main stages of LB film fabrication are:

- preparation of subphase,

- monolayer formation,

- substrate treatment,

- determination of operating conditions for monolayer transfer,

- monolayer transfer onto solid substrate.

1.1.2. Preparation of subphase and formation of cadmium stearate or lead stearate monolayer.

The water for subphase preparation was purified by triple distillation. Organic contaminations were oxidized using potassium permanganate addition at the second stage of 
In the case of cadmium stearate monolayer formation, cadmium chloride was added to purified water to obtain $0.25 \mathrm{mM}$ solution with pH6.2.

For lead stearate formation, subphase was $0.03 \mathrm{mM}$ solution of lead nitrate (PH5.8).

Monolayers were formed by spreading of $1 \mathrm{mg} / \mathrm{ml}$ solution of stearic acid in hexane. To obtain a uniform monolayer, the stearic acid solution was spreaded by drops to total amount of 0.1 micrograms per square $\mathrm{cm}$.

1.1.3. Monolayer study at a subphase surface.

The monolayer was compressed at a speed of 10 square $\mathrm{cm} / \mathrm{min}$. The surface pressure - area dependence was recorded during this process. This curve (called "isotherm") is presented at Fig.1. It shows a linear region with a bent indicating monolayer collapse at the pressure value of $67 \mathrm{mN} / \mathrm{m}$ for both cadmium and lead stearate. The area per stearic acid salt molecules was estimated from these plots to be equal $20 \mathrm{~A}$. Monolayer transfer for the both stearic acid salts was carried out at the surface pressure value of $28 \mathrm{mN} / \mathrm{m}$.

\subsubsection{Substrate treatment}

\subsubsection{Substrate cleaning}

There are following methods to clean substrate surface:

1. Substrate is washed in detergent solution followed by distilled water;

2. Substrate is washed in potassium hydrocarbonate solution, in water, in hydrochloric acid solution completed by careful washing in distilled water;

3. Substrate is kept for several hours in solution of potassium bichromate in sulphuric acid $115 \mathrm{mg}$ of potassium bichromate per $500 \mathrm{ml}$ of concentrated sulphuric acid) then for $I$ hour in pure sulphuric acid and washed carefully in distilled water;

4. Substrate is boiled in a mixture of 7 parts of water, 2 parts of hydrogen peroxide and 1 part of ammonium hydrcxide, then washed in bidistillate, then boiled in a mixture of 7 parts of water, 2 parts of hydrogen peroxide and 1 part of hydrochloric acid and finaliy washed carefully in distilled water;

5. Substrate is washed in sulphuric acid solution, then in distilled water followed by long-term isopropanol vapor treatment;

6. Substrate is plasmochemically treated in weak discharge in argon-oxygen gaseous mixture.

Each one of the methods described above allows to get clean hydrophilic surface of silicon substrate. It is worth noting that ultrasonic treatment is effective in the case of cleaning in 
organic solvents. Ultrasonic treatment of silicon substrate in alkaline solvents or in water causes surface etching and thus increases surface roughiness.

In the present work substrates were cleaned using method 3 .

\subsubsection{Substrate hydrophobisation}

The most universal method of obtaining hydrophobic surface is treatment of cleaned substrate in $5 \%$ solution of dichlorodimethylsilane in hexane (or octane, or benzene). For this purpose a clean dry substrate is immersed into

dichlorodimethylsilane solution for 20 minutes, then washed with hexane, acetone and hexane again.

silicon substrate may be hydrophobised also by immersion into hydrofluoric acid for 1-2 seconds and immediate washing in water. The substrate becomes hydrophobic because the top silicon oxide layer is etched off. To avoid effect of silicon oxidation in air, LB film must be deposited onto such substrates not later than in 1-2 minutes after etching in hydrofluoric acid.

In the present work substrates were hydrophobised using dichlorodimethylsilane solution.

\subsubsection{Deposition of monolayers onto substrates.}

Monolayers of cadmium stearate and lead stearate were deposited onto hydrophobised silicon substrates. The deposition was carried out at the different substrate velocities ranging from 1.5 to 20 $\mathrm{mm} / \mathrm{min}$. After deposition of the first and the second bilayers, the sample was dried in air for 5 minutes. It was found that this drying leads to better film uniformity. Starting with the third bilayer, substrate dipping was carried out without special drying.

\subsubsection{Description of LB film samples.}

The described method was used for the fabrication of LB film sampies of cadmium and lead stearate for structural studies. The total number of fabricated samples was over 60 . They differed in number of deposited layers, transfer regime and monolayer conditions. The samples were used for optimization of deposition conditions using (1) visual LB film quality estimation, (2) $x$-ray diffraction and (3) electron diffraction.

1.2. Pieliminary structure studies of cadmium stearate and lead stearate LB films.

\subsubsection{X-ray diffraction study technique}

In $X$-ray diffraction experiments, two small-angle diffractometers were used:

- the diffractometer with linear beam collimation using

triple-slit geometry,

- diffractometer AMUR- $K$ with kratky collimation system.

The both diffractometers were designed in Small-Angle Scattering Laboratory of the Institute of Crystallography of Russian Academy of Sciences by L.A.Feigin, L.Yu.Mogilevsky and A.T.Dembo. The both devices were equipped with linear position-sensitive 
detectors, developed in the Institute of Nuclear Research of Siberian Division of Russian Academy of Sciences (Novosibirsk). The $X$-ray tubes with copper anode and sharp-focus were used. The $\mathrm{Cu}-\mathrm{K}$ alpha radiation (wavelength $1.542 \mathrm{~A}$ ) was Ni-filtered. The sample-to-detector path $(700 \mathrm{~mm})$ was evacuated.

Detector resolution was equal 0.01 degrees.

The detector was movable to cover angular range up to 20 degrees. zero angle position was calculated by means of extrapolation of several mirror reflection maxima obtained at different angles from ethalone sample.

During diffraction experiment, the flat substrate covered with IB film has been uniformly rotated against $X$-ray beam and scattering intensity was summed over the whole available angular range.

Experimental data were stored and analyzed using a personal computer connected with the diffractometer.

A schematic representation of the experiment is shown in Fig. 2.

\subsubsection{Electron diffraction study technique}

Study of LB film structure by electron diffraction was carried out by means of the EMR-102 electron diffractometer (made by pO "Electron", Sumy city, former USSR). An electron diffractometer has some constructional features making it different from electron microscope. Its optical scheme includes the only condenser lens placed between an electron source and a sample. The condenser focuses both incident and diffracted beams on the screen. This scheme is an experimental base for classical electron diffraction studies, widely developed in Russia where its main line - structural electron diffraction analysis (analog of $X$-ray structure analysis) - was established and a wide spectrum of analytical and structural problems was solved.

This scheme provides the maximum diffraction pattern performance and reflection peak sharpness. This method of electron diffraction has a conventional title "High Resolution Electron Diffraction (HRED)". Electron energy range was 10-100 keV.

Depending on experiment geometry, two kinds of electron diffraction method are distinguished: Reflection High Energy Electron Diffraction (RHEED) and Transmition High Energy Electron Diffraction (HEED).

For the study of samples on silicon substrates RHEED method was used. For HEED experiments LB films were deposited onto special grid with $0.2 \mathrm{~mm}$ windows, covered with thin celluloid film.

Sample holder allowed to move a sample in the $10 \mathrm{~mm}$ range in longitudial and transverse directions; to rotate a sample around the beam axis up to 360 degrees and tilt it to 90 degrees angle.

Diffraction patterns could be visualized on the screen, photographed to $9 \times 12 \mathrm{~cm}$ photoplate or recorded using electrometric registration system.

1.2.3. Description of samples chosen for LB film structure study. 
The organic LB layer should serve as a base for further growth of oriented non-organic fi.lm. The first stage was to estimate how substrate influences resulting LB film structure. It was decided to clarify if LB film formation is different for the cases of crystalline and amorphous substrates. For this purpose, for the both compounds, cadmium stearate and lead stearate, three sets of samples were prepared. Each set included samples of 1, 3, 5 and 10 bilayers. In the first set as substrates were chosen chemically polished silicon plates of (111) orientation. In the second set, silicon orientation was (100). The third set of LB films was prepared on the rough side of silicon plates where the surface layer was disturbed in the coarse of mechanical treatment. All three kinds of surfaces visually appeared as mirror-flat.

In order to clarify the influence of deposition conditions, each set of samples was repeated twice: with fast deposition (15 mm/min) and slow one $(2.5 \mathrm{~mm} / \mathrm{min}$ down and $7 \mathrm{~mm} / \mathrm{min}$ up).

For electron diffraction studies besides the described above samples on silicon substrates, a special set on celluloid film was fabricated.

\subsubsection{Discussion of results of preliminary studies}

\subsubsection{Substrate quality estimation}

Substrate surface quality was monitored using electron diffraction (RHEED). The silicon plates of (111) and (100) crystal orientations were used. Depending on the method of their treatment, silicon surface was either amorphous (mechanically polished substrates, fig. 3) or monocrystalline (chemically polished samples, fig.41.

1.2.4.2. Results of visual observation of monolayer transfer onto substrates

Visually, the quality of monolayer transfer onto substrate was monitored by observation of the meniscus. It appears at the line of monolayer-substrate surface juncture. The smooth meniscus indicates uniform monolayer deposition over the whole substrate surface. The meniscus with "teeth" or ruptures shows that there are bad-adhesy sites on the substrate and monolayer deposition is not uniform.

In the coarse of visual observation it was shown that good uniform meniscus is easily formed at the rough surface. At the smooth surface the uniform meniscus was achieved after special care to surface treatment and experimental details. Small divergence of optimal air temperature and humidity and of optimal subphase constitution led to the slipping down of the first monolayer.

Low deposition speed marifested itself in visual transparency and uniformity of deposited LB film. As a result of high-speed deposition, LB film showed white dust appearing if visualized at sliding angle.

1.2.4.3. Results of $X$-ray study 
$X$-ray diffraction curves were obtained for all three sets of investigated samples. All curves showed Bragg diffraction peaks corresponding to $49.0 \mathrm{~A}$ spacing for both cadmium stearate and lead stearate LB films (Fig.5). Each curve showed a number Bragg reflections, their intensity and width was dependent on the number of deposited bilayers. For the samples of 10 and 20 bilayers the number of observed reflection orders was more than 10, peak intensities were high and the peak widths were small. For the sample with 3 bilayers peak intensity was decreased and only 3 or 4 were visible.

For LB films, deposited onto smooth surfaces, besides Bragg reflections also Kiessig fringes (interference maxima from total film thickness) were visible. They allow to estimate overall film thickness. For the case of rough surfaces Kiessig fringes were absent.

The difference of deposition speed was not manifested in $X$-ray diffraction pattern.

\subsubsection{Results of electron diffraction study}

Electron diffraction patterns were obtained for all series of samples. The films consist of crystallites (flat domains) with basis plane orientation being parallel to substrate and an axis perpendicular to it.

Preliminary analysis of the diffraction pattern shows a dependence of IB film structure of the experimental conditions (Fig.6,7). Misorientation of domains depends on silicon surface treatment and on film deposition conditions.

Fig.6a. Electron diffraction pattern on mechanically polished silicon surface (11l). The structure is amorphous.

Fig.6b. Electron diffraction pattern of chemically polished silicon surface. The structure is monocrystalline.

Fig.7a. Electron diffraction pattern of 3-layered cadmium stearate film, deposited onto mechanically polished silicon substrate (111).

Fig.7b. Electron diffraction pattern of 3-layered cadmium stearate film, deposited onto chemically polished silicon substrate (111).

Moscow April 2, 1993

Principal investigator

Researches :

N.Stiopina

V.Safronov

L. Yanusova

I. Samoilenko

V.Klechkovskaya

E. Rakova

(Film fabrication)

(Film Eabrication)

( $X$-ray studies)

( $X$-ray studies)

(Electron diffraction)

(Electron diffraction) 


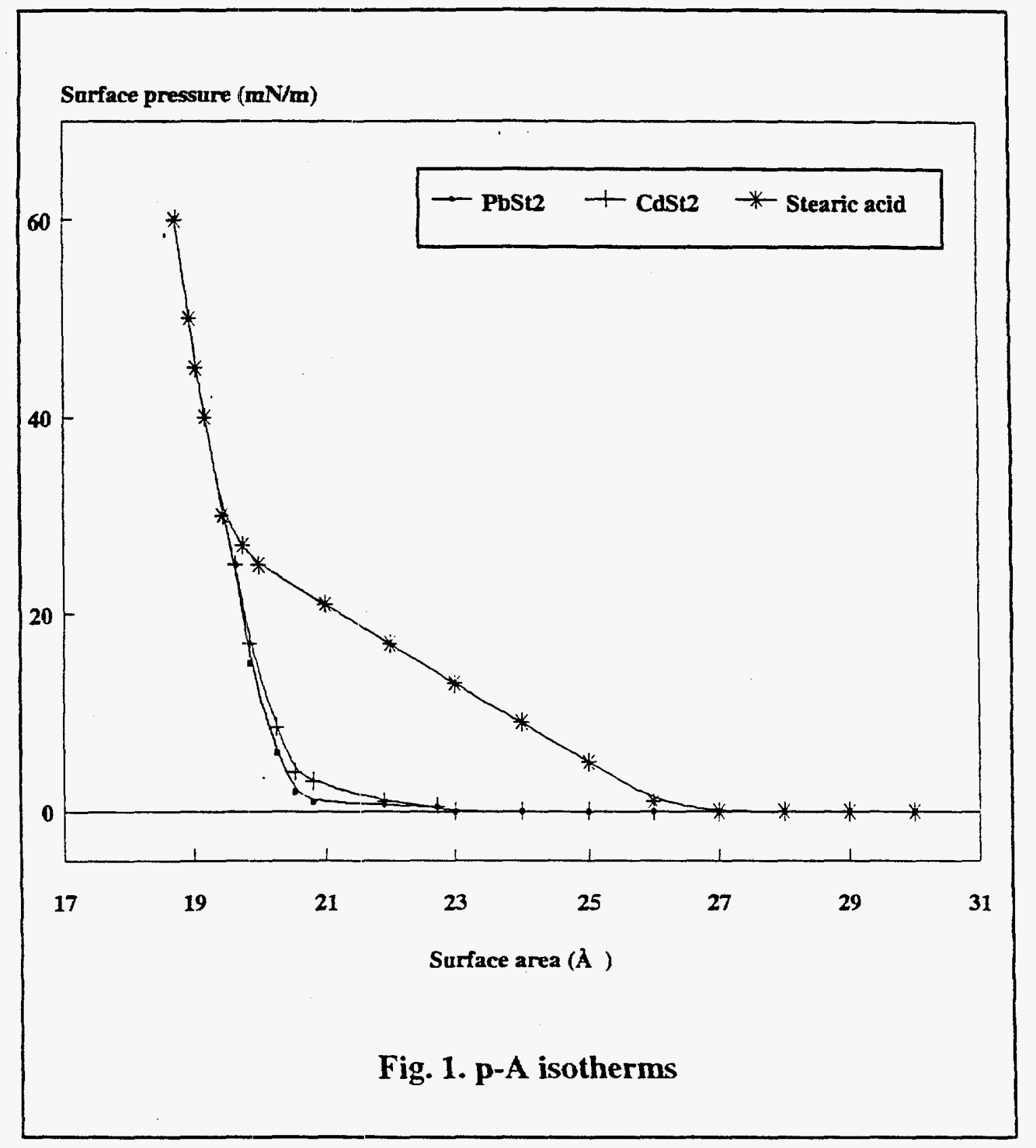




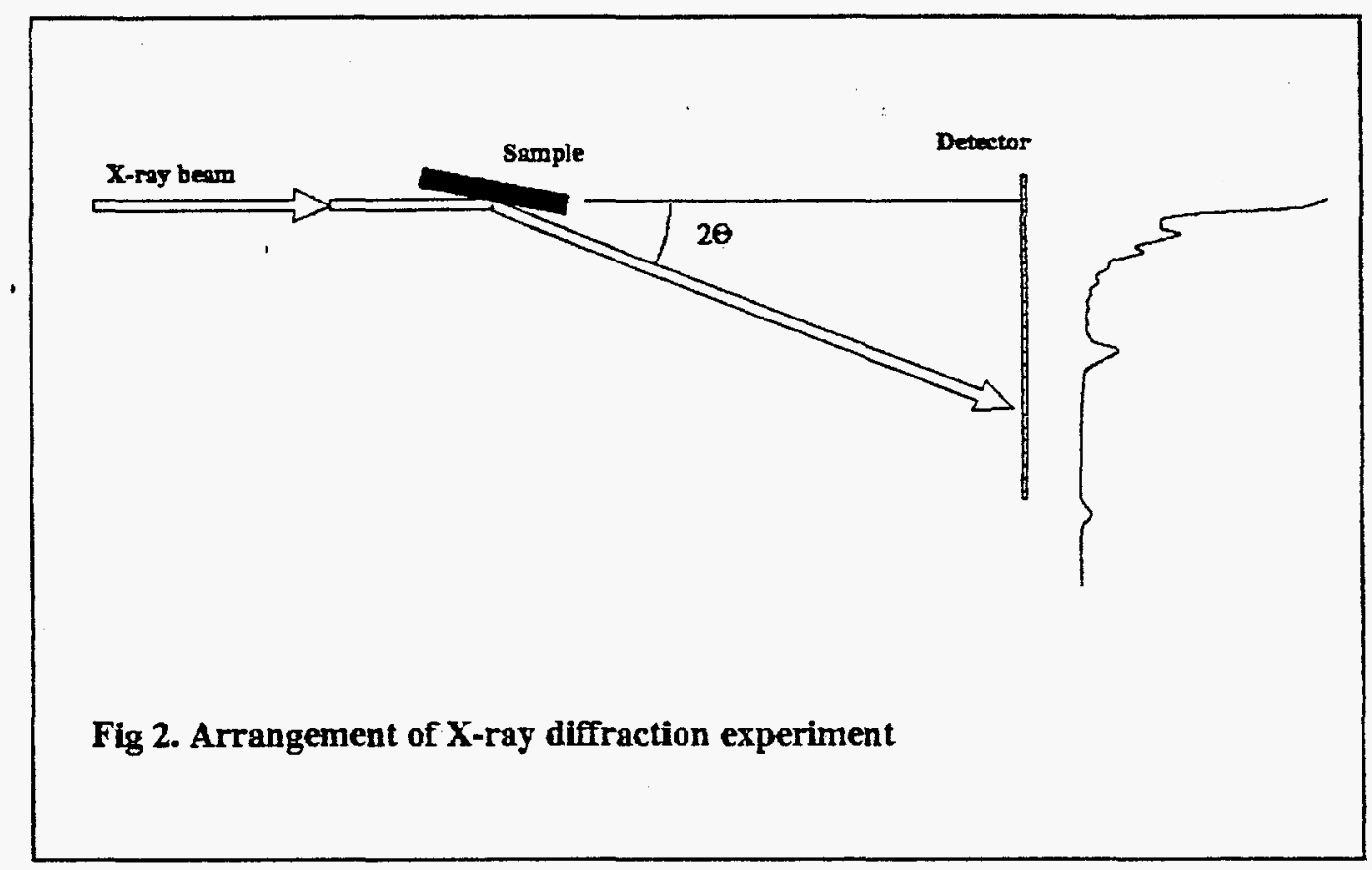




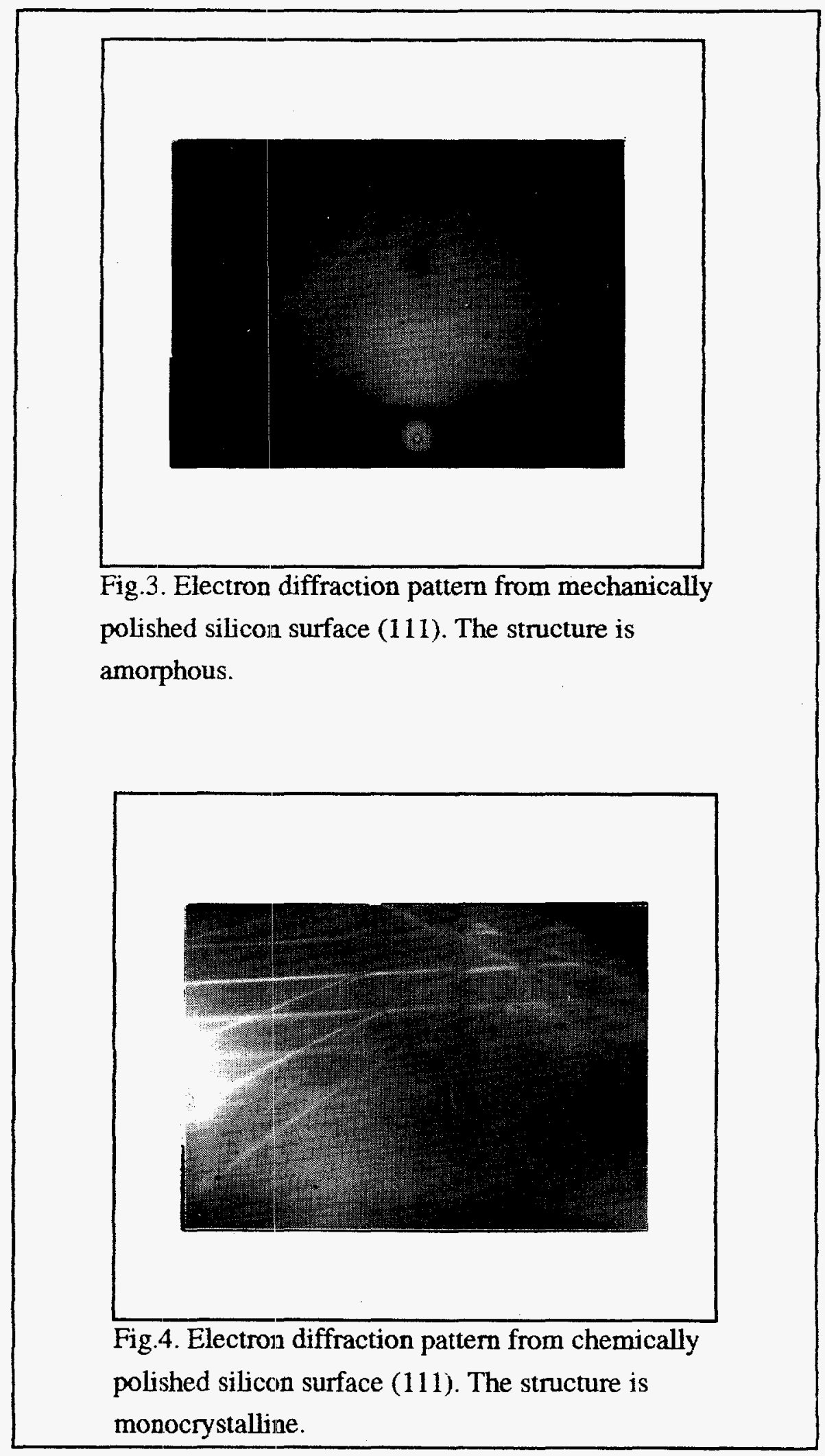


Fig 5. X-ray diffraction pattern of

10 bilayers Cast2

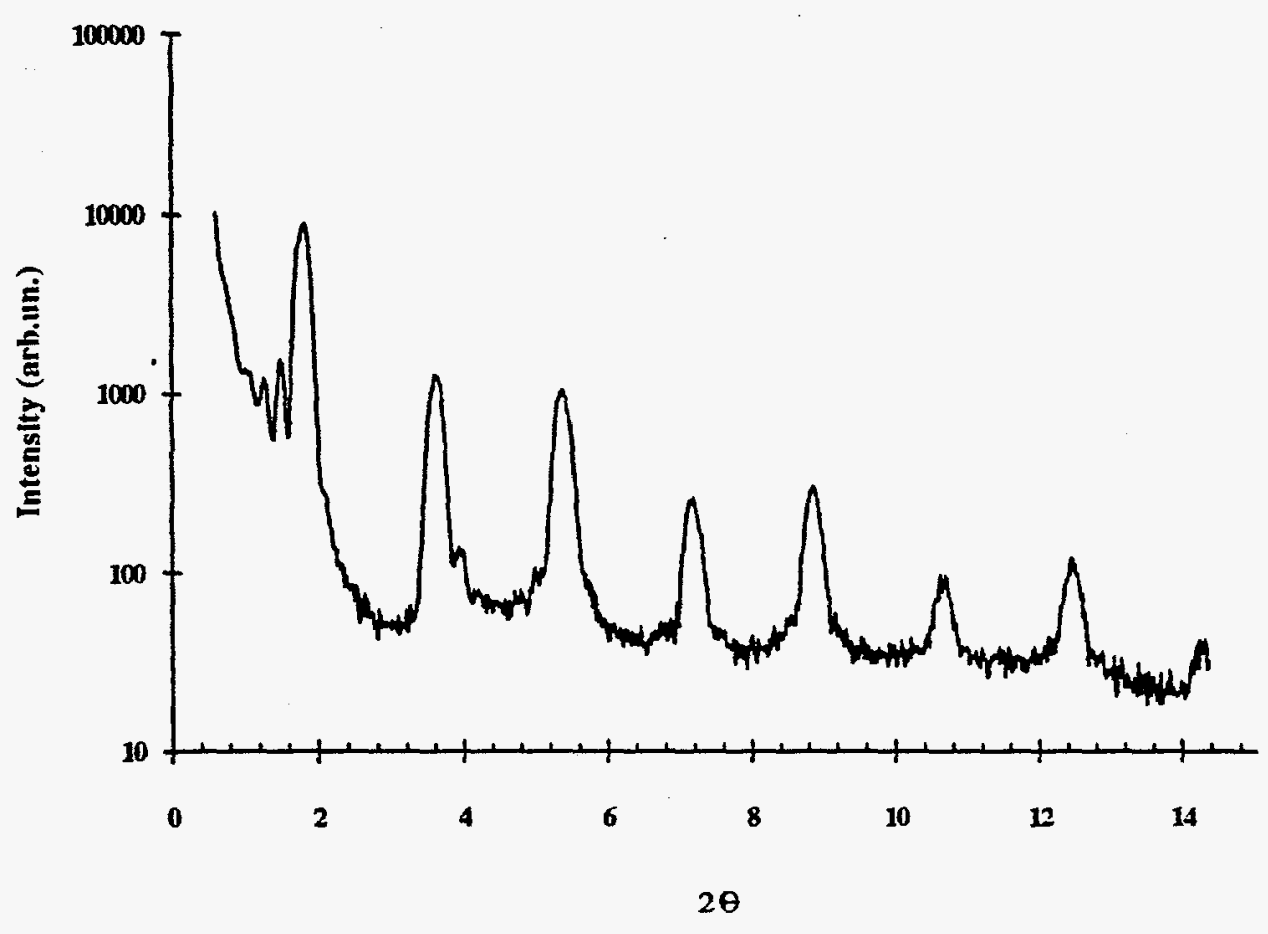




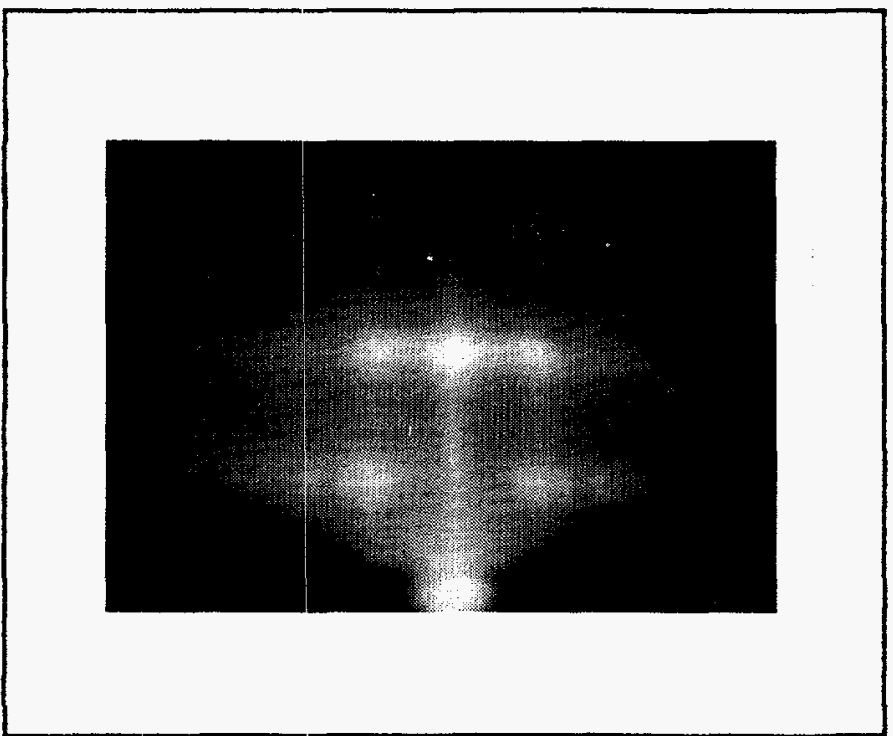

Fig.6. Electron diffraction pattern of 3-layered cadmium stearate film deposited onto mechanically polished silicon substrate (111).

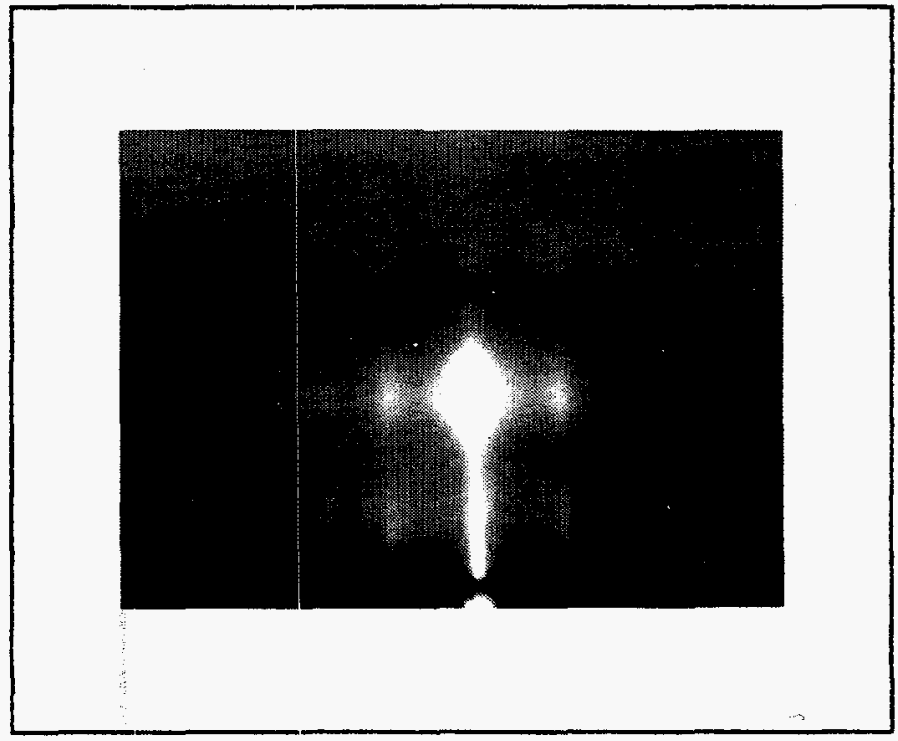

Fig.7. Electron diffraction pattern of 3-layered cadmium stearate film deposited onto chemically polished silicon substrate (111). 


\title{
Chapter 5.2
}

\section{Preparation and Electron Diffraction Study of PbS Films on Langmuir Layers of Fatty Acid Lead Salts}

\section{Feigin, V. Klechkovskaya, E. Rakova, I. Samoilenko, N. Stiopina, and L. Yanusova Institute of Crystallography, Russian Academy of Sciences}

\author{
J. Cesarano III \\ Sandia National Laboratories
}

\begin{abstract}
$\underline{\text { Abstract }}$
Semiconductor lead sulphide films were grown on Langmuir falty acids layers used as substrates. Growth was carried out in the aqueous solutions by chemical reactions at room temperature. Two growth different techniques were employed. The first of them uscd as a substrate a fatty acid monolayer floating on the surface of $\mathrm{Pb}\left(\mathrm{NO}_{3}\right)_{2}$ ayucous solution in a Langmuir trough. $\mathrm{S}^{2}$ - ions were introduced into the reaction chamber through gaseous $\mathrm{H}_{2} \mathrm{~S}$ dissolution or thiourea dissolution. The second technique used a solid Langmuir-Blodgett film of fatty acid on a Si plate as a substrate. Laycr-hy-layer chemisorbtion of $\mathrm{Pb}^{2+}$ and $\mathrm{S}^{2-}$ ions was performed through successive immersions of the substrate in solutions. The structure of Langmuir layers and PbS films was studied by high-energy electron diffraction (HEED) and by elcctron microscopy and X-ray rehectivity as well. Lead sulphide epitaxy with (111) $\mathrm{PbS} / /(001) \mathrm{PbSt}_{2}$ orientation took place on the noating monolayer in a Langmuir trough under strict surface pressure control and employment of gaseous $\mathrm{H}_{2} \mathrm{~S}$ as a source of sulphur ions. Growth of polycrystalline or textured films with mixed orientations of crystallites by (0)(1), (0)11) and (iil) faces parallel to the suhstrate was ohserved in other cases.
\end{abstract}




\section{Introduction}

Langmuir layers of lead fatty acids salts at the aqueous solution surface form generally domains containing hydrophilic $\mathrm{Pb}^{2+}$ "heads" directed to the solution and hydrophobic "tails" oriented perpendicularly to the solution surface [1, 2]. Hcads in each domain form regular two-dimensional hexagonal lattice with interatomic spacings close to those in the lead sulphide lattice [3]. Such arrangement provides a possibility for oriented growth of non-organic semiconductor compound of $\mathrm{PbS}$ on Langmuir layers of organic lcad compounds (stearate, behenate, arachidate etc.).

A process combining preparation of the oriented substrate and growth of the lcad sulphide film was described in recent papers $[3,4]$. A Langmuir monolayer of lead arachidate was employed as a substrate. Oriented nicrocrystals of $\mathrm{PbS}$ grew on the subphase-monolayer interface due to chemical reaction between $\mathrm{Ph}^{2+}$ cathions and $\mathrm{S}^{2-}$ anions.

The work presented is concented with a variety of techniques of growing $\mathrm{PhS}$ on organic substrates. In addition to the technique presented in [3,4], we used the layer-bylayer chemisorbtion of ions $\mathrm{Pb}^{2+}$ and $\mathrm{S}^{2-}$ from solutions of corresponding electrolytes onto solid Langmuir-Blodgett layers and deposition from thiourea solution onto a noating monolayer and onto solid Langmuir-Blodgett substrates $|5,6|$.

\section{Experiment}

The structure of Langmuir substrates and lead sulphide lilms was examined at succesive stages of the growth by high-energy electron diffraction (HEED) with the use of EMR-102 clectron diffraction camera (produced by Electron, Ukrainc) at accelerating voltage of $75 \mathrm{kV}$. This method was used at two modifications: transmission mode with 
tilting the sample in the angular range from $0^{\circ}$ to $80^{\circ}$ and reflection mode (RHEED) at grazing incidence of the electron beam onto the sample [7]. The ordering of LangmuirBlodgett layers in the direction normal to the surface was also examined by X-ray reflectivity in the range of $\mathrm{X}$-ray beam incidence angle from $0^{\circ}$ to $10^{\circ}$. The small-angle $\mathrm{X}$-ray diffractometer AMUR-K at $\mathrm{CuK}_{\alpha}$ radiation (wavelength $1.54 \AA$ ) was employed for this purpose [8]. Morphology and structure of lead sulphide films were studied by transmission electron microscopy (TEM).

\section{Results and discussion}

3.I. PVS growth on a floating monolayer, $S^{2-}$ ions are produced by $\mathrm{H}_{2} \mathrm{~S}$ solving

This procedure consists of lead sulphide deposition through a chemical reaction between $\mathrm{Pb}^{2+}$ and $\mathrm{S}^{2-}$ ions by the technique advanced in [3]. The subphase in a Langmuir trough contained aqueous solution of $\mathrm{Pb}\left(\mathrm{NO}_{3}\right)_{2}$ of $310^{-5} \mathrm{M}$ concentration at $\mathrm{pH}=5.5$. The fatty acid solution in chlorophorm of $1 \mathrm{mg} / \mathrm{ml}$ concentration was applied on the surface of the subphase. The resulting monolayer was compressed by a barricr to $28 \mathrm{mN} / \mathrm{m}$ surface pressure. Sulphur anions were provided by solving gaseous $\mathrm{H}_{2} \mathrm{~S}$ arisen by hydrolysis of $\mathrm{Na}_{2} \mathrm{~S}$. The low $\mathrm{H}_{2} \mathrm{~S}$ pressure prevents a spontaneous generation of $\mathrm{PhS}$ clusters in the solution. Duration of the film growth was varied in the range of $0.5-15$ hours. A c mposite film consisting of a Langmuir monolayer with a grown $\mathrm{PbS}$ film was then applied on a silicon substrate or on a copper grid hy horizontal lift to prepare it for structural investigation.

Electron diffraction pattems from the initial $\mathrm{PbSL}$ film on celluloid are shown on Fig.1. At nomal incidence of the electron beam, the system of Debye rings is ohscrved (Fig. 1a). At inclined incidence of the electron beam (Fig. Ib), reflexes of equal indices $h$ and $k$ are located at elliptic arcs, with the index $l$ taking on values $-l, \ldots,-2,-1,0,+1$, 
$+2, \ldots,+l$. Such a space separation of reflexions points to existence of preferential orientation of domains comprising the Langmuir layer as well as to fonnation of a texture with the $c$ axis perpendicular to the substrate. Estimated size of a single domain was found to be greater than the coherence length of the electron beam $(-200) \dot{A}) .28$ $\mathrm{mN} / \mathrm{m}$ value of surface pressure was found the best to obtain an ordered layer.

Nucleation and growth of $\mathrm{PbS}$ film occured at the Langmuir monolayer-subphase interface. The layer aquired grey color at prolonged duration of growth.

Fig. 2 shows the micrograph of a $\mathrm{PbSt}_{2}$ monolayer exposed to $\mathrm{H}_{2} \mathrm{~S}$ during 2.5 hours. The particies of triangular shape are the $\mathrm{PbS}$ islands grown under $\mathrm{PhS}$ 2 $_{2}$ monolayer and oriented by (111) face parallel to the surface. Misorientation of separate $\mathrm{PbS}$ particles with respect to each other is up to $5^{\circ}$ and is likely caused by domains misorientation in the $\mathrm{PbSt}_{2}$ layer. The linear size of the particles varied from 10()$\left.(1) 40\right)$ $\dot{A}$, average surface density of particles was $210^{-10} \mathrm{~cm}^{-2}$. Particles are twinned along the (111) plane. Twinning is known to be inherent for epitaxial growth of PbS because nucleation at twin positions is of equal probability.

RHEED pattern from this film was obtained for a comparatively large surface region of $0.04 \mathrm{~mm}^{2}$ area at grazing incidence of electron beam onto the sample (Fig. 3a). The intense point 111-refiex demonstrates the existence of (111) PbS preferential orientation parallel to the substrate. As the growth duration increases up to 15 hours, $\mathrm{PbS}$ particles $c(011)$ and (001) oricntations appear (Fig. 3b).

3.2. PbS growth an a floating monolaver, $S^{2-}$ ions are produced by thiourea solving

This technique differs from that above by delivering sulphur ions not from the gaseous phase but from the thiourca solution. For this purpose, the subphase prepared in 
a Langmuir trough was of the following composition: $1 \mathrm{ml}$ of $0.175 \mathrm{M} \mathrm{Pb}\left(\mathrm{NO}_{3}\right)_{2}, 6 \mathrm{ml}$ of $0.57 \mathrm{M} \mathrm{NaOH}, 2 \mathrm{ml}$ of $1 \mathrm{M}$ thiourea, $180 \mathrm{ml}$ of $\mathrm{H}_{2} \mathrm{O}$.

$\mathrm{PbS}$ films were obtained both on a Langmuir monolayer and on a solid Langmuir-Blodgett films deposited on a silicon substrate. To obtain an ordered Langmuir layer, excessive amount of fatty acid was applied on the surface of the subphase with no compression by a barrier. According to [8], this way to compress a Langmuir layer makes it possible to produce an ordered monolayer with the $c$ axis perpendicular to the surface.

Electron diffraction data revealed that $\mathrm{PbS}$ films grown through this technique were polycrystalline (Fig. 4). The possible reason of non-oriented growth is the fonnation of $\mathrm{PbS}$ clusters in colloid state which is observed visually by the solution opalescence.

\subsection{Layer-by-layer chemisorbtion of ions}

Langmuir-Blodgett films of lead stearate and lead arachidate of even and odd numbers of monolayers deposited onto silicon wafers of (111) and (001) orientations were employed as substrates.

Perfection of $\mathrm{PbSl}_{2}$ films against orientation of the $\mathrm{Si}$ substrate and its preliminary treatment was studied by RHEED and by X-ray reflectivity. LangmuirBlodgct films were of a textured polycrystalline structure with the $c$ axis perpendicular to the su: face on the Si substrates of both orientations. RHEED patterns (Fig. 5) contain a system of narrow streaks perpendicular to the sample shadow. The intensity modulations along the streaks reveal the periodicity of the layer packing in the direction of the nomal. Geometry of the diffraction patten does not change under azimuthal scamning the reciprocal lattice. Thus, the film consists of the domains oriented hy (0)1) 
plane parallel to the surface and randomly oriented in the surface plane. Dimensions of coherently scattering regions (domains) were grealer than 200$) \AA$.

Preliminary treatment of the Si surface was found to influence essentially thc structure of Langmuir-Blodgett films. For $\mathrm{PbSt}_{2}$ films deposited on chemically polished substrates, fitting of X-ray reflectivity data (Fig. 6a) revealed that roughness of the surface did not excecd $10 \AA$. By contrast, the diffraction curve from the film deposited onto a mechanically polished substrate (Fig. 8b) shows no Kiessig fringes. So the surface of such films is much more rough. This fact leads to the conclusion that thin dielectric Langmuir films of high perfection can be built-up only on chemically polished Si substrates. This requirement was met for experiments presented below.

The Si substrate with a deposited Langmuir-Blodgelt film was succesively immerced in $0.01 \mathrm{M} \mathrm{Pb}\left(\mathrm{NO}_{3}\right)_{2}$ solution of $\mathrm{pH}=2.8$ (cathion source), in watcr, in 0.01 $\mathrm{M} \mathrm{Na} 2 \mathrm{~S}$ solution of $\mathrm{pH}=11.6$ (anion source), in water, and such a cycle was repeated. $\mathrm{Pb}^{2+}$ ions are assumed to bc adsorbed on the LB-film surface. At immersion in Na2S solution, reaction with $\mathrm{S}^{2-}$ ions from the solution occured resulting in $\mathrm{PbS}$ fonnation as well as $\mathrm{S}^{2-}$ ions adsorbtion. Excessive ions were washed out in distilled water. Time of the sample exposure in every solution was about $40 \mathrm{scc}$.

RHEED patterns from lead sulphide films grown by layer-by-layer chemisorbtion on a solid Langmuir-Blodgett substrate revaled the polycrystalline structure of those films. The size of crystallites was estimated by a half-width of diffraction maxima and its value varied from 100 to $500 \AA$ as a number of deposition cycles increased from 5 to 60 .

Non-oriented growth of lead sulphide on the Langmuir-Blodgett solid films and its oriented growth on the floating Langmuir monolayer can be explained in ternus of lattice mismatch at the epitaxy.

It is known that oriented growth takes place at the small dimensional mismatch of atomic nets in conjugative planes of the substrate and the film, as a rool. Let us consider the atomic nets shown on Fig. 7. Lead sulphide is of cubic structure, space group Fm3m, 
$a_{0}=5.95 \mathrm{~A}$. At the $<110>$ directions, closely packed chains of $\mathrm{Pb}$ atoms are localed. The interatonic $\mathrm{Pb}-\mathrm{Pb}$ spacing in these chains is $4.20 \mathrm{~A}$. Al the (111) plane, $\mathrm{Pb}$ atoms form the hexagonal net (Fig. 7a). Ordered monolayers of fatty acids form also hexagonal twodimensional lattice an the air-water interface, $a_{0}=4.8 \mathrm{~A}[10]$ (Fig. $7 \mathrm{~b}$ ). The "head-hcad" spacing in directions of $<21>$ type is close to the doubled $\mathrm{Pb}-\mathrm{Pb}$ spacing in directions of $<01>$ type. The similar symmetry and the small dimensional mismatch provide the possibility of $\mathrm{PbS}$ epitaxy on the fatty acids floating monolayers.

By contrast to the floating monolayers, the $\mathrm{PbSt}_{2}$ structure in the solid LangmuirBlodgett films is represented in a pseudoorthorhombic unit cell, space group $P 2_{1} / \mathrm{h}$, periods $\mathrm{a}=4.96 \mathrm{~A}, \mathrm{~b}=7.39 \mathrm{~A}, \mathrm{c}=96 \mathrm{~A}, \beta=90^{\circ}$ [11]. Two-dimensional lattice in the (001) plane is of two-fold symmetry (Fig. 7c). This results in the angular and dimensional mismatches which cause non-oriented growth of lead sulphide on the $\mathrm{PhS}_{2}$ Langmuir-Blodgett films deposited on silicon substrates.

Growth of oriented non-organic films from solution in situ on Langmuir laycrs of organic compounds is a promising way to produce various epitaxial heterostructures containing organic and non-organic constituents and to simulate processes occured in the nature. 


\section{References}

1. L'vov Yu.M., Feigin L.A., Soviet Physics Crystallography, v. 32, No 3 (1987), p.379

2. Peterson I.R., J. Phys. (D), v. 23 (1990), p. 379

3. Zhao X.K., Yang Y., McCormick L.D., Fender J.H., J. Phys. Chem., v.96, No 24 (1992), p.9993

4. Zhao X.K., McCormick L.D., Appl. Phys. Lett., v. 61 , No 7 (1992), p. 849

5. Nikolau Y.F., Appl. Surf. Scl., v. 22/23 (1985), p. 1061

6. Davis J.L., Norr M.K., J. Appl. Phys., v. 37, No 4 (1966), p. 1670

7. Pinsker Z.G., Electron diffraction. Buttersworth, London (1954)

8. Mogilevsky L.Y., Dembo A.T., Svergun D.I., Feigin L.A., Kristallografia, v. 29 (1984), p.587 (in Russian)

9. Legrand J.F., Renault A., Konovalov O.V., Chevigny E., Als-Nielsen J., Gruebel G., Berge B., Submitted to Thin Solid Films (1993)

10. Jacquemain D., Wolf Sh.G., Leveiller F., Deutsch M., Kjaer K., Als-Nielsen J., Lahav M., Leiserowitz. L., Angew. Chem. Int. Ed. Engl., v. 31 (1992), p. 130

11. Ivakin G.I., Erokhin V.V., Klechkovskaya V.V., Biol. Membrany, v. 7 (1991), p.1154 (in Russian) 


\section{Figure captions}

Fig. 1. Transmission electron diffraction patterns from a lead stearate Langmuir-Blodgett film on celluloid taken at normal ( $a$ ) and oblique $(b)$ electron beam incidence.

Fig. 2. Electron micrograph of $\mathrm{PbS}$ oriented particles grown on the floating $\mathrm{PbSt}_{2}$ monolayer compressed to surface pressure $28 \mathrm{mN} / \mathrm{m}$. Duration of growth $\mathrm{t}=2.5$ hours.

Fig. 3. RHEED-patterns from $\mathrm{PbS}$ films grown on the floating $\mathrm{PbSt}_{2}$ monolayer at different durations of growth: $\mathrm{t}=2.5$ hours $(a)$ and $\mathrm{t}=15$ hours $(b)$.

Fig. 4. RHEED-pattern from a $\mathrm{PbS}$ film grown on the $\mathrm{PbSl}_{2}$ Moating monolayer, $\mathrm{S}^{2-}$ anions were produced by thiourea solution.

Fig. 5. RHEED-pattern from $\mathrm{PbSt}_{2}$ Langmuir-Blodgett film (thickness of 10 bilayers) deposited onto chemically polished Si substrate.

Fig. 6. X-ray reflectivity curves of $\mathrm{PbSt}_{2}$ Langmuir-Blodgett films deposited onto chemically polished (a) and mechanically polished $(b)$ Si substrate.

Fig. 7. Scḩemes of atomic arrangement for (111) $\mathrm{PbS}$ plane (a), (001) $\mathrm{PbSt}_{2}$ in closed hexagonal $(b)$ and orthorombic $(c)$ packing. 

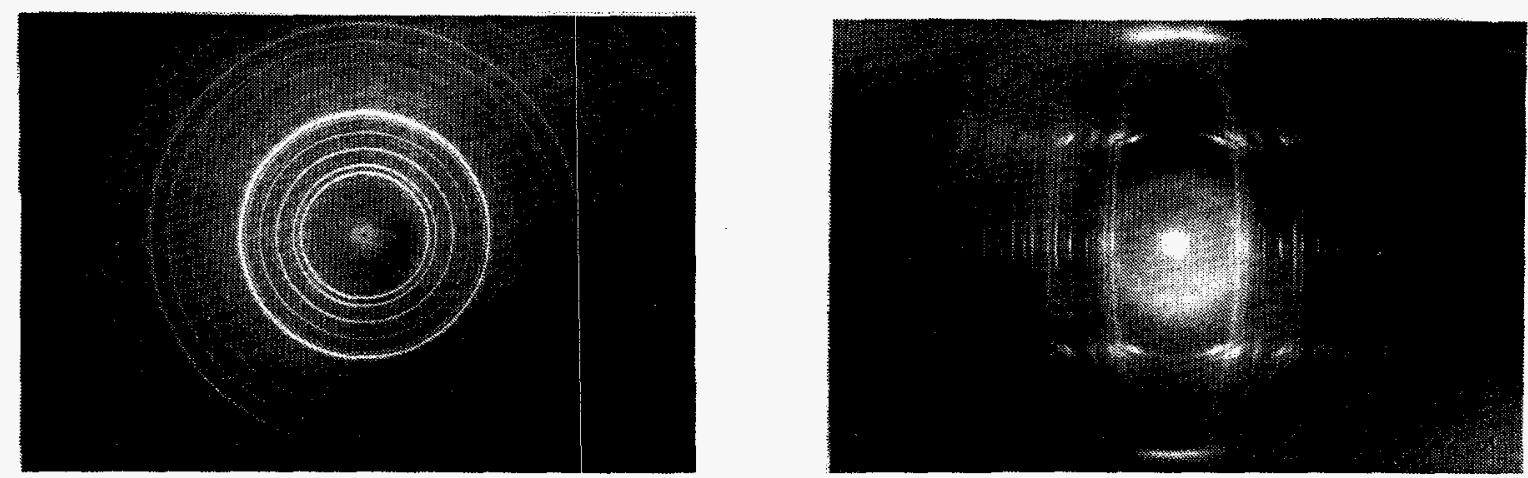

Figure 1a

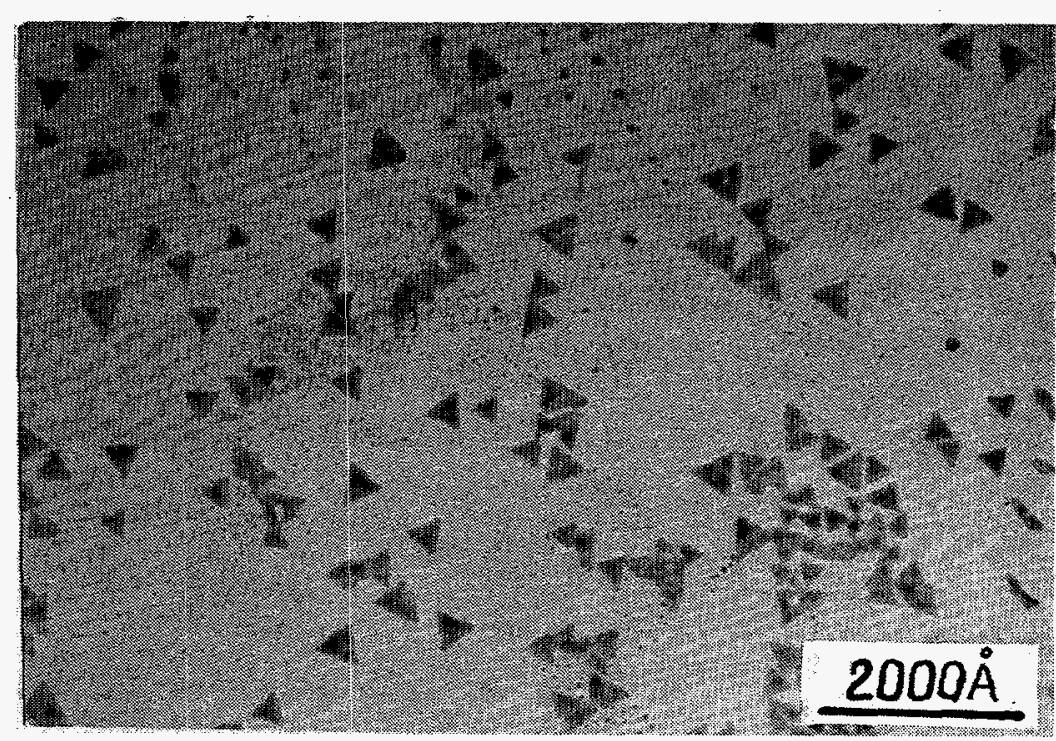

Figure 1b

Figure 2

$$
--,-\cdots
$$

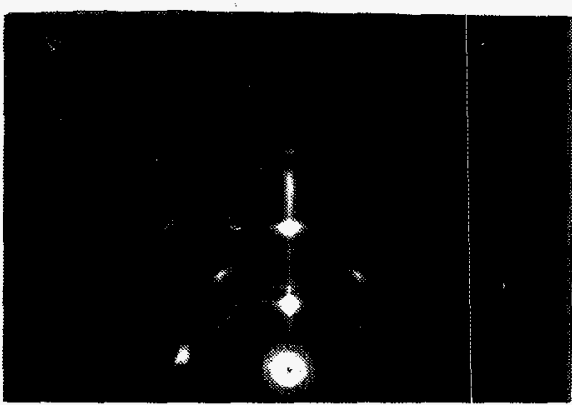

Figure 3a

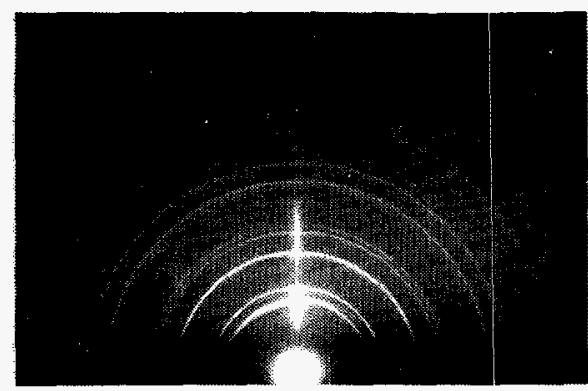

Figure 4

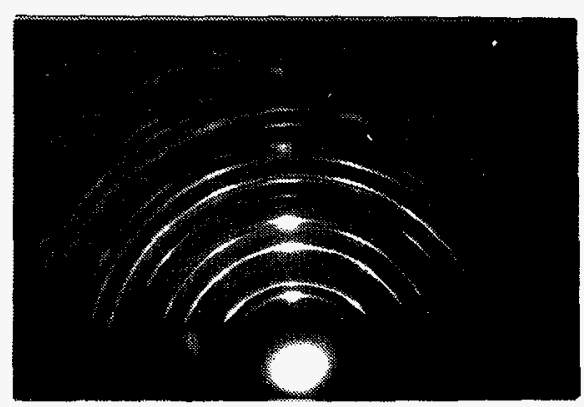

Figure 3b

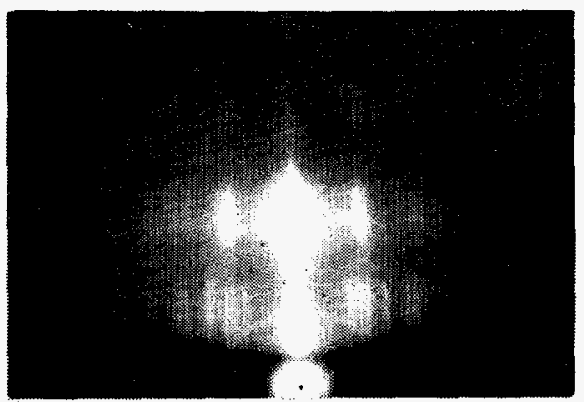

Figure 5 


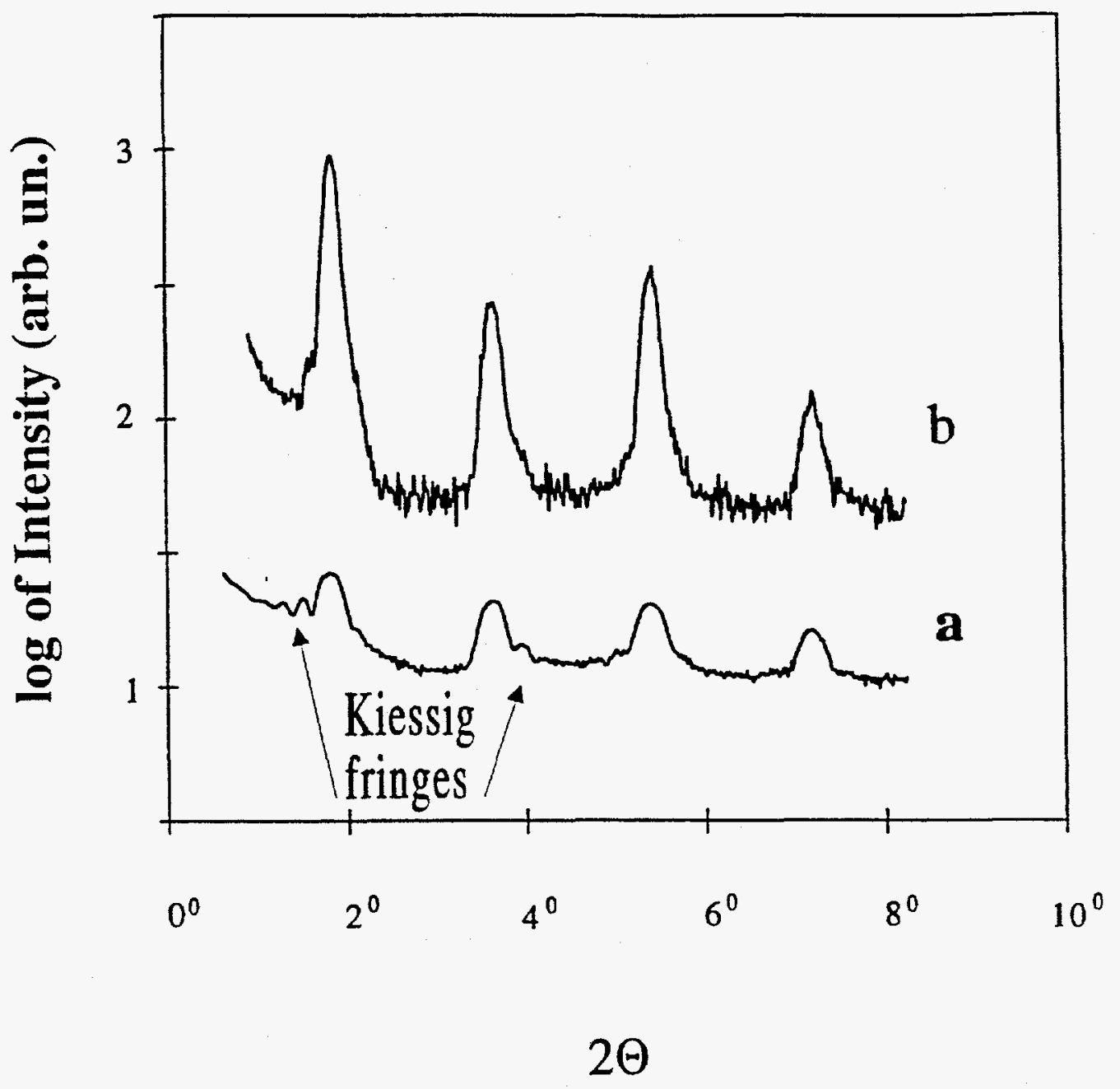

Figure 6 

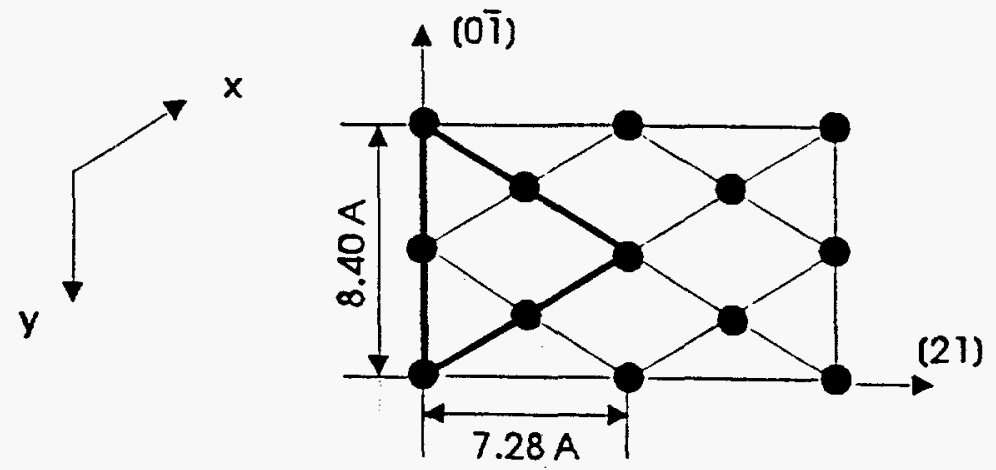

a
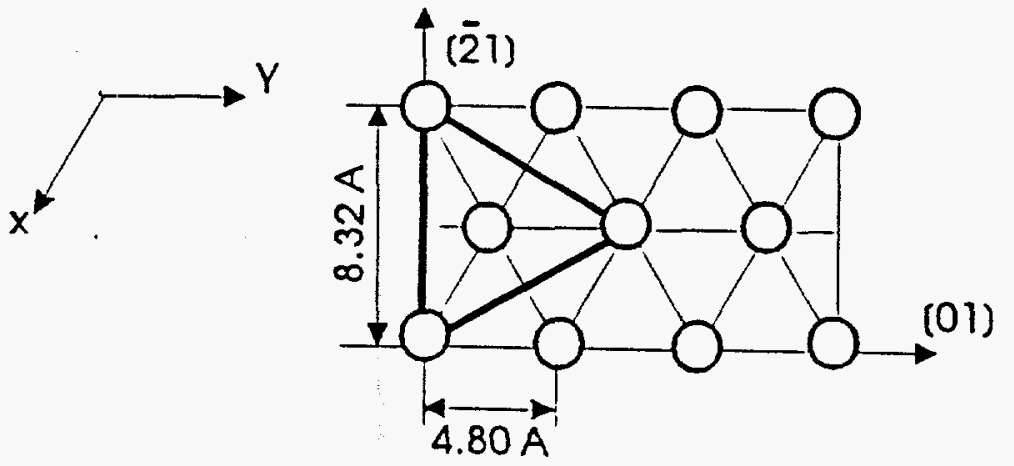

b
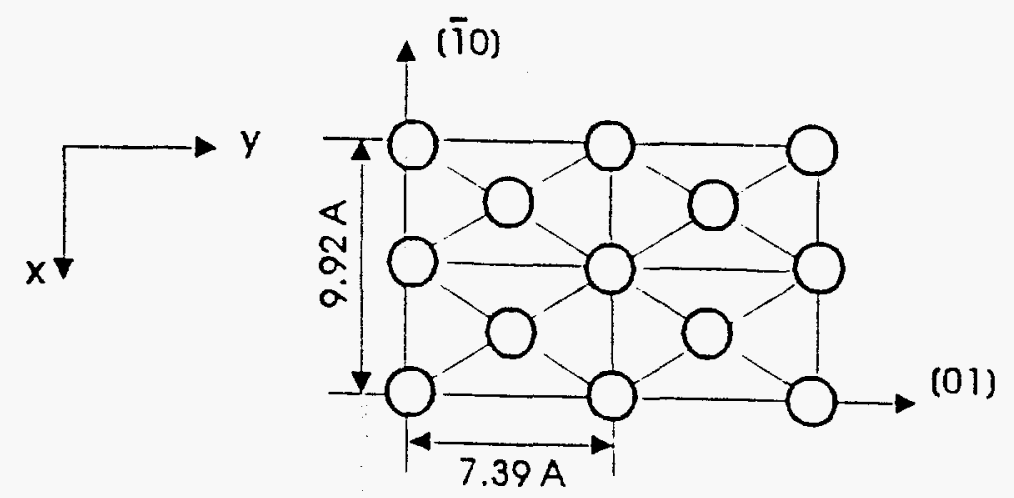

Figure 7 


\title{
Chapter 5.3
}

\section{Electron Diffraction Study of CdS Films Grown on Langmuir Layers of Fatty Acid Lead Salts: Structure and Orientation}

L. Feigin, V. Klechkovskaya, E. Rakova, I. Samoilenko, N. Stiopina, and L. Yanusova Institute of Crystallography, Russian Academy of Sciences

\section{J. Cesarano III}

Sandia National Laboratories

\begin{abstract}
The oriented CdS films were grown on the floating cadmium arachidate ( $\left.\mathrm{CdArh}_{2}\right)$

Langmuir monolayers from solution due to the interaction between $\mathrm{Cd}\left(\mathrm{NO}_{3}\right)_{2}$ soluted in the subphase and gaseous $\mathrm{H}_{2} \mathrm{~S}$. The inhomogeneous distribution of $\mathrm{CdS}$ crystallites on $\mathrm{CdArh}_{2}$ was observed. According to High Energy Electron Diffraction data, the cubic CdS crystallites are oriented by (111) plane parallel to the (001) plane of hexagonal $\mathrm{CdArh}_{2}$ at the following mutual relation:
\end{abstract}

(111) [110] CdS || (001) [100] CdArh 2 


\section{Introduction}

Heterostructures made of alternating layers of organic and non-organic layers are of interest in view of their prospective employment in molecular electronics as well as in view of simulating of biomineralization phenomena in the nature. The technique of fabrication of such heterostructures through crystallization of nonorganic components from the oversaturated aqueous solutions on a Langmuir layer has been intensively developed in recent years [1-4]. Growth of the non-organic layer is usually caused by a chemical reaction at the interface between the Langmuir monolayer and the aqueous subphase.

This technique is applicable for the growth of compounds which are of low solubility in water. Particularly, this procedure is promising for CdS as its solubility product is $10^{-28}$. Reports on CdS growth on Langmuir layers were presented in $[3,4]$. Cadmium sulfide was deposited onto Langmuir layers due to interaction between $\mathrm{CdCl}_{2}$ soluted in the subphase and $\mathrm{H}_{2} \mathrm{~S}$ provided from gaseous phase. Particulate $\mathrm{CdS}$ films on a Langmuir layer of heptadecylmalonic acid di (2-aminoethylamid) revealed the dependence of the absorbtion band edge position on the size of the deposited CdS particles [3]. Also, variation of the CdS film density for different compositions of the subphase used and for the kind of amphiphilic compounds in the Langmuir monolayer was observed [4]. Structural parameters of those films were not presented.

This work deals with growth of CdS films from a solution on the Langmuir monolayers of cadmium arachidate $\left(\mathrm{CdArh}_{2}\right)$ and cadmium behenate $\left(\mathrm{CdBeh}_{2}\right)$ as well as with study of the structure of such films and the mutual orientation of the films and the substrates by high-energy electron diffraction (HEED) and by transmission electron microscopy (TEM). 


\section{Experiment}

Growth of $\mathrm{CdS}$ films on the floating layer of $\mathrm{Cd}$ arachidate was performed in the Langmuir trough through the following procedure. The $510^{-4} \mathrm{M}$ aqueous solution of $\mathrm{Cd}\left(\mathrm{NO}_{3}\right)_{2} 4 \mathrm{H}_{2} \mathrm{O}$ was used as the subphase. Value of the subphase $\mathrm{pH}$ was set to 5.5 by adding nitric acid. $1 \mathrm{mg} /$ solution of arachidic acid $\mathrm{C}_{19} \mathrm{H}_{39} \mathrm{COOH}$ in chlorophorm was applied onto the surface of the subphase and then the monolayer of fatty acid was compressed to surface pressure of $28 \mathrm{mN} / \mathrm{m}$. Such value corresponds to the mostly ordered packing in the monolayer as it was previously revealed by electron diffraction data. Cadmium suiphide was produced through the reaction between $\mathrm{Cd}^{2+}$ cation and $\mathrm{S}^{2-} / \mathrm{HS}^{-}$anions, which were delivered to the subphase from gaseous $\mathrm{H}_{2} \mathrm{~S}$ provided by hydrolysis of $0.02 \mathrm{M} \mathrm{Na}_{2} \mathrm{~S}$ solution. Time of growth was varied from 0.5 to 3 hours under controlled surface pressure in the monolayer.

The procedure of $\mathrm{CdS}$ growth on the $\mathrm{CdBeh}_{2}$ monolayer was different from that above. The subphase was placed in a Petri dish. The composition of the subphase was following: $20 \mathrm{ml}$ of $0.1 \mathrm{M} \mathrm{Cd}\left(\mathrm{NO}_{3}\right)_{2}, 75 \mathrm{ml}$ of $6 \mathrm{M} \mathrm{NH}_{4} \mathrm{OH}, 40 \mathrm{ml}$ of $1 \mathrm{M}$ $\mathrm{CS}\left(\mathrm{NH}_{2}\right)_{2}$, and $75 \mathrm{ml}$ of $\mathrm{H}_{2} \mathrm{O} .1 \mathrm{mg} / \mathrm{l}$ solution of behenic acid $\mathrm{C}_{21} \mathrm{H}_{43} \mathrm{COOH}$ in chlorophorm was applied onto the surface of the subphase. Compression of the produced Langmuir monolayer was provided by the technique of "excessive droplet". According to [5], this technique is suitable for obtaining an ordered cadmium arachidate monolayer at the subphase surface.

The structure of Langmuir layer as well as the structure of cadmium sulphide films grown on them was studied by TEM on an electron microscope BS-540 and by HEED at $E=75 \mathrm{keV}$ on an electron diffractometer EMR-102. Diffraction patterns were obtained in transmission mode in the range of sample tilting of $0.80^{\circ}$ (oblique textures technique).

Samples for structural characterization were prepared by deposition of the Langmuir monolayer with the grown CdS film onto the copper grid. The grid was preliminary covered with a thin amorphous layer of cellulose which was transparent for 
electron beam and did not produce its own diffaction pattern. The sample was removed from the solution through the "horizontal lif" technique.

\section{Results and discussion}

3.1. The structure of a monolayer of cadmium arachidate used as a substrate for CdS growth

Some ways of aliphatic acids molecules packing in the Langmuir monolayer on the subphase surface are theoretically possible [6]. In the temperature range of 10 $30^{\circ} \mathrm{C}$ and in the surface pressure range of $10-40 \mathrm{mN} / \mathrm{m}$, a hexagonal and four types of rhombic two-dimensional phases were observed by diffaction of synchrotron radiation at grazing incidence mode "in situ" from floating monolayers of acids $\mathrm{C}_{19} \mathrm{H}_{41} \mathrm{COOH}$ and $\mathrm{C}_{21} \mathrm{H}_{43} \mathrm{COOH}[7,8]$. We had to transfer the films to solid substrates to carry out electron diffraction study of them Obviously, this process may change the original packing of molecules in the layer. For example, in the case of cadmium stearate in Langmuir-Blodgett films built: of 10-20 bilayers at room temperature the rhombic phase with periods $a=4.96 \mathrm{~A}$ and $\mathrm{b}=7.39 \mathrm{~A}$ was revealed. This phase transforms to the hexagonal one at heating to $60^{\circ} \mathrm{C}[9,10]$. Fig.1 presents the electron diffraction pattern from a monolayer of $\mathrm{CdArh}_{2}$ on a celluloid substrate taken at normal incidence of the electron beam to the sarnple. The reflexes in the shape of pronounced spots and arcs are arranged with the six-fold symmetry. Reflections indices and their intensities correspond to a hexagonal packing of molecules in the domains constituing the film The lattice period $a=4.80 \mathrm{~A}$, the [001]-direction is perpendicular to the film surface. Domains are misoriented to the angles up to $10^{\circ}$. The hexagonal phase is dominant though a thombic phase with the periods $a=4.96 \mathrm{~A}$ and $\mathrm{b}=7.39 \mathrm{~A}$ is also revealed by two weak rings which are due to the most intensive reflections of this phase.

As can be seen in the phase diagram of $\mathrm{C}_{21} \mathrm{H}_{43} \mathrm{COOH}$ [11] shown on Fig. 2, the conditions of films growth presented above are close to the triple point $A$ where probable is the coexistence of the rhombic phase with the hexagonal one. 


\subsection{The structure of CdS film and mutual orientations of CdS film and}

\section{CdArh2 substrate.}

It is known that CdS exists in two structural modifications: cubic (sphalerite type) and hexagonal (wurtzite type). At $\mathrm{CdS}$ growth from the solution containing $\mathrm{NO}_{3}$ anion, observed is usually the cubic modification with the period $a=5.83 \mathrm{~A}$ and space group $\mathrm{F} \overline{4} 3 \mathrm{~m}[12]$.

The CdS cubic cell is presented on Fig. 3. Atoms of $\mathrm{Cd}$ and $\mathrm{S}$ are embedded at sites of face-centered sublattices displaced to $1 / 4$ of the spatial diagonal to one another. The structure do not possess the centre of symmetry and $\langle 111\rangle$ directions are polar in it. $\{111\}$ planes consist of cations or anions which alterate layer-by-layer in the $\langle 111\rangle$ directions and are charged positively $\left(\mathrm{Cd}^{2+}\right.$ planes) or negatively ( $\mathrm{S}^{2-}$ planes). This produces the strong electrostatic interaction at the interface during growth.

At the (111) plane, atoms of the same name arrange in a regular hexagonal net well matched by its period with the hexagonal net formed by hydrophilic $\mathrm{Cd}^{2+}$ heads in a compressed monolayer of cadmium arachidate (Fig. $4 \mathrm{a}, \mathrm{b}$ ).

Fig. 5 shows the electron diffaction pattern from the CdS film grown on the floating cadmium arachidate monolayer during 3 hours. Reflections both by the film and by the substrate are presented thus enabling their mutual orientation to be determined. The ring nearest to the primary beam consists of 6 reflexes and is associated with the (100) plane of $\mathrm{CdArh}_{2}$. The next ring is associated with the (111) CdS plane. The reflections of these rings are turned to $30^{\circ}$ to one another. Strong reflections positioned at the ring indicated by the arrow coinside. They are responsible for the reflection $220 \mathrm{CdS}(\mathrm{d} 220=2.06 \mathrm{~A})$ and for the reflection 200 from the hexagonal phase of $\mathrm{CdArh}_{2}(\mathrm{~d}=2.08 \mathrm{~A})$.

The analysis of the diffraction pattern makes it possible to conclude that both the CdS film and the CdArh 2 substrate consists of domains, the plane with the axis of the 3 rd $(6$ th) order of which is oriented parallel to the substrate surface, i.e.

(111) $\mathrm{CdS} \|$ (001) $\mathrm{CdArh}_{2}$. 
Directions of the $\langle 110\rangle$ kind in the CdS are parallel to directions of the $\langle 100\rangle$ in the CdArh2. In two-dimensional coordinates, the latter corresponds to the parallelity of [01] CdS and [ $\overline{2} 1] \mathrm{CdArh}_{2}$ directions (see Fig.4). The domains are turned with respect to one another to angles up to $10^{\circ}$ in the plane of the sample. Strictly speaking, 111 reflections of CdS may not appear in the diffaction pattern if the sample is oriented by its (111) plane parallel to the substrate. Their existence indicates that the domains of the film are misoriented in the bulk. It is of interest to note that at initial stages of growth (growth duration $\sim 0.5$ hours), reflexes from the CdS are distorted (Fig. 6, shown by the arrow). This distortion can be explained by the influence of crystallites shape and their strong interaction with $\mathrm{CdArh}_{2}$ - layer. Some part of CaS crystallites are misoriented what is possibly due to formation of CdS clusters in the subphase or due to growth on the CdArh 2 domains of orthorhombic structure.

\subsection{Morphology of CdS films}

Samples were examined by TEM at successive stages of growth. Fig. 7 shows micrographs from the samples after 0.5 (Fig. 7a) and 3 (Fig. 7b) hour duration of the reaction. It is seen that nucleation of CdS islands is inhomogeneous in active points at the monolayer-subphase interface. On growing up, islands form a continuous layer. It is worthwile noting that $\mathrm{CdS}$ islands are not faced contrary to $\mathrm{PbS}$ islands grown at the same conditions [13, our data in print]. It follows from the phenomenological theory of crystal growth that origination of singular faces during the crystal growth depends on the ratio of specific crystallization heat to $\mathrm{kT}$ : the larger this ratio, the larger probability of origination of a singular face. Probably, values of specific crystallization heat for $\mathrm{PbS}$ and $\mathrm{CdS}$ at conditions of growth from the solution under chemical reaction are essentially different.

\subsection{CdS growth at supplying $\mathrm{S}^{2-}$ ions from the solution of $(\mathrm{NH})_{2} \mathrm{CS}$}

Employment of solved thiourea as a source of $\mathrm{S}^{2-}$ ions is more suitable because it eliminates the inconvenience of usage of gaseous $\mathrm{H}_{2} \mathrm{~S}$. However, CdS films 
grown by this technique both on the behenic acid monolayers and on the arachidic acid ones were polycrystalline. It seems that essential part of CdS crystallytes nucleated in the subphase and then deposited onto the monolayer. As compared to this results the preceding technique allows the monitoring of $\mathrm{CdS}$ growth. Maintaining both low $\mathrm{H}_{2} \mathrm{~S}$ pressure and acidic conditions in the subphase suppresses the origination of $\mathrm{CdS}$ clusters in the bulk of the subphase thus resulting in growth of CdS particles mainly at the monolayer-subphase interface.

\section{Conclusions}

Oriented CdS films were grown on a floating $\mathrm{CdArh}_{2}$ monolayer. Films are of mosaic structure with the preferrable orientation of the (111) face parallel to the surface. On the base of diffraction patterns analysis, orientational relations between the hexagonal phase of the cadmium arachidate Langmuir monolayer and the cubic phase of the cadmium sulphide film grown on it were obtained. It turned out that

(111) CdS \| (001) CdArh 2

[1]̄0] CdS $\|[100] \mathrm{CdArh}_{2}$ 


\section{References}

1. S.Mann. Nature. 332, 1988, p.119.

2. S.Rajam, B.R.Heywood, J.B.A.Walker, S.Mann, RJ.Davey, J.D.Birchall. J.Chem.Soc.Far.Trans. 87, 1991, p.727.

3. K.C.Yi, J.H.Fendler. Langmuir. 6, 1990, p.1519.

4. X.K.Zhao, S.Xu, J.H.Fendler. Langmuir. 7, 1991, p.520.

5. J.F.Legrand, A.Renault, O.V.Konovalov, E.Chevigny, J.Als-Nielsen, G.Gruebel, B.Berge. Thin Solid Films. (in press).

6. V.M.Kaganer, V.L.Indenbom J.Phys II France. 3, 1993, p.813.

7. B.Lin, M.C.Shih, T.M.Bohanon, G.E.Ice, P.Dutta. Phys.Rev.Lett. 65, 1990, p.191.

8. R.M.Kenn, C.Bolnn, A.M.Bibo, I.R.Peterson, H.Mohwald, K.Kjaer, J.AlsNielsen. J.Phys.Chem. 95, 1991, p.2092.

9. G.I.Ivakin, V.V.Klechkovskaya. Izv. Acad. Nauk., ser. phys. 57, N2, 1993, p.30. (in Russian).

10. G.I.Ivakin, V.V.Erokhin, V.V.Klechkovskaya. Biol.Membranes. 7, 1990, p.1154.

11. D.Jacquemain, Sh.G.Wolf, F.Leveiller, M.Dentsch, KKjaer, J.Als-Nielsen, M.Lahav and L.Leiserowitz. Angew.Chem.Int. Ed.Engl. 31, 1992, p. 130

12. R Sato. Acta Cryst. 15, 1962, p.1109.

13. X.K.Zhao, J.Yang, L.D.McCormick and J.H.Fendler. J.Phys.Chem vol. $96, \mathrm{~N} 24,1992$, p.9933. 
Figure captions

Fig. 1. Electron diffraction pattern from $\mathrm{CdArh}_{2}$ monolayer. The domains of hexagonal phase oriented by $(001)$ plane parallel to the surface coexists with the domains of polycrystalline orthorhombic phase.

Fig.2. Phase diagram for behenic acid Langmuir layer (according to [11]).

Fig.3. The scheme of CdS cubic unit cell.

Fig.4. The atomic nets in (111) - CdS plane (a) and (001) plane of hexagonal CdArh 2 (b).

Fig.5. Electron diffraction pattern from the CdS-film grown on $\mathrm{CdArh}_{2}$ - monolayer . ( 3 h growing).

Fig.6. Electron diffraction pattern from the CdS-film on $\mathrm{CdArh}_{2}$ floating monolayer ( $0.5 \mathrm{~h}$ growing). The arrow shows $111-$ reflections of distorted form.

Fig.7. TEM - micrographs of CdS-films on $\mathrm{CdArh}_{2}$ floating monolayer, $\mathrm{X} 20.000$.

(a) - CdS-islands at the initial stage of growth,

(b) - CdS - film after $3 \mathrm{~h}$ of growth. 


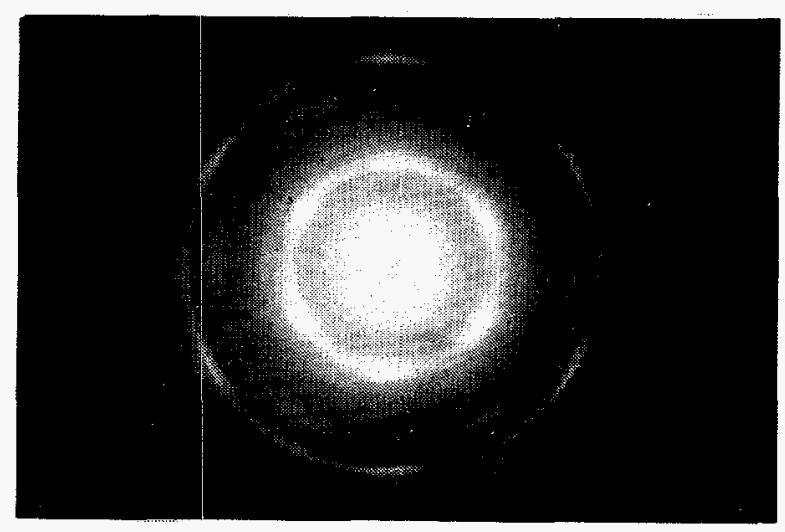

\section{Figure 1}

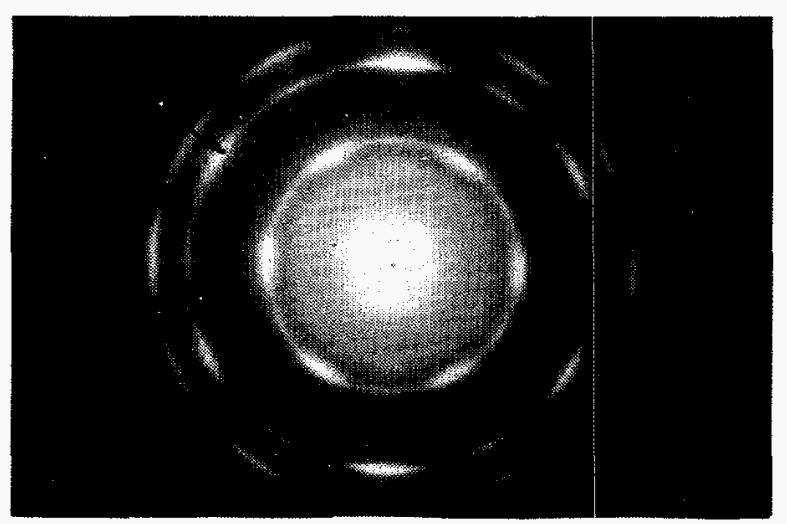

Figure 5

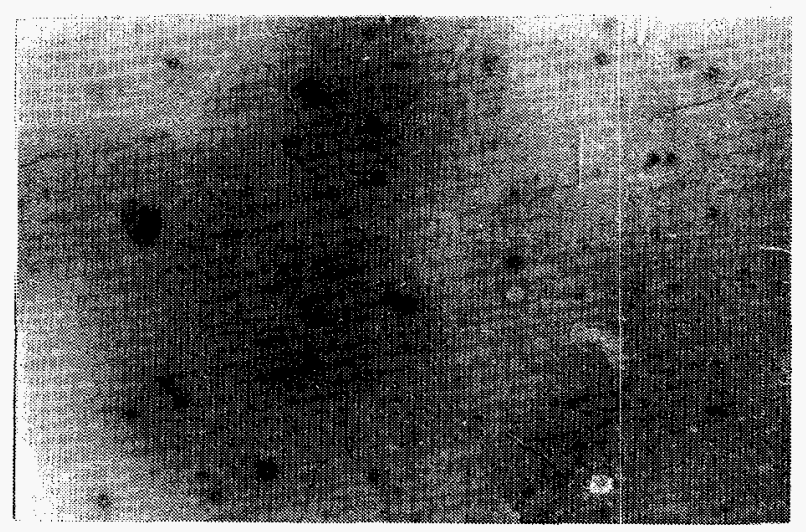

Figure 7a

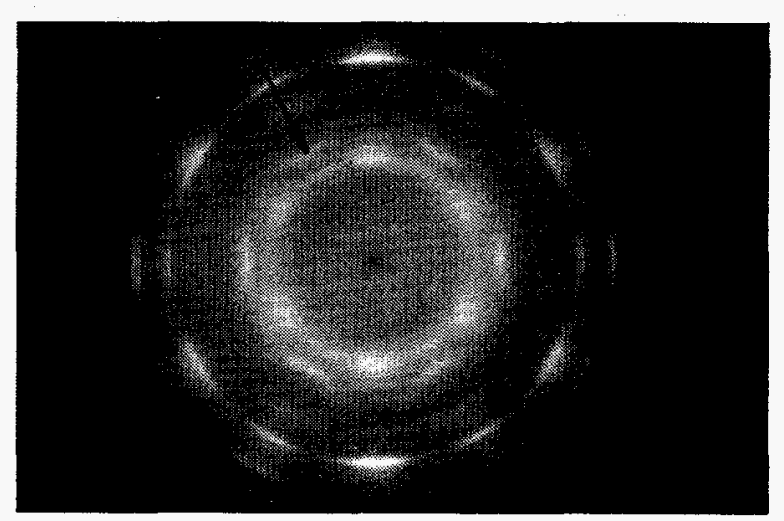

Figure 6

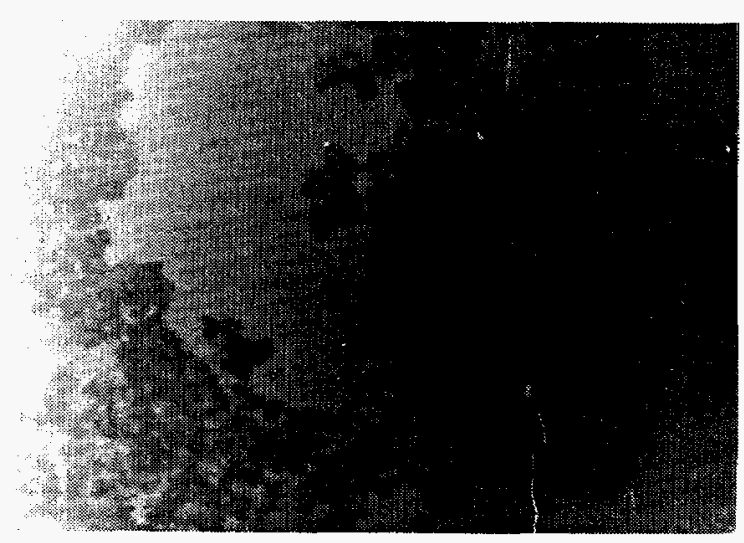

Figure $7 b$ 


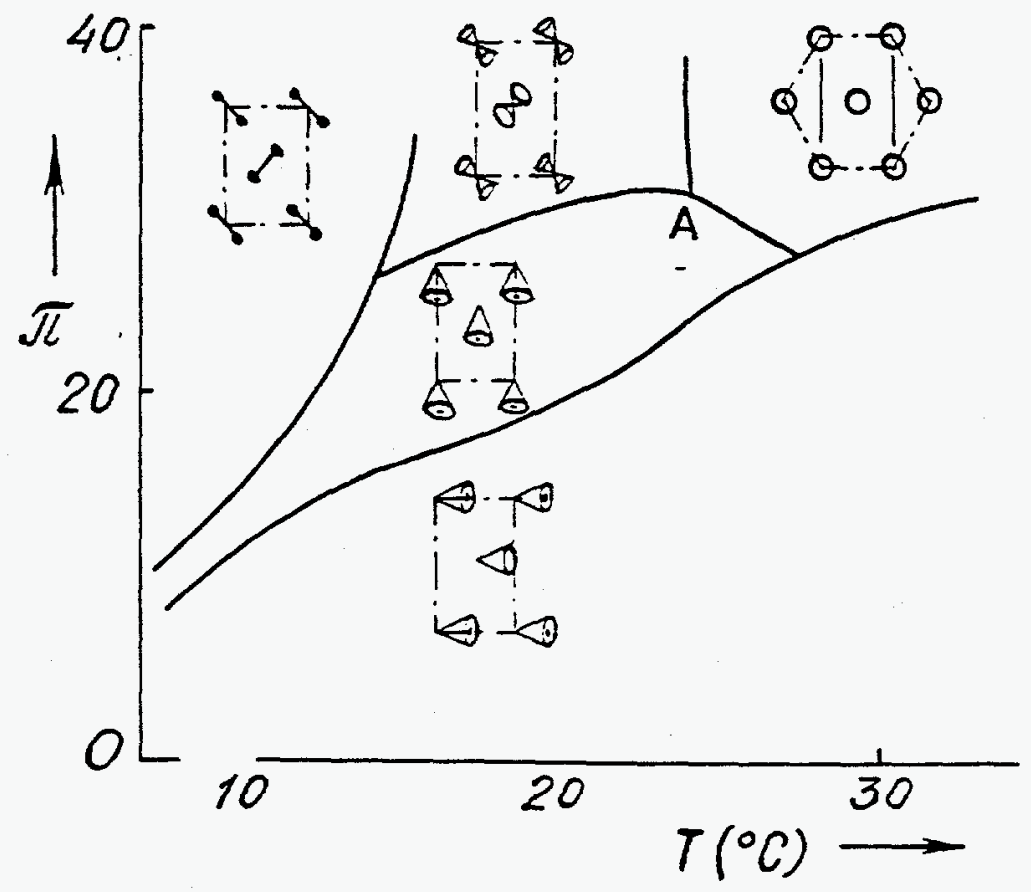

Figure 2 


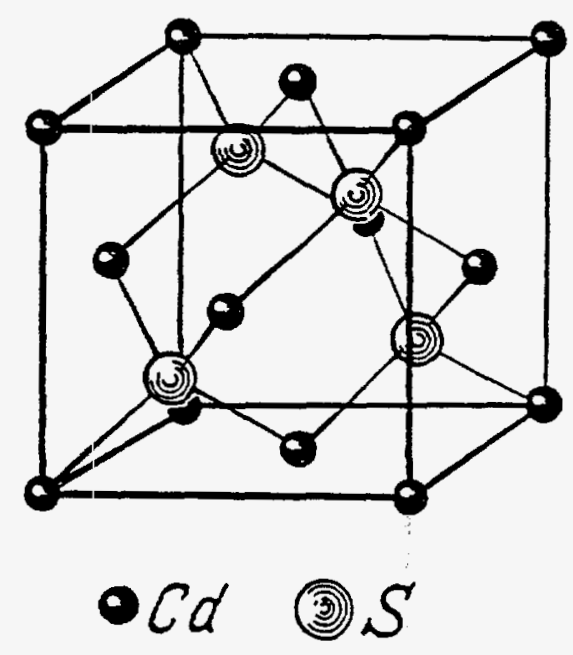

Figure 3 

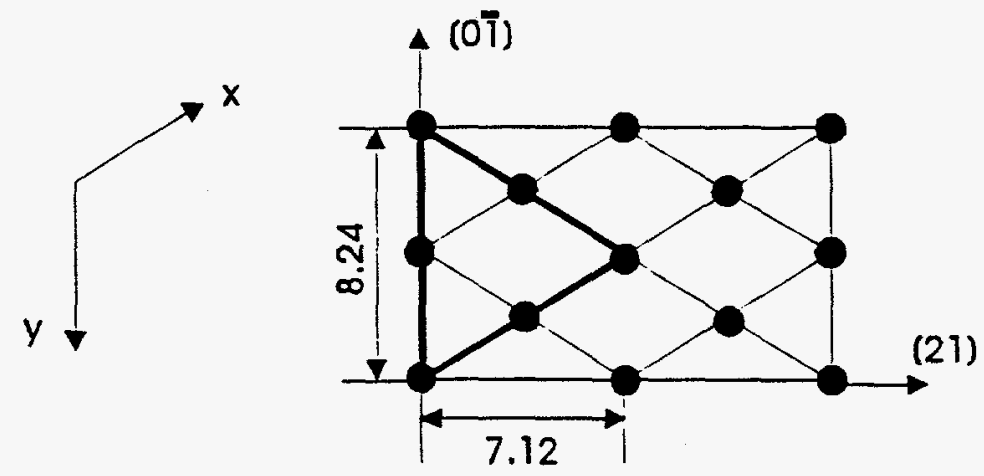

a
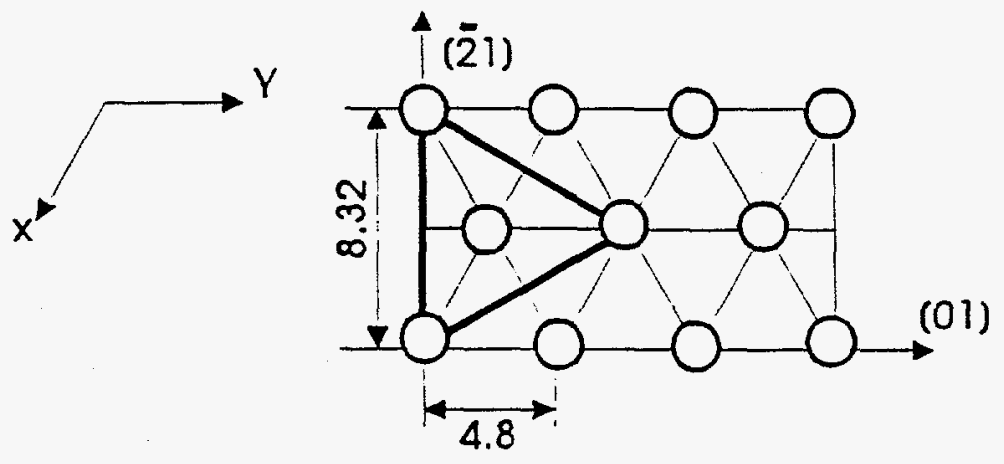

b

Figure 4 


\title{
Chapter 5.4
}

\section{Electron and X-ray Characterization of Langmuir - Blodgett Films and the Fabrication of Inorganic Ceramic Films on the LB Structures}

\begin{abstract}
Current report presents results of the second stage of investigation under the contract $\mathrm{AE}-3528$.

The work includes the results of studying molecular packing structure against of number of deposited layers, film surface quality, speed of the film deposition and other parameters. It contains also the description of method of chemical adsorption of ions from solution and preliminary results on abilities of deposition of the ceramic layers onto LB films.
\end{abstract}

\section{STRUCTURE OF THE Si-SUBSTRATE SURFACE.}

We used the Si-substrates of (III) and (001) orientations. Mean square deviation of the orientation from the true crystallographic faces was monitored by $x$ ray diffractometer and did not exceed 2.5 grad. Preliminary treatment of substrates was different: some specimens were mechanically polished (serie $A$ ), and other ones were chemically polished (serie B).

Surface structure was studied by refrection high energy electron diffraction (RHEED) at accelerated voltage of $75 \mathrm{kV}$. The surface of A-specimens was amorphous as a result of crystal breaking at the contact with abrasive materials. Diffuse halo alone was present in diffraction pattern from these specimens (see fig. 3 in Report I).

The surface of B-specimens was monocrystalline. RHEED-patterns contained Kikuchi-lines and point reflections (see fig.4 in Report 1).

The surface of A-specimens was rough in optical microscope and contained scratches, hillocks, pits and other polishing defects. The surface of B-specimens was rather smooth in compair to former

The structure of LB-films on Si-substrates depended on the surface roughness. Electron diffraction data showed that the lateral size of the domains in the films on smooth substrates was, as a rule, larger than on rough ones.

Film thichkness was determined using computer fit by the Simplex method.

2. X-RAY CHARACTERIZATION OF LB FILMS OF Cd STEARATE FABRICATED AT DIFFERENT CONDITIONS

\subsection{X-RAY CHARACTERIZATION OF HYDROFHOBISATION LAYER}

Using the $X$-ray diffraction method we studied the difference of surfaces of "pure" (untreated) and hydrophobized silicon plates, used as substrates for LB deposition.

Fig. 1 shows $X$-ray diffraction curves for silicon substrates: A - untreated substrate, B - hydrophobised with dichlorodimethylsilane. The thin layer of silicon oxide. present at the untreated substrates, do not manifest itself at the diffraction curve becuse of not enough sensitivity of $\mathrm{X}$-ray equipment used. The thickness value of this layer (15 
angstrom) was taken from [1]. The electron density of dichlorodimethylsilane layer is not very much different from silicon oxide so the diffraction curve from the sample containing the both layers (B) shows the broad diffraction maxima corresponding the total thickness of 26 angstrom. Thus the thickness of hydrophobic dichlorodimethylsilane layer is 11 angstrom.

\subsection{LB FILMS OF CD AND Pb STEARATES ON Si(111) AND Si(100)}

$X$-ray diffraction curves, obtained for $L B$ films on the monocrystalline silicon substrates of different crystal plane orientations did not show significant distinction. This fact was apparently due to the presence of amorphous silicon oxide and dichlorodimethylsilane layers preventing direct contact of ordered silicon atoms snd LB film molecules.

\subsection{IHB FILMS ON THE ROUGH AND SMOOTH SURFACES}

We studied LB films deposited onto the chemically and mechanically polished silicon plates. The latter had a mechanically disturbed layer on the cop. At the X-ray diffraction curves shown at Fig.2(A,B) one can ses well defined differences: for the case of smooth (chemically polished) substrate, in addition to Bragg maxima, the Kiessig oscillations are observable. These oscillations originate from the interference of $X$-ray beams, reflected from the air-film and film-substrate surfaces, and indicate that the roughness of these surfaces are about $10 \mathrm{~A}$ or less. Kiessig oscillations were absent for the case of rough (mechanically polished) surfaces due to weak reflection from the interface between the films and the substrates.

\subsection{ESTIMATION OF DEPOSITION SPEED INFLUENCE ONTO THE QUALITY OF OBTAINED LB FILMS}

We obtained $X$-ray diffraction curves for LB films deposited at different speed. Fig. 3 shows the diffraction curves for cadmium stearate $L B$ films deposited at $A$ ) $1.5 \mathrm{~mm} / \mathrm{min}$ (slow) and $B$ ) 20 $\mathrm{mm} / \mathrm{min}$ (fast). As it seen from the figure, there were no much differences, but it is noteworthy that kiessig oscillation periodicity was somewhat different. It means the higher thickness of "fast" film. Roughness of bilayers interfaces is also ligher that results from higher diffuse scattering level. However this observation can not be regarded as the reproducible regularity and requires more careful studies.

\subsection{ESTIMATION OF EILM SPACING AND THICKNESS}

Absorption and refraction in the films were not taken into account because of low film thickness. Spacings were calculated using Bragg law. The films of $\mathrm{Cd}$ and $\mathrm{Pb}$ stearates showed the spacing values of 49 angstrom that correspond to $Y$-type molecular packing (head-to-head, tail-to-tail).

Film thickness was estimated for the samples on smooth substrates from the period of Kiessig fringes. It was mentioned 
in the previous report that molecular packing in this case was better but the film deposition was more problematic especially for the starting layers. It was found that the real number of deposited layers may be different from the number of dipping cycles. Fig.4-6 show some typical $X$-ray diffraction curves for Cd stearate IB films with different numbers of layers.

The overall thickness of 3-cycle sample of Cd stearate LB film was about $195 \mathrm{~A}$. This means that the thickness of hydrophobic underlayer was about 40 A and LB films consisted of 3 bilayers. The same value of the underlayer thickness and coincidence of numbers of belayers and dipping cycles was obtained for 5-cycle sample also. It should be noticed that the coincedence achieved of numbers of bilayers and dipping cycles is not reliably controlled in the tecnological process and must be examined for every $L B$ film after its fabrication. The validity of the last remark can be demonstrated by results for the 10-cycle and 20-cycle films. For the case of 10-cycle sample, the discrepancy between of the number of deposited layers and the overall film thickness appears. Predicted film thickness was $49 * 10+40=530 \mathrm{~A}$, but the real thickness calculated from Kiessig oscillations was $440 \mathrm{~A}$. For 20 bilayers the predicted thickness value was $1020 \mathrm{~A}$ but the real one -745 and 570 (for samples on the rough and smooth silicon surfaces respectively).

2.6. X-RAY STUDY OF FATTY ACID SALT LF FILMS WITH DIFFERENT FLUOROCARBONE CHAIN LENGTH: C18(STEARATE), C20 (ARACHIDATE) AND C22 (BEHENATE)

Besides the stearic acid salts, we determined spacing values for LB films of cadmium salts of fatty acids with. slightly different hydrophobic tail lengths.

Fig.7 (A-C) shows $\mathrm{X}$-ray diffraction curves for Cd-behenate (C22), Cd-arachidate(C2O) and Cd-stearate (C18). The angular distance between Bragg maxima is smaller for longer chains indicating higher spacing value (they are 58.2, 53.9 and $49.2 \mathrm{~A}$ respectively). The increase of spacing (the unit cell includes two molecules) per addition of two $\mathrm{CH} 2$ groups equals 2.5 angstrom that is in agreement with vertical chain orientation in the films.

\subsection{X-RAY STUDY OF FATTY ACID SALT LF FILMS WITH DIFFERENT DEGREE OF ACID-SALT CONSTITUTUON}

The influence of $\mathrm{pH}$ value onto the character of deposition of cadmium salt of behenic acid was estimated. The behenic acid was chosen because it provides more stable monolayers in the acid form relative to shorter tail acids.

Fig. 8 shows X-ray diffraction curves for Cd-behenate (C22) LB films deposited at different $\mathrm{pH}$ values to provide different degree of acid hydrogen substitution with metal. Curve $A$ shows typical behenic acid spacing of 52.5 angstrom corresponding to tail tilt of about 30 degrees to vetical (pH3.3, the acid groups are in protonated state according to (2]). At pH4.7 (that correspondes to $7 \%$ substitution of acid hydrogen with cadmium in monolayer (2]) the drastic deterioration of Bragg maxima takes place (curve $B$ ). The film in preferentially salt state (pH 6.25, curve $C$ ) shows the Bragg maxima of 58.2 
angstrom spacing corresponding to vertical chain orientation.

These data show that the subphase $\mathrm{pH}$ value essentially influences on the constitution and structure of fatty acid salt LB films.

\subsection{THE METHOD OF REFLECTOMETRY STUDIES AND MODELLING OF ELECTRON DENSITY PROFILES}

Arrangement of the $\mathrm{X}$-ray diffractometer used was presented in the previous report. Change of incidence angle is performed by slow continuous rotation of the sample. The pattern obtained results from accumulating intensity over all angle range during the measurement time. It should be noticed that this tecnnique provides not "true" reflectivity curve because besides the specular scattering signal diffuse scattering and background also contribute to the pattern obtained. The latter prevents from exact evaluation of electron density profile but spatial structural parameters can be obtained because the diffuse scattering pattern has its maxima at the same position as that of specular reflectivity. So only thicknesses of sublayers can be evaluated reliably from such patterns.

Estimation of thicknesses values was proceeded in the following way. The spacing and the total thickness of the film can be roughly evaluated by positions of Bragg's and Kiessig maxima at the reflectivity curve. Those values were taken as the first approximation in the fitting procedure. First approximations of values of optical parameters were taken from [1]. The expression for scattered intensity was that of the kinematical approach, i.e. Fourier transformation of the Patterson function of electron density distribution. Correction for refraction was made in the equation for scattering vector. The latter is essential in the vicinity of the critical angle. Then parameters of the initial model were modified to reach the best correspondence between experimental data and those calculated according to the theoretical approach. Fitting was proceeded with the use of the simplex method. The procedure was stopped when the best coincedence of maxima at the experimental curve and at the theoretical one was reached. As was highlighted above only spatial parameters obtained through fitting are of value.

\subsection{FITTING RESULTS}

Diffractograms of the 10-cycle and two 20 -cycle samples were choosen for fitting. For the superlattices investigated the following pattern of constituents alterating was choosen:

Substrate | Sublayer | 1st_bilayer | ... | Nth_bilayer | Vacuum while the pattern of bilayer was

$C E_{-} t a i l-\mid-C d-1-C_{-}$tail

In the table below spatial parameters of investigated structures obtained with the fitting are given. As was remarked above, only these parameters are of value. Therefore optical constants of partial sublayers are not presented in the table. values of these constants were of order of those taken from [1]. Thicknesses are in angstroms. 


$\begin{array}{lrccc}\text { Sample } & \text { N } & \text { Sublayer } & \text { CH_tail } & \text { Cd } \\ \text { 20-cycle, fast } & 17 & 56 & 22 & 5.4 \text { deposition } \\ \text { 20-cycle, slow } & 13 & 48 & 22 & 5.1 \text { deposition } \\ \text { 10-cycle } & 9 & 45 & 21.4 & 6.4\end{array}$

3. ELECTRON DIFFRACTION STRUCTURE ANALYSIS OF THE LEAD AND CADMIUM STEARATE IB FILMS.

Electron diffraction patterns were obtained from lead stearate and cadmium stearate LB films on substrate - holders with $2 \mathrm{~mm}$ dia holes covered with celluloid thick film almost not distorting the diffraction pattern.For the transmission electron diffraction study from 12 to 30 bilayers were deposited.

Thus obtained films were studied in an EMR-I02 electron diffraction camera at accelerated voltage of 50 and $75 \mathrm{kV}$. The diffraction patterns were recorded onto photoplates both normally to the electron beam and at an angle of 50 grad to it. The reflec-tion intensities were measured on a Carl zeiss Jena G111 microphotometer.

\section{I FORMATION OE ELECTRON DIEFRACTION PATTERNS FROM} PLATELED-LIKE TEXTURE

The use of specially designed electron diffraction cameras with the diameter of the beam on the specimen equal to $0.2-0.3$ $\mathrm{mm}$ allows one to irradiate a large surface area of the specimen with crystaliites arranged randomiy with respect to azimuth but with the basal planes being parallel to the substrate (platelet-like texture). This results in the formation of specific electron diffraction patterns from these texture iliustrated by figure 1 . The points of reciprocal lattices of different crystaliites merge together to form continuous rings. Electrons have a very small wavelength, and therefore the Ewald sphere degenerates into a plane. The respective electron diffraction pattern is, in fact, the cross section of the rings by this plane in the reciprocal space (figure 1 ). If an electron diffraction pattern is obtained in the plane normal to the beam, it contained hko rings alone (figure $2 a$ ). If the LB film is inclined to the electron beam, the section of continuous rings by the plane in the reciprocal space gives rise t? pairs of arcs lying on the directions parallel to the axis about which the specimen is rotated. In addition, new arcs appear due to reflection from the planes with l\#0 (figure 2b). The angular width of these arcs is determined by a smali angular scatter of the basal planes with respect to the substrate. In the reciprocal space, the rings corresponding to the reflections with the constant $h$ and $k$ indices and different 1 indices $(1=\ldots-2,-1,0,+1,+2, \ldots)$ are located on the surfaces of coaxial cylinders with the $[001]$ axis (figure 1). Thus the arc-like reflections are located on ellipses with constant $h$ and $k$ and different 1 . Reflections having the same $l$ indices are arranged along the layers lines. The described patterns are called oblique-texture electron diffraction patterns.

In practice, electron diffraction patterns obtained at an angle of about $60 \mathrm{grad}$. to the beam contains the number of 
reflections sufficient for the structure determination.

\subsection{STUDY OF THE STRUCTURE OF PbST AND CDSt LB FILMS}

Arrangement of reflections on electron diffraction patterns of oblique texture type from LB films of PbSt and CdSt along ellipses and layer lines is characteristic of polycrystalline texture. Intensities of reflections (fig.2) don't decrease monotonously, but form areas of strong layer lines with subperiod $c^{\prime}=2.54 \mathrm{~A}$ which is connected with periodicity of carbon atom arrangement in aliphatic chaines. The obtained transmittion oblique-texture diffraction patterns provided the determination of a pseudoorthorombic monoclinic unit cell with the parameters $a=4.96 \mathrm{~A}, b=7.38 \mathrm{~A}, c=96 \mathrm{~A}$. The extinctions on the electron diffraction pattern indicated the space group $\mathrm{F} 21 / \mathrm{b}$.

The further structure analysis is conducted, as usual, by analysing reflection intensities. The intensities of more than 200 crystallographically nonequivalent reflections were determined on a microphotometer. The transition from intensities to squeres of structure amplitudes was performed by the kinemati- cal scattering law. knowing the set of structure amplitudes, we constructed the Patterson projection onto the xy plane and three- dimensional cross-sections of patterson function $P(x y z)$. It was found that the arrangement of chains in the monolayer corresponds to the close packing analogous to that in the paraffin structure. Lead atoms in adjacent monolayers are shifted by a half translation along the b-axis. The boundary between layers is characterized by the closest packing of terminal groups of hydrocarbon chains, and for this reason unit cell consists of two bilayers which are shifted with respect to each other on the half of one of the basic plane translations.

The model of structure was refined using three-dimensional Fourier synthesis of electrostatic potential. Because of unevennes cutting of structure amplitude rows there are spurious peaks on Fourier maps, and their existence was monitored by Fourier synthesis using theoretical structure amplitudes for model structure with experimental cutting. The scheme of molecule arrangement in unit cell is shown in figure 3 .

Let us discuss now electron diffraction patterns of oblique texture type from LB films of Pbst2 and Cdst2 (figure 2b,c). Unlike classical crystalline texture, reflections on diffraction patterns from PbSt2 overlap starting from the 5-th ellipse, and then ellipses consist of solid lines. On the diffraction pattern from CdSt2 (fig. 2c) such overlapping takes place un the second ellipse. Intensities of reflections (fig.2) with increasing index 1 don't decrease monotonously, but form areas of strong layer lines which is connected with periodicity of carbon atom arrange- ment in aliphatic chaines. Electron diffraction patterns obtained at long exposition show that reflections from pbst2 are sharp up and that the third serong layer line from cdst2(besides all above mentioned characteristic features) becomes solid one, the intensity being quite equal to the intensity of background.

LB films consist of layers of parallel arranged molecules, so we tried to analyse diffraction patterns from PbSt2 and CdSt2 within the frame of the approach, developed by $B . \vec{k}$.Vainshtein ("Diffraction of $\mathrm{X}$-rays by chain molecules." Elsevier Publishing company, 1966, pp. 255-338) for complexes of parallel arranged chain molecules. The disappearence (diffusion) of reflections on ellipses on texture diffraction 
patterns from such specimens is due to the tangential distortions, connected with inclination of molecules in a layer; the stronger this inclination is, the lower indexes of reflections affected by this effect are. (It should be noted that inclinations of molecules were discovered earlier in LB films of cadmium arachidate by infrared spectroscopy). Our estimations using electron diffraction patterns showed that there are possible inclinations equal to 0.5 grad. for Pbst2 and 1-2 grad. for Cast2.

According to vainshtein the effect of diffusion of layer lines (for example, of the third strong layer line on diffraction pattern from CdSt2) can be explained by the parallel shift of molecule mass centers in the directions of their axes. Then for cdst this value is of order of $0.2 \mathrm{~A}$.

\section{THE PRELIMINARY DATA ON CDS AND PbS FILMS}

\subsection{THE METHOD OF CAS AND PbS FABRICATION}

The ability of deposition of the CaS and PbS layers onto the LB film underlayers by the method of succesive chemical adsorption of ions from aqueous solution was studied.

One of the methods of fabrication of thin films of water-insoluble ionocovalent compounds is the chemical reaction between the adsorbed cations and anions at a solid-liquid interface. Thus, for cos film fabrication, it is necessary to dip a substrate into $\mathrm{Cd}(\mathrm{NO} 3) 2$ (cation) and $\mathrm{Na} 2 \mathrm{~S}$ (anion) containing solutions succesively several times. It is suggested that at the first stage of the process $C d(2+)$ ions are adsorbed at the surface. Then, inmersion into Na2S solution causes $S(2-)$ ions to be chemically bound to form CdS film. Redundant ions are washed away with distilled water after each dipping. In order to reach thermodynamic equlibrium between substrate and electrolite or water the substrate should be kept in the liquid for the necessray time. As a result of this process, an epitaxial layer or texture is proposed to be formed.

The reaction of CdS fortnation was the following: $\mathrm{Cd}(\mathrm{NO} 3) 2+\mathrm{Na} 2 \mathrm{~S}=\mathrm{CdS}+2 \mathrm{NaNO} 3$

and for the case of $\mathrm{pbs}$

$\mathrm{Pb}(\mathrm{NO} 3) 2+\mathrm{Na} 2 \mathrm{~S}=\mathrm{PbS}+2 \mathrm{NaNO} 3$

The reactions are carried out in the course of chemosorption. The fo:lowing electrolyte solution were used: $0.01 \mathrm{M}$ Na2S $(\mathrm{pH} 11.6: ; 0.01 \mathrm{M} \mathrm{Cd}(\mathrm{NO} 3) 2(\mathrm{pH} 2.8) ; 0.01 \mathrm{M} \mathrm{Pb}(\mathrm{NO} 3) 2$ (pH2.8);

The substrates were kept in electrolyte for about 40 seconds. Then they were washed carefully in distilled water for about $1.5 \mathrm{~min}$.

The substrates used for CdS and PbS deposition were silicon plates covered with 3 bilayers of cadmium stearate or lead stearate Langmuir-Blodgett films respectively. The substrates covered with polymeric LB films of polyimide, diacetylene and acetomyristate cellulose were also tried. 50 cycles of chemical adsorption were carried out.

The qualitative visual estimation of wetting properties have shown that initially all samples were hydrophobic. Cadmium 
stearate and diacetylene films became hydrophilic after the numerous dippings into electrolytes (especially Na2s). The reason of this phenomenon is not clear. Hydrophobic properties of LB films of polyimide, cellulose ester and cadmium stearate were not significantly influenced by dipping into electrolyte.

\subsection{PRELIMINARY DATA ON THE STRUCTURE OE CAS AND PbS LAYERS.}

The structure of $\mathrm{CdS}$ and PbS layers deposition onto Si-LB-substrates by the method of successive ionic layer adsorption was studied by RHEED.

Diffraction patterns contained Debye-rings (fig.), thus the structure was polycrystalline. The size of the separate crystallites was estimated from the half-width of diffraction maxima. It varied in the range of 100-500 A as the number of the deposition cycles increased from 5 to 60 .

Analysis of the scattered intensities in diffraction patterns from Cas-layers showed that some reflections, namely: 200, 400 and 420 , were absent or their intensity was weaker in compair to the calculated values. This can be explained by the orientation of CdS-crystallites by (111)-face parallelly to the substrate and by the formation of texture with [111]-axis.

We suppose to obtain the additional detailed morphological data for the checking of this assumption. The structure of Pbs-layers was polycrystalline, and the size of crystallites became larger as the thickness increased.

\subsection{CONCLUSIONS}

These results showed the principle possibility for the growing of CaS and PbS layers on the Si-LB substrates by the successive ionic layer method. The structure of the layers was polycrystalline. There are two ways to improve this situation: 1) optimization of the growth parameters in this method; 2) use of the another method for the growth. Both these possible ways are discussed.

\section{References}

I. Konovalov O.V., Kristallografia(Russian), 37 (1992)192.

2. Richardson R.M., Roser S.J. //Liq.Crystals. 2(6)(1987)797.

\section{FIGUEE CAPTIONS}

Fig.I. X-ray diffraction curves for silicon substrates: (a) untreated substrate, (b) - hydrophobised with dichlorodimethylsilane.

Fig.2. X-ray diffraction patterns of 20-cycle cdst fabricated on the smooth (a) and rough (b) Si-surface.

Fig.3. X-ray diffraction patterns of 20 -cycle cdst fabricated by LB method with slow (a) and fast (b) speed of dipping.
Fig.4. X-ray
diffraction patterns
of 3 -cycle cast
(a) and
5-cycle cast
(b) on Si-substrate. 
Fig.5. X-ray diffraction patterns of 10 -cycle cast (a) and fitting curve (b).

Fig.6. X-ray diffraction patterns of 20-cycle cdst (a) and fitting curve (b) .

Fig.7. X-ray diffraction curves for $A$ : Cd-behenate (C22), $B$ : $C d$-arachidate $(20)$ and $C$ : Cd-stearate (C18).

Fig.8. X-ray diffraction curves for Cd-behenate LE films deposited at different pH values (salt content): A: pH3.3 (0\%); B: pH4.7 (7\%) and C:pH6.25 (80\%).

Fig.9. Formation of the obliquid-texture electron diffraction patterns (the case of an orthogonal lattice). P is the Ewald sphere.

Fig.10. Electron diffraction patterns from lead stearate: (a) phi=0 deg. (hk0-rings); (b) - phi=50 deg.; (c) - electron diffraction patterns from cadmium stearate, phi=50 deg.

Fig.11. Projections of the lead stearate structures on to the $X Y-$ and $Y Z-p l a n e s$.

Fig.12. RHEED-pattern from CdS-layer deposited onto CaSt2 LE film. 
Fig-

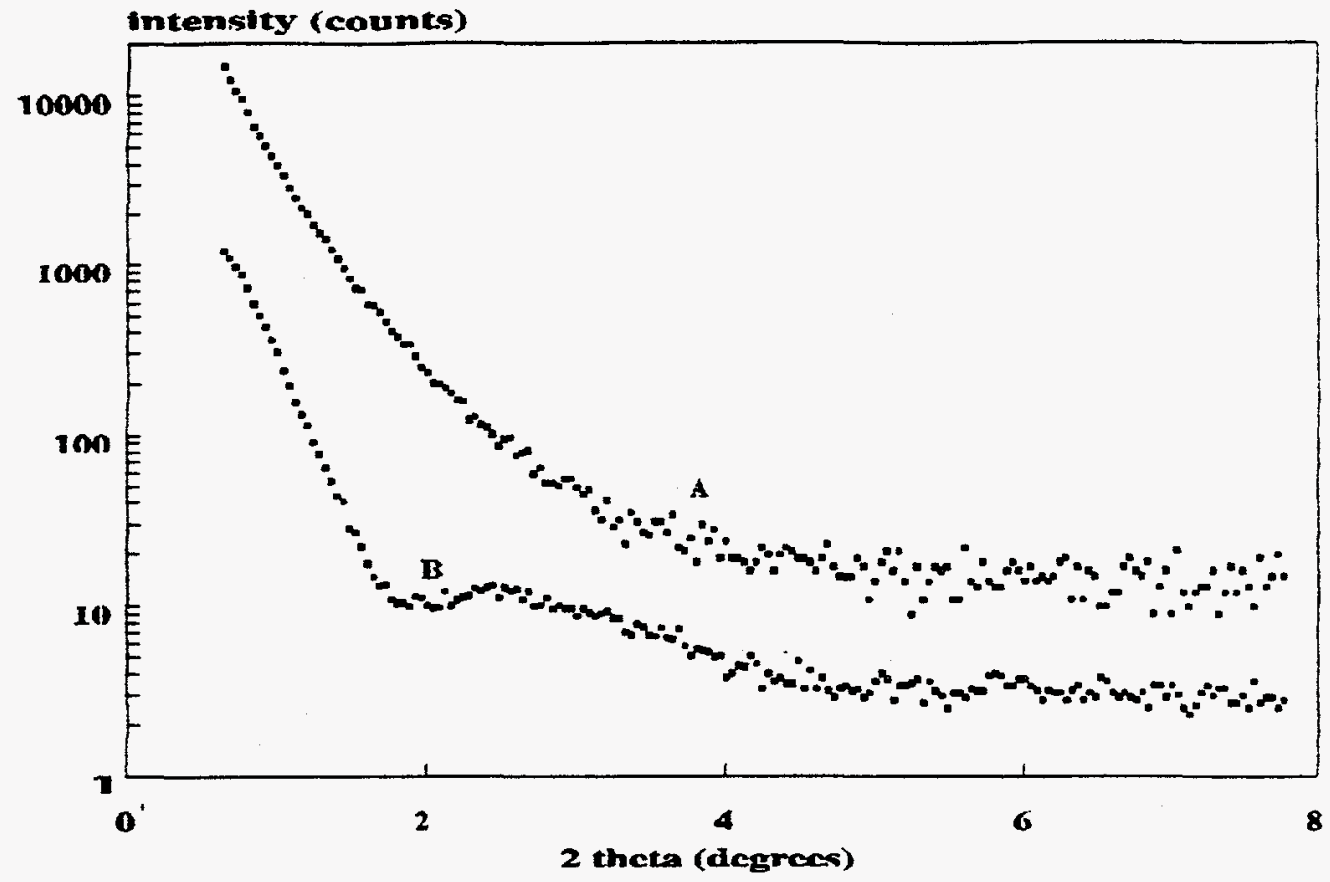

Fig.2

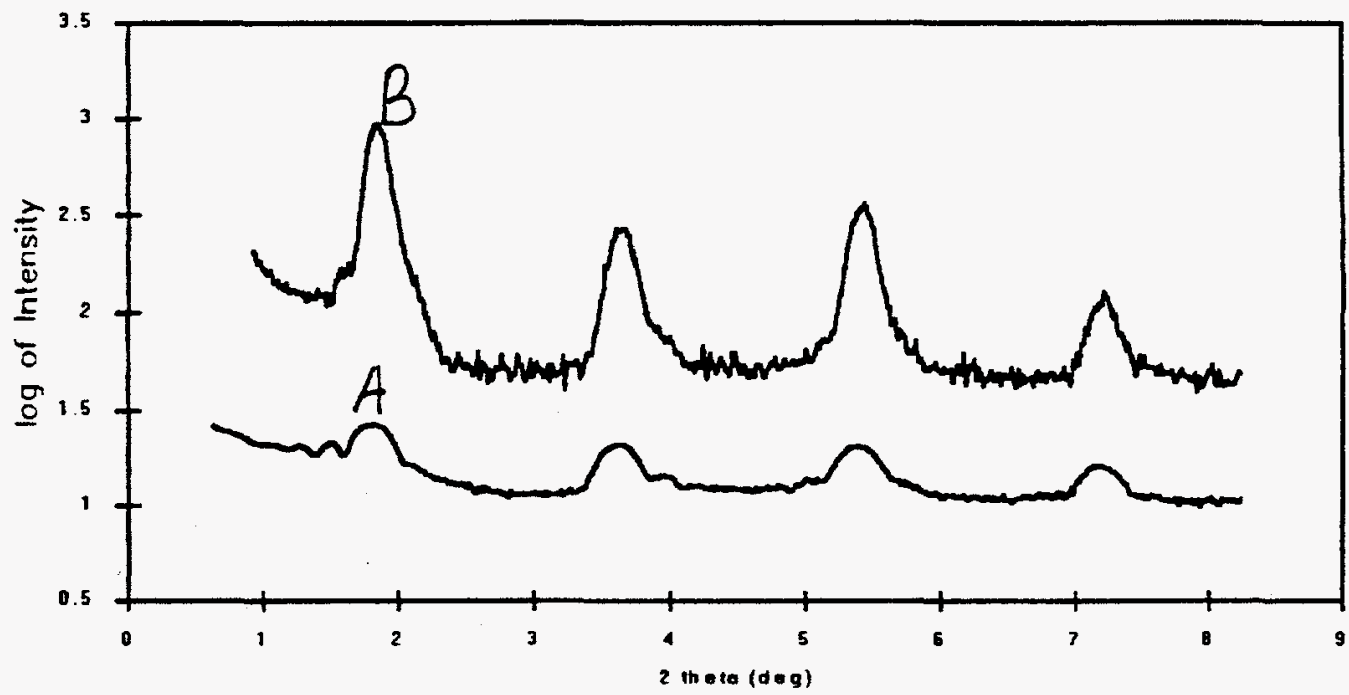


Fig. 3

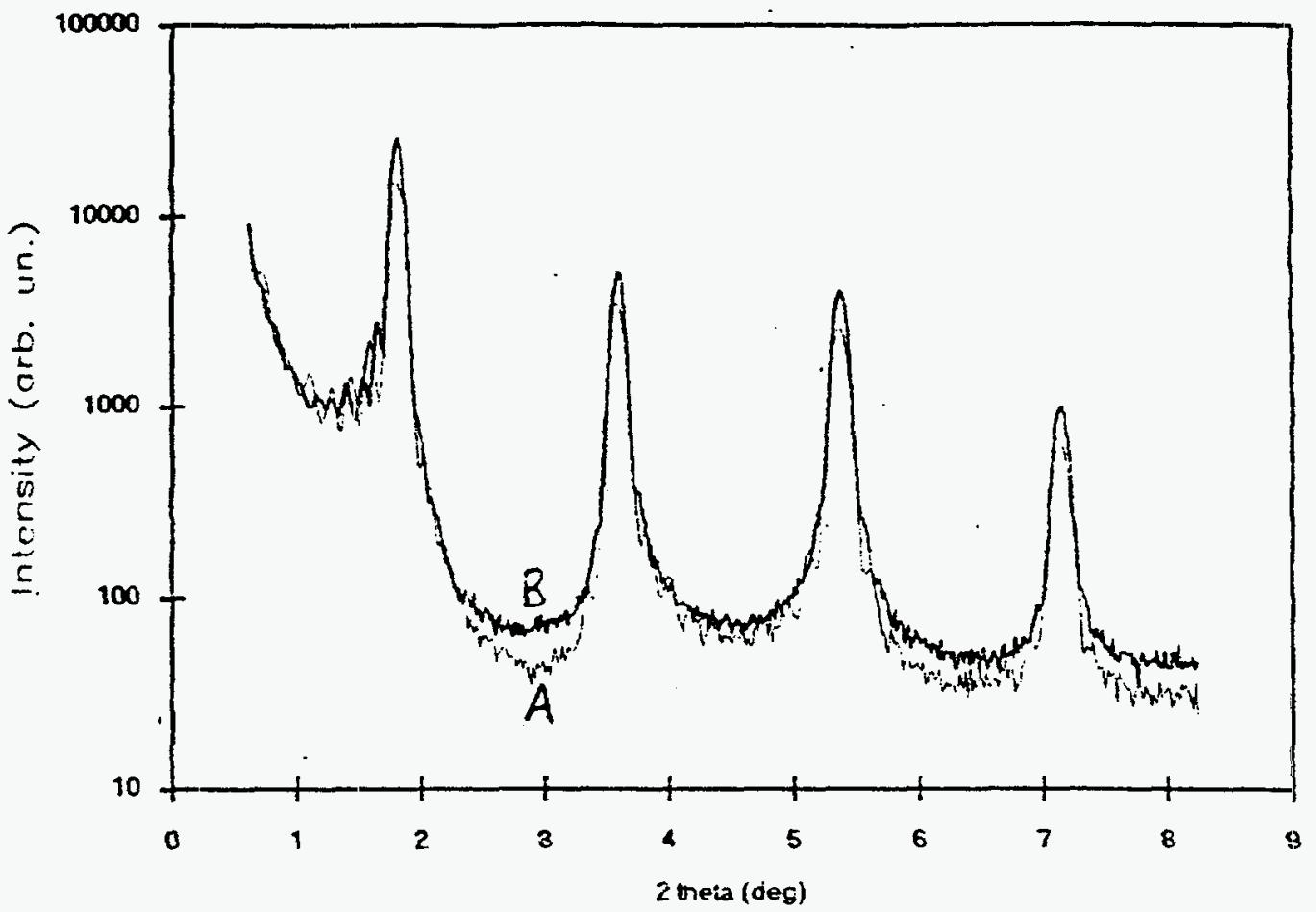

Fig. 4

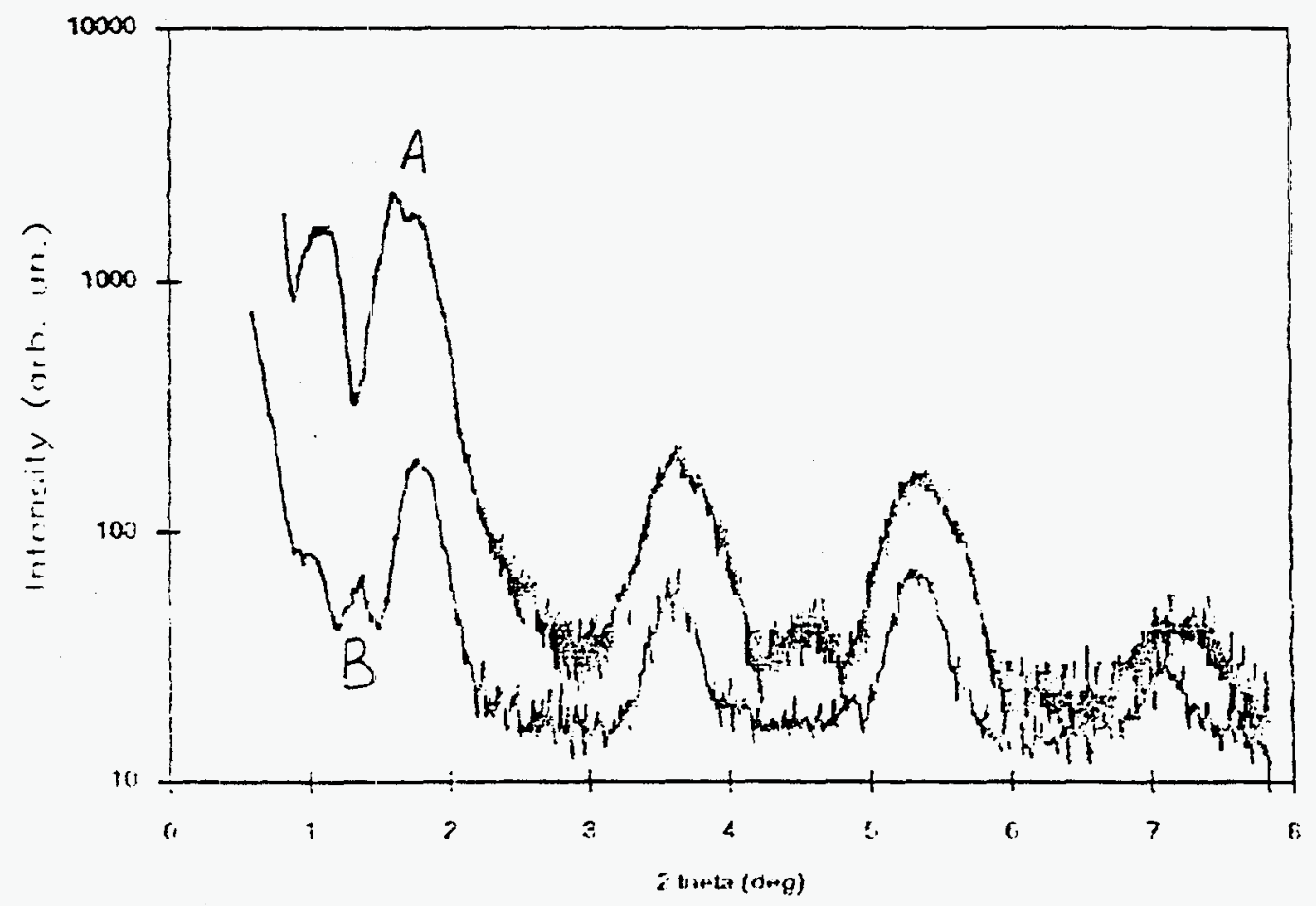

82 
Fig.6

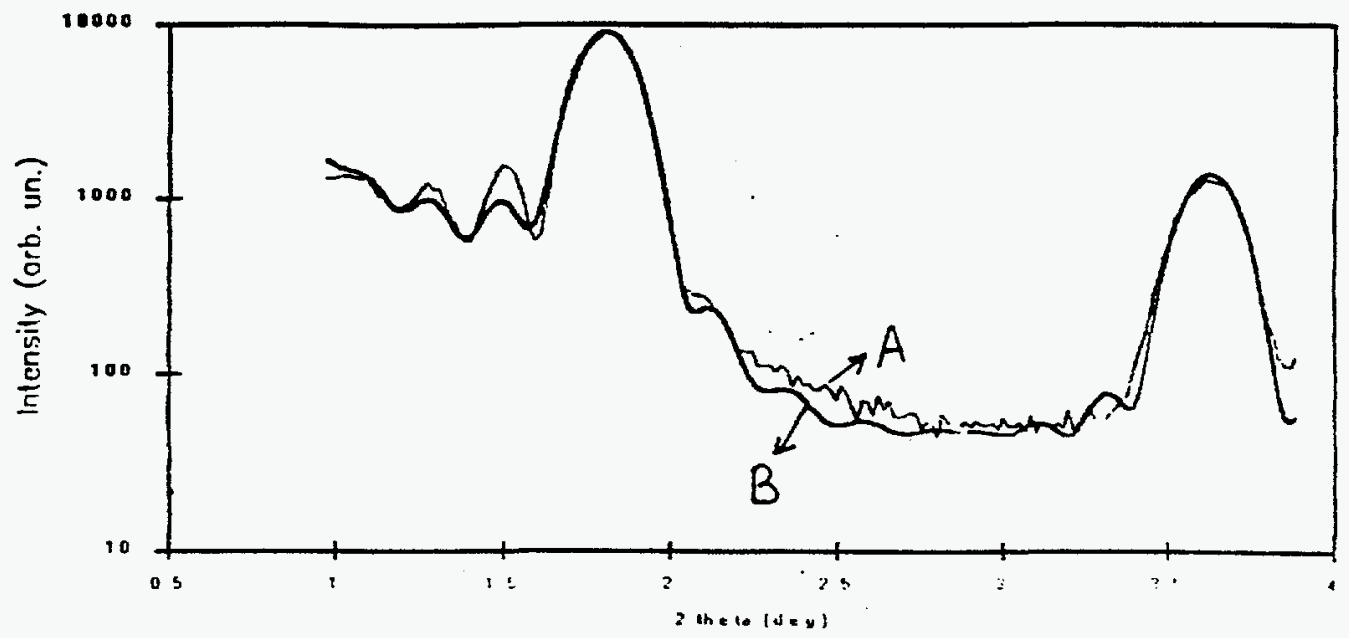

Fig. 6

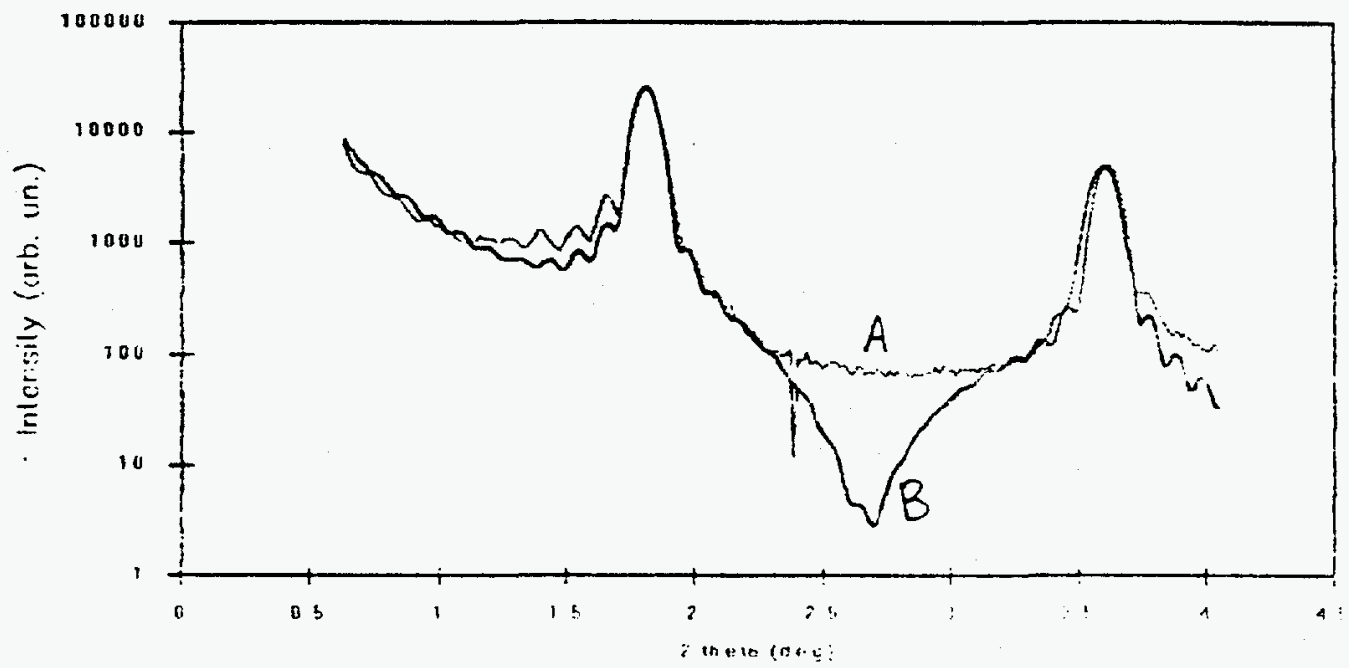


Fig.7

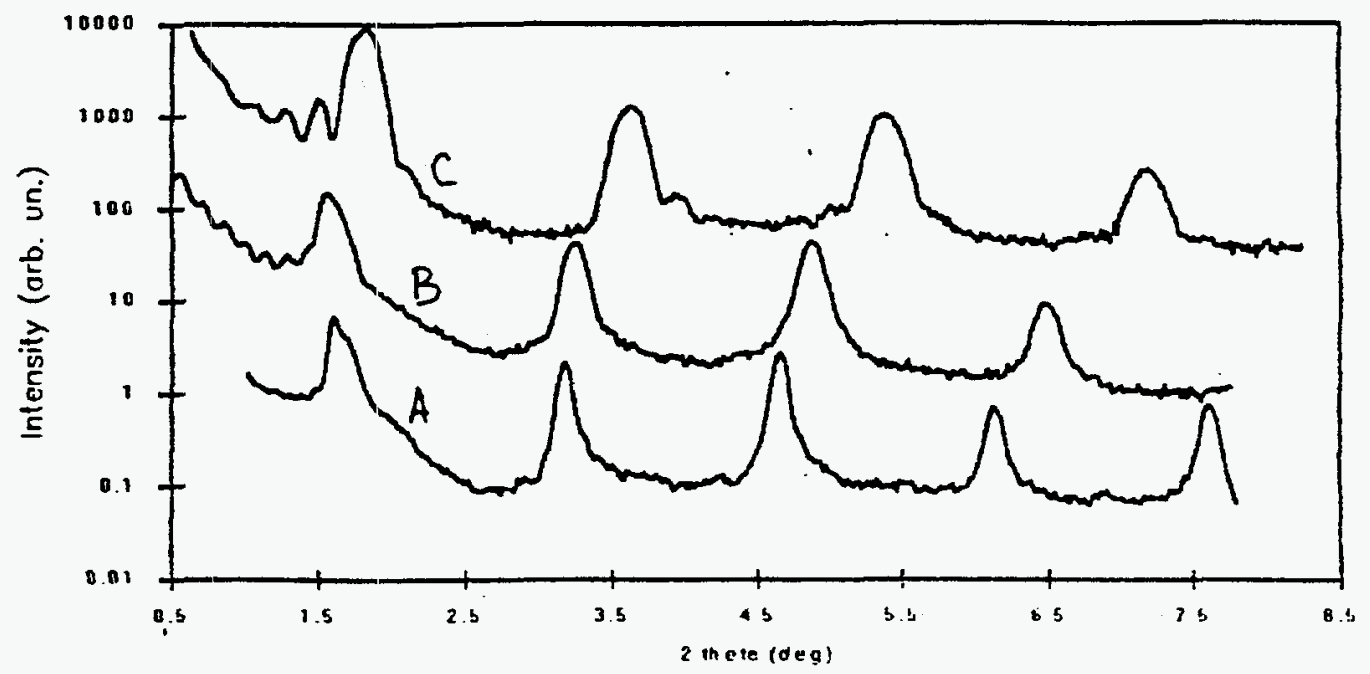

Fis. 8

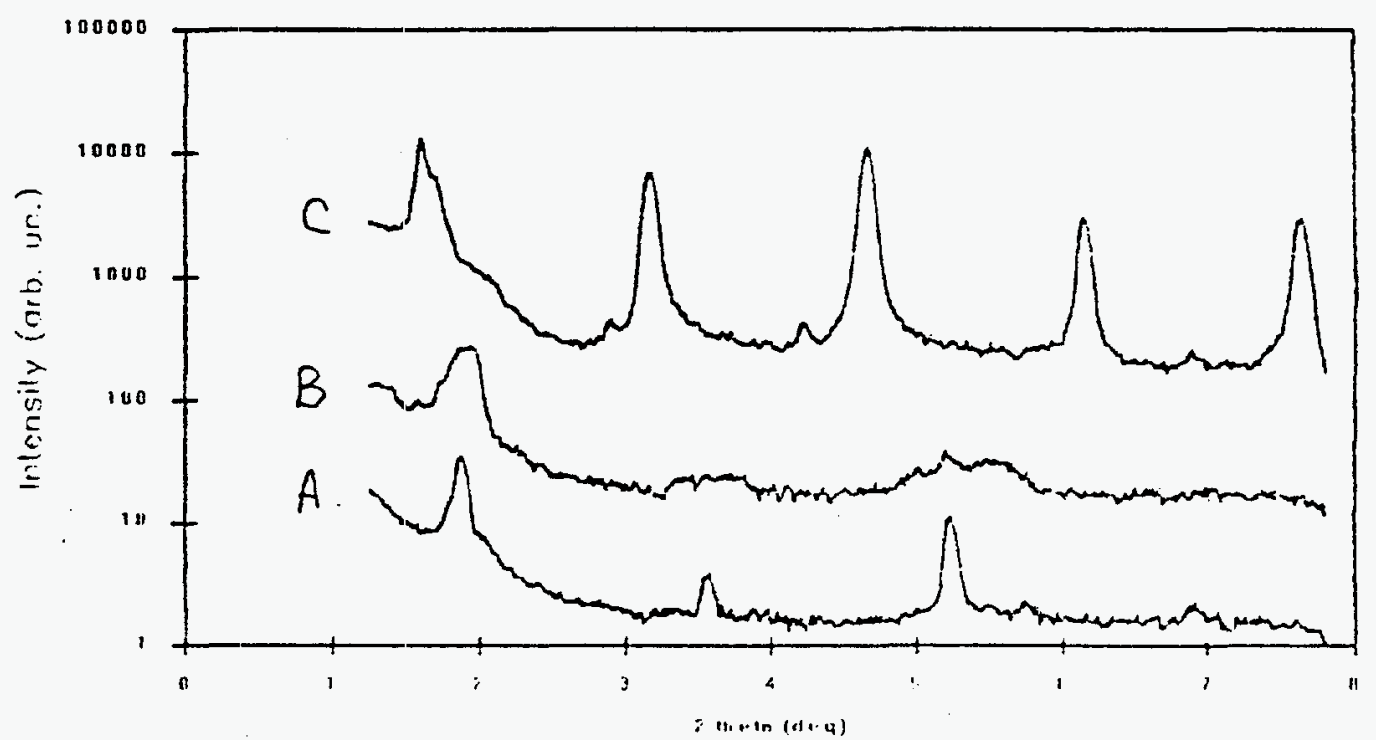


Fig. 9

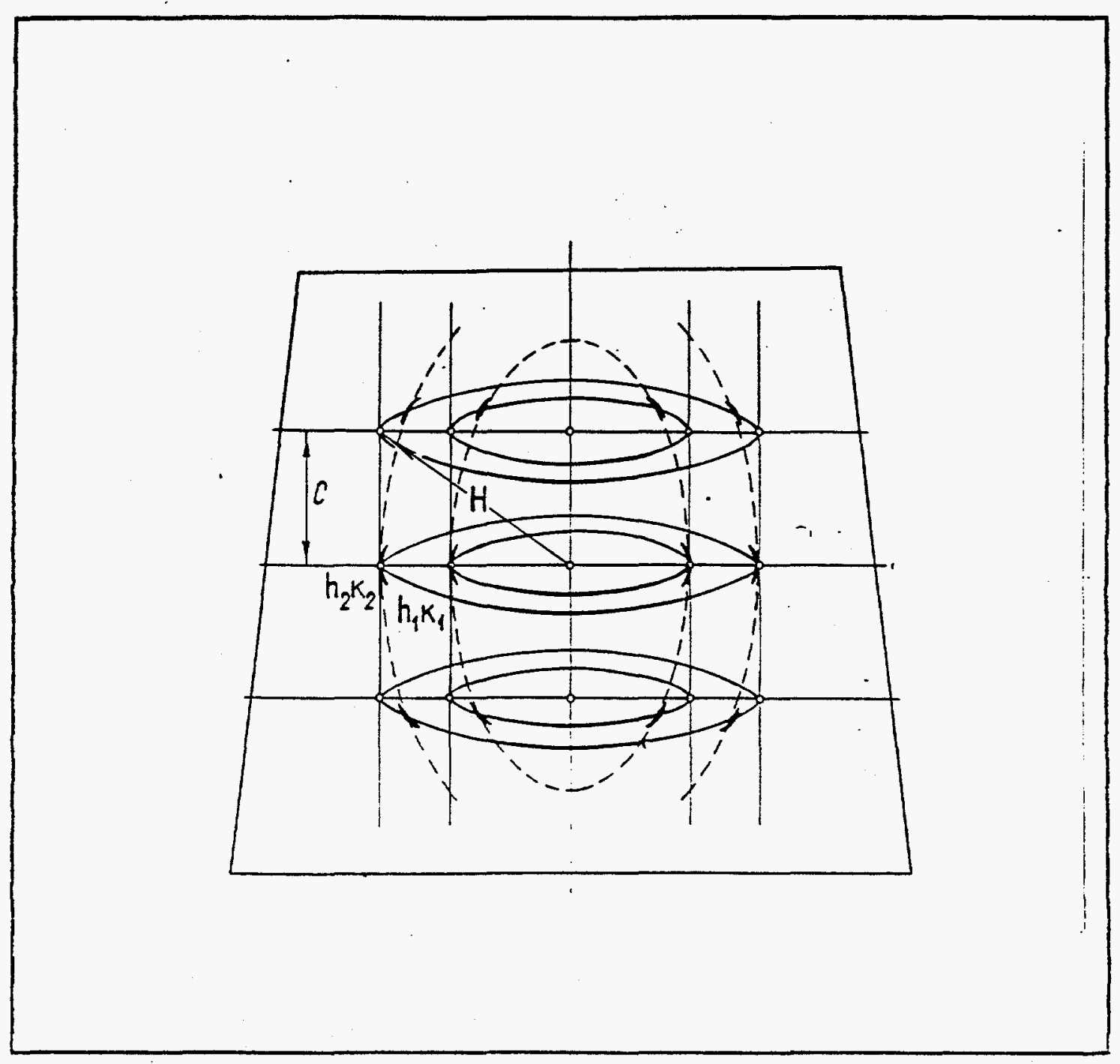


Fig. 10

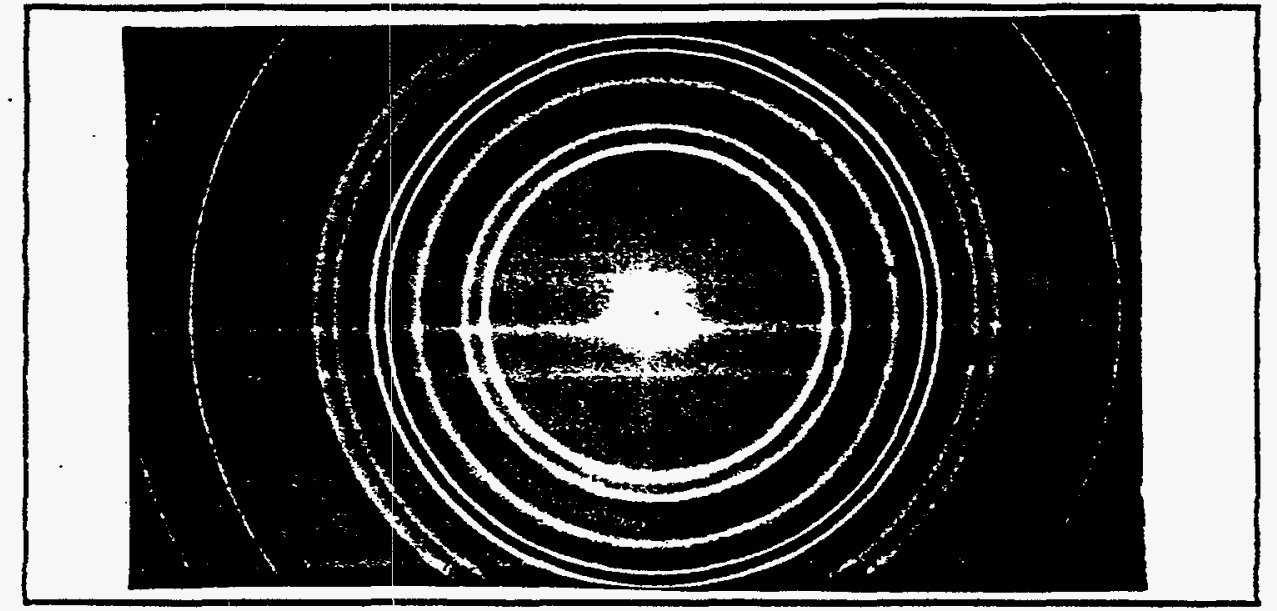

b
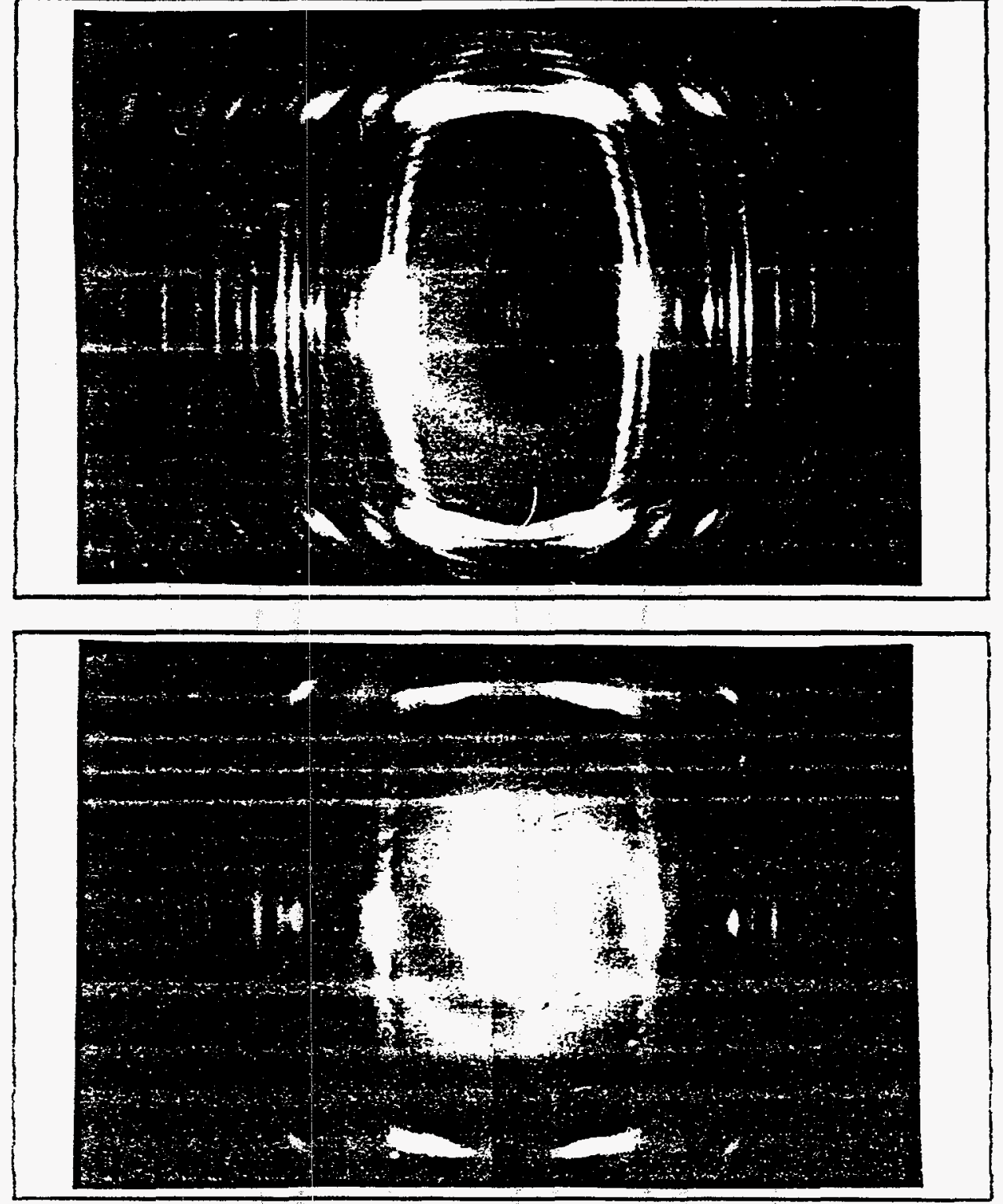
Fig. 11

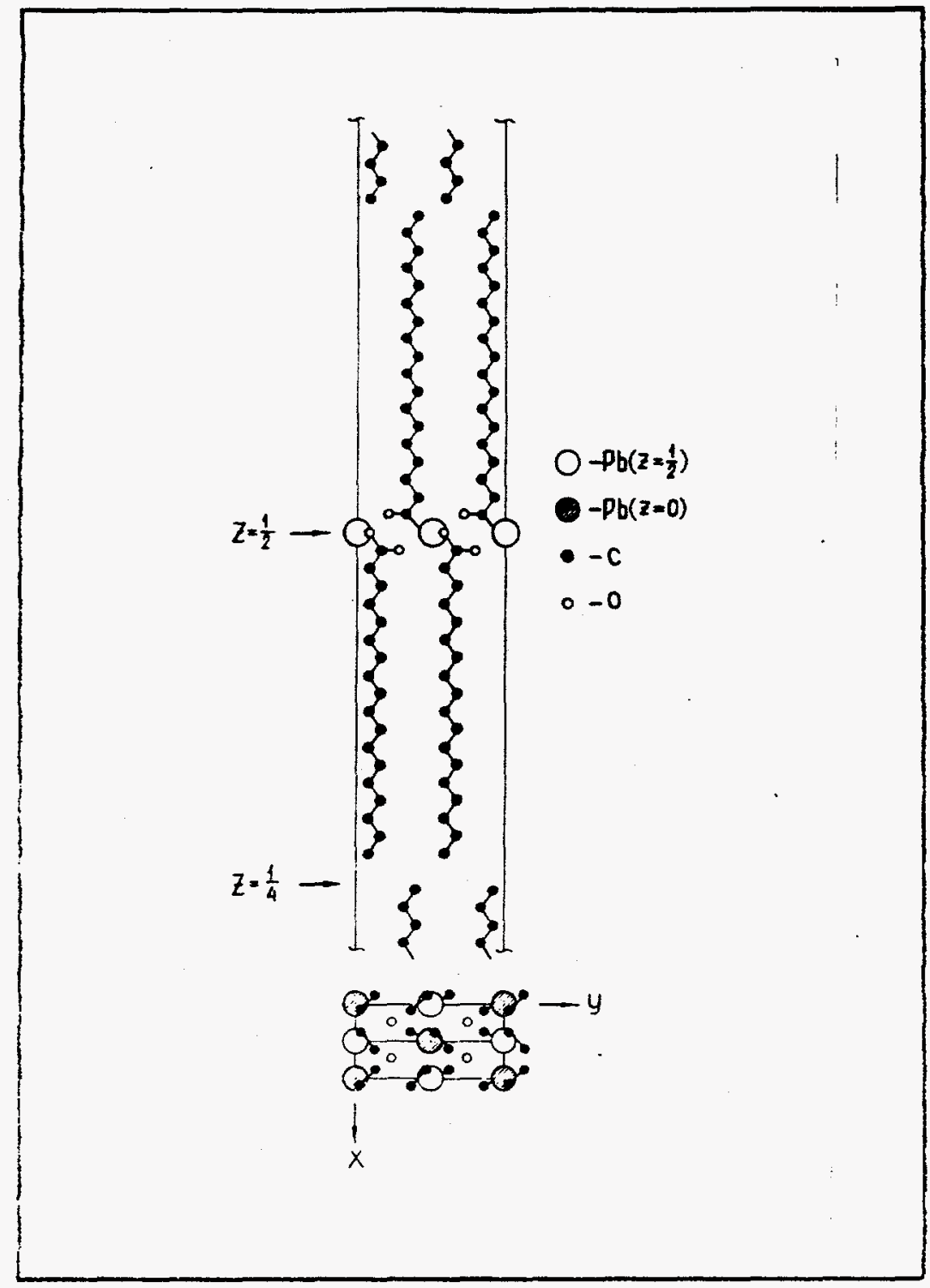

1-ig. 12

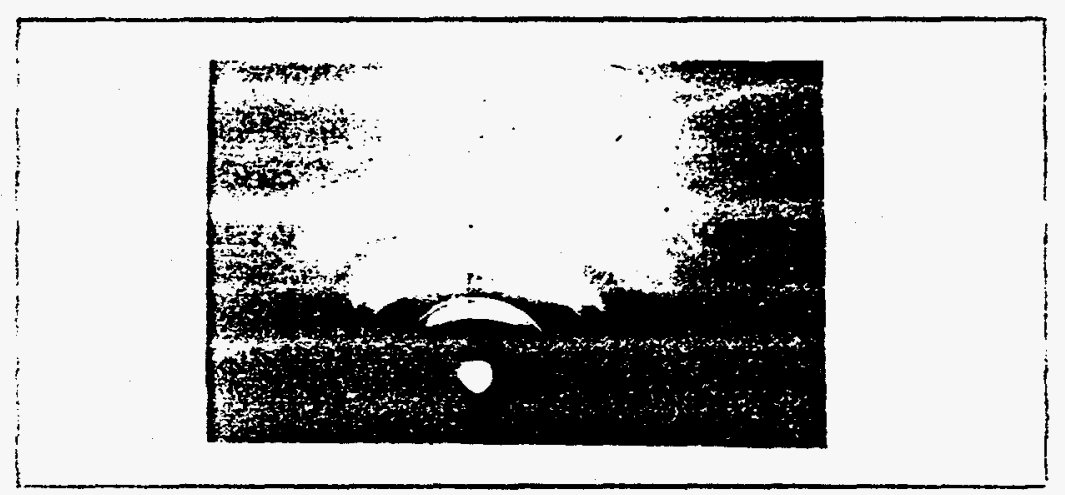




\title{
Chapter 5.5
}

\section{Characterization of Ceramic Films Grown on Langmuir - Blodgett Films on Silicon}

\begin{abstract}
Current report presents results of the Task 4 of investigation under the contract $A E-3528$. The work includes the results on analysis of the literature evidences on possible ways of oriented growth, the description of techniques used for growing $\mathrm{PbS}$ and CdS films, and data on atomic structure and thicknesses of the films obtained.
\end{abstract}

The processes of forming Langmuir-Blodgett (LB) films of $\mathrm{Pb}$ and Cd fatty salts and the influence of growth conditions and substrates quality on films structure were considered in the reports on the previous stages. Preliminary experiments on the deposition of polycrystalline ceramic films of pbs and Cas onto hydrophobic surfaces of LB films of fatty acids salts of Co and $\mathrm{Pb}$ confirmed the efficiency of the techniques used. The Task 4 was aimed at the characterization of uniformity, structure, orientation, and crystallite size of the ceramic thin films. Special attention at the stage presented was paid to the technology of oriented crystalline films growth.

\section{General features of oriented films growth}

The oriented growth of one substance on the crystalline substrate is referred to as epitaxy. The mutual orientation of the substrate and the layer grown is usually caused by the coincidence of some close packed crystallographic directions in the substrate and in the layer. Epitaxial growth is available not only for isostructural pairs of crystals but also for pairs of crystals which differ in structure and/or in type of chemical bonding [Landolt-Bornstein, 1972], [Palatnik et al., 1972]. In many cases, separate nuclei of new phase and aggregates of them are forming at the initial stage of the crystal growth on the substrate. Then those aggregates become larger and can coalesce to produce a continuous layer. Preference of a specific crystalline orientation with respect to the others can originate both at the stage of the new phase nucleation and at the nuclei growth. Epitaxial growth is essentially affected both by thermodynamic and by kinetic factors. The influence of kinetic factors increases as adhesion of the condensate onto the substrate decreases. The adhesion degree can vary essentially even for the same substance depending on the thickness of the layer jrown. The latter means that growth conditions for thin and thick films can vary largely. Thus, when selecting optimal conditions for epitaxial growth it is necessary to esimate importance of all factors mentioned above for a specific technique of films growth. There is a lot of various teciniques to obtain epitaxial layers: vacuum evaporation, crystallization from the gaseous phase, crystallization from solutions or melts. We adopted the technique of growth from solutions at room temperature as this technique requires conditions similar to those in processes occured in living beings.

2. Crystallization from solutions by means of chemical reaction.

Three main techniques of groth from solutions are known:

- solution temperature variation (cooling or setting up a 
temperature gradient)

- variation of the solution composition (evaporation of the solvent or adding the condensate substance to the solution)

- a chemical reaction in the solution (also electrochemical processes)

The third method was choosen to grow thin films of lead sulphide and cadmium sulphide. Crystallization caused by a chemical reaction is based on formation of solid products during the chemical interaction of solved compounds. Chemical reactions in solutions nun at sufficiently high rate. This leads to a high level of supersaturation, and precipitation of small-sized crystallites occurs. Therefore, control of the reaction rate becomes of great importance in optimization of conditions of epitaxial growth. The reaction rate can be retarded either by means of controlling the rate of supply of reagents into the reaction region or by using initial reagents of low solubility. This retardation can be implemented through some special techniques such as using semipermeable membranes to control ions diffusion into the reaction region, slow adding reagents solutions in a dropwise manner into the reaction region, increasing ions diffusion path etc. Increasing ions diffusion path can be achieved by lowering reagents concentration in the solution, by spatial separation of reagents solutions into two enclosed vessels or by increasing the solvent viscosity (for example, with the use of gels). Beside the retardation of the reaction rate it is necessary to take into account the parameters which can influence on adhesion of the substance onto the substrate.

3. Pbs and CdS crystallization techniques.

Films of PbS and CdS can be grown by chemical deposition of water-insoluble substances from solutions. The mechanism of slow generating $52-$ ion is of importance in processes of thin metal sulphides films growth. We examined two different ways to produce the $52-$ ion for the chemical reaction. Usually this reaction resulted in a formation of a system of a matrix formed by $L B$ technique and a metal sulphide layer. Several techniques of deposition of this system onto the solid substrate were also studied. They were the original schaefer technique and its modifications:

- original schaefer technique (horizontal lift). The solid substrate surface is brought into contact with the film at the air side of the air-subphase interface and then the substrate is Iifted away from the interface;

- The hydrophobized substrate surface is contacted with the film at the air side and drowned down to the subphase. Then the air-subphase interface is cleaned from the remainder of the film and the substrate is dipped off the subphase. This technique will be referred below as air-subphase-air ilft;

- The hydrophilic substrate surface is contacted with the film at the subphase side and lifted away from the air-subphase interface. This technique will be referred below as subphase-air lift;

\subsection{Sulphide ions are provided by H2S}

This approach uses a chemical reaction between H2S in the 
atmosphere surrounding the subphase and the subphase containing $\mathrm{Pb} 2+$ or $\mathrm{Ca} 2+$ ions. H2S was given by evolving from the aqueous solution of Na2s:

$$
\mathrm{Na} 2 \mathrm{~S}+\mathrm{H} 2 \mathrm{O}=\mathrm{Na}++\mathrm{OH}-+\mathrm{HS}-+\mathrm{S} 2-+\mathrm{H} 2 \mathrm{~S}
$$

The vessel with the Na2s solution was placed near the solution containing metal ions that will be referred to as the subphase. Released H2S molecules diffused to the air-subphase interface where the reaction took place and cds or PbS formed.

Reference

X.K. Zhao et al, J. Phys. Chem., v.96, No 24 (1992), pp. $9933-9939$

\subsubsection{Matrix is the LB film on the Si substrate.}

The Si substrate with 5 monolayers of $\mathrm{Pb}$ stearate was dipped into the vessel with the subphase solution. Another vessel containing solution of $\mathrm{Na}$ sulphide was placed near the first one. These two vessels were covered by a glass cap. A Pbs layer of specific grey color at the solution-air interface becomes visible after 30 minutes after the beginning of the reaction. As time of the reaction increases the thickness of the film also increases while the solution in the first vessel remained transparent. The latter means that Pbs did not precipitate onto the matrix and the reaction seemed to take place only at the solution-air interface. Corresponding RFEEDpattern from such PbS layer is shown in Fig. 1 .

3.1.2 Matrix is the uncompressed monolayer of fatty acid on the

subphase surface

$\mathrm{Pb}(\mathrm{NO} 3) 2$ solutions of concentrations 3 10E-4 M or 3 10E-5 M and of $\mathrm{pH} 5.5$ were used as a subphase. The subphase was poured into a petri dish and then the behenic acid layer was spread over the surface of the subphase. Na2s solution was of $0.02 \mathrm{M}$ concentration. The vessels were arranged in the same manner as above. A grey inhomogeneous film of PbS was formed after 20 minutes ifrom the beginning of the reaction. The matrix-PbS syste:l was then deposited onto a si substrate. All of 3 techniques descripted above were used. Optical microscope views of the films obtained showed that the films were of inhomogeneous polycrystaliine structure. Poor quality of the films, was the reason to modify conditions of films preparation. 3.1.3 Matrix is the fatty acid monolayer on the subphase surface
under controlled surface pressure

$\mathrm{Pb}(\mathrm{NO} 3) 2$ solutions of 3 IOE-5 $\mathrm{M}$ concentrations and of $\mathrm{pH}$ 5.5 was used as a subphase. The subphase was poured into a Langmuir trough and then the behenic acid layer was spread over the surface of the subphase and compressed to surface pressure 
of 28 dyne $/ \mathrm{cm}$. Na2s solution was of $0.02 \mathrm{M}$ concentration and of $\mathrm{pH}$ 11. The Petri dish containing about $20 \mathrm{ml}$ of Na2S solution was placed near the trough. Time of the reaction was 3 hours. Deposition of the films obtained was performed by the horizontal Iift technique onto a Si substrate. A specific feature of those films was that their surfaces were "dry" i.e. they looked like hydrophobic. Electron diffraction study showed that beside polycrystalline regions partially ordered regions existed in those films. Ordered regions were textured with the orientation (111) parallel to the substrate (see Fig. 2).

\subsubsection{Increasing the reaction time}

To enlarge the thickness of the metal sulphide film the reaction conditions of 3.1 .3 were applied for 24 hours reaction time. During the night period monitoring of the surface pressure was not executed. Next day the shining dark grey film of Pbs was observed on the surface of the subphase. The film looked to be inhomogeneous. It could not be deposited onto the substrate by the horizontal lift technique but the use of two other techniques made possible to obtain pbs films. Cds films were obtained in a similar way. $\mathrm{Cd}(\mathrm{NO} 3) 2$ solutions of 1 10E-5 M concentrations and of $\mathrm{pH} 6.2$ was used as a subphase. 24 hours after the beginning of the reaction a shining yellow cds film formed on the surface of the subphase. Electron diffraction data are presented at Figures 3-4.

\subsection{Sulphide ions are provided by thiourea reaction.}

Hydrolythic decomposition of thiourea in an alkali solution results in that 52 - ions production:

$\mathrm{NH} 2 \mathrm{CSNH} 2+2 \mathrm{H} 2 \mathrm{O}=2 \mathrm{NH} 3+\mathrm{CO} 2+\mathrm{H} 2 \mathrm{~S}$

Metal ions in an alkali solution exist as soluble complex compounds :

$\mathrm{CO}(\mathrm{OH}) 2+4 \mathrm{NH} 3=[\mathrm{Cd}(\mathrm{NH} 3) 4](\mathrm{OH}) 2$

$\mathrm{Pb}(\mathrm{OH}) 2 \vdots+2 \mathrm{NaOH}=\mathrm{Na} 2[\mathrm{~Pb}(\mathrm{OH}) 4]$

H2S produced by the reaction (1) reacts with metal ions and metal sulphide is produced.

Rंeferences:

Inderjeet Kaur et al., J. Electrochem Soc., v.127, No 4, 1980, pp. $943-948$

John L. Davis, Marriner K. Norr, J. Appl. Phys., V.37, No 4, 1966, pp. 1670-1674 


\subsubsection{Matrix is the uncompressed monolayer of fatty acid on the}

subphase surface

The subphase was prepared by pouring into the Petri dish the following components: $20 \mathrm{ml}$ of $0.1 \mathrm{M} \mathrm{Ca}(\mathrm{NO} 3) 2$ solution, 75 $\mathrm{mI}$ of $6 \mathrm{M} \mathrm{NH} 4 \mathrm{OH}$ solution, $40 \mathrm{ml}$ of $1 \mathrm{M}$ thiourea solution and 200 $\mathrm{ml}$ of water. A monolayer of behenic acid was spread over the surface of the subphase. A yellow layer of Cas precipitate formed after 30 minutes from the beginning of the reaction. Deposition onto the substrate was performed by techniques of horizontal lift and of subphase-air lift. A similar experiment on formation of PbS film was performed. The subphase consisted of the following components: $1 \mathrm{ml}$ of $0.175 \mathrm{M} \mathrm{Pb}(\mathrm{NO} 3) 2$ solution, 6 $\mathrm{ml}$ of $0.57 \mathrm{M} N a O H$ solution, $2 \mathrm{mI}$ of $1 \mathrm{M}$ thiourea solution and $180 \mathrm{ml}$ of water. Small separate crystallites formed on the subphase surface, not a uniform film. Electron diffraction data on samples obtained by this technique revealed no preferential crystallographic orientation in the films. They were polycrystalline.

\subsubsection{Matrix is the IB film on the Si substrate.}

The subphase was prepared by pouring into the petri dish the following components: $30 \mathrm{ml}$ of $0.57 \mathrm{M}$ NaOh solution, $10 \mathrm{ml}$ of $0.175 \mathrm{M} \mathrm{Pb}(\mathrm{NO} 3) 2$ solution, $10 \mathrm{ml}$ of $1 \mathrm{M}$ thiourea solution and $85 \mathrm{ml}$ of water. 5 monolayers Pb stearate film was placed into the subphase immediately after pouring the subphase components together. Electron diffraction data show that not PbS but monoclynic sulphur contributes mainly (see Fig. 5). Sulphur is a by-product of the reaction used. Separate $S$ particles were of several microns in size and oriented by $c$-axis parallel to the substrate (see Fig. 6). We suppose that the formation of monoclinic sulphur was due to insufficient purity of initial reagents.

\section{Structural characterization}

\subsection{Ellipsometry study (Courtesy by Dr. Tronin A.Yu.)}

Ellipsometry can estimate the effective refraction index and the jveraged thickness of thin films. This technique can not prowide detailed information about inner film structure. However, it is helptul for prompt monitoring over a process of growth. Only values of film thickness were of physical meaning because interpretation of the refractive index value is quite amigigous due to complex structure of the films. Two samples were studied by ellipsometry. The first sample (\#23) was a film of PbS on PbBeh2 matrix deposited onto Si during 15 hours. The second sample (\#5) was prepared by 3.3 technique with deposition time $=3 \mathrm{~h}$. For the sample \#23 the thickness (PbS+PbBeh2) was estimated to be about 270 Angstroms. Thickness of the sample \#5 was 67 Angstroms. It should be mentioned that the accuracy of the last figure is poor. Nevertheless, it is seen that ellipsometry can provide realistic data on growth rate. 


\subsection{Electron diffraction study}

Results of electron diffraction analysis are presented by Figure captions.

\section{$4.3 \mathrm{x}$-ray diffraction study}

Unfortunately, samples obtained were of poor quality to study them by $\mathrm{X}$-ray reflectometry because the films were not continuous along the plane. Therefore, reflectivity data treatment became ambiguous. Some attempts were made to obtain diffraction peaks from the films in the direction normal to the substrate but they were of no success. It should be noticed that such peaks can be observed only at proper adjustment of the film with respect to a primary $\mathrm{X}$-ray beam. This requirement is caused by weak interaction between $x$ rays and the substance of the film and small amount of the substance in the region of interaction. Probably, use of 2 dimensional detector can simplify a procedure of such an adjustment but at any case this problem is more hard than that in a case of electron diffraction.

\section{Peculiarities of metal sulphides deposition onto LB substrate}

5.1 Films obtained by air-subphase-air lift were of the best quality among aIl of them. The poorest results was for horizontal lift. The latter is explained by strong attraction of the film by the subphase that prevents any attachment of the film to the substrate.

5.2 A ceramic film becomes thicker as increases the time of its contact with H2S. But its homogeneity in plane as well as out of plane is lost.

5.3 The monitoring of surface pressure of a monolayer on the subphase essentially improves quality and reproducibility of textures of the films obtained.

5.4 Comparison between PbS and CdS films revealed that PbS orientation was better than that for CdS regardless of a technique they were obtained through.

\section{Proposals for further investigations.}

6.1 It is known that in some cases of epitaxial film growth heating of the film for some minutes results in the reconstruction of initially amorphous layer to a crystal structure. Heating temperature is much lower than melting temperature.

6.2 Quality of films can be improved by more accurate matching of parameters of the LB layer to those of the ceramics. This can be achieved by

- varying surface pressure of the matrix monolayer;

- using LB films of other amphiphilic compounds such as cellulose polymers, natural lipids etc.

- more correct control of reaction rate;

- low temperature annealing of the films. 
A series of experiments was made on the growing of Pbs and Cas films from aqueous solutions on the surface of fatty acids salts containing cations of $\mathrm{Pb}$ and $\mathrm{Cd}$. Two different techniques were used to feed sulphur ion into the reaction region: 1) H2S solving from the gaseous phase; 2) thiourea reaction in the subphase. Varied in experiments were the growth time, the technique of films deposition from the subphase onto the solid substrate, thiourea solution concentration. Crystallographic orientation and structure of films obtained was investigated by electron diffractior. The following basic results were obtained:

1. If feeding 52 - ions from the gaseous phase into the subphase the oriented PbS(CdS) particles were observed for the films grown on LB matrixes comrpressed to surface pressure of 28 dyne/cm. For the case of PbS films three preferential face orientations paraljel to LB matrix were occured: (111), (011), (001). Two first of them give evidence of ordered epitaxial growth while the (001) orientation is typical for spontaneous Pbs particles formation. Epitaxial particles are usually misoriented with respect to each other. Estimation of misorientation angles was made through the measurement of dimension of reflexes of several indices. The value of this angle was of order of $+/-10$ degrees for (110) faces orientation and somewhat less for (111) orientation. The least misorientation of $+/-2.5$ deg was observed for the Pbs film grown on the PbBeh? matrix under pressure 28 dyne/cm monitoring during 3 hours. for the case of cas films the only epitaxial orientation of the (111) face parallel to the matrix was observed. Separate particles (blocks) were misoriented by angles of $+/-(2.5-5)$ degrees to each other and twinned around the [111] plane. This can be explained either by better ordering in CdBeh2 matrix than in PbBeh2 matrix or by more suitable parameters of the matrix-film interface in the case of Cas. Particle misorientation can be caused by misorientation of LB matrix domains, kinetic nature of deposition process as well as supersaturation, reaction rate, diffusion parameters etc. Influence of those parameters on films quality is the matter of further investigations.

2. Preliminary results were obtained for the case of productiun of $\mathrm{Sz}$ - ions by thiourea reaction. It was shown that build-up of PbS (CdS) films on LB matrix is possible. However, additional efforts are necessary to match properly the growth conditions. At present, only polycrystalline layers were obtained.

Principal investigator Lev A. Feigin

Stuff:

Elena V. Rakova

Vera V. Klechkovskaya

Ludmila G. Yanusova

Nina D. Stiopina

Viktor $V$. Safronov

Ivan I. Samoilenko 
RHEED - reflection high energy electron diffraction; TED transmission electron diffraction

Fig. 1. RHEED pattern for PbS layer grown on the air-subphase interface with no LB matrix. S2- ions were provided by H2S solving. Debye rings are clearly seen indicating to polycrystalline structure of the layer. Kikuchi lines are due to scattering by supporting Si substrate.

Fig. 2. Morphology and structure of PbS layer grown on PbBeh2 matrix. S2- ions were provided by H2S solving. Pressure at the beginning of the growth was 28 dyne/cm. The surface is rough, the layer consists of PbS crystallites oriented preferentially by (111) face paraliel to the surface (shown by arrows). According to the RHEED pattern, the layer consists of crystallites of (111), (011) and (001) orientations. Misorientaion is $+/-5$ deg for (111)-oriented crystallites and $+/-10 \mathrm{deg}$ for (011)-oriented crystallites.

Fig. 3. RHEED pattern for PbS film grown on PbBeh2 matrix under 28 dyne/cm pressure during 3 hours. S2-ions were provided by H2S solving. Preferential orientation of crystallites is (111) face parallel to the surface. Misorientation is about $+/-2.5$ deg.

Fig. 4. TED pattern for CdS layer grown on CdBeh2 layer. S2- ions were provided by H2S solving. Crystallites are oriented by (111) face parallel to the surface and twinned around [111] axis. Crystallite size is less than 50 Angstroms. Crystallites of hexagonal modification (wurtzite) are present in the film.

Fig. 5. RHEED pattern for PbS film grown in $\mathrm{Pb}(\mathrm{NO} 3) 2+\mathrm{NH} 2 \mathrm{CSNH} 2$ solution of high concentration. Substrate-air lift was used to deposit the film onto LB matrix. Observable are particles of monoclinic sulphur and a small amount of $\mathrm{PbS}$.

Fig. 6. Separate sulphure particles on the PbSt2 surface. Magnification 4200 .

Fig. 7. Morphology and structure of Cas layer grown on CdSt2 matrix. 52 - ions were provided by thiourea reaction in the solution of low concentration. Air-subphase-air lift was used to deposit the film onto the substrate. The CdS structure is polycrystalline. 


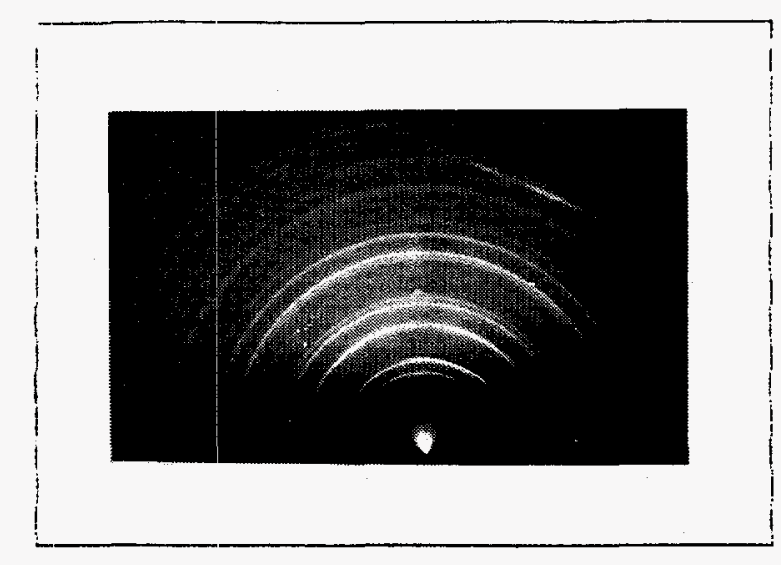

\section{Fig. 1}

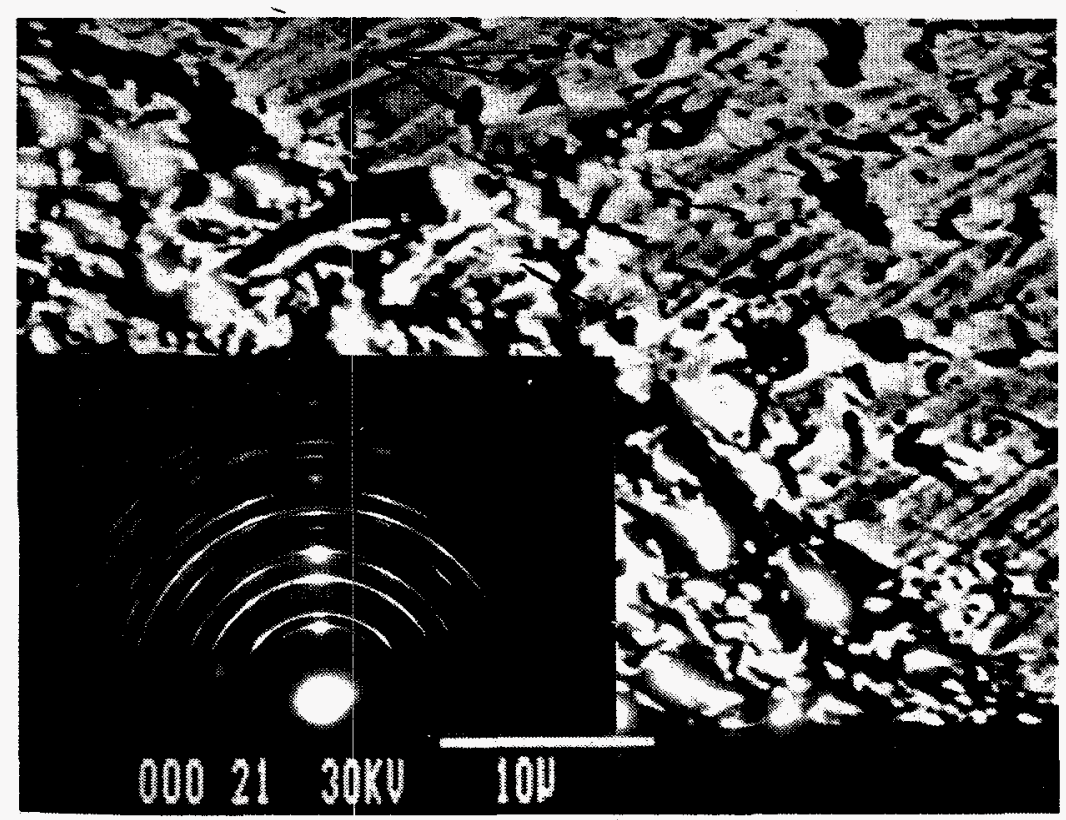

Fig. 2 


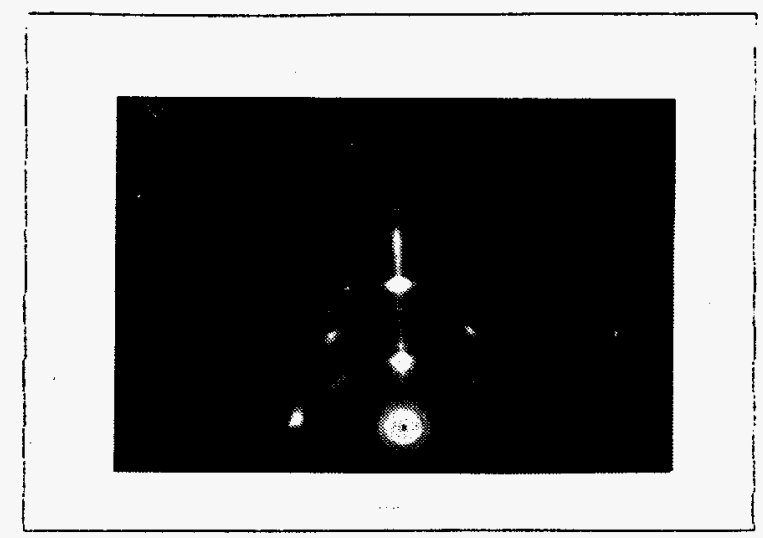

Fig. 3
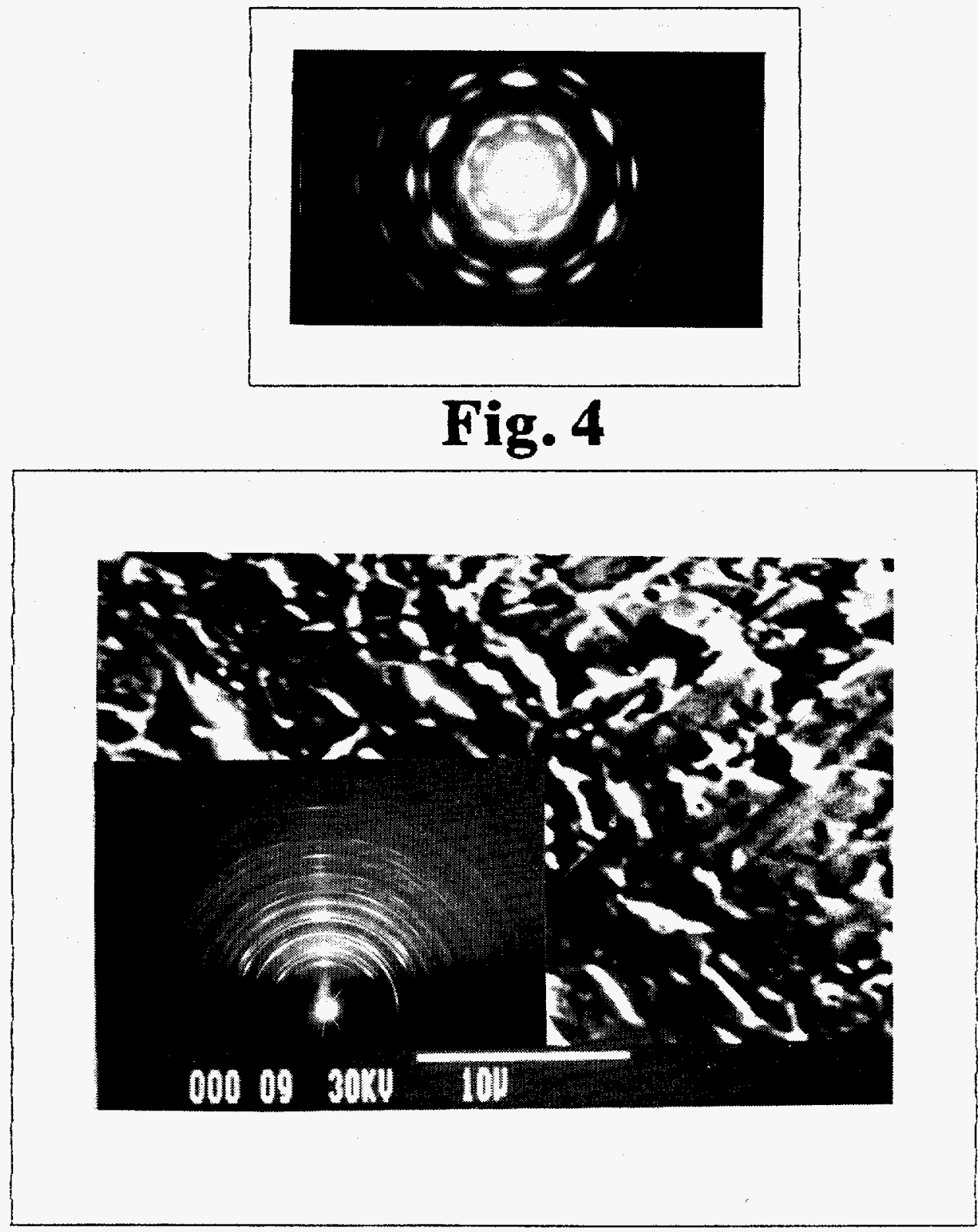

Fig. 5 


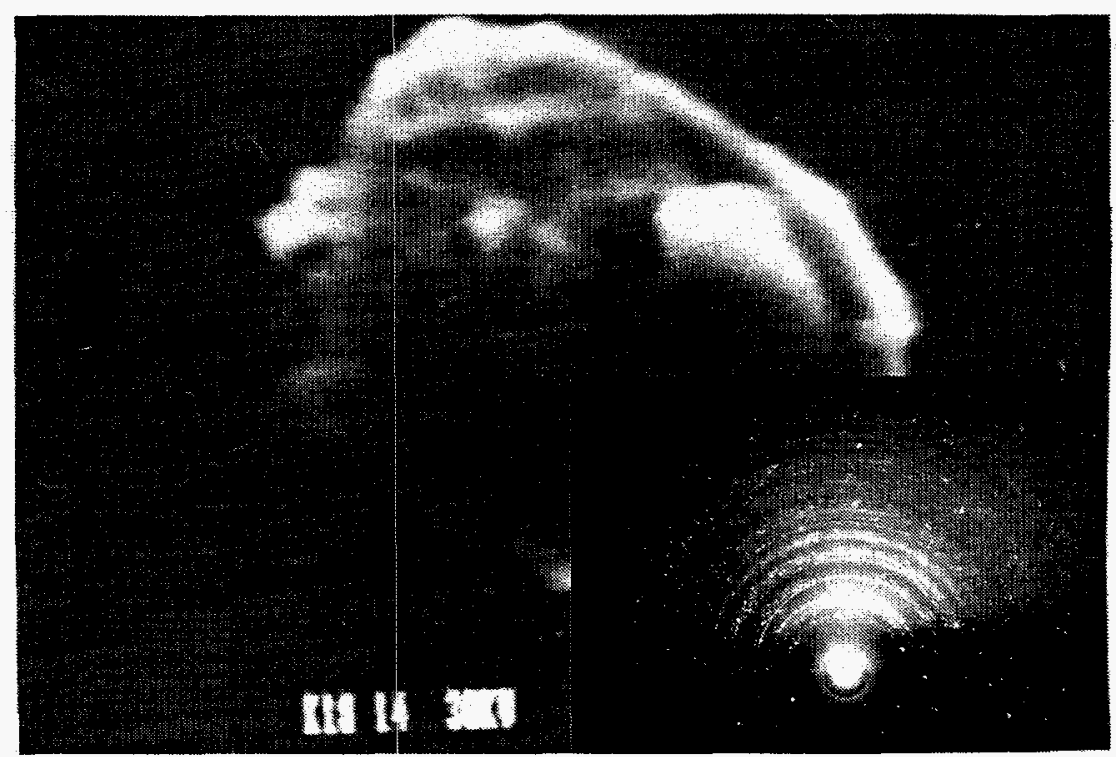

\section{Fig. 6}

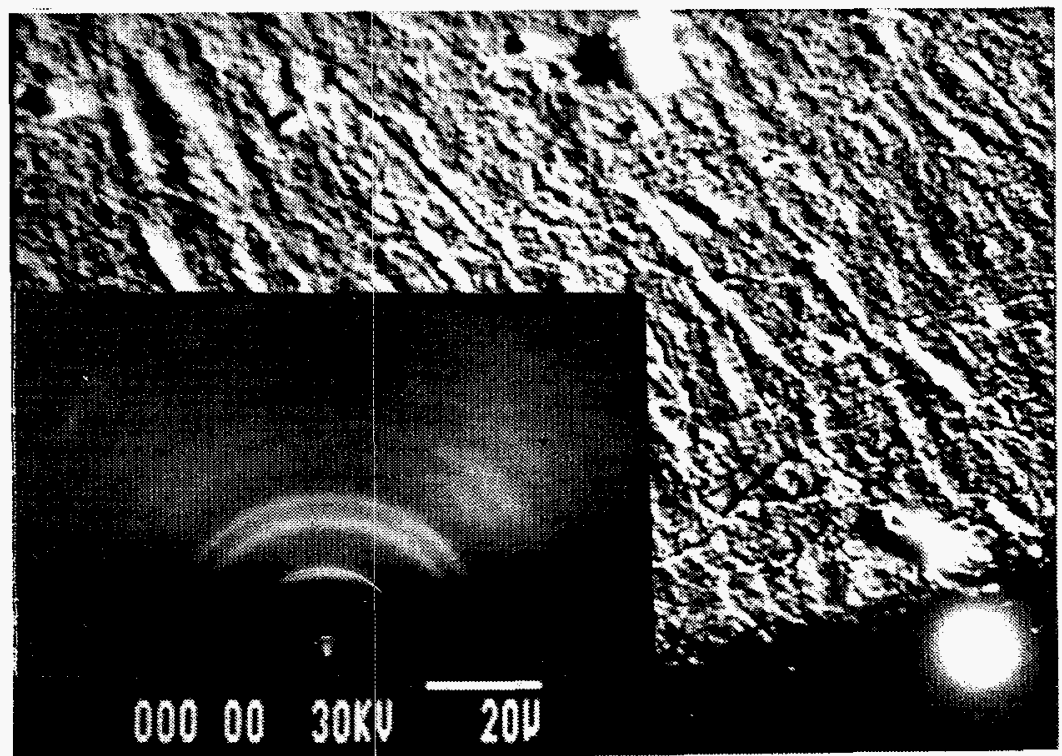

Fig. 7 


\title{
Chapter 6
}

\section{Custom-Synthesized Oligopeptides for Biomimtetic Mineralization Studies}

\author{
M.H.E. Martin and J. Cesarano \\ Sandia National Laboratories
}

Custom-synthesized oligopeptides offer great convenience and flexibility in the fabrication of Langmuir-Blodgett films for biomimtetic mineralization studies.

\section{Merrifield Synthesis of Amphiphiles}

It is known that proteins (natural polypeptides) and protein-based molecles are omnipresent in the organic matrices of mineralized tissues - bone matrix, for example, is composed entirely protein-based materials with $85-90 \%$ of the matrix made of a polypeptide called type I collagen ${ }^{1}$. Polypeptide homopolymers show a wide range of solubilities depending on their amino acid compositions (see Table 1). For example, poly (aspartic acid) is very water soluble, while poly(phenylalanine) is water insoluble. Thus, it is clear that amphiphilic peptide-based molecules can be made via the construction of oligopeptides with both hyrophilic and hydrophobic blocks. An example of such an amphiphile is shown in Figure 1.<smiles>NC(CC(=O)O)C(=O)O</smiles><smiles>NCC(=O)O</smiles>

$$
\text { Aspartic Acid = Asp } \quad \text { Glycine }=\text { Gly }
$$

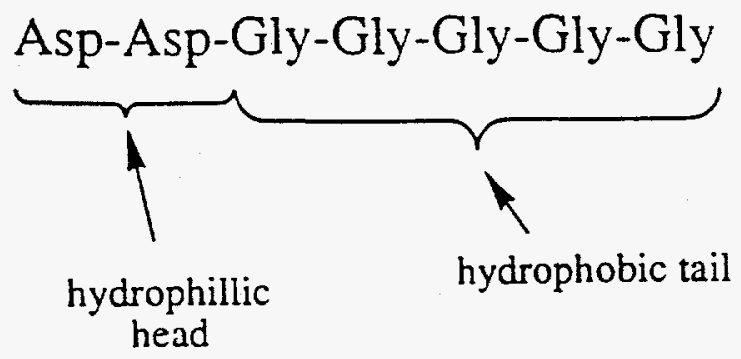

Figure 1 Asp2Gly5, an example of an amphiphilic oligopeptide. 


\section{Table 1 - Solubilities of Primary Amino Acid Homopolymers 2 (Decreasing Water Solubility)}

\begin{abstract}
Amino Acid Homopolymer (L-unless noted)
\end{abstract}

Arginine $-\mathrm{HCl}$ Aspartic Acid $-\mathrm{NaCl}$ Glutamic Acid $\bullet \mathrm{NaCl}$ Lysine $\cdot \mathrm{HCl}$ Asparagine

Glutamine

Proline

Histidine

Histidine $\bullet \mathrm{HCl}$

Tyrosine

Cysteine

Glycine

Methionine

Tryptophan

Valine

Isoleucine

Leucine

Alanine

Serine

Threonine

Phenylalanine

\author{
Molecular Weight \\ Range (k)
}

$5-15$

$5-15$

2-15

$10-30$

5-15

$15-50$

$10-40$
$15-30$

Solubility

( $\mathrm{mg} / \mathrm{ml}$ in $\mathrm{H}_{2} \mathrm{O}$ unless noted)

$\left(\mathrm{H}_{2} \mathrm{O}\right.$ soln. clr. clrless unl. noted)

\section{$\mathrm{H}_{2} \mathrm{O}$ Soluble}

50

50

50

50

(solubility approx. from structure) (solubility approx. from structure) 50 (faint yellow color)

$0.1 \mathrm{~N} \mathrm{HCl} 10 \mathrm{mg} / \mathrm{ml}$

$0.1 \mathrm{~N} \mathrm{HCl} 10 \mathrm{mg} / \mathrm{ml}$ $1 \mathrm{~N} \mathrm{NaOH} 25 \mathrm{mg} / \mathrm{ml}(0.1 \mathrm{~N} \mathrm{w} /$ USnd)

(solubility approx. from structure)

\section{$\mathrm{H}_{2} \mathrm{O}$ Insoluble}

5-10

5-15

$5-15$

5-10

3-15

$10-2.5$

5-10

$5-15$
$25 \mathrm{mg} / \mathrm{ml}$ in diClAA

$20 \mathrm{mg} / \mathrm{ml}$ diClAA, 50 miFlAA

$25 \mathrm{mg} / \mathrm{ml}$ in DMF

triFlAA $25 \mathrm{mg} / \mathrm{ml}$

(solubility approx. from structure)

$10 \mathrm{mg} / \mathrm{ml}$ in triFlAA

$5 \mathrm{mg} / \mathrm{ml}$ hot diClAA

(solubility approx. from structure)

$5 \mathrm{mg} / \mathrm{ml}$ in hot diClAA
$5 \mathrm{mg} / \mathrm{ml}$ hot diClAA

The great advantage of working with peptides is that there are many different amino acids available for incorporation into the amphiphile and the subsequent tailoring of the structure of the Langmuir-Blodgett film. The actual synthesis of the oligopeptides has been fully automated based on the solid-phase technique that was introduced by R.B. Merrifield in 1963. Merrifield syntheses involve the sequential addition of tertbutoxycarbonyl ( $\mathrm{t}-\mathrm{BOC}$ ) protected amino acids to a peptide chain that is being grown on a chloromethylated polystyrene substrate/support. A schematic of the Merrifield solidphase synthesis of peptides is shown in Figure 2. 


\section{Basic Merrifield Synthesis}

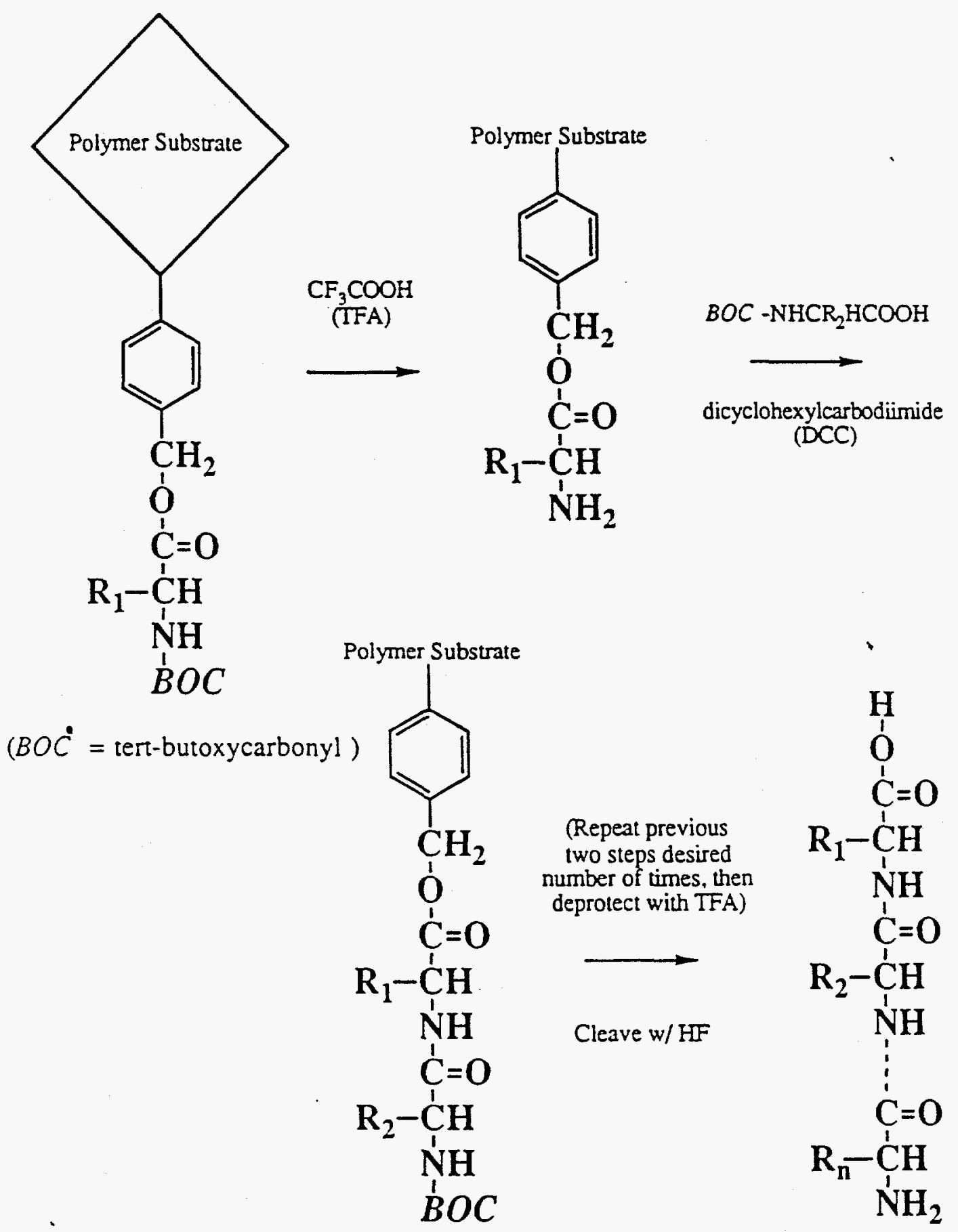

Figure 2 Basic Merrifield Solid-Phase Synthesis of Peptides.

For our applications, the end functionality of the final oligopeptides is very important. The options at the $\mathrm{N}$-terminal end are amine or acetylamide, and the options at the $\mathrm{C}$ - 
terminal end are free acid or amide (see Figure 3). Because we want the two ends to have different attitudes toward water, the amine/free acid combination is most likely prohibited. Merrifield synthesis of peptides are locally available with an approximate turn around time of 1 week ${ }^{2}$. The routine nature of the synthesis of an almost endless variety of amphiphiles will provide excellent design sequence and iteration opportunities.

\section{Merrifield Synthesis End Group Options}

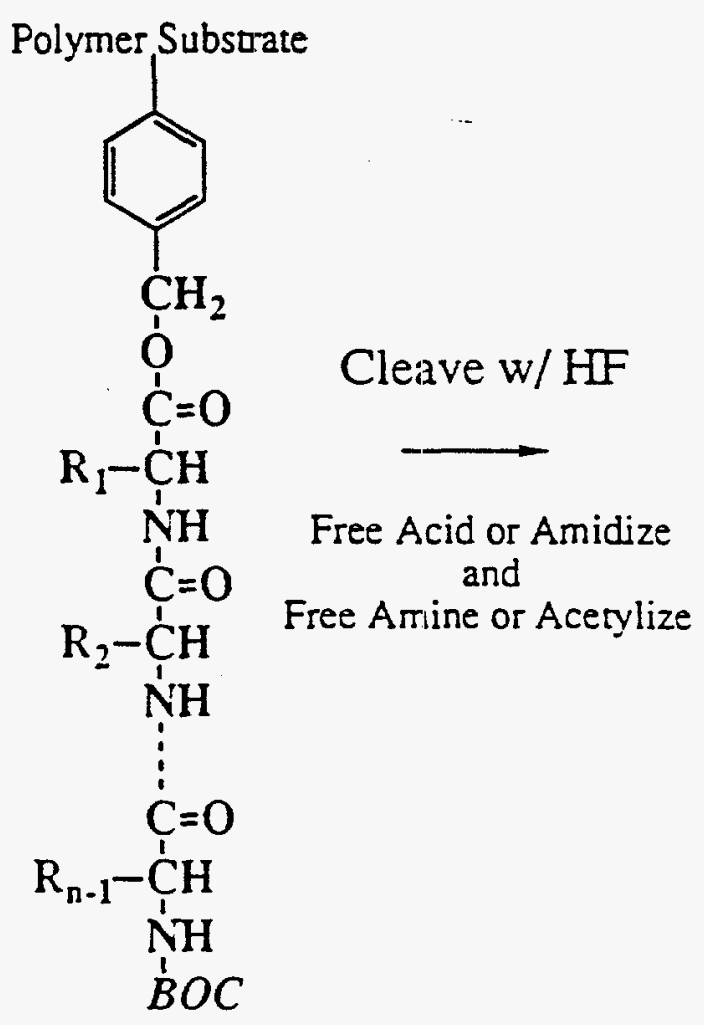<smiles>[R]C(N)C(=O)NC([R17])C(=O)NC([R1])C(=O)NC([R1])C(=O)O</smiles><smiles>[R]C(NC)C(N)=O</smiles>

Possible Products:

(carboxylic acid or amide)- $\mathrm{AA}_{1}-\mathrm{AA}_{2}-\cdots-\mathrm{AA}_{(\mathrm{n}-1)}$ - $\mathrm{AA}_{\mathrm{n}}$-(amine or acetylamide)

NOTE: An economical approach to making a series of similar amino acids is to have the $\mathrm{AA}_{1}-\mathrm{A} \mathrm{A}_{\mathrm{m}}(\mathrm{m}<\mathrm{n})$ sequence in common.

Figure 3 End functionality options in Merrifield synthesis. 
From past structure studies of synthetic peptide molecules we can estimate the sorts of structures that we'd expect our films to adopt. Bulk samples of L-alanyl-glycyl-glycine reportedly have a monoclinic structure (space group $P 2{ }_{1}$ ) with $a=12.20 \AA, b=5.38 \AA$, $c=7.90 \AA$, and $\beta=102.1^{\circ 3}$. Looking down the chain axes the molecules are arranged approximately hexagonally $\left(\mathrm{c} / \mathrm{b}=1.47 ; \mathrm{c} / \mathrm{bHCP}_{\mathrm{H}} \cdot \mathrm{ideal}=1.73\right)$. Interchain hydrogen bonding is an important consideration here ${ }^{4,4}$, and it is basically this interaction that is responsible for the structure's deviation from cubic. In the case of a monolayer of this material we would expect an arrangement that was similar to the basal plane of the bulk sample's psuedo-hexagonal structure (see Figure 4). We would also predict that the chain axes will be tilted about $12^{\circ}$ from vertical with respect to the substrate due to interchain hydrogen bonding.
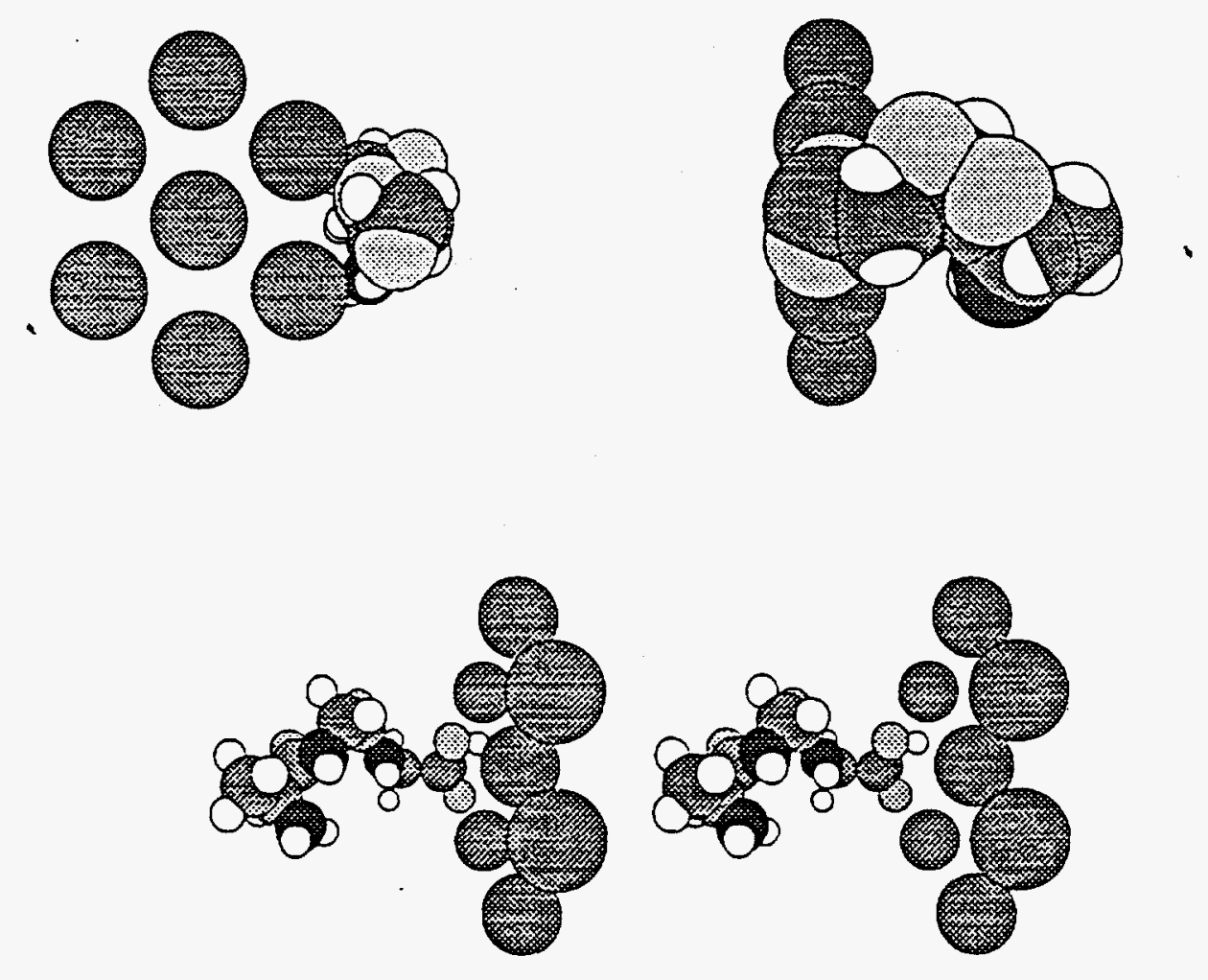

Figure 4 Above left: 'basal plane' view of psuedo-hexagonal arrangement of alanylglycyl-glycine molecules. Above right: view rotated $90^{\circ}$ from 'basal plane'. Bottom:

Stereoscopic view of Ala-Gly-Gly molecule on pseudo-hexagonal lattice. Note: The AlaGly-Gly molecule is not shown in its energy minimized configuration. 
A major unproven hypothesis in biomineralization is that lattice matching between the charged sites of the organic matrix and a crystallographic face of the desired inorganic phase is a neccessary condition for mineralization to occur ${ }^{6}$. The amphiphilic oligopeptide approach to fabricating synthetic mineralization templates offers flexibility with respect to the spatial arrangement of the charged sites that will allow us to rigorously test this hypothesis. For example, consider the free acid of acetylated Gly-Gly-Gly-AlaGly (abbreviated Ac-Gly3-Ala-Gly-OH) - see Figure 5.<smiles>CC(=O)NCC(=O)C(C)(C)NC(C)C(=O)NCC(=O)O</smiles>

Figure 5 Structure of Ac-Gly3-Ala-Gly-OH. The free carboxylic acid provides the charged site on the finished template.

There ate many means for adjusting the spacing of the charged site (carboxylic acid) spacing. For example, substituting another glycine for the alanine (thus giving us AcGly5-OH) would allow the charged groups to pack closer; if we instead substitute valine for the alanine (see Figure 6) the result would be a greater separation between charged groups; if we substitute aspartic acid for the terminal glycine the result would be a new, denser arrangement of charged sites (see Figure 7).<smiles>CC(=O)C(C)(C)NCC(=O)C(C)(C)NC(C(=O)NCC(=O)O)C(C)C</smiles>

Figure 6 Structure of Ac-Glyz-Val-Gly-OH. 
<smiles>CC(=O)C(C)(C)NCC(=O)C(C)(C)NC(C)C(=O)NC(CC(=O)O)C(=O)O</smiles>

Figure 7 Structure of Ac-Gly 4 -Asp-OH.

If the target mineral were a sulfide (e.g. $\mathrm{ZnS}$ ), a thiol group could be used as the charged siteby incorporating cysteine into the amphiphile - see Figure 8.<smiles>CC(=O)NCC(=O)C(C)(C)NC(C)C(=O)NC(CS)C(=O)O</smiles>

Figure 8 Structure of Ac-Gly3-Ala-Cys-OH.

Cysteine-containing proteins called metallothioneins are metal-binding proteins that are known to play a major role in the biometabolism of $\mathrm{Zn}, \mathrm{Cu}, \mathrm{Cd}, \mathrm{Hg}, \mathrm{Ag}, \mathrm{Au}$, and $\mathrm{Bi}^{7}$. Langmuir-Blodgett routes to the formation of sulfides have been previously investigated it was found by Smotkin et al. that CdS can be formed by the $\mathrm{H}_{2} \mathrm{~S}$ treatment of LB films of cadmium arachidate ${ }^{8}$.

Modifications to the oligopeptide amphiphile could be made for other reasons. For enhanced characterization opportunities the amphiphile could be "tagged" with halogenated amino acids (fluoro-, chloro-, and bromo-substituted are all commercially available); isotopically ( $13 \mathrm{C}$ and $15 \mathrm{O}$ ) and radioisotopically labelled (tritium and ${ }^{14} \mathrm{C}$ ) amino acids are also available commercially. Investigators have used polymerizable amphiphiles such as $\omega$-tricosenoic acid $\left[\left(\mathrm{CH}_{2}\right)=\mathrm{CH}-\left(\mathrm{CH}_{2}\right)_{20}-\mathrm{COOH}\right]$ for the modification and stabilization of the L-B film structures for use in photolithography. The vinyl groups can be polymerized by electon beam $9,10,11,12,13$. or X-ray radiation ${ }^{14}$ [T've only seen FTIR and dissolution time studies done on polymerization of these films - no structural 
characterization]. Allylglycine (see Figure 9) is a commercially available amino acid that could be incorporated into the amphiphile for subsequent polymerization.<smiles>C=C(CNC(=O)CNC(C)(C)C(=O)NCC(=O)O)C(C)=O</smiles>

Figure 9 Structure of Ac-allylglycine-Gly $4-\mathrm{OH}$.

Merrifield peptide synthesis route to amphiphiles is clearly very flexible, and would not only be useful in biomineralization studies but perhaps also in basic investigations of two-dimensional crystals prepared by LB techniques. 
p. 152 in On Biomineralization, H.A. Lowenstam and S. Weiner, Oxford Univ. Press, Oxford, England, 1989.

Eileen Shooter and Bob Gates - Sigma Chemical private communication.

UNM's Protein Chemistry Laboratory is under the direction of Dr. Andrzej Pastuszyn. They offer 0.5 millimole peptide syntheses at the cost of $\$ 100$ plus $\$ 50$ per amino acid group. Their upper limit is approximately 20 amino acids, and they offer a purity of approximately $95 \%$. Subsequent purifications can also be performed.

E. Subramanian and V. Lalitha, "Crystal Structure of a Tripeptide, L-AlanylGlycyl-Glycineand its Relevance to the Poly(glycine)-II Type of Conformation," Biopollymers, 22, 833-838 (1983).

J. Tormo, J. Puiggali, J. Vivies, I Fita, J. Lloveras, J. Bella, J Aymami, and J.A. Subirana, "Crystal Structure of a Helical Oligopeptide Model of Polyglycine II and of Other Polyamides: Acetyl - (glycyl- $\beta$-alanyl) 2 -NH Propyl,"Biopollymers, 32, 643-648 (1992).

K. Simkiss, "The Processes of Biomineralization in Lower Plants and Animals: An Overview," pp. 19-37 in Biomineralization in Lower Plants and Animals: International Svmposium. 15-19 April 1985. Birmingham. England, Systematics Assoc. Special Vol. No. 30, Oxford Univ. Press, 1986.

M. Vasak and J.H.R. Kagi, "Mammalian Metallothionein: Evidence for Metal Thiolate Clusters," pp 429-437 in Biomineralization and Biological Metal Accumulation, eds. P. Westbroek and E.W. de Jong, 1983.

E.S. Smotkin, C. Lee, A.J. Bard, A. Campion, M.A. Fox, T.E. Mallouk, S.E. Webber, and J.M. White, "Size Quantization Effects in Cadmium Sulfide Layers Formed by a Langmuir-Blodgett Technique," Chem. Phys. Lett., 152, 265-268 (1988). Polymerization of $\omega$-Ticosenoic Acid Multilayers," J. Colloid Interface Sci., $\underline{62}$, 509-523 (1977). 
10 A. Barraud, C. Rosilio, "Monomolecular Resists: A New Class of High Resolution Resists for Electron Beam Microlithography," Solid State Technol., 22, 120- 124 (1979).

11 A. Barraud, "Polymerization in Langmuir-Blodgett Films and Resist Applications," 'Thin Solid Films, 99, 317-321 (1983).

12 A. Barraud, "Dissolution Kinetics in Langmuir-Blodgett Films of Solid State Polymerized w-Tricosenoic Acid," Mol. Cryst. Liq. Cryst., 96, 353-359 (1983).

13 K. Ogawa, H. Tamura, M. Hatada, and T. Ishihara, "Radiation Effect of a High Energy Electron Beam on Thin Films of Saturated and Unsaturated Fatty Acids," Coll. Polym. Sci., 266, 525-531 (1988).

14 K. Ogawa, H. Tamura, M. Hatada, and T. Ishihara, "Polymerization and Submicron Patsern Fabrication on Saturated and Unsaturated Fatty Acid LB Films Using X-ray Irradiation," Langmuir, 4, 1229-1233 (1988). 


\section{Peptide Amphiphile Motivation}

Merrifield peptide synthesis offers great degree of flexibility and simplicity in design and synthesis:

Available amino acids, End groups

- Flexibility in character of hydrophilic groups (positive or negatively charged, single or double head)

- Selection of hydrophobic tail sequence may offer many different packing types

- More comparable to proteins of biological systems $\left(\mathrm{CaCO}_{3}\right.$ and hydroxyapatite studies)

- Greater range of working temperatures for deposition due to higher melting points of peptides. 


\section{Primary Protein Amino Acids}

Alanine<smiles>CC(N)C(=O)O</smiles>

Aspartic acid

( $\mathrm{R}=\mathrm{OH}$ )

Asparagine

$\left(\mathrm{R}=\mathrm{NH}_{2}\right)$

Glutamic acid

$(R=O H)$

Glutamine

$\left(\mathrm{R}=\mathrm{NH}_{2}\right)$

Histidine +

Leucine

Methionine

,

Proline

Threonine

Tyrosine<smiles>[R]C(=O)CC(N)C(=O)O</smiles>

- ) $\mathrm{R}-\mathrm{CO}-\left(\mathrm{CH}_{2}\right)_{2}-\mathrm{CH}^{\mathrm{NH}}$

$\mathrm{CO}_{2} \mathrm{H}$

Glycine<smiles>NC(Cc1c[nH]cn1)C(=O)O</smiles><smiles>CC(C)CC(N)C(=O)O</smiles>

$\mathrm{CH}_{3}-\mathrm{S}-\left(\mathrm{CH}_{2}\right)-\mathrm{CH}_{2}^{-\mathrm{NH}_{2}}$<smiles>O=C(O)C1CCCN1</smiles>

${ }_{\mathrm{CH}_{3}}^{\mathrm{HO}} \mathrm{CH}-\mathrm{CH}^{-\mathrm{NO}_{2} \mathrm{H}}$<smiles>NC(Cc1ccc(O)cc1)C(=O)O</smiles>

Lysine

Serine

Valine
Arginine<smiles>N=C(N)NCCCC(N)C(=O)O</smiles>

Cysteine<smiles>NC(CS)C(=O)O</smiles>

Isoleucine<smiles>CCC</smiles><smiles>CC(C)C(N)C(=O)O</smiles><smiles>NCCCCC(N)C(=O)O</smiles>

Phenylalanine<smiles>NC(Cc1ccccc1)C(=O)O</smiles>

Tryptophan<smiles>NC(CO)C(=O)O</smiles><smiles>CC(C)C(N)C(=O)O</smiles>

Also available commercially are fluorinated primary amino acids, isotopically labelled primary amino acids, and many non-primary amino acids including those with polymerizable groups such as allylglycine.

From Chemistry and Biochemistry of the Amino Acids, edited by G.C. Barrett, Chapman and Hall, London 1985 
Primary Amino Acid Basic Structure (except Proline)<smiles>[R]C(N)C(=O)O</smiles>

Examples of Hydrophillic Primary Amino Acids<smiles>CC(CCCC[AlH2])C(=O)O</smiles>

Lysine $\cdot \mathrm{HCl}$<smiles>[13CH3]C(=O)[13C](=O)[13C](=O)O</smiles>

Aspartic Acid<smiles>N=C(NCCCC(N)=[Ni])C(=O)O</smiles>

Arginine $\cdot \mathrm{HCl}$<smiles>O=C(O)CC([AlH2])C(=O)O</smiles>

Glutamic Acid

\section{Amino Acid Polvmer}<smiles>[R]C(C)C(=O)NC([R3])C(=O)NC([R])C(=O)NC([R])C(=O)NC</smiles>

Examples of Hydrophobic Primary Amino Acids<smiles>NC(Cc1ccccc1)C(=O)O</smiles>

Phenylalanine<smiles>CC(C)CC(N)C(=O)O</smiles>

Leucine<smiles>CC(C)C(C)C(=O)O</smiles>

Valine<smiles>CC(N)C(=O)O</smiles>

Alanine<smiles>NCC(=O)O</smiles>

Glycine

\section{Example of}

Protein-like Amphiphile:

Asp-Asp-Leu-Leu-Leu-Leu-Leu-Leu

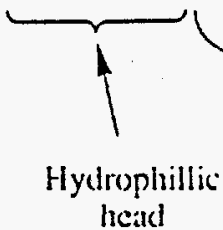

hydropilobic tail 


\section{Experimental}

The discussed molecules were synthesized by the Peptide Chemistry Laboratory of the University of New Mexico University Hospital Cancer Center/ University of New Mexico Biochemistry Department using an Applied Biosystems Model 430A automated Merrifield synthesizer. The molecules were all prepared using standard t-BOC chemistry in $0.5 \mathrm{mmol}$ quantities and were sequence verified on a Applied Biosystems 470A while still on the polystyrene substrate/resin. The molecules were cleaved from the resin with HF, washed with diethyl ether and extracted with acetic and/or trifluoroacetic acids, and then freezedried. The purity of the isolated material was then verified by high pressure liquid chromatography (Hewlett Packard 1090 with a Vydac C18 column) with a gradient mobile phase (2\%/minute from $0.1 \%$ TFA / $99.9 \% \mathrm{H} 2 \mathrm{O}$ to $0.1 \%$ TFA / $4.9 \% \mathrm{H} 2 \mathrm{O} / 95 \%$ acetonitrile). See Figure 1 for the primary structure and adopted nomenclature of the molecules to be discussed.

The pressure-area isotherms were performed on a Nima Technologies model 2011 L-B Trough (radial barrier sweep) using subphases based upon ion exchanged water of very high purity (18 M $\Omega-\mathrm{cm}$ ). Unless otherwise stated the barrier speed was $50 \mathrm{~cm}^{2} / \mathrm{sec}$.

Phe 6 -Asp was dissolved in a $0.78 \mathrm{mg} / \mathrm{ml}$ concentration in DMF:benzene $=1: 2$ and deposited on silanated silicon wafer from an aqueous, $\left[\mathrm{CdCl}_{2}\right]=2.5 \mathrm{E}-4 \mathrm{M}, \mathrm{pH}=6.2$ subphase. 10 bilayers were applied using the L-B deposition method at a constant pressure of $28 \mathrm{mN} / \mathrm{m}$. 


\section{Oligopeptides Amphiphiles Synthesized}<smiles>CC(=O)NCC(=O)NC(C)C(=O)O</smiles>

G4D

acetyl-Gly 4 -Asp-free acid

$\mathrm{MW}=403.5$

$0.5 \mathrm{mmole}=201 \mathrm{mg}$<smiles>CC(=O)NC(CC(C)C)C(=O)C(C)NC(CC(=O)O)C(=O)O</smiles>

$\underline{\text { L6D }}$

acetyl-Leu-Asp-free acid

$\mathrm{MW}=854.2$

$0.5 \mathrm{mmole}=427 \mathrm{mg}$<smiles>CC(=O)NC(Cc1ccccc1)C(=O)NC(C)CC(NC(CC(=O)O)C(=O)O)C(=O)O</smiles><smiles>CC(=O)NC(Cc1ccccc1)C(=O)NC(CC(C)C)C(=O)C(C)(C)NC(CC(=O)O)C(=O)O</smiles>

The oligopeptide amphiphiles depicted above (along with F6D, presented on the next page) where synthesized using a Merrifield technique. The compositions were verified by protein sequencing, HPLC, and 1H NMR. G4D is water soluble and therefore could not be used for Langmuir film fabrication. L6D, F3L3D, and (FL)3D had enough amphiphilic character to sit at the air/water interface but yielded weak monolayers with low collapse pressures. However, the phenylalanine groups in F6D structure (shown below) provided a great deal of hydrophobic character in the tail of the molecules and yielded strong monolayers and LB films with very interesting behavior. 


\section{$\mathrm{F}_{6} \mathrm{D}$}

acetylated phenylalanine ${ }_{6}$ aspartic acid - free acid

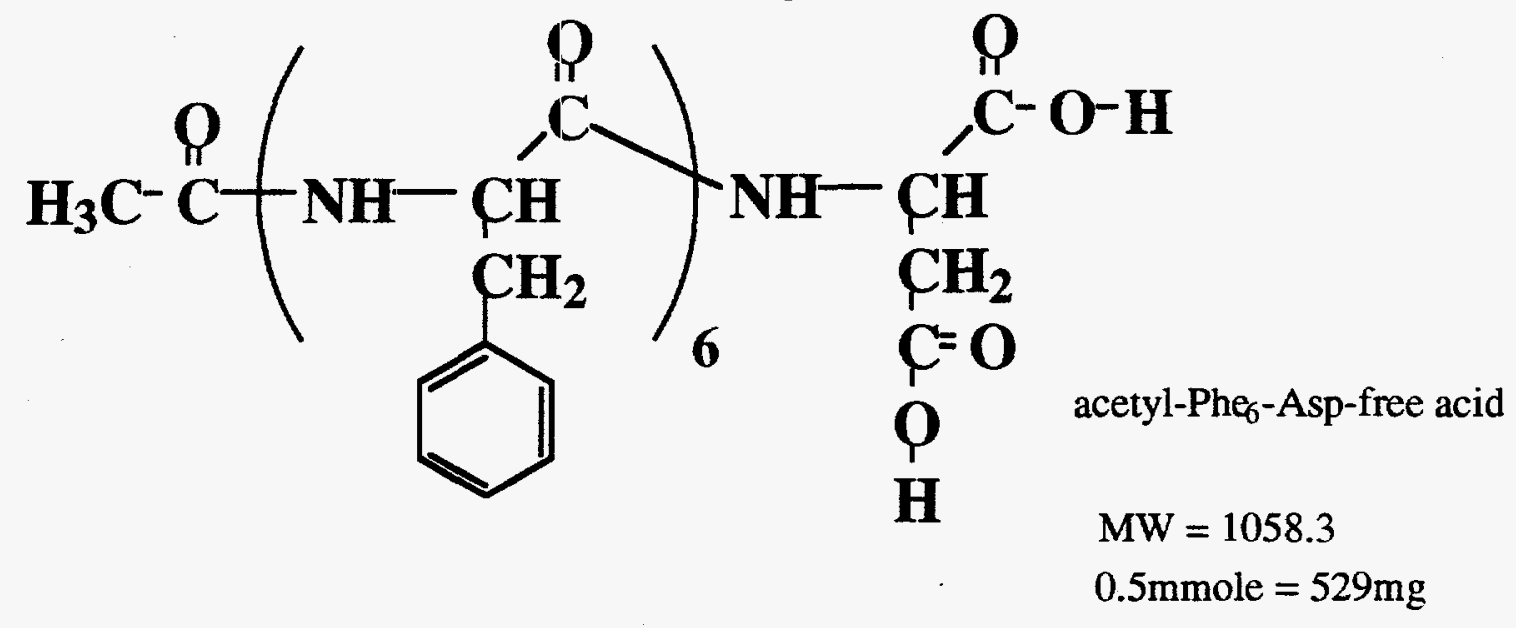

Side View
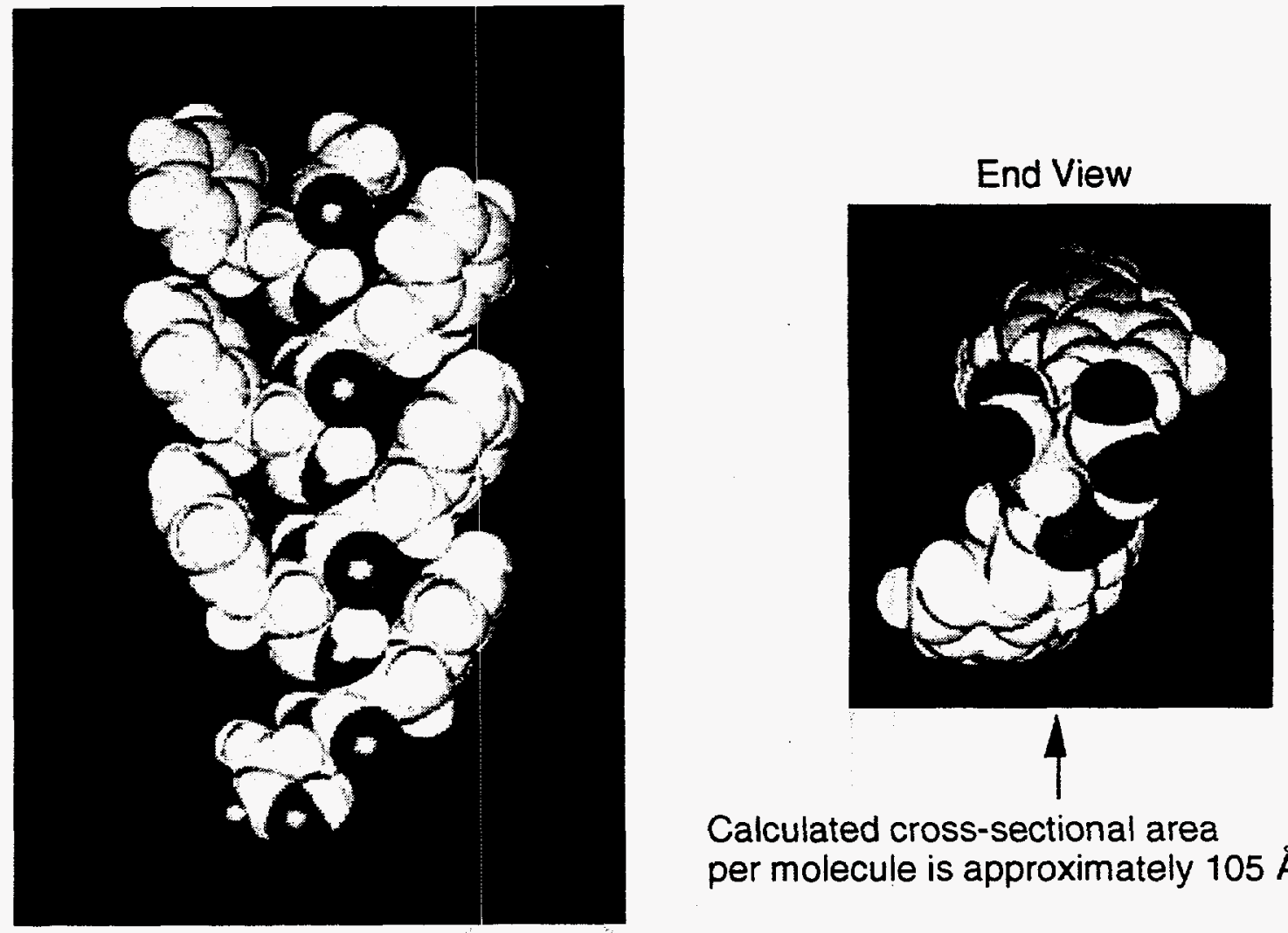

Calculated cross-sectional area

per molecule is approximately $105 \AA^{2}$ 
For the experiment below, F6D was dissolved into a 1:1 DMF/Butanol solvent at a concentration of $0.69 \mathrm{mg} / \mu \mathrm{l}$. $260 \mu \mathrm{l}$ of the solution was spread onto deionized water. There was a waiting period of 30 minutes before compressing the barriers at an area rate of $50 \mathrm{~cm}^{2} / \mathrm{min}$.

Pressure-Area Isotherm

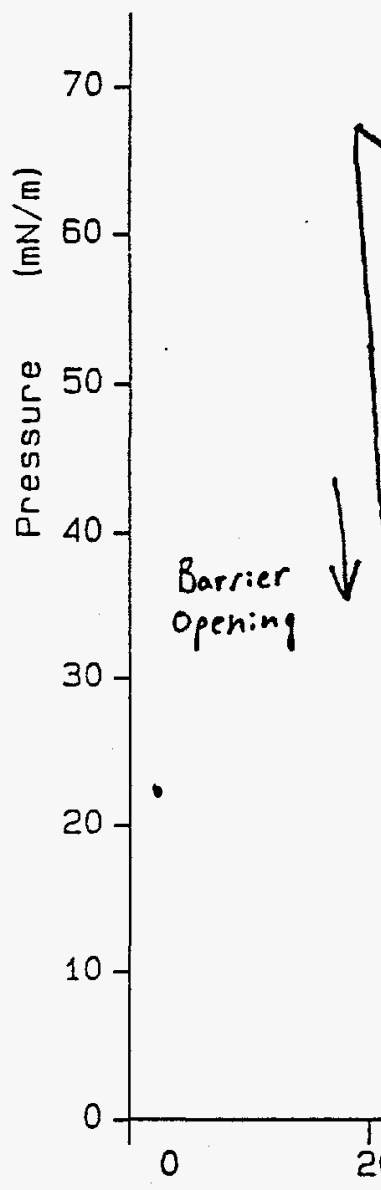

$F_{6} D \quad M W 10.58 .3$

File: ninov 4

Date: Nov 4. 1993.

Sirti-pliasc DI $\mathrm{H}_{2} \mathrm{O}$

Solvent 2infF/Butand $/: 1$

Cone. 0.690 unglue

lacirime $260 \mu l$

$V_{B} 50 \mathrm{~cm}^{2} / \mathrm{min}$

Wait 30 min

The figure above shows the typical monolayer behavior for F6D as it is compressed while on a deionized water subphase. The films are strong with a collapse pressure $>50 \mathrm{mN} / \mathrm{m}$. The pressure area isotherm actually looks similar to curves for fatty acids however, there are two interesting features. First, the limiting compressed molecular spacing is approximately $29 \AA^{2}$ per molecule. This is very small considering that if the molecules packed in a simple cubic arrangement with their major axis normal to the air-water interface, the area per molecule would be no less than $105 \AA^{2}$ (see previous page). Therefore, the molecules must be able to nestle into one another's cavities with the phenylalanine groups interlocking. This gives rise the high strength and high collapse pressure. Further evidence for phenylalanine group interlocking is that upon release of pressure on the film (barriers are opened) the structure is irreversible. The molecular spacing per molecule remains small. This is contrary to monolayers of fatty acids which typically are reversible and spring back to a liquid state when pressure is removed. 
Below, F6D was dissolved into a 1:1 DMF/Butanol solvent at a concentration of 0.852 $\mathrm{mg} / \mu \mathrm{l} .250 \mu \mathrm{l}$ of the solution was spread onto deionized water. There was a waiting period of 15 minutes before compressing the barriers at an area rate of $50 \mathrm{~cm}^{2} / \mathrm{min}$.

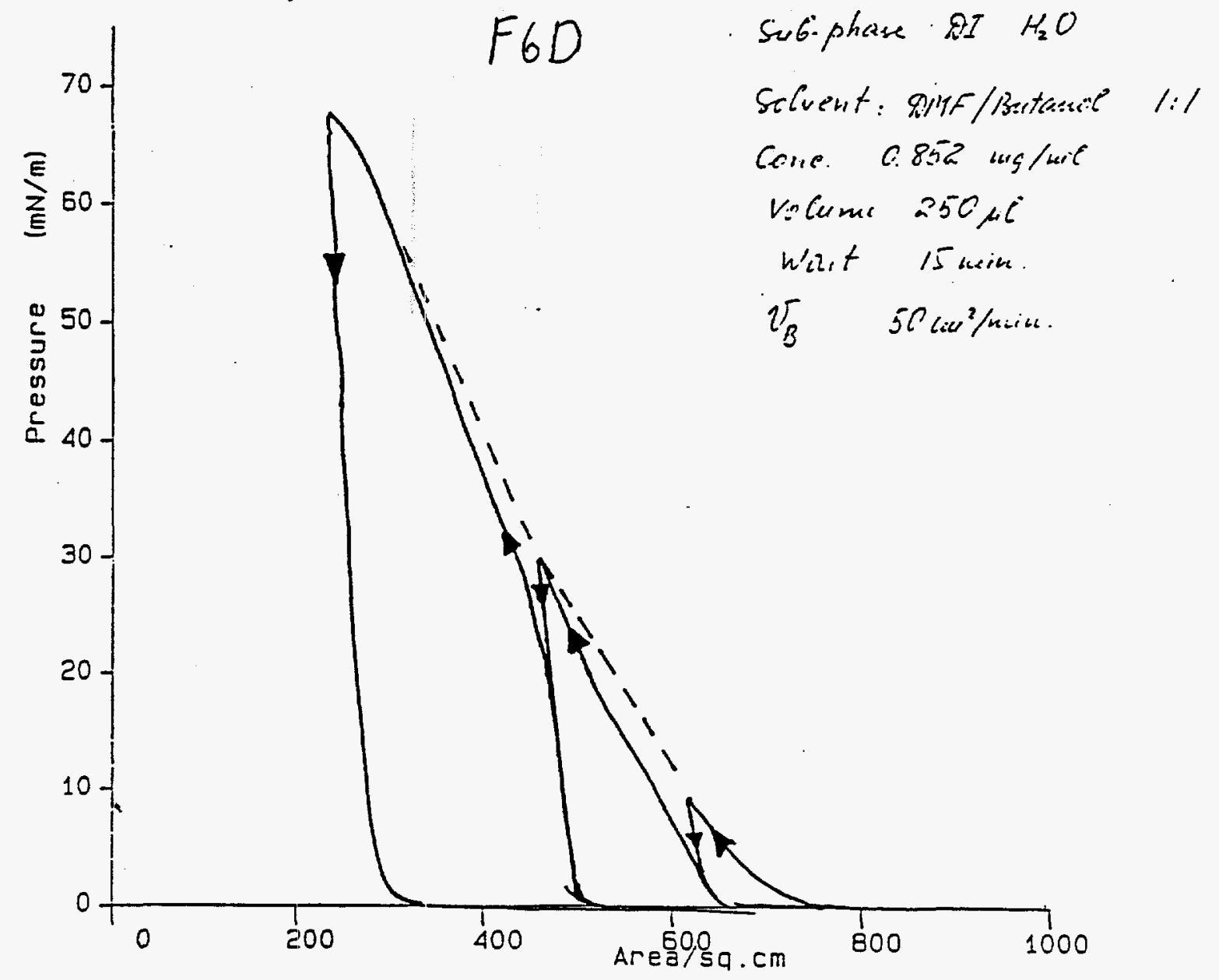

The figure above shows the compression decompression behavior for an $\mathrm{F} 6 \mathrm{D}$ monolayer. The barriers where closed to an arbitrary area and then reopened to $1000 \mathrm{~cm}^{2}$. After a 15 minute wait the barriers were compressed to a smaller area and once again reopened. This procedure was completed for up to six decreasing areas however, for clarity, only three sequences are shown. In every case the monolayer structures compresses irreversibly. The behavior of the F6D molecules is analogous to micro-Velcro with the phenylalanine groups interlocking more densely as more pressure is applied. However, as pressure is released, this quasi-self assembled structur: remains intact. Note that if you connect the peaks of each compression curve, you get the original pressure area isotherm dipicted on the previos page.

Our thought was that this behavior may be useful more making template films which have variable spacing between functional groups. However, this same behavior is responsible for yielding very strong monolayers, unfortunately, the monolayers are so rigid that they are difficult to use for making LB films. In any event, we were able to fabricate some films and use them as templates for biomimetic growth.

The deposited LB films of Cd-F6D were of relatively poor quality because of their stiffness, but preliminary small angle $\mathrm{x}$-ray scattering experiments agreed with ellipsometry measurements; a bilayer spacing of approximately $50 \AA$ which is quite comparable to twice the minimized chain length plus a few angstroms for the bilayer cation. Results on using Cd-F6D as a template for the growth of CdS films is reported in one of the following sections. 


\title{
Chapter 7
}

\section{Fabrication of Ordered Langmuir Monolayers of Acetyl-Phenylalanine6-Aspartic Acid}

\author{
Lev Feigin, Institute of Crystallography, Russian Academy of Sciences
}

\section{Introduction}

Precipitation and growth of a highly-oriented inorganic phase on an organic matrix at molecular level is usually referred to as biomineralization. Biomineralization in ceramic growth exhibits such advantages as the possibility of control of the film crystalline orientation in the act of forming, formation of coatings which contain nanoscaled crystallites, suitability of a wide variety of materials to be used as a substrate, non-expensive temperature and pressure conditions of biomineralization, low cost of fabrication of films of complex composition.

Properties of thin-film structures depend considerably on the size, the shape and the orientation of crystallites of the specific substance included in the film. Also, it is essential to meet conditions which optimize the crystallite origination at the interface of the organic phase and the inorganic phase and the further growth of the inorganic film. These reasons make it nessesary to investigate thoroughly the microstructure and the morphology of the material of interest and the nature of molecular processes at the film- sublayer interface.

A number of recent experimental works [1-3] dealt with the fabrication of closely packed polycrystalline films of oxides, hydroxides, sulphates, carbonates on an organic sublayer. An effort to sinulate the biomineralization process was made in the works [4-6].

A compressed Langmuir monolayer is widely used as the substrate for crystallization of the inorganic phase from the liquid subphase in studies on biomineralization process. A Langmuir monolayer can be easily characterized and, if nesscsary, modified to required values of parameters. The possibility to compress a Langmuir monolayer gives the opportunity investigation of the influence of the ordering of the molecular arrangement in the organic substrate on inorganic crystallites orientation. Another way to vary parameters of the monolayer is a modification of functional groups in the amphiphilic compound forming the monolayer.

Previous investigations revealed that the majority of natural macronolecules which contribute to inorganic crystallites growth, contain functional groups of anionic type such as sulphate, phosphate, carboxylic groups. For example, mollusc proteins contain aspartic acid [7]. The functional groups are capable to associate ions of the subphase thus stimulating the nucleation of crystallites on the organic substrate.

The oriented growth is possible at the condition of a close dimensional matching and a stereochemical correspondence between the structure of a grown crystal face and the positions of polar functional groups in the organic substrate. It was established that variation of the monolayer charge influences markedly the structure and the morphology of the crystals fonmed under the monolayer [8-9]. The state of a double 
electrical layer in the Langmuir monolayer can promote the kinetics of growth. Also, such phenomena as solvatation, ionic adsorbtion, Van der Vaals interaction in the Langmuir monolayer affect the growth significantly.

By now investigations of the inorganic growth were performed for monolayers of fatty acids, aliphatic amines, aliphatic alchohols, phospholipides and other materials [9].

The adequate simulations of the nature biomineralization process is the growth of inorganic compunds on a Langmuir monolayer of synthetic polypeptides.

This work was aimed at 2 problems:

1) determination of optimal conditions for fabrication of a Langmuir monolayer of acetyl-phenylalanine6-aspartic acid (F6D) on the aqueous subphase and study of its structure

2) determination of the optimal conditions for inorganic film growth on the F6D monolayer.

F6D used in experiments was synthesized at Advanced Materials Laboratory in Dr. J. Cesarano group by M. Hogan.

The structure of the Langmuir monolayer, of the inorganic layer underneath was investigated by electron diffraction, electron microscopy, and small-angle X-ray scattering (details on experimental techniques see in Report 1, 1993). Primarily, the influence of the subphase composition and the composition of the solvent for F6D on the structure of the Langmuir monolayer was examined.

\section{Experiment}

A monolayer of $F 6 D$ was formed at the air-subphase interface by spreading $F 6 D$ solution in a mixed solvent. The F6D monolayer was exposed before compression for time varied from $20 \mathrm{~min}$ to 48 hours. Then the monolayer was compressed to the surface pressure of $25-28 \mathrm{mN} / \mathrm{m}$ which corresponds to the closest packing of molecules in the monolayer. The procedure was performed at room temperature. The monolayer was compressed at rate of $50 \mathrm{~cm} / \mathrm{min}$.

Samples for investigation were prepared by deposition of the Langmuir monolayer onto a silicon substrate as well as onto a copper grid which was preliminary covered with a thin amorphous cellulose layer. This layer is transparent for an electron bearn and does not produce any essential diffraction. A monolayer was deposited by Langnuir-Blodgett technique at lifting rate of $10 \mathrm{~mm} / \mathrm{min}$ or by horizontal lift (Schacfer technique).

\section{Choice of the solvent}

Preparation of the true F6D solution is necessary for obtaining the F6D monolayer covering the subphase. This problem can be solved only by the appropriate 
choice of the solvent. The solvent composition is of little importance if the solvent can easily evaporate or dissolve in the subphase. However, if solvent molecules can integrate into the monolayer then the microstructure of the Langmuir film is likely to be changed.

Additives to the solvent can change the rate of F6D spreading over the subphase surface and thereby homogeneity and microstructure of the final monolayer can be changed. Moreover, additives can essentially influence the orientation of the amphiphilic molecules at the air-subphase interface.

Our experiments revealed that $\mathrm{N}, \mathrm{N}$-dimethylformamide (DMF) and $\mathrm{N}$-methyl2-pyrrolidinone (MP) can be choosen as suitable solvents for F6D. But employment of these solvents is limited. It is due to the fact that amphiphile solution is suffisiently heavy and strongly interacts with water in the subphase and so a droplet of such solvent can go down.

We chose benzene, 1-butanol, and chloroform as additives to the solvent to obtain more homogeneous distribution of the substance over the the surface of the subphase in shorter time. It was noticed in [10] that these solvents are strong dispersers of amphiphilic substances.

Thus, 3 types of mixed solvents for F6D were employed in this work:

1) DMF-benzene (volume relation 1:2)

2) MP-benzene $(1: 2)$

3) DMF-butanol (1.5:1).

Concentration of F6D in solutions was $0.4 \mathrm{mg} / \mathrm{ml}$.

It should be noticed that F6D is dissolved better if the amphiphile is preliminary added with the solvent (DMF or MP) and the solution is put in a refrigerator for some hours. And only then the second solvent can be added. Organic solvents can be mixed only to some extent and so application of excess of another solvent or evaporation of the solvent in storage can result in turbidity of the solution or precipitation of the amphiphile.

\section{Choice of the subphase composition}

Additives which can influence the molecules arrangement in the Langmuir monolayer may be injected not only into the solvent at the early stage of formation of the monolayer but also into the subphase immediately. Additives of the aqueous subphase such as acids, bases, formic acid interact with the hydrophilic part of amphiphilic nolecules and so they can act as dispersers or as a kind of "fillers" of the monolayer. Appropriate are additives which make the monolayer more ordered and llexible and which provide a conpromisc between molecular interaction in the monolayer and that one in the subphasc.

A molcculc of F6D contains 2 carboxylic groups (Fig.1) and so it was of interest (1) estimate the infuence of the carboxylic groups dissociation degree on the ordering 
of the monolayer. By other words, the influence of the subphase $\mathrm{pH}$ and of the nature of cations on the structure of the monolayer was under investigation.

It was established that the ordering of the monolayer can be improved if molecules of the monolayer are associated with a polymer solved in the subphase [11]. F6D in the subphase contains groups of anionic kind and so it was reasonable to expect that the monolayer would become more ordered when associating it with a polymeric additive of cationic kind - polyallylamine (PAA).

We studied F6D monolayers formed on the following subphase compositions:

$1-2.5 \cdot 10^{-4} \mathrm{M} \mathrm{CdCl}_{2}$ solution, $\mathrm{pH}=5.5-5.8$

$2-5 \cdot 10^{-4} \mathrm{M} \mathrm{MgCl}_{2}$ solution, $\mathrm{pH}=6.7$

3 - pure water

4 - water acidified with nitric acid to $\mathrm{pH}=4.0$

$5-0.02 \mathrm{mg} / 1$ aqueous polyallylamine solution

\section{Analysis of $\pi-A$ isotherms}

Quantitative information on amphiphile molecule dimensions can be obtained from a $\pi$-A isotherm which shows a dependence of the surface pressure $\pi$ in the monolayer on the area $A$ per a molecule in the monolayer. In estimating the area per a molecule in the monolayer, it is a common practice to use the following technique. First the tangent to the linear part of the isotherm is drawn and then the tangent is extrapolated to zeroth value of $\pi$. The linear part is believed to correspond to the dense layer. But Langmuir cosidered this procedure not to be grounded theoretically and he reasoned that for such estimations it is sufficient to choose a point at the $\pi$ - $A$ isotherm in the range of $15-30 \mathrm{mN} / \mathrm{m}$ [12]. If a curve in the region of the condensed state is practically vertical (case of falty acids, alchohols etc.) then the estimations by both techniques are close. However, when the behaviour of amphiphilic substance on various subphases is compared and the $\pi$-A isotherms are of essential slope, it is reasonable to use the second technique of choosing the point for comparative estimation of the area A. For investigated F6D monolayer, estimaion of the area was performed at the value of pressure of $28 \mathrm{mN} / \mathrm{m}$.

The stability of a fatty acid monolayer is controlled by the chain-chain interaction. It is seen from Fig. 1 that a F6D molecule does not contain large purely hydrophobic regions like hydroçarbon chains in fatty acid. Anidic bonds are proper for the wholc length of the F5D molecule and so those regions exhibit hydrophilic hehaviour. Hydrogen bonds arise at those regions. Thus, two factors determine the intcraction between molccules of F6D. Hydrogen bonds between chains of residues of amino acids stabilizes significantly the F6D monolayer. But at contact with a subphase of acidic reaction, nytrogen atoms in peptide groups can be protoned and the latter 
can result in mutual repulsion between F6D molecules. Moreover, the conformation of F6D molecule can be changed.

\subsection{Results obtained in Advanced Materials Laboratory}

We used DMF-butanol (1:1) and DMF-benzene (1:2) as solvents for F6D. No dependence of area per molecule in the dense layer on the time of exposure of the monolayer on the subphase before its compression was observed in the range of exposure time up to 3 hours. $\pi$ - $A$ isotherms were saved in files $\mathrm{n} 2$ nov $10, \mathrm{n} 1$ nov 10 , $\mathrm{n} 1$ nov $1, \mathrm{n} 2$ nov 11 . Injection of $\mathrm{Cd}^{2+}$ ions into the subphase did not influence noticably the area per molecule in the case of files $n 1$ nov 11 and $n 1$ nov 12 .

The value of area per molecule (A) for the case of DMF-benzene solvent was reproducible well ( $40 \mathrm{~A}^{2} / \mathrm{mol}$ ). In the case of DMF-butanol solvent, the spread of experimental data turned out significantly more wide $\left(33-41 \mathrm{~A}^{2 / \mathrm{mol}}\right)$. Compressing the layer repeatedly resulted in the considerable decrease of the area per molecule (down to $25-35 \mathrm{~A}^{2} / \mathrm{mol}$ ). At the same time, the $\pi$-A curve remained a straight line at $\pi>62 \mathrm{mN} / \mathrm{m}$ indicating that the collapse of the monolayer did not occured. Volume of the substance applied onto the subphase was (10-12) $10^{16}$ molecules per $1000 \mathrm{~cm}^{2}$.

\subsection{Results obtained in the Institute of Crystallography}

1. The dependence of area per molecule on the time of the monolayer exposure before its compression. $A$ increases by $-2 A^{2}$ for $2-3$ hours exposure in the case of solvents DMF-butanol (1.5:1) and MP-benzene (1:2). For prolonged exposures ( -15 hours) $A$ increases by $-10 \mathrm{~A}^{2}$ at subphase compositions 1,2 and 3 . Applied volume of F6D was $(10-12) \cdot 10^{16}$ molecules per $1000 \mathrm{~cm}^{2}$ for DMF-butanol and 10) $\cdot 10^{16}$ molecules per $1000 \mathrm{~cm}^{2}$ for MP-benzene (Fig. 2-5).

2. At exchanging of $\mathrm{CdCl}_{2}$ subphase by $\mathrm{MgCl}_{2}$ subphase (solvent - DMFbutanol), A varies a little: 57 and $58 \mathrm{~A}^{2}$ correspondingly. It shoud be noticed that this value is $17 \mathrm{~A}^{2}$ greater than those obtained in the AML with the same solvent (Fig. 5).

3. Case of MP-benzene (1:2) solvent. $A$ is $69 \mathrm{~A}^{2}$ for $\mathrm{CdCl}_{2}$ subphase and $68 \mathrm{~A}^{2}$ for the acidified aqueous subphase of $\mathrm{pH}=4.0$ (Fig. 5).

4. Case of DMF-chloroform (1.5:1) solvent. A for the subphase of pure water is $45 \mathrm{~A}^{2}$. A for the subphase of $\mathrm{pH}=4.0$ is $64 \mathrm{~A}^{2}$. One of possible causes of comparatively low value of $A$ for this solvent can be the loss of the substance at its applying onto the subphase. The solution is comparatively heavy and so a part of it can drop into the subphase (Fig. 3).

5. Collapse of the F6D monolayer came at $\pi-47 \mathrm{mN} / \mathrm{m}$. In the case of water subphase of $\mathrm{pH}=4.0$, the collapse came at $44 \mathrm{mN} / \mathrm{m}$. The results above reveal that the monolayer is dispersed better in the case of MP- henzene as the solvent and acidified water of $\mathrm{pH}=4.0$ as the subphase. 
Hydrophilic parts of F61D can make hydrogen bonds with the subphase at prolonged contact with the aqueous subphase and so it is reasonable to expect that the monolayer would be dispersed over the aqueous surface and that a F6D molecule would contact with the water over greater area. This feature of the monolayer spreading would be observed to higher extent in the acidic environment when protonation of nytrogen atoms is very probable and, further, repulsion between the molecules and change of the conformation of the F6D molecule itself appear. But repulsion between carboxylic groups is smaller in strongly acidic subphase because acidic environment suppresses dissociation of the acids in the subphase.

Thus, it was shown that packing of F6D molecules in a Langmuir monolayer is influenced by such factors as metal ions content in the subphase, value of the subphase $\mathrm{pH}$, time of F6D exposure before compression, solvent composition.

$$
\pi-A \text { isotherms of (FL) } 3 \text { and (F3L3) }
$$

Analysis of the data on $\mathrm{p}-\mathrm{A}$ isotherms we obtained when working with synthetic peptides acetyl-(phenylalanine-isopropylalanine)3-aspartic acid (FL)3 and acetylphenylalanine3-isopropylalanine3-aspartic acid(F3L3) at J. Cesarano's group shows that provided DMF-butanol was used as the solvent for those substances, a plateue was observed on the $\pi-A$ isotherms (files $n 1$ nov $5, \mathrm{n} 2$ nov 4,3 nov $3, \mathrm{n} 2$ nov 3 ). This plateu was not observed for the solvents MP-benzene (1:3) and DMF-chloroform (3:2) (files n11 nov2, n9 nov 1, n11 nov 1 nina 5). Unfortunately, the data obtained are not reliable for quantitative analysis because the Wilhelnui balance operated inaccurately during the measurements.

Langmuir anticipated clusters origination to be one of the causes for the plateue in the $\pi-A$ isotherms of fatty acids to appear [12]. At compressing, the number of the clusters increases while surface pressure remains the same. In the case under consideration, clusters could be formed at incomplete spreading the amphiphile over the subphase surface. So, the special attention should be paid to accurate determination of the amphiphilc amount applied onto the subphase because it is important to hold the compromimise between the forces which hold a molecule in the monolayer at the interface and those which are responsible for arranging molecules in the crystal.

Fig. 6 shows $\pi$-A isotherms of (FL) 3 on the subphase of $2.5 \cdot 10^{-4} \mathrm{M} \mathrm{CdCl}_{2}$; solvent - mixtuirc $1 \mathrm{mll}$ DMF: $(0.2-0.5) \mathrm{ml} \mathrm{CHCl} 3: 2 \mathrm{ml}$ benzene. Area per molecule is 120 $\mathrm{A}^{2}$ at $20 \mathrm{mN} / \mathrm{m}$. $\pi$-A isotherms are well reproducible and reversible at pressure up to $22 \mathrm{mIN} / \mathrm{m}$. The (FL) 3 morolayer is less stable than the F6D monolayer. Films deposited onto Si substrates by Shaefer technique were quite inhomogeneous as rcvealed visually. Thus, further investigation is necessary for obtaining the perfect (FL) 3 solution. 
4. Fabrication of LB films and their investigation by X-ray reflectivity.

$\mathrm{X}$-ray reflectivity investigation was used to study the structure of the F6D monolayer. At first, the properties of F6D monolayers deposition onto a hydrophobic Si substrate were studied. It turned out that the the monolayer of F6D on the subphase was "rigid" (inflexible) and so it was transferred badly. One of the possible reasons of the poor deposition is the insufficient hydrophobity of the "tail" of the F6D molecule (Fig. 1). If so, all the area of the bilayer deposited is insufficiently hydrophobic and at further dipping of the substrate into the subphase it can leave the substrate. This mechanism seems also to be responsible for capturing large amount of water at the deposition. This water destabilizes the film deposited so far. The transfer is better if each deposition of a bilayer is followed by prolonged drying. Deposition of the F6D monolayer was performed at $\pi=28 \mathrm{mN} / \mathrm{m}$ from the $2.5 \cdot 10^{-4} \mathrm{M} \mathrm{CdCl}_{2}$ subphase and at $\pi=24 \mathrm{mN} / \mathrm{m}$ from the acidic $\mathrm{pH}=4.0$ subphase.

It was noted above that the monoloyer compression should be performed in 2-3 hours after spreading the F6D solution over the subphase. The multilayer film on $\mathrm{Si}$ substrate (Shaefer technique) was homogeneous in surface as seen visually.

Fig. 7 presents the reflectivity pattem by the F6D LB film of 12 layers (subphase - 2.5.10-4 $\mathrm{M} \mathrm{CdCl}_{2}$; solvent - DMF-butanol, $\mathrm{pH}=5.5$ ). No Bragg peak is observed. The total film thickness by Kiessig fringes is $-240 \mathrm{~A}$. Under assumption that all of 12 monolayers were transferred completely, the monolayer thickness in the film is about $20 \mathrm{~A}$. However, this value is possibly underestimated due to incomplete transferring.

Absence of Bragg peaks is explained by the poor X-ray contrast between constituents of the film. We believe that this caused by the low variation of the electron density along the F6D molecule.

The attempt to transfer the F6D monolayer from the subphase containing 0.02 $\mathrm{m} g / \mathrm{ml}$ polyallylamine was made to obtain more ordered LB film. The monolayer turned out to be unstable. At constant $\pi=24 \mathrm{mNN} / \mathrm{m}$, the area occupied by the monolayer decreased. So, fabrication of the LB film of this monolayer was not succesful.

The attempt to build up a superlattice of alterating layers of $F 6 D$ and hexadecylanine for more accurate determination of the bilayer spacing was unsuccesful too. It is likely that it was caused by the unfortunate choice of the substratc $\mathrm{pH}=5.5$. In acidic environment, dissociation of carboxylic groups of F6D is suppressed. Also, amine groups of hexadecylanine are protonized and so amine nolecules repulse in the monolayer. More detailed study is needed to fabricate the supcrlattice. 


\section{Electron diffraction study of F6D LB films.}

Electron diffraction was used to study F6D bilayer films transferred onto the grids which were deposited by the amorphous monomolecular layer of cellulose. Each of the samples was examined at normal incidence of the electron bearn onto the film surface $(\phi=0)$ as well as at tilting the samples with respect to the beam $(\phi=0)$. These techniques provides information on molecules packing in the plane of the sample (at normal incidence) and three-dimensional packing (at tilting) [13].

LB films of F6D fabricated through all procedures mentioned above were studied.

In the cases of the pure ageous subphase and the $\mathrm{CdCl}_{2}$ subphase, the structure of bilayer LB films was not affected by the solvent composition. All the diffraction patterns demonstrate blurred rings due to the amorphous phase in the bilayer and the pronounced reflex of $\sim 4.73 \mathrm{~A}$ spacing which turns to the arc of $-30^{\circ}$ at tilting the sample (Fig. $8 \mathrm{a}, \mathrm{b}$ ).

In the case of the subphase acidified to $\mathrm{pH}=4.0$, the fraction of the amorphous constituent is less. The patterns at normal incidence (Fig. 9a) show Debye rings which are evident for two-dimensional ordering of F6D molecules in the plane of the Langmuir layer. Transformation of the rings to the arcs at tilting the sample to the beam (Fig. 9b) proves that the molecules are oriented preferentially in the perpendicular direction. By the "normal" pattern shown at Fig. 9a, the spacings were calculated (Table 1), the projections net was drawn and then the following parameters of a planar cell were obtained: $a=11.3 \mathrm{~A}, b=4.73 \mathrm{~A}, \beta=80^{\circ}$. Exanination of the "oblique" pattern ( $\mathrm{Fig} .9 \mathrm{~b}$ ) indicates that exist a periodicity of $-5.6 \mathrm{~A}$ in the direction perpendicular to the layer. Angular misorientation of the molecules with respect to the normal to the layer is $-10^{\circ}$.

In the casc of the $\mathrm{MgCl}_{2}$ subphase, as is in the case above, observed is the ordering of texture kind in the nutual arrangement of F6D molecules (Fig. 10) though the sct of spacings differs from that of the previous case of the acidic subphase. Besides, it is clearly demonstrated by the pattern obtained at tilting the sample (Fig. 10b) that the LB film contains the polycrystalline and texture phases.

The spacings calculated from the diffraction patterns are presented in Table 2. The dilliracton pattem corresponds to the rectangular cell of parameters $a=22.0 \mathrm{~A}, \mathrm{~b}=$ 9.46 A. For the direction perpendicular to the layer, determination of the spacing is involved because weak reflexcs of non-zeroth indices 1 are superposed on the quite strong anorphous "halo". By now, the polycrystalline phase tumed out not to be identificd beciause of low number of reflexes. 
6. Comparison between electron diffraction data and numerical modeling of the close packing of 2 and more F6D molecules.

Electron diffraction data obtained do not provide the complete determination of the structure. So, a kind of errors and trials technique was used for this purpose. At first, the spatial configuration of the F6D molecule had to be determined. The reconstructed molecular configuration was computed by Allinger's FORCE Field program.

It is known that chains of polypeptides contain the same skeleton which joins radicals. Molecules of polypeptides can be of various conformations [14-15].

In the case of $\alpha$-spiral, each of peptide group is associated with a fourth similar group count through hydrogen bond. The value of $14.9 \mathrm{~A}$ is peculiar for the external a-spiral diameter of almost all polypeptides of the molecular weight less $300,000 . \alpha$ spiral conformation of F6D molecule is shown at Fig. 11.

Beside the $\alpha$-spiral structure of the chain which is characterized by saturation of hydrogen bonds inside the molecule, intermolecular hydrogen bonds may arise between different regions of polypeptide chains. In this case, the chains must be naximally extended and packed parallel to each other. Lateral groups (radicals) are positioned perpendicularly to the bonds between two neibouring molecules in this case. This structure was referred to as a $\beta$-structure of polypeptides by Pauling.

Many of polypeptides are structured in the form of regular $\beta$-structures in the films. Sometimes they coexist with regions of disordered amorphous phase. Energy of hydrogen bonds $(6-10 \mathrm{kCal} / \mathrm{mol})$ is greater than energy of Van der Vaals interaction $(1-2 \mathrm{kcal} / \mathrm{mol})$. So, polypeptides packing is mainly ruled by the principle of hydrogen bonds saturation and only after this saturation the principle of the closest packing operates.

In the casc of the $\beta$-structure of F6D molecule, strong bydrogen bonds between the skeletons of molecules (oxygen of one of them and hydrogen of the neibouring) at their parallel packing are of the peculiar spacing of $-4.7 \mathrm{~A}$ that was observed over the variety of the diffraction patterns from the samples fabricated through different procedures.

For the subphases of pure water and of $\mathrm{CdCl}_{2}$ solution, the structure was described well by the clusters of of the $\beta$-structure nolecules ananged parallel and associated by hydrogen $\mathrm{O}-\mathrm{H}$ bonds with each other (Fig. 12). The clusters are included in an anorphous phase.

At acidifying the subphase to $\mathrm{pH}=4.0$, a more perfect packing of molecules in the LB layer was observed. The cell of parameters of $a=11.3 \mathrm{~A}, b=4.7 \mathrm{~A}$ and $\beta-80^{\circ}$ werc obtained by clectron diflraction. The best found model of possible packing is presented in Fig. 13. The characteristic spacing of $5.6 \mathrm{~A}$ in the nombal to the layer 
corresponds to the distance between radicals in the model. Therefore, molecules are preferentially oriented perpendicularly to the layer plane by their skeletons.

If the subphase is added with $\mathrm{Mg}$ ions, according to data on the cell parameters, F6D molecules maintain their $\beta$-structure but the skeletons are positioned in the layer (axis a - molecule length, axis b - double spacing between neighbouring molecules skeletons along hydrogen bonds).

It should be noted that the model above is one of possible but not the unique one because structural data on the normal direction are not available so far.

\section{CdS growth beneath the floating F6D monolayer.}

Recently (see the previous report, 1994), we have studied growth of a CdS film on the arachidic acid monolayer and conditions were found for oriented origination of CdS crystallites on the ordered monolayer.

This work was concemed with preliminary experiments on growth of CdS crystals on the F6D monolayer. Solution of F6D in DMF-benzene was applied onto the $5 \cdot 10^{-4} \mathrm{M} \mathrm{CdCl}_{2}$ subphase acidified with $\mathrm{HCl}$ to $\mathrm{pH}=5.5$. Being exposed during 2 hours, the layer was compressed. The dish with $0.02 \mathrm{M} \mathrm{Na}_{2} \mathrm{~S}$ solution was placed near the Langmuir trough. $\mathrm{H}_{2} \mathrm{~S}$ molecules released by hydrolysis spread by diffusion to the subphase surface.

Being exposed with $\mathrm{H}_{2} \mathrm{~S}$, the $\mathrm{F} 6 \mathrm{D}$ monolayer becomes unstable. The area occupied by the monolayer at maintaining the constant surface pressure $(\pi=28 \mathrm{mN} / \mathrm{m}$ in the experiment) decreases. After its 3 hours exposure in $\mathrm{H}_{2} \mathrm{~S}$ atmosphere, the monolayer was transferred onto the $\mathrm{Si}$ substrate by the horizontal lift technique. Electron diffraction study revealed that the F6D monolayer was covered with the polycrystalline CdS film. Conditions on epitaxial growth of a non-organic film on the F6D layer are the matter of further studies. Of interest are peculiarities of formation of the ordercd layer as well as the proper choice of the substance to be grown so that the orientational relations between the organic and the non-organic lattices were met properly.

\section{Conclusion}

The data obtained shows that a homogeneous Langmuir layer formed at employment of mixtures DMF-benzenc and MP-benzene as the solvents for F6D. However, such layers werc poorly deposited onto substrates by Langmuir-Blodgett technique. The best quality of the transferred films was that of films formed on the acidilied to $\mathrm{pH}=4.0$ subphasc. X-ray diffraction pattems by the films were not detailed what can be due to the intemal structure of F6D molecules.

Electron diffraction data revealed that the molecules ordering in the monoloyer is mainly detcmince hy the subphase composition while the influcnce of the solvent 
composition on the monolayer ordering was not observed. The most ordered were films formed on the acidified subphase and on the subphase containing $\mathrm{Mg}$ ions which demonstrated two-dimensional ordering. The peculiar spacing for closely packed $\beta$ form F6D molecules of 4.7 A value was observed for all samples investigated.

It should be noted that requirements on the quality of the Langmuir monolayer depend on the purpose of its further employment and they are different for the case of the nonolayer deposition onto a solid substrate and for the case of epitaxial growth of an inorganic substance on the monolayer.

The experiment on CdS growth on F6D monolayer revealed that the CdS film was really formed though it was polycrystalline, possibly, because of mismatching between the lattices of $C d S$ and of F6D.

The monolayer on the subphase of $\mathrm{MgCl}_{2}$ solution turned to be the mostly ordered and so it would be promising to study growth inorganic compounds containing $\mathrm{Mg}, \mathrm{Ca}, \mathrm{Ba}$ on a $\mathrm{F} 6 \mathrm{D}$ monolayer.

Dissolving F6D and its spreading over the suphase surface might be improved with the use of such substances as iso-butanol, pentanol, formic acid, dichloroacetic acid as additives for the solvent. But this is the matter for further investigations.

Another factor strongly affecting the structure of the monolayer is temperature. The structure of polypeptides is very sensitive on the temperature at which they formed and so the structure the film of an inorganic compound on a polypeptide can vary widely. The temperature factor is also the matter of further investigation. 
Table 1

Electron diffraction pattern, Fig.9 ,a. ( subphase $\mathrm{pH}=4,0,1$ bilayer ) $\mathrm{r}$ - radius of ring, d-interplanar distance, $\mathrm{h}, \mathrm{k}$ - Miller indexes

\begin{tabular}{|c|c|c|}
\hline $2 \mathrm{r}(\mathrm{mm})$ & $\mathrm{d}(\mathrm{A})$ & $\mathrm{hk}$ \\
\hline 18 & 4.73 & 10 \\
\hline 22.5 & 3.78 & 03 \\
\hline 36 & 2.36 & 20 \\
\hline 45 & 1.89 & 06,23 \\
\hline 55 & 1.55 & 30,25 \\
\hline 62 & 1.37 & 33,26 \\
\hline 72 & 1.18 & 40 \\
\hline
\end{tabular}

Table 2

Electron diffraction pattern, Fig. 10 ,a. (subphase with $\mathrm{MgCl}_{2}, 1$ bilayer ) $r$ - radius of ring. $d$-interplanar distance, $b, k$ - Miller indexes

\begin{tabular}{|c|c|c|}
\hline $2 \mathrm{r}(\mathrm{mm})$ & $\mathrm{d}(\mathrm{A})$ & $\mathrm{hk}$ \\
\hline 15,5 & 5,48 & 04 \\
\hline 18 & 4,73 & 20,14 \\
\hline 19,3 & 4,40 & 05,22 \\
\hline 21 & 4,04 & 23,15 \\
\hline 23,2 & 3,67 & 24,06 \\
\hline 25 & 3,40 & 16 \\
\hline 28 & 3,04 & 32,17 \\
\hline 29,5 & 2.88 & 33,26 \\
\hline 31,2 & 2.72 & \\
\hline 38 & 2.24 & \\
\hline
\end{tabular}




\section{FIGURE LEGENDS}

1. Chemical structure of F6D

2. $\pi-A$ isotherms of $F 6 \mathrm{D}$ : DMF-butanol solvent, $\mathrm{CdCl}_{2}$ subphase, the time of the monolayer exposure before its compression $20 \mathrm{~min}$.(1), 4 hours (2), 15 hours (3).

3. $\pi$-A isotherms of F6D: DMF-chloroform solvent, pure water subphase, the time of the monolayer exposure before its compression $20 \mathrm{~min}$.(1), 3 hours (2). DMFchloroform solvent, water acidified subphase $\mathrm{pH}=4.0$, the time before compression 3.5 hours (3).

4. $\pi-A$ isotherms F6D: MP-benzene solvent, water acidified subphase $\mathrm{pH}=4.0$, the time of the monolayer exposure before its compression $20 \mathrm{~min}$.(1), 48 hours (2).

5. $\pi$-A isotherms F6D: DMF-butanol solvent, the time of the monolayer exposure before its compression $20 \mathrm{~min}$., $\mathrm{MgCl}_{2}$ subphase (1) and $\mathrm{CdCl}_{2}$ subphase (2) . MP-benzene solvent, $\mathrm{CdCl}_{2}$ subphase, the time before compression $20 \mathrm{~min}$.(3), 15 hours (4).

6. P-A isoterms (FL)3: DMF-benzene-chloroform solvent, $\mathrm{CdCl}_{2}$ subphase, the time of the monolayer exposure before its compression 40 min.(1) and 15 hours (2)

7. X-ray small angle diffraction pattern from 6-bilayer LB F6D film.

8. Electron diffraction pattern from LB bilayer film F6D, subphase-pure water or $\mathrm{CdCl}_{2}$ solution. The patterns obtained at $\phi=0^{\circ}$ (a), at $\phi=56^{\circ}$ (b)

9. Electron diffraction pattem from a single $L B$ bilayer film of $F 6 D$, water acidified subphase $\mathrm{pH}=4.0$. The patterns obtained at $\phi=0^{\circ}$ (a), at $\phi=54^{\circ}$ (b)

10.Electron diffraction pattem from a single $\mathrm{LB}$ bilayer film of $\mathrm{F} 6 \mathrm{D}, \mathrm{MgCl} 2$ subphase. The patterns obtained at $\phi=0^{\circ}$ (a), at $\phi=60^{\circ}$. (b).

11. The spiral conformation of F6D molecule

12. The possible contact of F6D molecules of $\beta$-structure. There are bydrogen bonds betucen molecules.

13. The possible packing of molecules according to the unit of $a=11.3 \mathrm{~A}, b=$ 4.7A, $\beta=80^{\circ}$. Projection (plan view) along the backbone of molecule 


\section{REFERENCES}

1. S.Mann and J.P. Hannington, J.Colloid. Interface Sci., 122, 326, (1988)

2. X.K. Zhao and J.H.Fendler, J.Phys. Chem. 9, 3716, (1991)

3. R.Brigid Heywood, Sundara Kajam and Stephen Mann, J.Chem. Soc. Faraday Trans., 87, 735-743, (1991)

4. L.Addadi and S.Weiner, Mol. Cryst. Liq. Cryst, 134, 305, (1986)

5. E.M.Landau, R.Popovitz-Biior, M.Levanon, L.Leiserowitz, M.Lahav, J.Sagiv Mol. Cryst.Liq.Cryst, 134, 323, (1986)

6. E.M.Landau, S.Grayer Wolf, M.Levanon, L.Leiserovitz, M.Lehav, J.Sagiv, J. Am. Chem. Soc., 111, 1436, (1989).

7. B.C.Bunker, P.C.Rieke, B.J.Tarasevich, A.A.Campbell, G.E.Fryxell, G.L.Graff, L.Song, J.Liu, J.W.Virden, G.L.Mc.Vay, Science,v.264, 48-55, (1994)

8. C.Yi.Kyunghee and Janos H.Fendler, Langmuir 6, 1519-1521, (1990)

9. Xiao Kang Zhao, Shuqian Xu, Janos H.Fendler, Langnuir, 7, 520-524, (1991)

10. T.Ishii, Thin Solid Films, 178, 47-52, (1989)

11. N.D.Stepina, R.V.Tal'rose, T.L.Lebedeva, L.G.Yanusova, Polyn.Sci. USSR, v.35, 4, 184-187, (1993)

12. L.George, J.R.Gaines, Insoluble Monolayers at Liquid-Gas interfaces.

Interscience publishers a Division of John Wiley \& Sons, INC.

Yew York, London, Sydney, 1966.

13. B.K.Vainshtein and V.V.Klechkovskaya. Proc.R.Soc.Lond. A, v. 442 73-84, (1993).

14. E.Brand, J.T.Edsall, J. biol. Chemistry, 241, (1966), s.2491

15. F.M.Pohl. Angcu:Chem., 84, (1972), s.93 


\section{$\mathrm{F}_{6} \mathrm{D}$}

acetylated phenylalanine ${ }_{6}$ aspartic acid - free acid

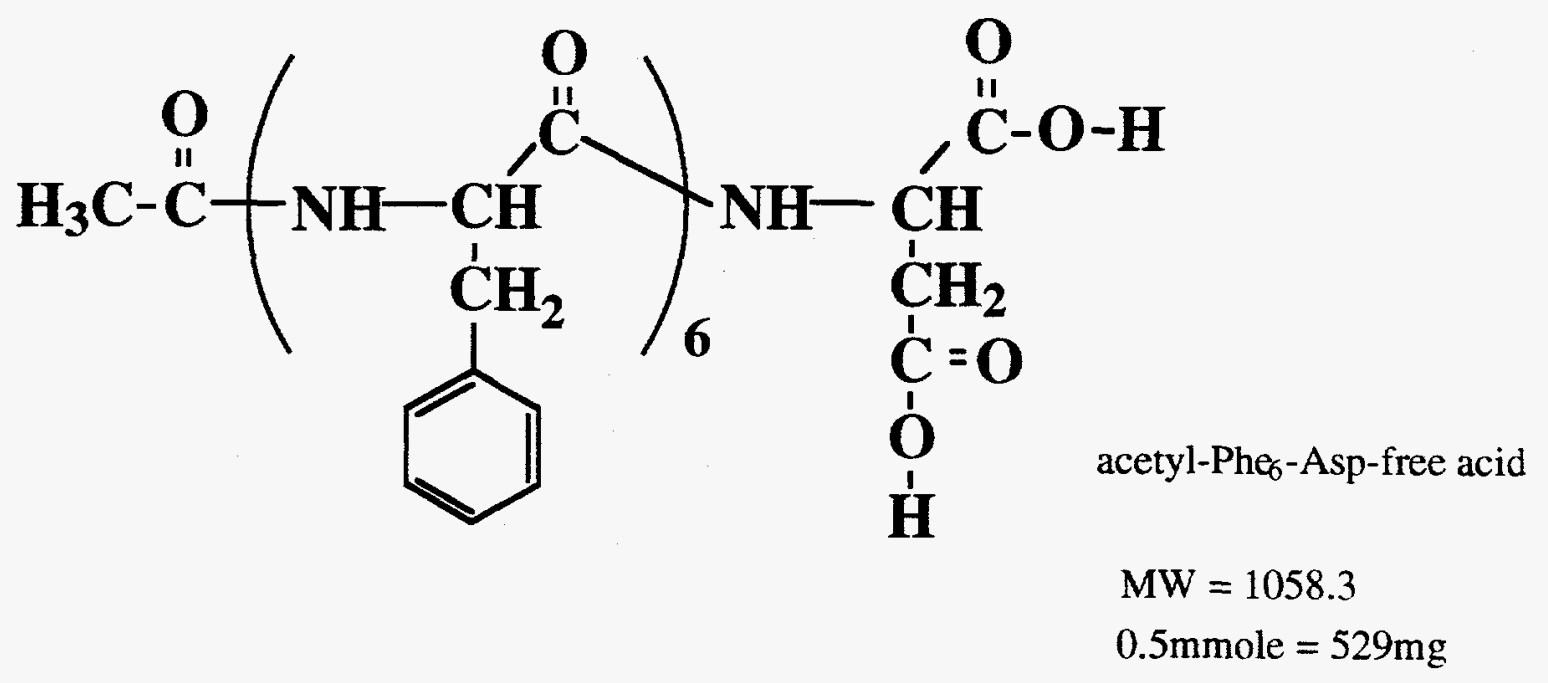

Figure 1 


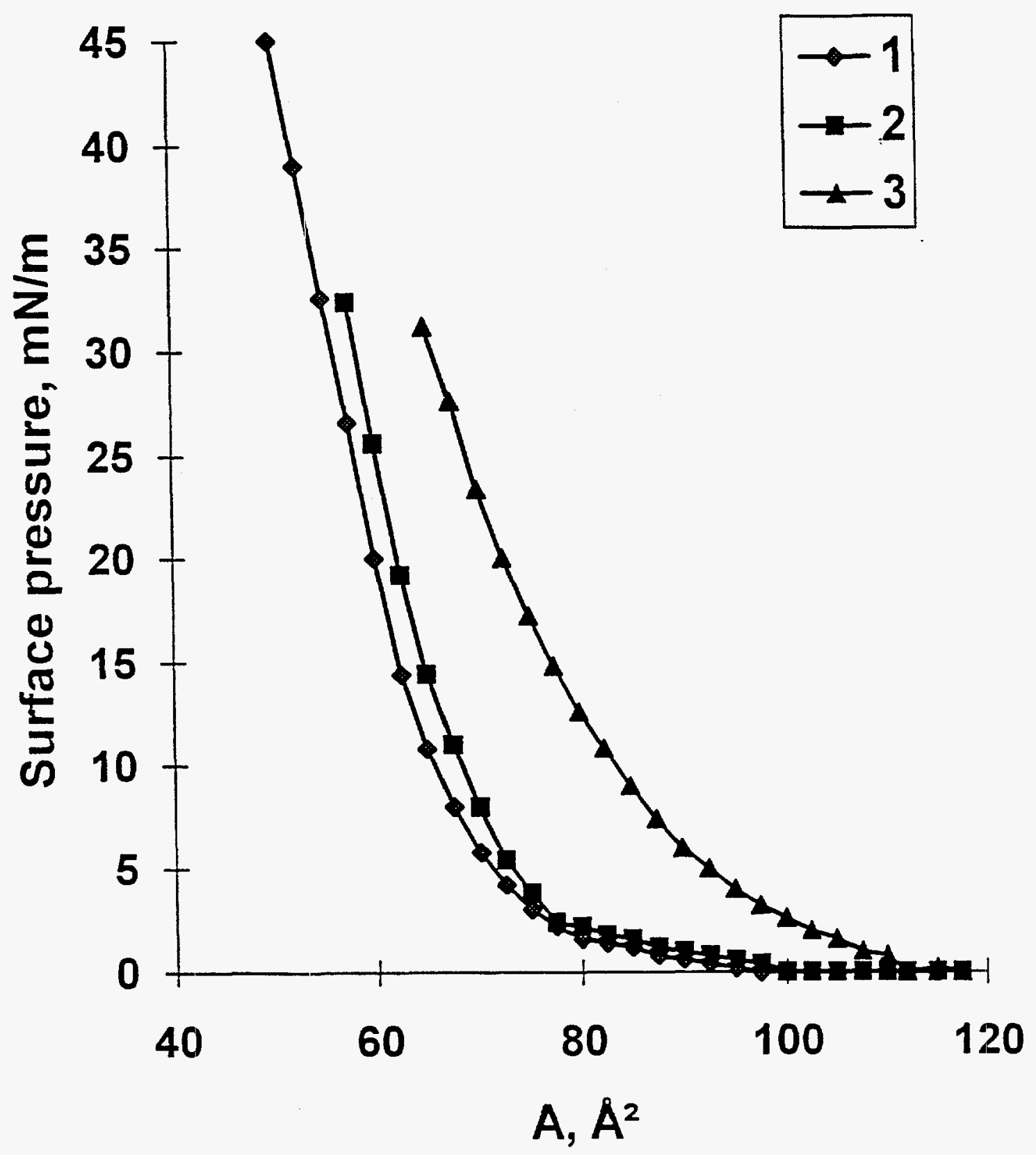

Figure 2 


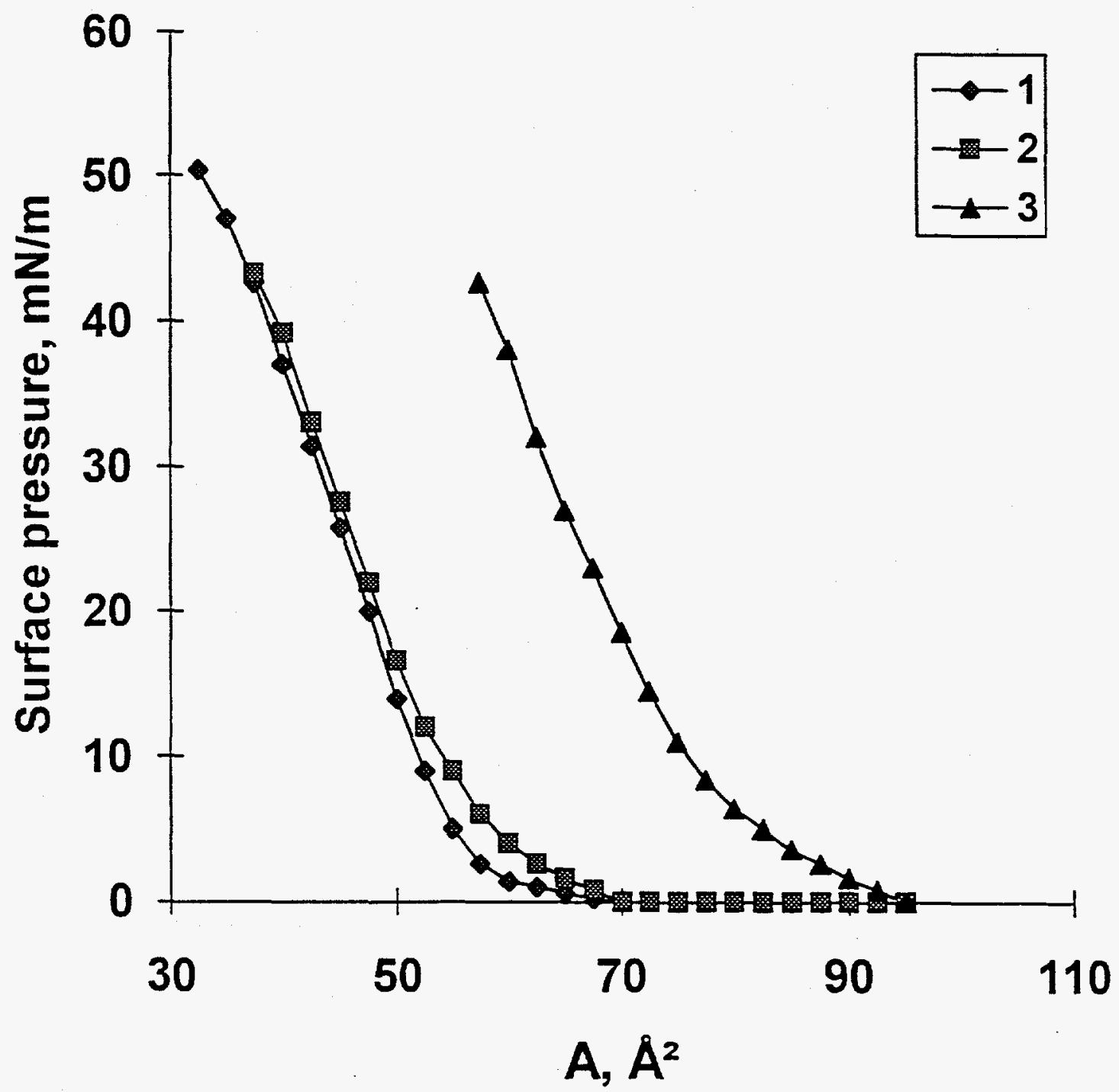

Figure 3 


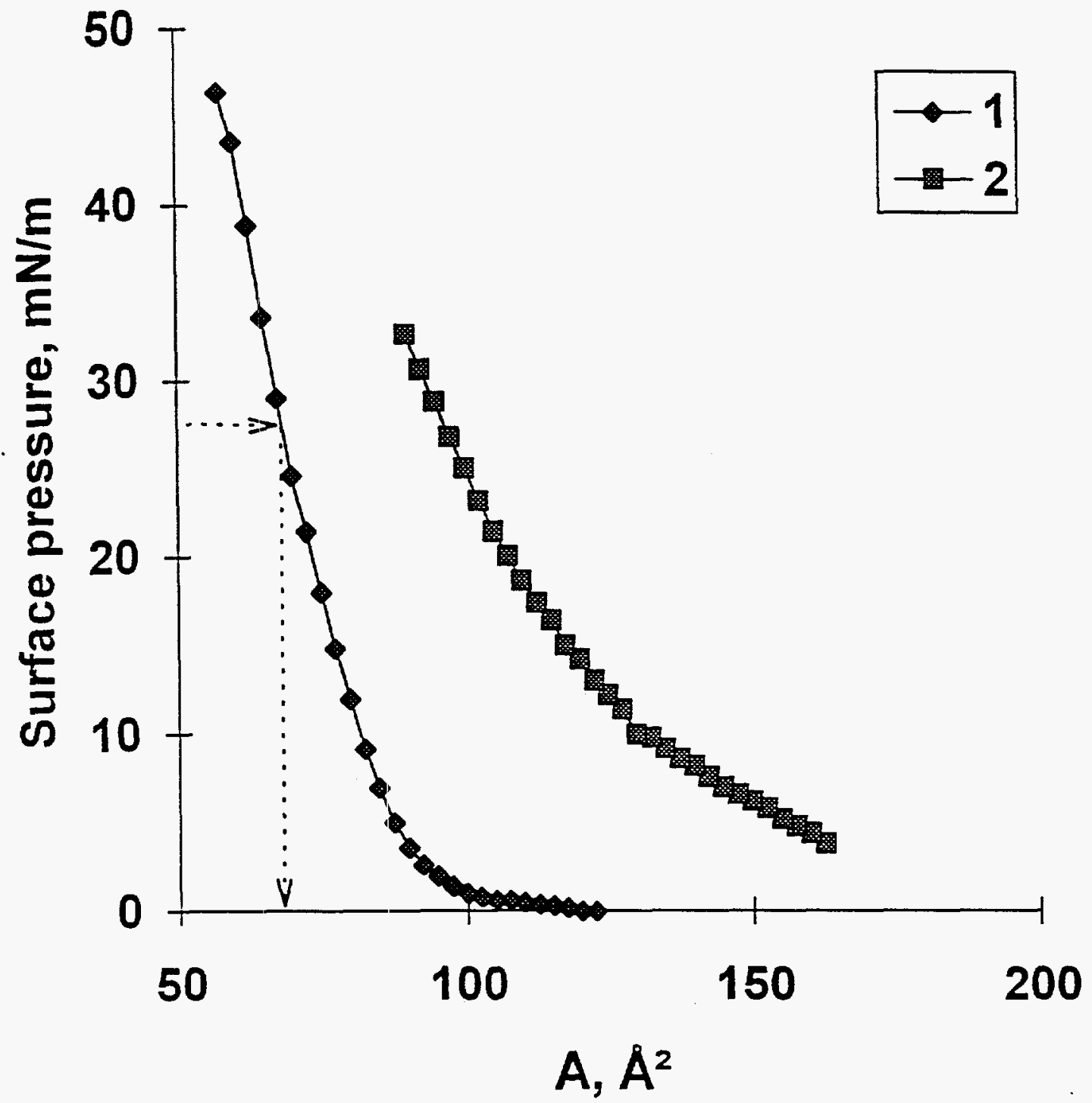

Figure 4 


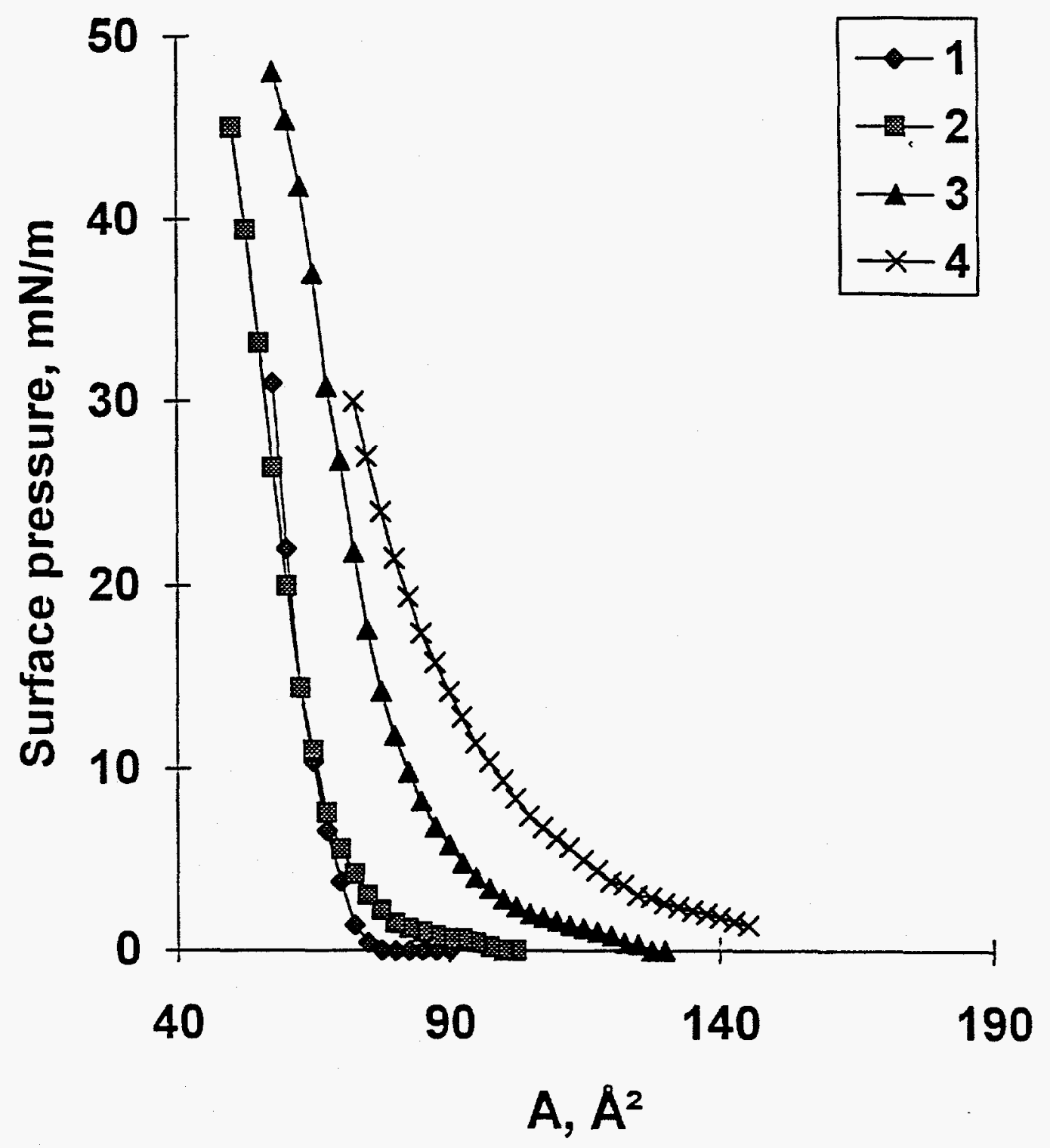

Figure 5 


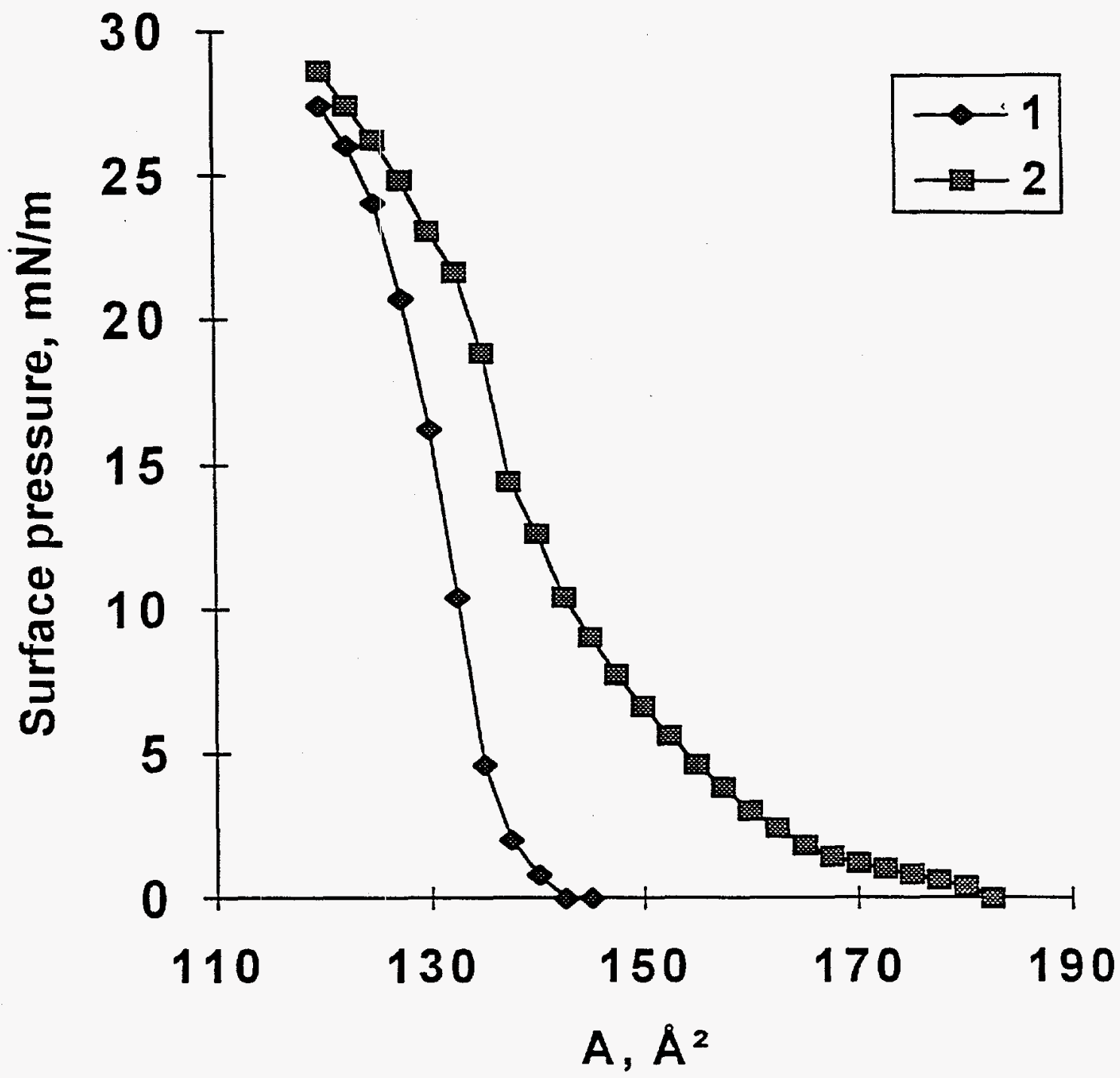

Figure 6 


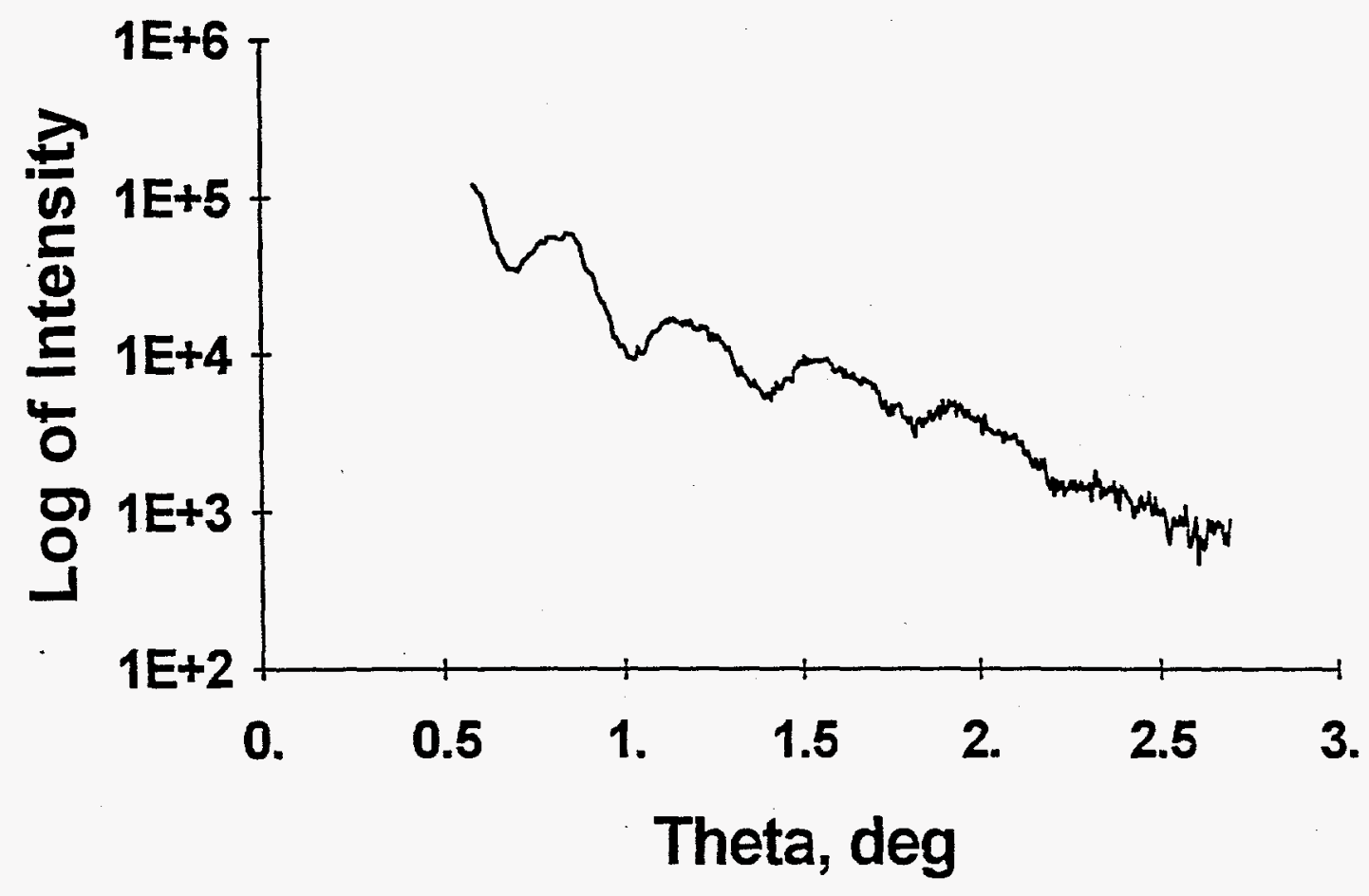

Figure 7 


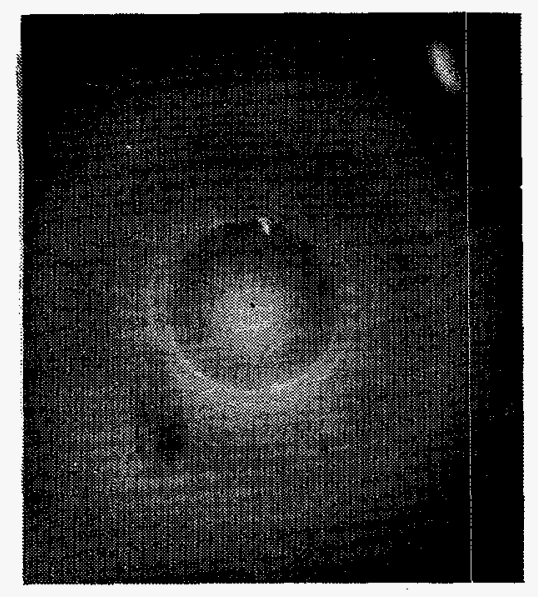

Figure 8a

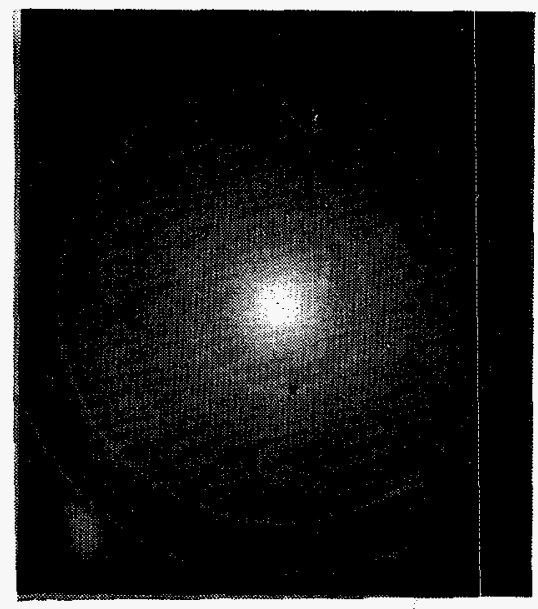

Figure 9a

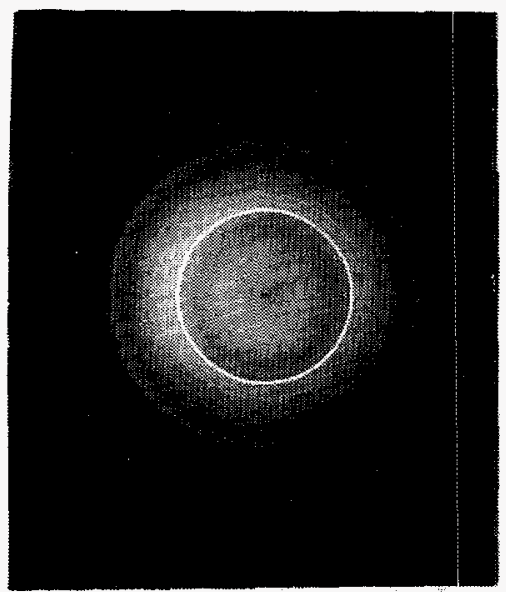

Figure 10a

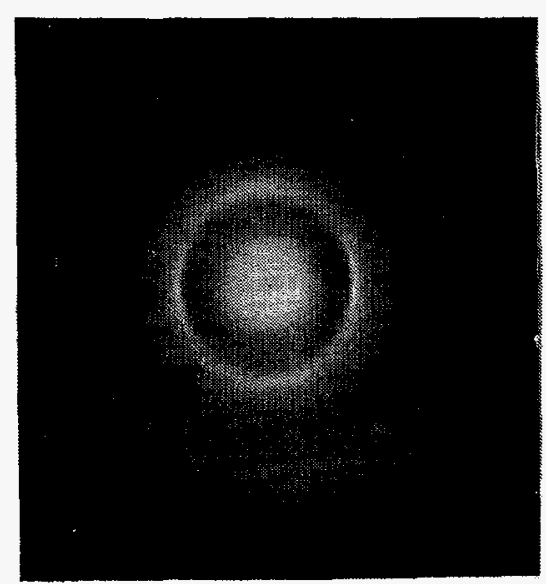

Figure 8b

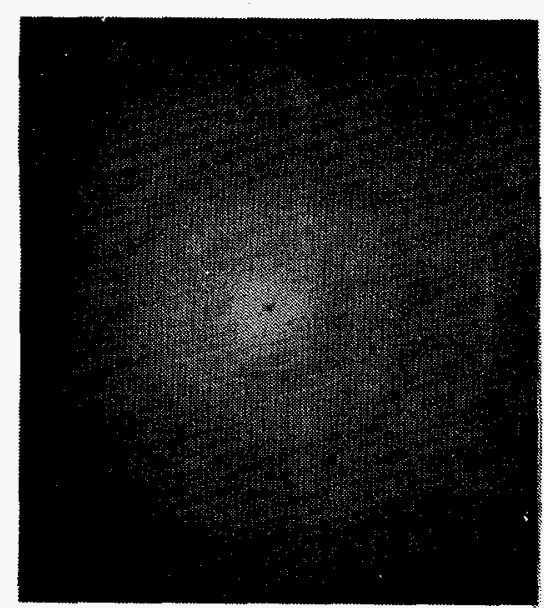

Figure 9b

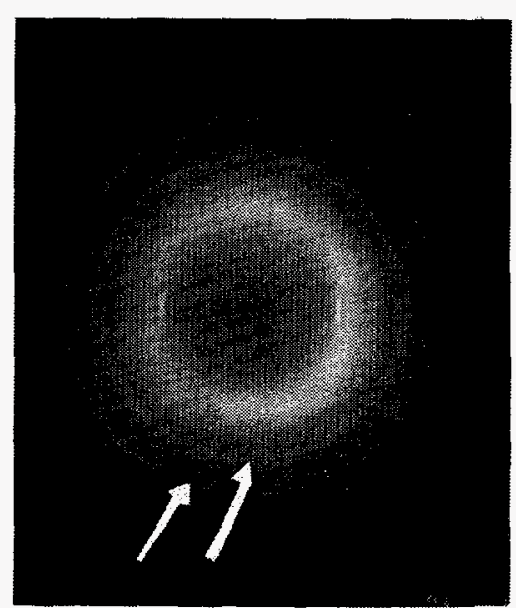

Figure 10b 


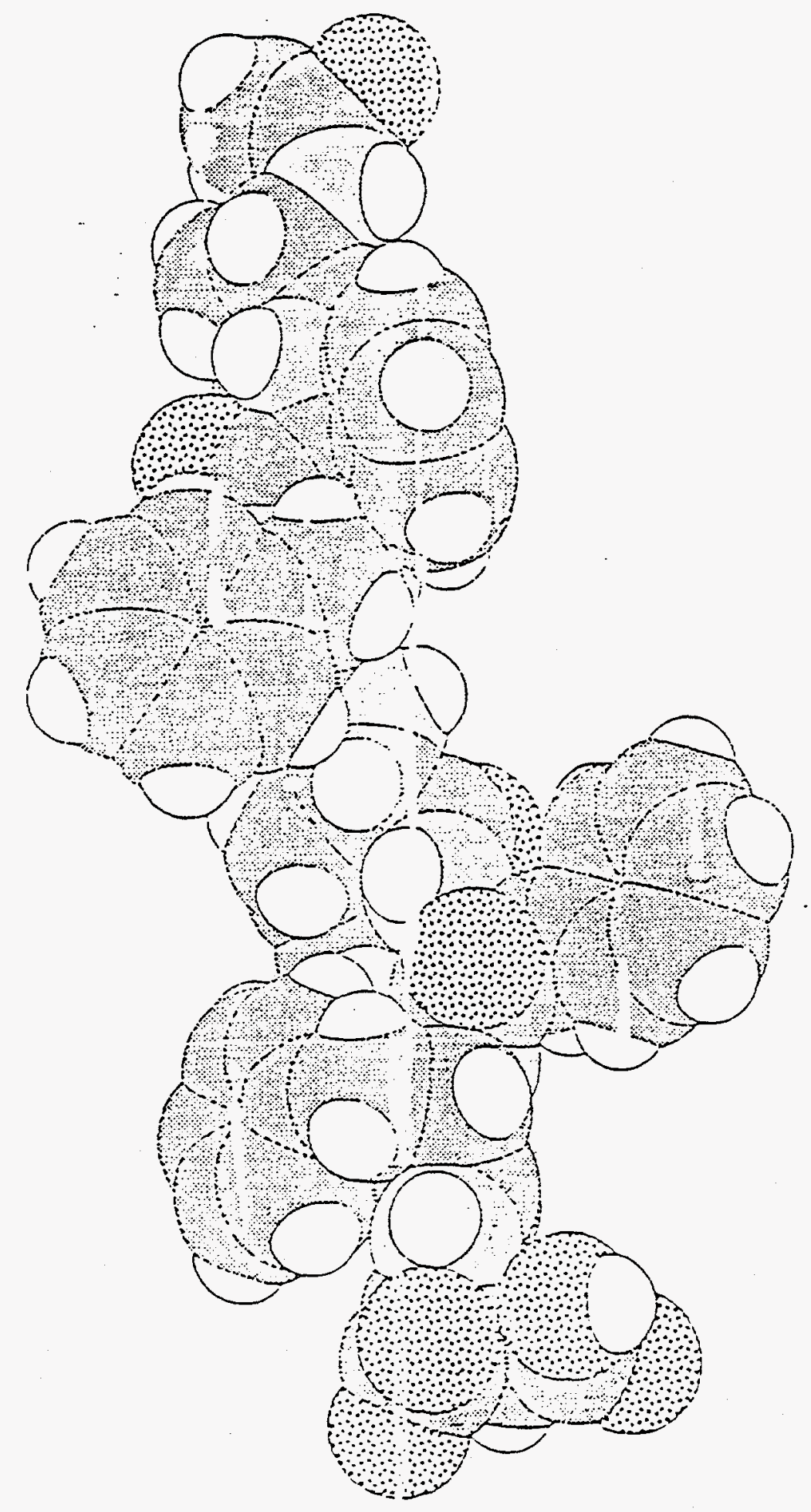

Figure 11 


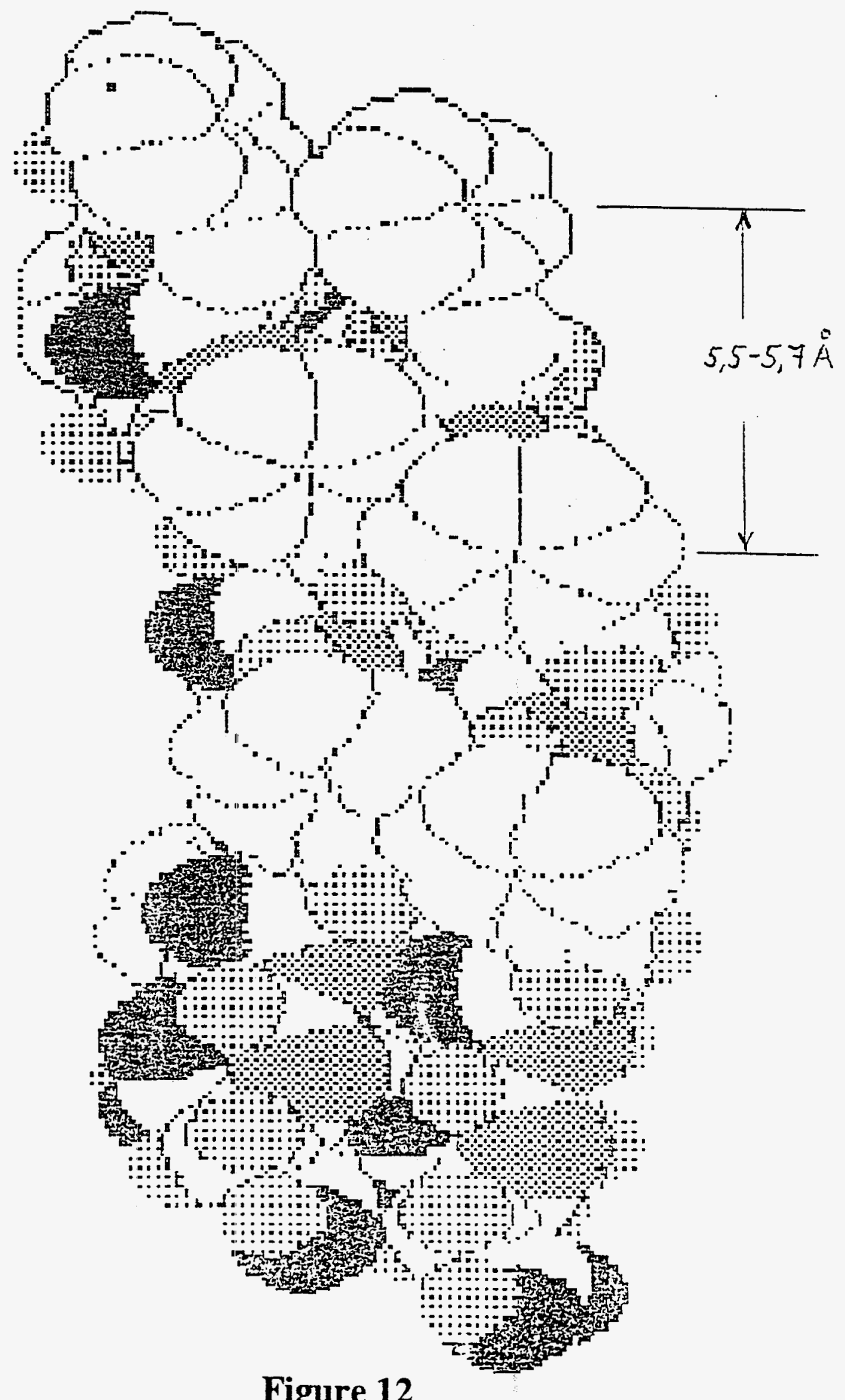




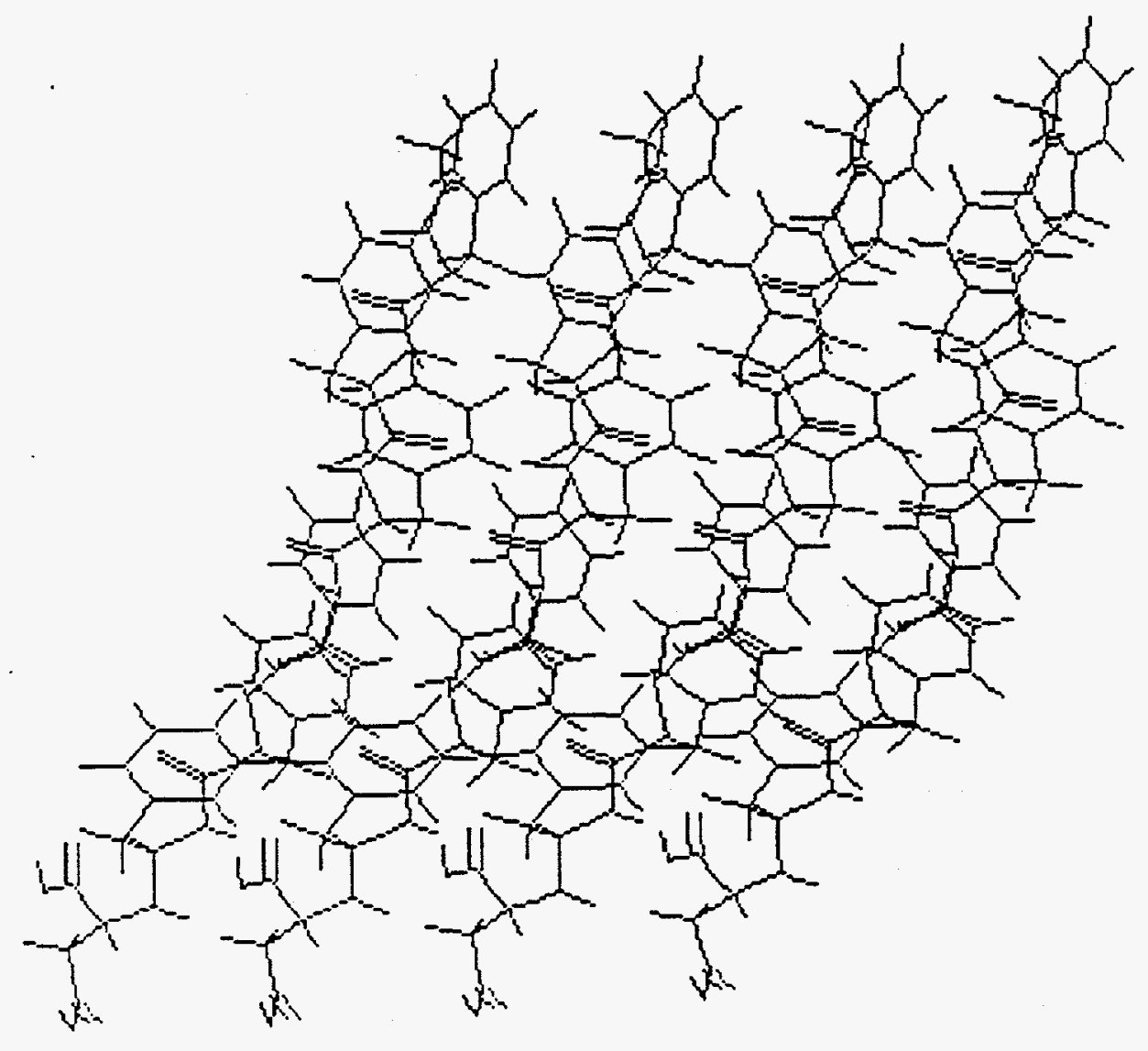

Figure 12a 


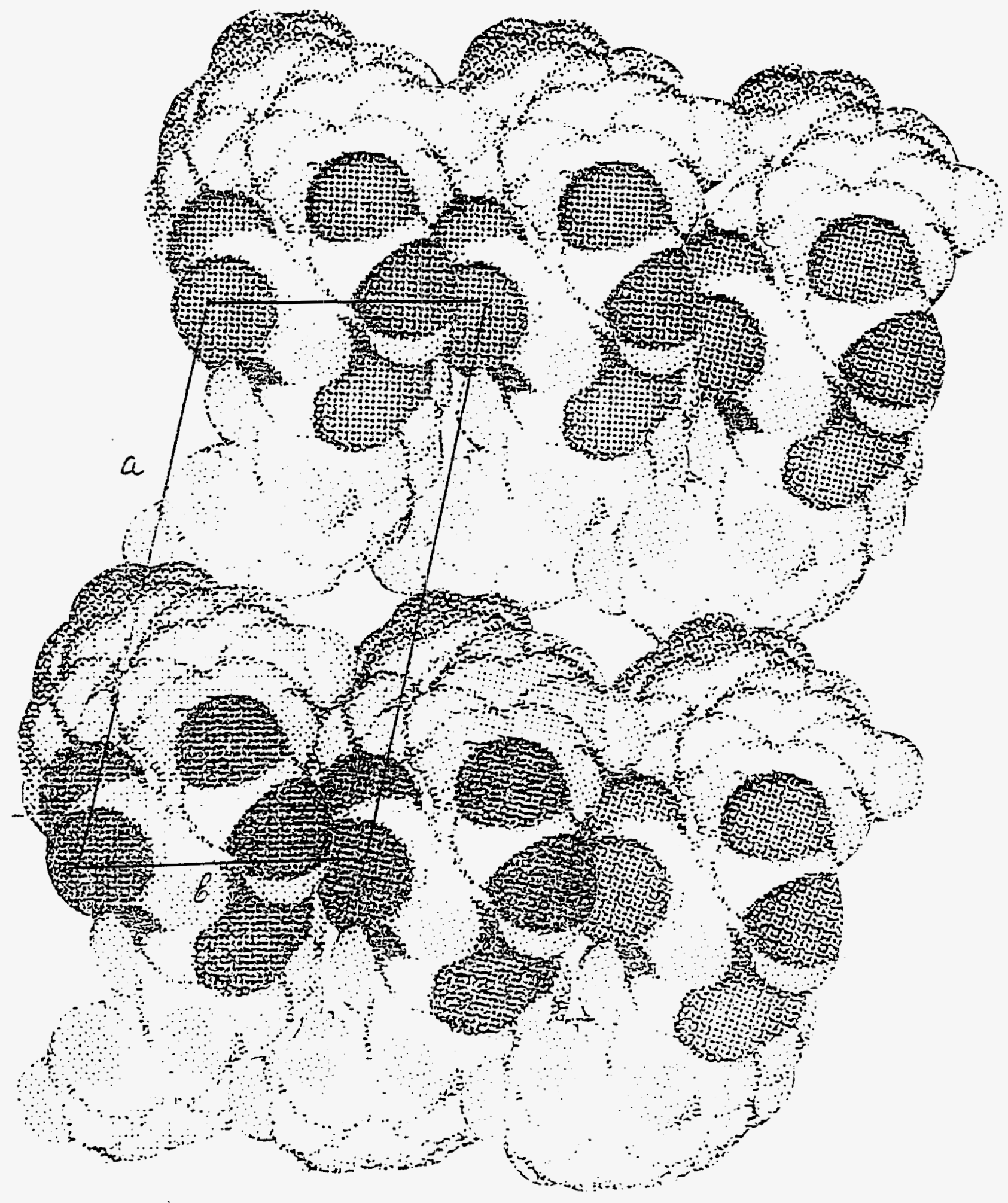

Figure 13 


\section{Chapter 8}

\section{Design and Synthesis of an Amphiphilic Porphyrin}

John Shelnutt

Another very interesting molecule that may have utility for biomimetic nucleation and growth is Ni-lipo-porphyrin. Although we never actually had the opportunity try to complete biomimetic growth on LB films of this material we were able to design,

synthesize, and show that it is amphiphilic and capable of forming monolayers on an air water interface. The molecule was eventually used in mixed monolayer applications and is discussed in "Designed Supramolecular Assemblies for Biosensors and Photoactive Devices" (SAND 97-0258).

The lipoporphyrin, nickel(II) 2,3,7,8,12,13,17,18 - octa(acetic acid-methylester) $5,10,15,20$ - tetra(phenyl eicosanate)porphyrin (NiLipoP), was computer-designed using molecular mechanics calculations to predict structure. Synthesis methods are reported in SAND 97-0258. The chemical representation and the energy minimized structure are shown below.
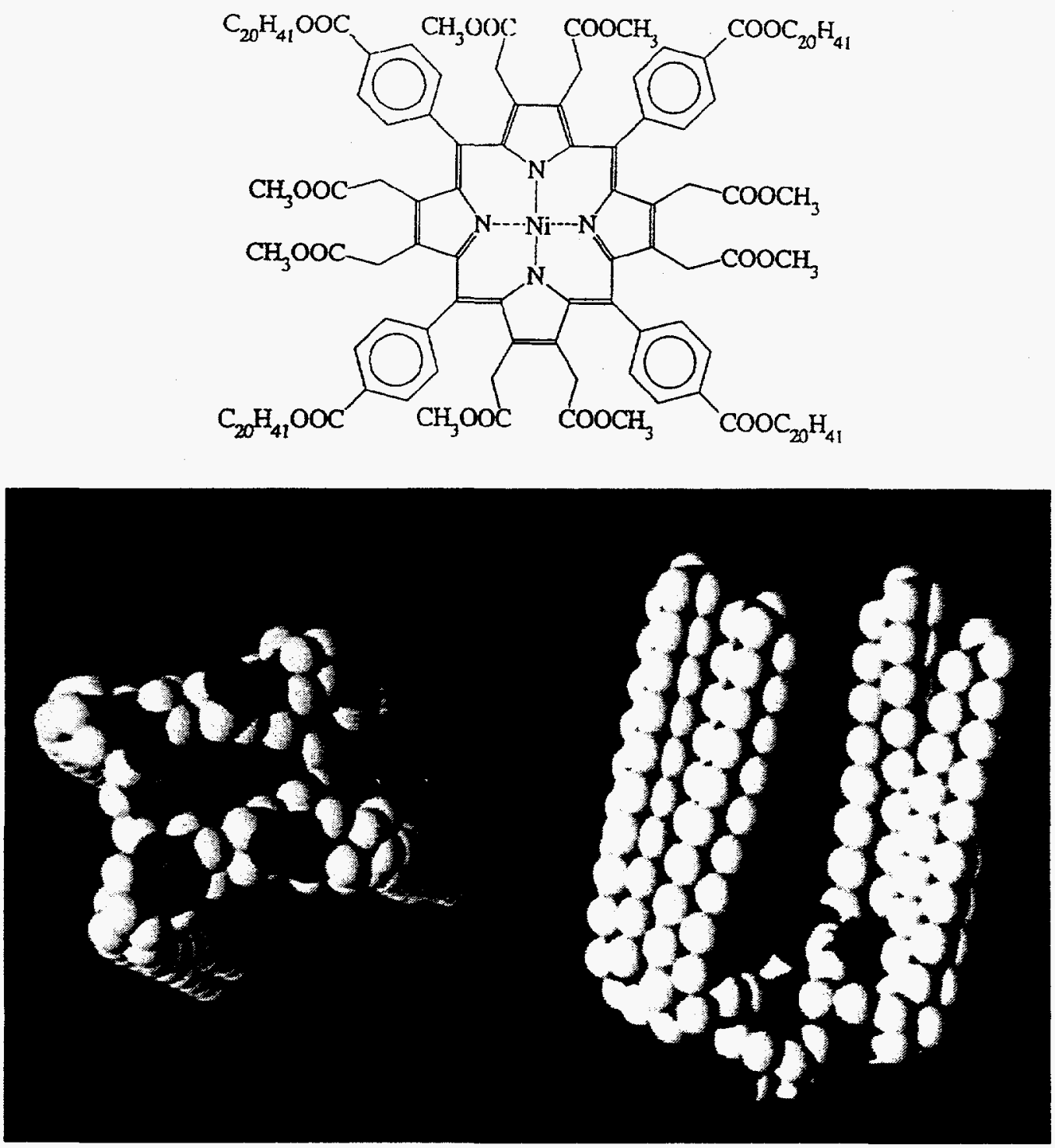


\title{
Chapter 9
}

\section{Review of Seashell Structure and Precipitation of Calcium Carbonate}

As part of this project a contract was granted to Prof. Gillian Bond at New Mexico Tech. As part of that contract, Ronald Baker and Suzanne Paradis completed Master's Theses on the study of calcium carbonate formation within seashells and also studied biomimetic methods of growing calcium carbonate.

\section{Baker, R M; Biomimetic Structure and Processing, Master's thesis at New} Mexico Institute of Mining and Technology, 1993.

\author{
Paradis, S; "Precipitation of Calcium Carbonate: Factors Affecting the \\ Polymorph, Morphology, and Rate", Master's thesis at New Mexico Institute \\ of Mining and 'Technolo;gy, 1995.
}

Their work lead to a greater understanding of the biomimetic process and showed us the importance of controlling the local chemistry in the direct vicinity of the templating organic molecules. It was determined that the local chemistry (which may be very different than the bulk solution chemistry) primarily determines the phase of the precipitate. The organic template only serves to orient the crystals. This lead to the idea of trapping enzymes within the templating monolayer to control the chemistry at the nucleation sites and to the further development of using electrochemistry for biomimetic growth (Modeling and Characterization of Molecular Structures in Self-Assembled and Langmuir-Blodgett Films for Controlled Fabrication, SAND 97-2395).

The next three pages have six micrographs from the thesis of Suzanne Paradis and show examples of how the phase or phases of calcium carbonate that precipitate is controlled by the chemical environment of the solution. Also, the presence of organic molecules can promote nucleation and growth on their surfaces and determine the orientation of the crystals formed. Some more insight is given with regard to these concepts in the contained article entitled "Review and Examination of Naturally Occurring and Biomimetically Prepared Ceramic Thin Films." 


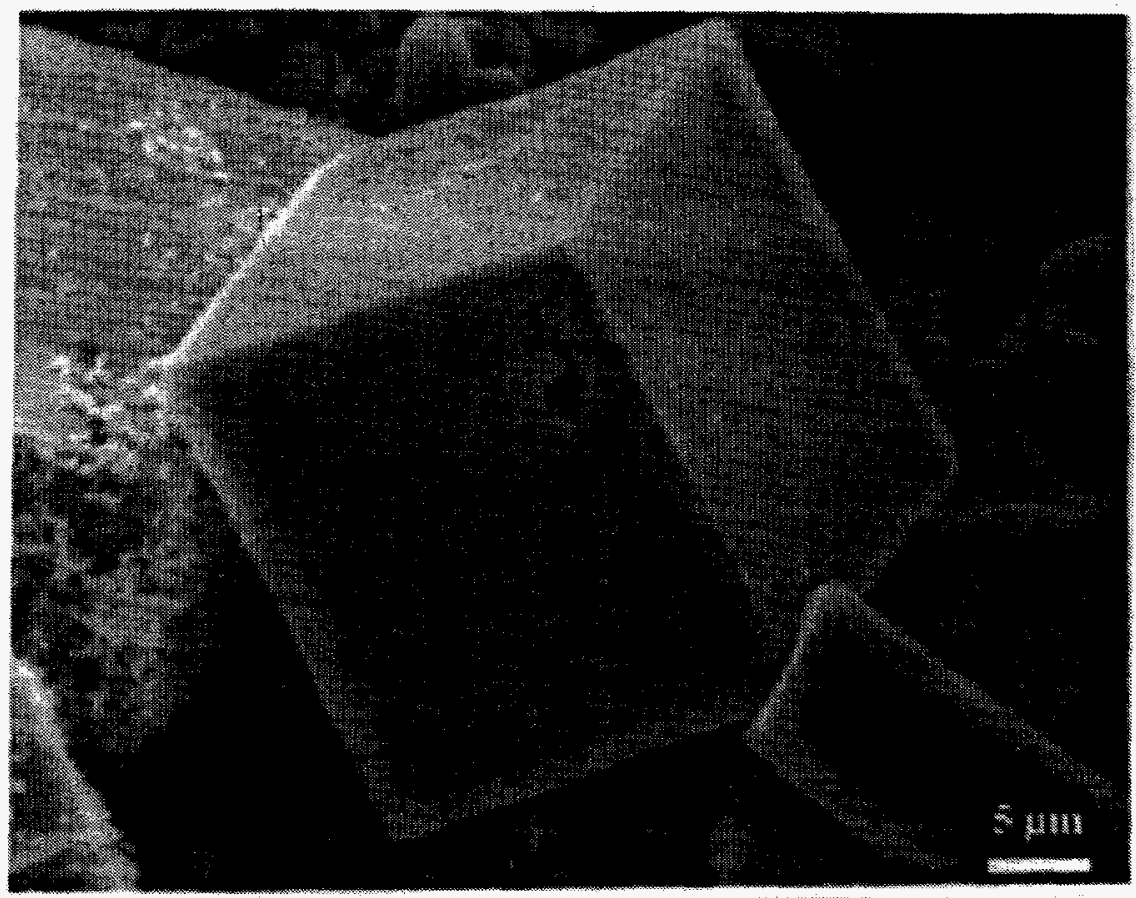

SEM micrograph of a typical crystal found in the control solution. Calcite crystal, rhombohedral in shape. Figure 56 from Suzanne Paradis, Master's thesis at New Mexico Institute of Mining and Technology, 1995.

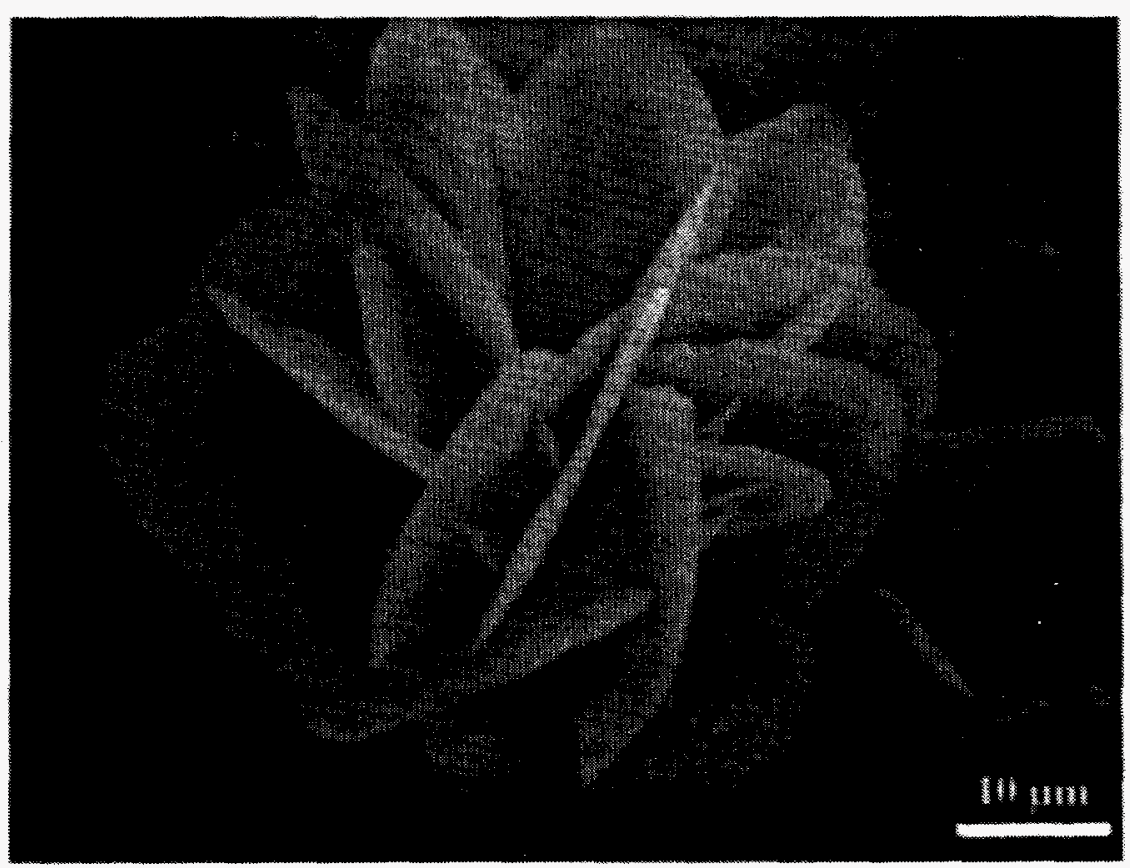

SEM of a vaterite floret crystal found in the control solution. Figure 57 from Suzanne Paradis, Master's thesis at New Mexico Institute of Mining and Technology, 1995. 


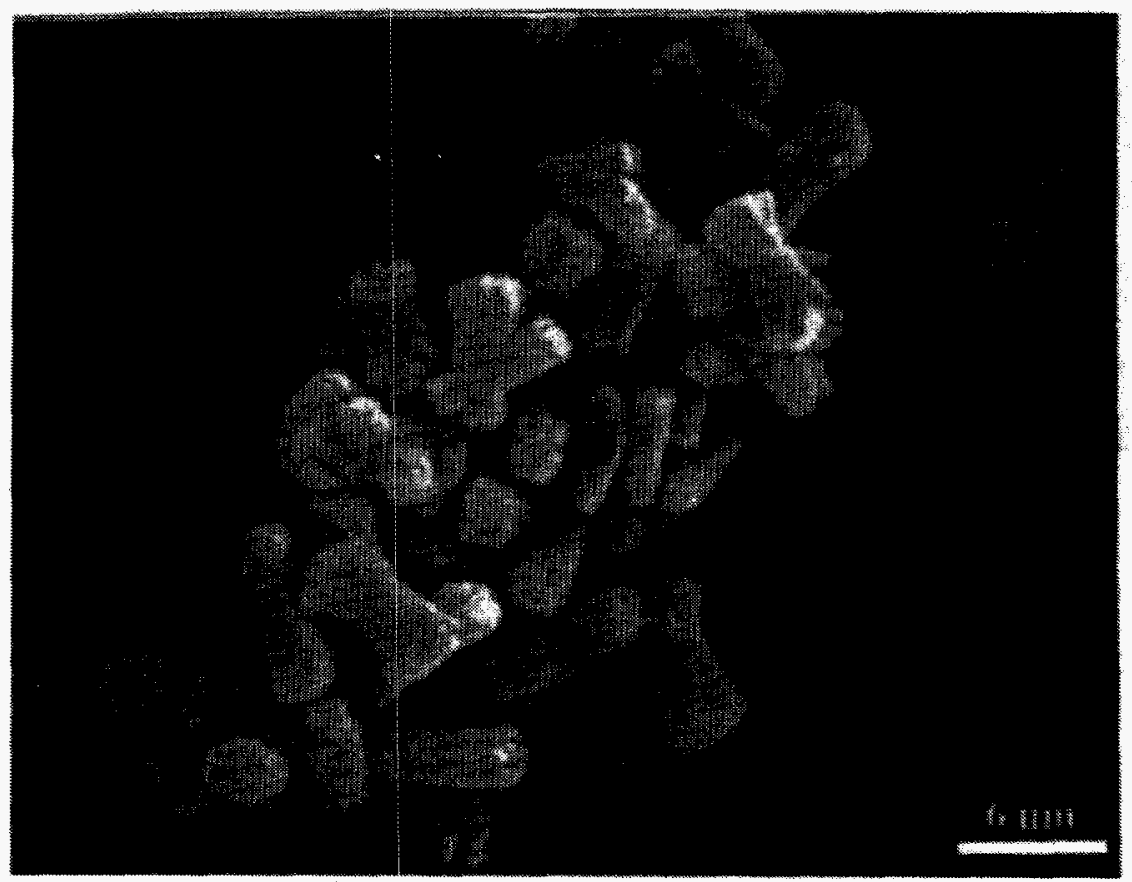

SEM of crystals from artificial sea water with $\mathrm{Mg}$. Broom-like crystals. Figure 31 from Suzanne Paradis, Master's thesis at New Mexico Institute of Mining and Technology, 1995.

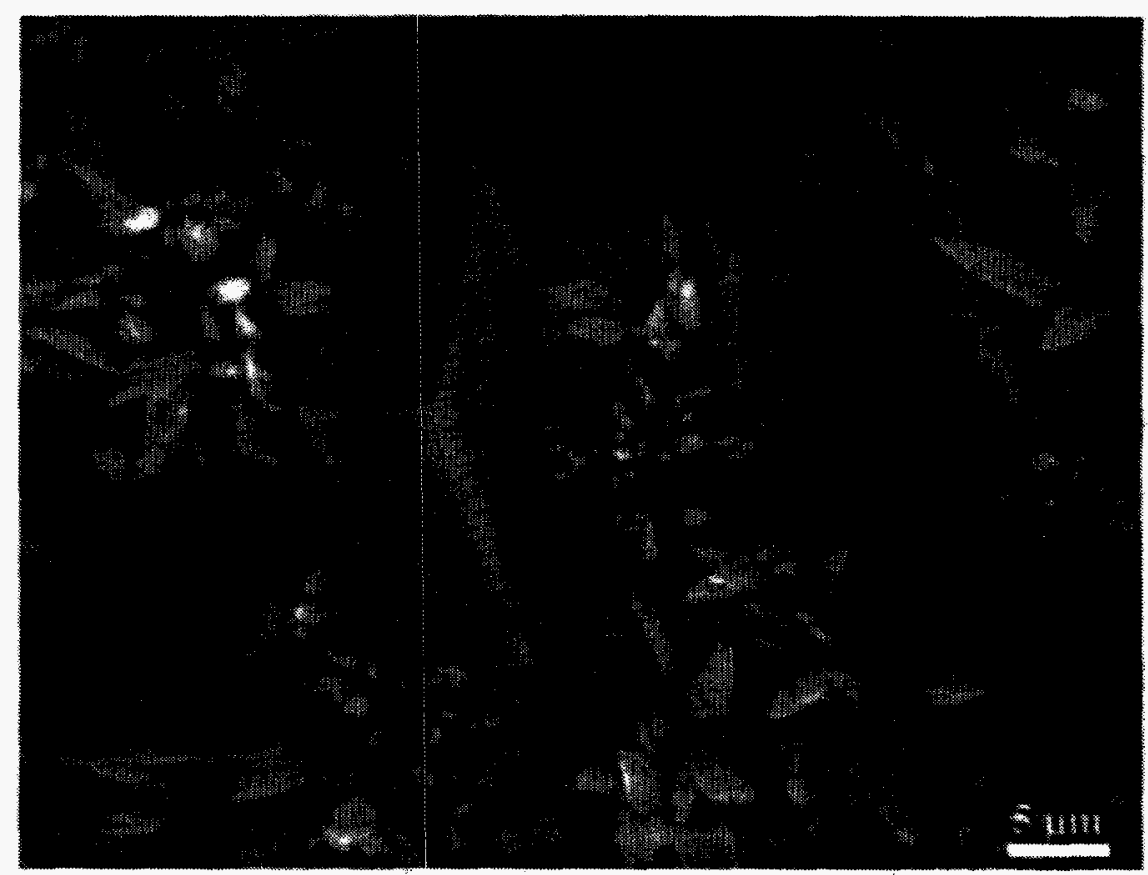

SEM micrograph of crystals from artificial sea water with $\mathrm{Mg}$ in the presence of a monolayer of stearic acid. Acicular and rhombohedral crystals. Figure 38 from Suzanne Paradis, Master's thesis at New Mexico Institute of Mining and Technology, 1995. 


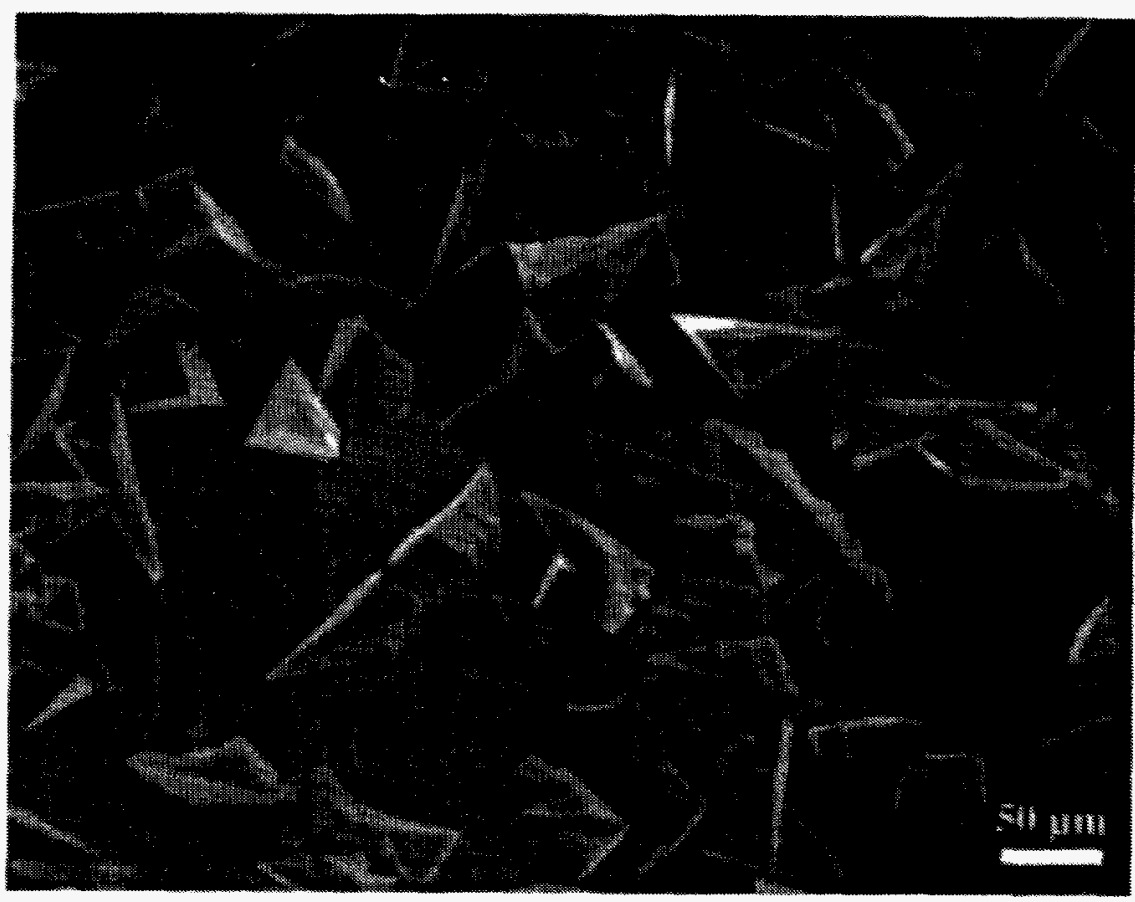

SEM micrograph for $\mathrm{CaCO} 3$ solution and a stearic acid monolayer. Oriented crystals are seen, the dominant form being the triangular one. Figure 44 from Suzanne Paradis, Master's thesis at New Mexico Institute of Mining and Technology, 1995.

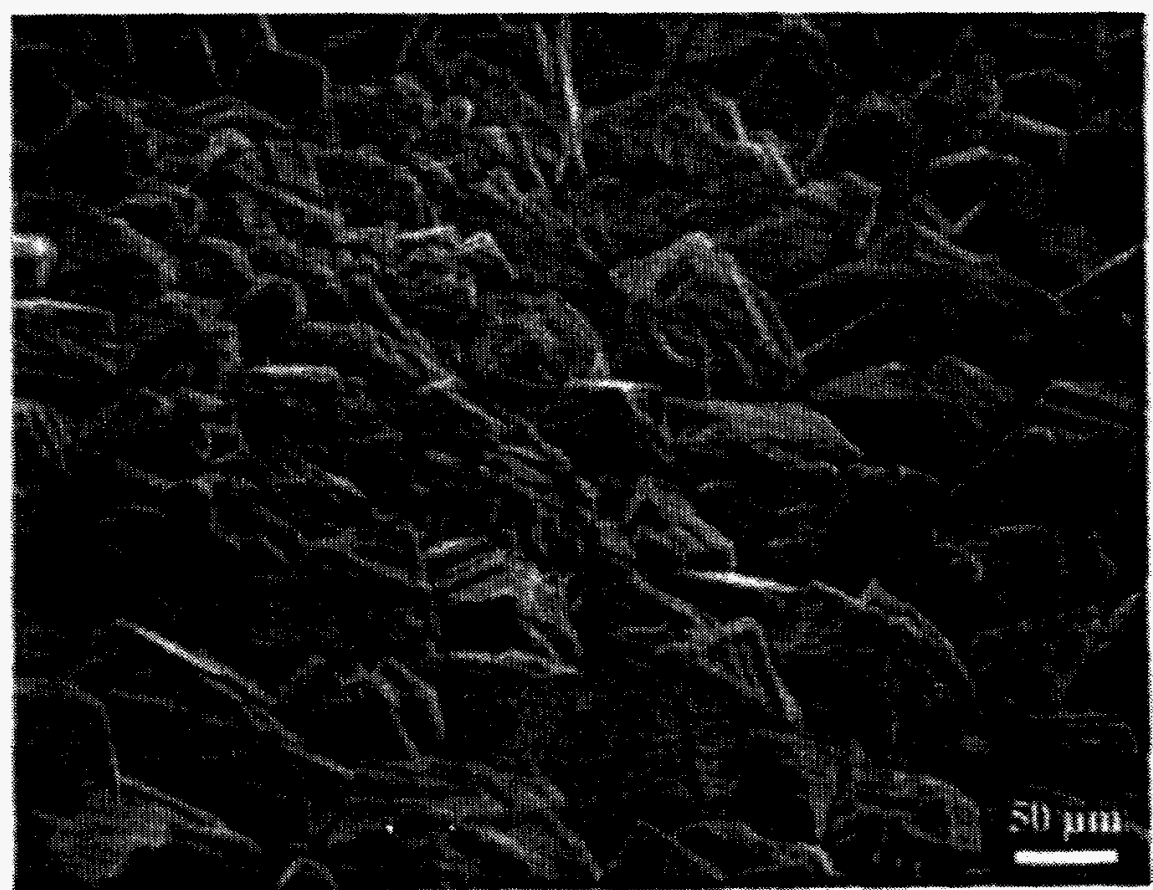

SEM micrograph for $\mathrm{CaCO} 3$ solution with carbonic anhydrase enzyme. General view of the dense crust showing only calcite crystals. Figure 67 from Suzanne Paradis, Master's thesis at New Mexico Institute of Mining and Technology, 1995. 


\title{
Chapter 9.1
}

\section{Review and Examination of Naturally Occurring and Biomimetically Prepared Ceramic Thin Films}

Gillian M. Bond and Suzanne Paradis; Department of Materials and Metallurgical Engineering, New Mexico Tech, Socorro, New Mexico: Joseph Cesarano III; Ceramic Processing Science Department, Sandia National Laboratories, Albuquerque, New Mexico

\begin{abstract}
Biomineralized structures such as mollusc shells are composite materials with sophisticated microarchitectures. Control of the size, shape and orientation of the crystals during biomineralization is generally attributed to the organic material that becomes incorporated into the composite material. It is often assumed that this same organic material determines the phase of the mineral that forms (calcite versus aragonite in mollusc shells). It is proposed here, however, based on both experimental data and a review of the literature, that control of the phase that forms is actually due to control of the local chemistry in the region where biomineralization is occurring.

Addition of the enzyme carbonic anhydrase to supersaturated solutions of $\mathrm{CaCO}_{3}$ and to artificial seawater has been shown to influence both the rate at which calcium carbonate is precipitated and the phase precipitated. These efforts are discussed in terms of the enzyme's influence on bicarbonate ion concentrations, calcium/bicarbonate ratios, and $\mathrm{pH}$.
\end{abstract}

\section{Introduction}

Biomineralized structural materials are complex composites, made up of very ordinary substances, that demonstrate superior mechanical properties, such as a combination of good stiffness, strength and toughness. Man-made ceramics, for example, are notoriously brittle, whereas biological ceramics, such às teeth and marine shells, are not. The microstructures of biological materials provide multiple mechanisms to forestall catastrophic failure, including crack deflection, crack branching, and energy absorption by lath or fiber pullout.

The complex composite architectures observed in these biomineralized structures are made possible by the ability of the natural systems to direct the nucleation and growth of the mineral crystals, and this control is generally attributed to the organic material that is also present in the final biomineralized composite. Such control of the crystallization process is of considerable potential interest for materials applications, for several reasons. In particular, the nucleation and growth of biominerals are controlled in such a way that nucleation is induced in certain locations and prevented elsewhere; the phase of the mineral deposited is determined; and the size, shape and orientation of the crystals is determined. A similar degree of control over crystallization processes would have potential applications in many areas of materials processing, including the growth of oriented thin films $[1,2]$.

Mollusc shells, which are composed mainly of calcium carbonate, are a good example of the types of influence that organic material is believed to exert on biomineralization processes. The proteins or glycoproteins generally associated with biomineralization contain a large fraction of acidic or polar amino acids, forming polyanions. It has been determined that these polyanions will nucleate calcification when they are fixed on a rigid substrate, but will inhibit it when they are in solution [3-7]. There are several aspects to the mechanism as it is currently understood. It is believed [4] that the fixed polyanions assist nucleation by providing a negatively charged surface that interacts electrostatically with cations (here calcium); in addition, their distribution on the substrate may provide a stereochemical "template" for the formation of an adsorbed layer of cations, thus controlling both the phase and orientation of the nuclei as well as their location. It is 
also believed that the polyanions in solution can help determine the crystal shape by selective adsorption onto certain faces [4,6,7]; the macromolecules "recognize" certain stereochemical motifs on these crystal faces, adsorb onto them, and thereby inhibit further growth on those faces. Extensive efforts have been made to elucidate the mechanisms and importance of molecular recognition involved in both crystal nucleation and adsorption onto crystal faces [8-12].

There are, in fact, many factors that may be important in the biological control of mineralization [13]. These include [14] the types of functional groups in the surface of the organic material, and their density, distribution and mobility, as well as the nature of the substrate to which they are attached. The role of the organic material may primarily be to lower the activation energy for the desired nucleation, by simple catalysis involving complementarity in electrostatic binding at the inorganic-organic interface [15]. Alternatively, the organic material may stabilize a specific conformation of the nucleus by structural or stereochemical recognition [15].

Various approaches to biomimicry in ceramic processing are being tried by different research groups, and there have been some notable successes. For example, considerable progress has been made towards the development of an improved processing route for very-highdensity magnetic recording media [1,2 ], the production of ultrafine ceramic particles [16,17], and the production of improved ceramic green bodies (as precursors to ceramic thin films) $[18,19]$. The growth of oriented thin films onto substrates such as silicon, however, is an area still awaiting a breakthrough.

One possible route to the growth of these thin films involves the use of suitably tailored Langmuir-Blodgett films to mimic the role of the organic material in biomineralization. Langmuir-Blodgett films are also being used extensively by Mann, Heywood and co-workers, as a means to explore molecular recognition at organic-inorganic interfaces, and its influence on the phase, morphology, and orientation of inorganic crystals deposited at the interface [20-27]. While adequate for that purpose, crystal deposition has so far, however, been too slow for adaptation to commercially useful systems.

The aim of the present study is two-fold: i) to review and elucidate further the factors that affect the phase deposited during biomineralization of mollusc shells, and analogous processes; and ii) to check the feasibility of a biomimetic method to accelerate mineralization rates.

\section{Background}

\section{a) Precipitation of Calcium Carbonate from Solution}

Calcium carbonate, the major constituent of mollusc shells, can crystallize as calcite, aragonite or vaterite. Calcite is the thermodynamically stable form at standard temperature and pressure, while vaterite is the least stable of the two metastable polymorphs. Mollusc shells are usually composed of aragonite, less commonly calcite, and sometimes both. Therefore, the question arises of how the phase is selected. It should first be pointed out that the chemistry of the seawater has a significant influence. Seawater contains -5 times as much magnesium as calcium. It has been known since 1909 [28] that the presence of magnesium ions favors the precipitation of aragonite over calcite. Bischoff [29-31] has demonstrated that magnesium ions strongly inhibit calcite nucleation. This may be because adsorbed magnesium makes the critical radius for nucleation larger, or because the strongly hydrated magnesium ions adsorbed at active calcite growth sites block further deposition due to the large energy required for their dehydration. Bischoff also observed that the formation of calcite is favored by low $\mathrm{pH}$ (that is high bicarbonate concentration), high calcium concentration, high ionic strength, low sulfate concentration, and particularly, of course, low magnesium concentration. The effect of sulfate has also been described by Busenberg and Plummer [32]. 
Simkiss [33] grew calcium carbonate from various "artificial seawaters" in the presence of excess bicarbonate ions. In the presence of magnesium, aragonite was deposited, while, in the absence of magnesium, the deposits were either calcite or calcite mixed with vaterite, depending on the cations present. Lippmann [34] reported that vaterite is favored if the $\left(\mathrm{HCO}_{3}^{-}\right):\left(\mathrm{Ca}^{2+}\right)$ ratio is high. Rushdi et al. [35] performed a detailed study of calcium-carbonate crystallization from solutions containing various $\left(\mathrm{Mg}^{2+}\right):\left(\mathrm{Ca}^{2+}\right)$ ratios, and various amounts of sodium carbonate to accelerate the crystallization. For $\left(\mathrm{Mg}^{2+}\right):\left(\mathrm{Ca}^{2+}\right)$ ratios greater than $4: 1$, only aragonite is formed. For ratios between 1:1 and 4:1, a mixture of aragonite and magnesian calcite (calcite containing some magnesium in the lattice) is formed; the proportion of calcite increases as the nucleation time decreases, due to additions of the appropriate amounts of sodium carbonate. High magnesium concentrations not only favor aragonite formation, but also slow the precipitation of any calcium carbonate. In the absence of an accelerator, Rushdi et al. [35] estimated that it would take $\sim 38,000 \pm 8,000$ years to nucleate calcium carbonate from artificial seawater containing the same level of magnesium as natural seawater.

Therefore, since the presence of $\mathrm{Mg}^{++}$promotes the stabilization of the aragonite phase, seawater has a relatively high concentration of $\mathrm{Mg}^{++}$, and the $\mathrm{pH}$ of seawater is generally $8-9$, the following questions are raised: Why are not all molluse shells aragonite? When calcite forms in mollusc shells, is it because the organism modifies the local chemistry, or because the organic component of the shell directly controls the nucleation and growth of the calcium carbonate phase (or both)?

\section{b) Precipitation in the Presence of Organics}

Mann, Heywood and co-workers have studied crystallization under Langmuir monolayers in order to elucidate the possible effects of the organic material on the phase, morphology and texture of the crystals deposited [20-27]. Our present concern is with their observations on the phase of calcium carbonate deposited. They first used stearic-acid monolayers, which present an array of negatively charged carboxylate groups to the solution below. At low calcium concentration $(4.5 \mathrm{mM})$ this resulted in predominantly vaterite formation. At high calcium concentration $(9 \mathrm{mM})$ calcite was formed. The phase was independent of the degree of compression of the monolayer. When octadecylamine monolayers were used, which present positively charged amine groups to the solution below, only vaterite was formed. Since vaterite formation is favored under conditions of high $\left(\mathrm{HCO}_{3}^{-}\right):\left(\mathrm{Ca}^{2+}\right)$ ratio, this latter effect can be attributed to accumulation of carbonate under the positively charged amine films. In both cases, the organic monolayer seems to induce a prefential orientation of the crystals that form. When a neutral monolayer is present there, the effects on the phases formed and orientation are reduced. Heywood and Mann only observed aragonite nucleation under their monolayers when they added magnesium to the solution. Indirectly this work seems to indicate that charged organic layers may control orientation of precipitating crystals but that the local chemistry determines the phase of the calcium carbonate. Our work presented below further substantiates this premise.

Recently Falini et al. [36] examined the effect of polyelectrolytes on deposition of calcium carbonate from solutions containing different $\left(\mathrm{Mg}^{2+}\right):\left(\mathrm{Ca}^{2+}\right)$ ratios. The polyelectrolytes were selected to provide different types of charged groups (sulfate or carboxylate) and different ordering of those groups. For sulfate groups, two carrageenans were used, while poly-L-aspartate (Pasp), poly-L-glutamate ( $\mathrm{Pglu}$ ) and polyacrylate (Pacr) were chosen to provide carboxylate groups. At relatively low $\left(\mathrm{Mg}^{2+}\right):\left(\mathrm{Ca}^{2+}\right)$ ratios, the carrageenans cause more aragonite to be formed while Pasp, Pglu, and (to a much lesser extent) Pacr cause vaterite to be formed. As the magnesium content increases, there gradually ceases to be any difference in the polymorph formed, with or without carrageenans, Pglu or Pacr. In the presence of Pasp, however, $100 \%$ calcite is formed at a $\left(\mathrm{Mg}^{2+}\right):\left(\mathrm{Ca}^{2+}\right)$ ratio of 2.5 . Even at $\left(\mathrm{Mg}^{2+}\right):\left(\mathrm{Ca}^{2+}\right)$ ratios as high as 10 (much higher than 
seawater) the precipitate still contains about $30 \%$ calcite. The influence of Pasp to promote the precipitation of calcite even from solutions with high concentrations of $\mathrm{Mg}^{2+}$ appears to be unique. This finding is particularly interesting since aspartic acid is the most abundant amino acid in the organic component of mollusc shells, and Addadi et al. [4] have observed that B-sheet Pasp adsorbed onto sulfonated polystyrene surfaces can influence the orientation of calcite growth. Without understanding the mechanism, Falini et al. [36] also conclude that the B-sheet structure of Pasp is responsible for the crystallization of calcite in the presence of magnesium.

In summary, there is substantial evidence that the local chemistry (magnesium levels, bicarbonate: calcium ratios, ionic strength, $\mathrm{pH}$, etc.) can influence what polymorph of calcium carbonate will crystallize. The formation of vaterite under Langmuir monolayers, as seen by Mann, Heywood and co-workers [20-26], can be explained in terms of high $\left(\mathrm{HCO}_{3}{ }^{-}\right):\left(\mathrm{Ca}^{2+}\right)$ ratios due to the physical nature of the experiment. Vaterite was only observed to form under stearic-acid monolayers when the calcium concentration was low. Crystallization in these experiments was from supersaturated calcium-carbonate solution, and occurred as $\mathrm{CO}_{2}$ was lost from the liquid surface (or through the monolayer). Thus the carbonate species should be particularly concentrated near the surface of the liquid; this is also the region where the stearic-acid carboxylate groups will have bound calcium ions, but presumably in lower density when the overall calcium concentration is low. The findings of Falini et al. [36] are more difficult to interpret, particularly since it is not clear whether the structure of the Pasp molecules directly affects the structure of the carbonate phase that precipitates, or if the Pasp molecules specifically modify the local chemistry near the surface of the growing crystals.

\section{c) Accelerated Precipitation in the Presence of an Organic Enzyme}

With regard to the second objective of this work, namely to check the feasibility of a biomimetic method to accelerate mineralization rates, it is important to gain knowledge from nature where biomineralization is in fact sometimes quite rapid. While biomineralization is frequently thought of as slow, the thin portions of the murex shell can be deposited as rapidly as $5 \mathrm{~mm}$ per day. These regions of rapid growth occur between the development of slower growing thick ridges on the shell called verises [37]. Avian eggshell deposition is also relatively fast. It is believed that the eggshell forms by binding of calcium ions to the organic matrix material, followed by reaction of those calcium ions with carbonate ions produced with the aid of the enzyme carbonic anhydrase in the oviduct [38-41]. The feasibility of accelerated mineralization in the presence of the enzyme and the effects (if any) on phase development and/or morphology are therefore of interest. Preliminary results are discussed below.

\section{Method and Materials}

\section{(i) Preparation of solutions}

Calcium carbonate was precipitated from two different types of solutions: supersaturated calcium-bicarbonate solutions (by analogy to the work, for example, of Mann and Heywood, and Falini et al.) and artificial seawater (by analogy to mollusc-shell mineralization, and the work, for example, of Rushdi et al.).

$\mathrm{CO}_{2}$ gas was bubbled through an aqueous suspension of $\mathrm{CaCO}_{3}$, to produce supersaturated bicarbonate solutions according to the reaction

$$
\mathrm{CaCO}_{3}(\mathrm{~s})+\mathrm{CO}_{2}(\mathrm{~g})+\mathrm{H}_{2} \mathrm{O}(\mathrm{l}) \rightarrow \leftarrow \mathrm{Ca}^{2+}(\mathrm{aq})+2 \mathrm{HCO}_{3}{ }^{-}(\mathrm{aq})
$$


The solution was then filtered $(0.22 \mu \mathrm{m}$ filter paper) to remove excess (undissolved) calcite crystals. The final $\mathrm{pH}$ was $6.0-6.3$.

Artificial seawater was prepared by dissolution, per $\mathrm{kg}$ of final solution in deionized water, of $23.926 \mathrm{~g} \mathrm{NaCl}, 0.677 \mathrm{~g} \mathrm{KCl}, 4.008 \mathrm{~g} \mathrm{Na}_{2} \mathrm{SO}_{4}, 11.37 \mathrm{~g}$ of a $1 \mathrm{M} \mathrm{CaCl}_{2}$ solution, and $56.2 \mathrm{~g}$ of a $1 \mathrm{M} \mathrm{MgCl}_{2}$ solution. It was then bubbled with air for 4 hours to equilibrate it with the atmosphere. This is a slightly simplified version of the artificial seawater described by Kester et al. [42]. It gives an ionic strength of 0.6928 and a pH of $\sim 8.0$. Addition of $\mathrm{Na}_{2} \mathrm{CO}_{3}$ accelerator raised the $\mathrm{pH}$ to $\sim 10.0$. In some experiments, the artificial seawater was bubbled, not with air, but for 3 hours with $\mathrm{CO}_{2}$; this resulted in a pH of $\sim 4.0$ (no accelerator added).

When $\mathrm{Na}_{2} \mathrm{CO}_{3}$ accelerator was used, it was from a $0.1 \mathrm{M}$ stock solution. The final concentration was $46.63 \mathrm{~g}$ (of stock solution) per $\mathrm{kg}$ of the final solution.

\section{(ii) Crystallization at stearic-acid monolayers}

Stearic-acid monolayers were formed in a Nima trough ( $1.8 \mathrm{l}$ capacity) by addition of a stearic acid/hexane mixture to the surface of either a supersaturated calcium-bicarbonate solution or artificial seawater (bubbled with air) with $\mathrm{Na}_{2} \mathrm{CO}_{3}$ accelerator. Films were compressed into the liquid phase for the supersaturated solution, and into the solid phase for the artificial seawater. Crystals were collected after 12 hours, on glass slides dipped through the monolayer-subphase interface, and analyzed by $\mathrm{x}$-ray diffraction.

\section{(iii) Crystallization in beakers}

Crystallization experiments were performed with: 1) artificial seawater (a) alone, (b) with $\mathrm{Na}_{2} \mathrm{CO}_{3}$ accelerator, (c) with enzyne (carbonic anhydrase) added, and (d) bubbled with $\mathrm{CO}_{2}$ instead of air and with enzyme (carbonic anhydrase) added, as well as 2) supersaturated calciumbicarbonate solutions (a) alone, (b) with $\mathrm{Na}_{2} \mathrm{CO}_{3}$ accelerator, and (c) with enzyme (carbonic anhydrase) added.

All crystals that formed were analyzed by X-ray diffraction.

\section{Results and Discussion}

In an effort to gain insight into the different roles of organized organic layers and local solution chemistry in the precipitation and orientation of different phases of $\mathrm{CaCO}_{3}$, experiments were completed both in bulk solutions and under Langmuir monolayers of stearic acid.

In bulk solutions, as expected, calcium carbonate precipitated slowly from supersaturated $\mathrm{CaCO}_{3}$ solutions alone, as a result of gradual degassing of $\mathrm{CO}_{2}$. As $\mathrm{CO}_{2}$ escapes from the air $/$ water interface, the local concentration of $\mathrm{CO}_{3}{ }^{2-}$ increases. When the kinetics of precipitation are faster than the diffusion of $\mathrm{CO}_{3}{ }^{2-}$ into the bulk solution then $\mathrm{CaCO}_{3}$ forms at the air / water interface. As expected, the phase precipitated was calcite (Figure 1) and precipitation occurred primarily at the air / water interface and at heterogeneous nucleation sites on the container surfaces. A method to enhance precipitation is to add sodium carbonate to supersaturated solutions of $\mathrm{CaCO}_{3}$. This results in more rapid crystallization of calcite, with precipitation occurring at the surfaces but also throughout the bulk of the solution since the concentration of $\mathrm{CO}_{3}{ }^{2-}$ was high 
everywhere. Experiments were also conducted in artificial seawater which had a $\left(\mathrm{Mg}^{2+}\right):\left(\mathrm{Ca}^{2+}\right)$ ratio of 5. Artificial seawater alone did not precipitate calcium carbonate. This is as expected, (since Rushdi et al. [35] predicted that it would take several thousand years for aragonite to precipitate spontaneously from artificial seawater). As with supersaturated $\mathrm{CaCO}_{3}$ solutions, when sodium carbonate was added to artificial seawater this led to some crystallization in the bulk of the solution. However, the product was entirely aragonite due to the high $\left(\mathrm{Mg}^{2+}\right):\left(\mathrm{Ca}^{2+}\right)$ ratio (Figure 2).

To examine the effect of organized organic layers on the growth of calcium carbonate, both the supersaturated solution of $\mathrm{CaCO}_{3}$ and the artificial seawater (with sodium-carbonate accelerator added) were used as subphases in the Langmuir trough, with a monolayer of stearic acid. For the supersaturated solution, this resulted in crystallization at the monolayer only, producing a highly textured calcite deposit (Figures 3 and 4). This is in keeping with the findings of Mann and Heywood[23-26] at higher calcium concentrations. Similarly, some crystallization also occurred from the artificial seawater; however, the product was aragonite. This is to be expected because of the large amount of magnesium present, and parallels the observations of Heywood and Mann [27] when they added magnesium chloride to their subphase.

The enzyme carbonic anhydrase was introduced to determine if it would accelerate the crystallization of calcium carbonate and/or affect the polymorph. Carbonic anhydrase is a zinc enzyme found in red blood cells, gastric mucosa, and various other animal tissues. It has a molecular weight of about 30,000 Dalton and catalyses the reversible hyration of carbon dioxide (the substrate) to bicarbonate in aqueous solutions. Carbonic anhydrase is one of the fastest enzymes known [43]. When carbonic anhydrase was sprinkled over the surface of a supersaturated solution of $\mathrm{CaCO}_{3}$, it resulted in rapid crystallization of a surface layer comprising calcite along with some vaterite (Figure 5). Since supersaturated solutions of $\mathrm{CaCO}_{3}$ are also saturated with $\mathrm{CO}_{2}$, there is a large resevoir of $\mathrm{CO}_{2}$ for production of bicarbonate ions in the presence of carbonic anhydrase. In a solution that already contained a high level of bicarbonate from dissolution of $\mathrm{CaCO}_{3}$, this would be expected to produce a high $\left(\mathrm{HCO}_{3}^{-}\right):\left(\mathrm{Ca}^{2+}\right)$ ratio, and hence it is not surprising that some vaterite was formed.

Addition of carbonic anhydrase to artificial seawater that had been bubbled with compressed air containing only trace $\mathrm{CO}_{2}$ produced no precipitation after 12 hours. This is not surprising since this artificial seawater contained essentially no carbon dioxide to become hydrated. Carbonic anhydrase was also added to artificial seawater that had been bubbled with $\mathrm{CO}_{2}$, (but contained no sodium carbonate). In the absence of the enzyme, this solution produced no precipitation. When a very small amount of enzyme was added $(7.3 \mathrm{mg}$ to $1875 \mathrm{ml})$, precipitation was still not evident. When a larger amount of enzyme was added $(30 \mathrm{mg}$ or more to $1000 \mathrm{ml}$ ), bulk crystallization was soon evident. X-ray diffraction revealed calcite mixed with some aragonite (Figure 6). This result was unexpected but consistant with the findings of Fallini et al. [36] when the protein Pasp is present. We believe that the carbonic anhydrase is adsorbed onto precipitating nuclei and can affect the local chemistry at the surface of the growing crystal. When carbonic anhydrase hydrolyzes carbon dioxide it produces a locally high bicarbonate concentration while simultaneously reducing the $\mathrm{pH}$. In bulk solutions, Bischoff [29-31] observed that both high bicarbonate concentrations and low $\mathrm{pH}$ tend to favor calcite formation. If the kinetics of precipitation at the surface of the growing crystals is faster than the diffusion of ions into the bulk solution, then it is believable that carbonic anhydrase could control the local chemsitry and promote the crystaliization of calcite even in artificial seawater. It should be noted that vaterite was not detected by $\mathrm{x}$-ray diffraction for these experiments in artificial seawater. This may be due to the fact that the artificial seawater has a high $\left[\mathrm{Mg}^{2+}\right]$ and a lower $\mathrm{pH}$ than supersaturated solutions of $\mathrm{CaCO}_{3}$. Also, since the artificial seawater contains a high calcium 
concentration but minimal bicarbonate concentration, the enzyme may not be able to produce a high enough $\left(\mathrm{HCO}_{3}^{-}\right)$: $\left(\mathrm{Ca}^{2+}\right)$ ratio to favor vaterite formation. In the supersaturated solutions of $\mathrm{CaCO}_{3}$ there is a large concentration of $\left(\mathrm{HCO}_{3}{ }^{-}\right)$present even prior to addition of the carbonioc anhydrase, and it is reasonable to expect that larger $\left(\mathrm{HCO}_{3}{ }^{-}\right):\left(\mathrm{Ca}^{2+}\right)$ ratios could be produced locally with carbonioc anhydrase present.

\section{Conclusions}

The purpose of this review and experiments was to gain an understanding of the effects that organic molecules can have on the biomimetic growth of calcium-carbonate crystals. It is commonly assumed throughout the literature that, because organized organic molecules control the size, shape and orientation of precipitating crystals, they also control the phase that forms. This gives an attractive but simplistic view of how organisms control the growth of calcium carbonate. That is, an organism provides an organized proteinaceous layer that provides total control over the crystallization process. The review and experiments discussed in this paper suggest, however, a more complicated reality in which the phase is controlled by the local chemistry at the surface of the growing crystal, keeping in mind that the local chemistry may be affected by specific adsorption of ions and large organic molecules; the organized organic layers serve to orient the crystals and perhaps determine their shape and size.

For the experiments reviewed in the literature and for the experiments performed for this paper, the formation of all three polymorphs of calcium carbonate could be explained in terms of the local chemistry, without the need to invoke any kind of templating for an ordered organic layer to produce a particular phase. Thus it is suggested that marine organisms such as molluscs may control the phase of calcium carbonate they deposit by controlling the local chemistry in the area where crystallization occurs by use of enzymes and proteins. It should be noted, however, that the control of crystal orientation is a very different matter. There is substantial evidence that charged organic layers can induce nucleation and growth of crystals with a preferred orientation. The question of whether the organic layer needs to be ordered (with two-dimensional crystallinity) to promote an epitaxial relationship with the inorganic crystal is still not understood.

The enzyme, carbonic anhydrase, produced considerable acceleration of the crystallization, not only from supersaturated solution of $\mathrm{CaCO}_{3}$, but also from artificial seawater (in which magnesium and sulfate ions tend to retard the crystallization). We now propose to incorporate it into Langmuir monolayers, and hope thus to be able to produce accelerated oriented crystallization.

\section{References}

1. B.J. Tarasevich and P.C. Rieke, Mat. Res. Soc. Symp. Proc. 174 (1990) 51.

2. P.C. Rieke, G.E. Fryxell, A.A. Campbell, S.B. Bentjen and B.J. Tarasevich,

Supramolecular Architecture: ACS Symnposium Series 499, Atlanta, GA. April 14-19. 1991, American Chemical Society, Washington, DC, 1992, p. 61.

3. L. Addadi and S. Weiner, Proc. Nat . Acad. Sci., 82 (1985) 4110. 
4. L. Addadi, J. Moradian, E. Shay, N.G. Maroudas and S. Weiner, Proc. Nat . Acad. Sci. $\underline{84}$ (1987) 2732.

5. M.A. Crenshaw, Mat. Res. Soc. Symp. Proc. 218 (1991) 185.

6. A. Berman, L. Addadi and S. Weiner, Nature. 331 (1988) 546.

7. J. Moradian-Oldak, F. Frolow, L. Addadi and S. Weiner, Proc. Roy. Soc. Lond. B, 247 (1992) 47.

8. L. Addadi, J. Moradian-Oldak and S. Weiner, Surface Reactive Peptides and Polymers, Discovery and Commercialization, ACS Symposium Series 444, Dallas, TX. April 12-13, 1989 American Chemical Society, Washington, DC, 1991, p. 13.

9. S. Mann, B.R. Heywood, S. Rajam and J.B.A. Walker, Surface Reactive Peptides and Polvmers, Discovery and Commercialization, ACS Symposium Series 444. Dallas, TX. April 12-13, 1991 p. 28.

10. C.S. Sikes, M.L. Yeung and A.P. Wheeler, Surface Reactive Peptides and Polvmers, Discovery and Commercialization. ACS Symposium Series 444. Dallas, TX, April 12-13, 1991 , p. 50.

11. A.P. Wheeler, K.C. Low and C.S. Sikes, Surface Reactive Reptides and Polymers, Discovery and Commercialization. ACS Symposium Series 444, Dallas. TX, April 12-13. 1991, p. 72.

12. A. Berman, J. Hanson, L. Lieserowitz, T.F. Koetzle, S. Weiner and L. Addadi, Science, 259 (1993) 776.

13. P. Calvert, Scripta Metall. et Mater. 31 (1994) 977.

14. P.C. Rieke, S.B. Bentjen, B.J. Tarasevich, T.S. Autrey and D.A. Nelson, Mat. Res. Soc. Svmp. Proc. 174 (1990) 69.

15. S. Mann, D.D. Archibald, J.M. Didymus, B.R. Heywood, F.C. Meldrum and V.J. Wade, MRS Bulletin 17 (October 1992) 32.

16. H. Liu, G.L. Graff, M. Hyde, M. Sarikaya and I.A. Aksay, Mat. Res. Soc. Svmp. Proc. 218 (1991) 115.

17. S. Bhandarkar, I. Yaacob and A. Bose, Mat. Res. Soc. Svmp. Proc. 180 (1990) 637.

18. P.D. Calvert and A. Broad, Mat. Res. Soc. Symp. Proc. 174 (1990) 61.

19. J.W. Burdon and P.D. Calvert, Mat. Res. Soc. Svmp. Proc. 218 (1991) 203.

20. S. Mànn, B.R. Heywood, S. Rajam and J.D. Birchall, Nature. 334 (1988) 692.

21. B.R. Heywood, S.R. Rajam, J.D. Birchall and S. Mann, Biochem. Soc. Trans.. 16 (1988) 824.

22. S. Mann, B.R.Heywood, S. Rajam and J.D. Birchall, Proc. Roy. Soc. Lond. A. 423 (1989) 457. 
23. S. Mann, B.R. Heywood, S. R.ajam, J.B.A. Walker, R.J. Davey and J.D. Birchall, Adv. Mater. 2 (1990) 257.

24. S. Mann, B.R. Heywood, S. Rajam and J.B.A. Walker, J. Phys. D: Appl. Phys. 24 (1991) 154.

25. B.R. Heywood, S. Rajam and S. Mann, J. Chem. Soc. Faraday Trans. 87 (1991) 735.

26. S. Mann, B.R. Heywood, S. R.ajam and J.B.A. Walker, Surface Reactive Peptides and Polymers. Discoverv and Commercialization. ACS Symposium Series 444, Dallas. TX. April 12-13,1991, p. 28.

27. B.R. Heywood and S. Mann, Chem. Mater. 6 (1994) 311.

28. H. Leitmeier, Z. Krvst. 47 (1909) 104.

29. J.L. Bischoff and W.S. Fyfe, Am. J. Science. 266 (1968) 65.

30. J.L. Bischoff, Am. J. Science, 266 (1968) 80.

31. J.L. Bischoff, J. Geophys. Res. 73 (1968) 3315.

32. E. Busenberg and L.N. Plummer, Genchim. Cosmochim. Acta, 49 (1985) 713.

33. K. Simkiss, Nature. 201 (1964) 492.

34. F. Lippmann, Sedimentary Carbonates Minerals. Eds W. von Engelhardt, T. Hahn, R. Roy, P. J. Wyllie, Springer-Verlag, New York 1973.

35. A.I. Rushdi, R.M. Pytkowicz, E. Suess and C.T. Chen, Geologische Rundschau. 81 (1992) 571.

36. G. Falini, M. Gazzano and A. Ripamonti, J. Crystal Growth. 137 (1994) 577.

37. Dr. Tucker Abbott, Bailey-Matthews Shell Museum, Sanibel Island, Florida, personal communication.

38. K. Simkiss and C. Tyler, Q. J. Microsc. Sci. 98 (1957) 19.

39. K. Simkiss, Biol. Rev. 36 (1961) 321.

40. K. Simkiss, Nature, 214 (1967) 84.

41. K. Simkiss, in T.C. Carter (ed.), Egg Ouality - A Study of the Hen's Egg, Oliver and Boyd, Edinburgh, 1968, p. 3.

42. D.R. 'Kester, I.W. Duedall, D.N. Connors and R.M. Pytkowicz, Limnology and Oceanography. 12 (1967) 176.

43. D.N. Silverman and S. Lindskog, Acc. Chem. Res. 21 (1988) 30. 
Figure 1: Precipitate from $\mathrm{CaCO}_{3}$ supersaturated solution: $\mathrm{XRD}$ pattern $\left(\mathrm{K}_{\mathrm{B}}\right.$ peaks are present).

Figure 2: $\quad$ Precipitate from $A S W+$ accelerator $\mathrm{Na}_{2} \mathrm{CO}_{3}: \mathrm{XRD}$ pattern $\left(\mathrm{K}_{\boldsymbol{B}}\right.$ peaks are present).

Figure 3: $\quad$ Precipitate from $\mathrm{CaCO}_{3}$ supersaturated solution + stearic acid: $\mathrm{XRD}$ pattern $\left(\mathrm{K}_{B}\right.$ peaks are present).

Figure 4: $\quad$ Precipitate from $\mathrm{CaCO}_{3}$ supersaturated solution + stearic acid: scanning electron micrograph of crystals produced.

Figure 5: $\quad$ Precipitate from $\mathrm{CaCO}_{3}$ supersaturated solution + carbonic anhydrase: $\mathrm{XRD}$ pattern $\left(\mathrm{K}_{\mathrm{B}}\right.$ peaks are present).

Figure 6: $\quad$ Precipitate from $A S W$ (bubbled with $\left.\mathrm{CO}_{2}\right)+$ carbonic anhydrase: $\mathrm{XRD}$ pattern $\left(\mathrm{K}_{\mathcal{B}}\right.$ peaks are present). 


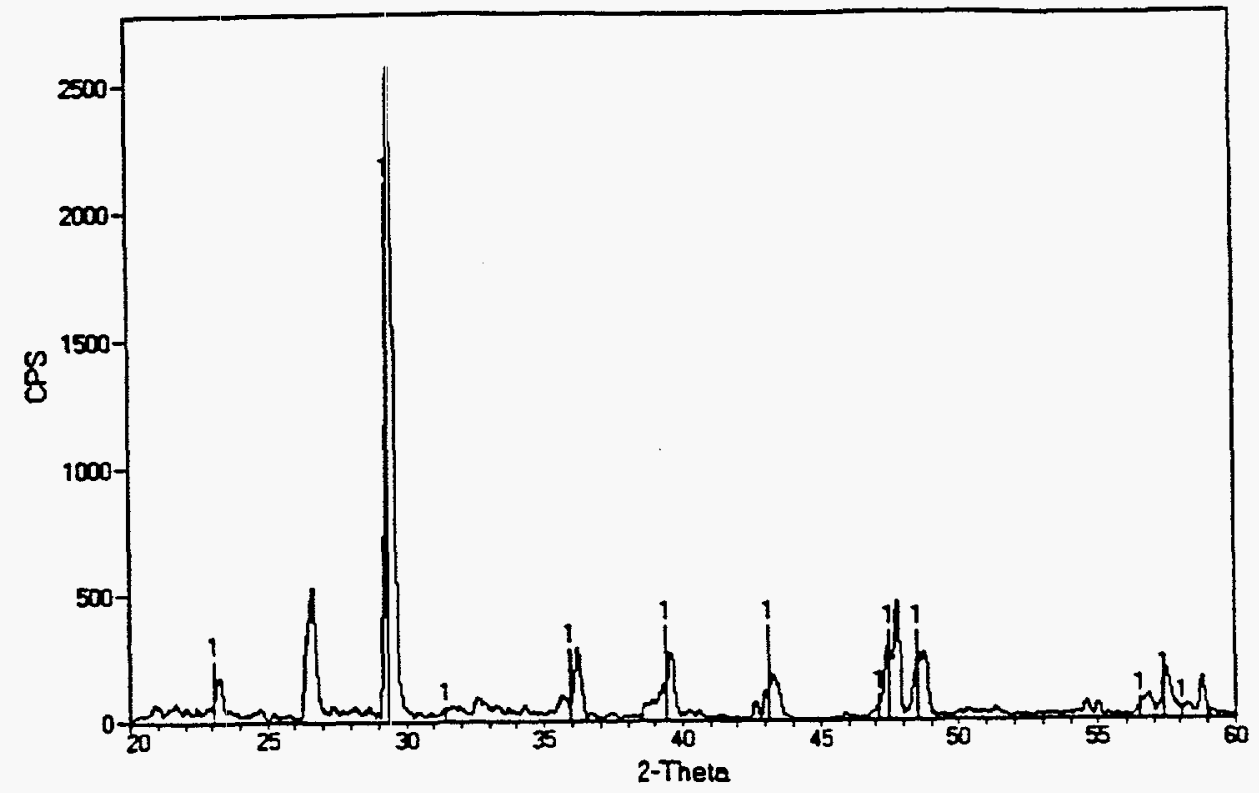

1) 05-0586: Cacie. sn + Cac033

Figure 1

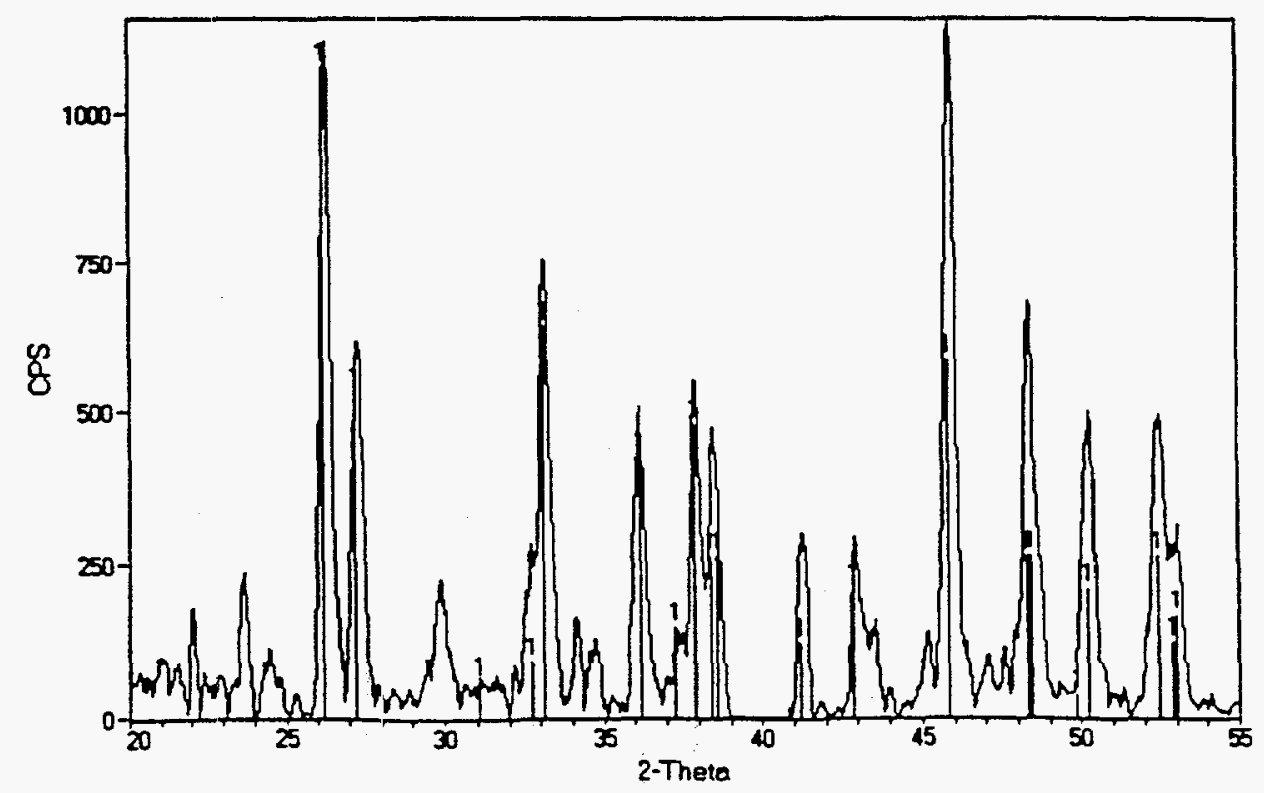

1) 41.1475: Aroponite - CACO3

Figure 2 


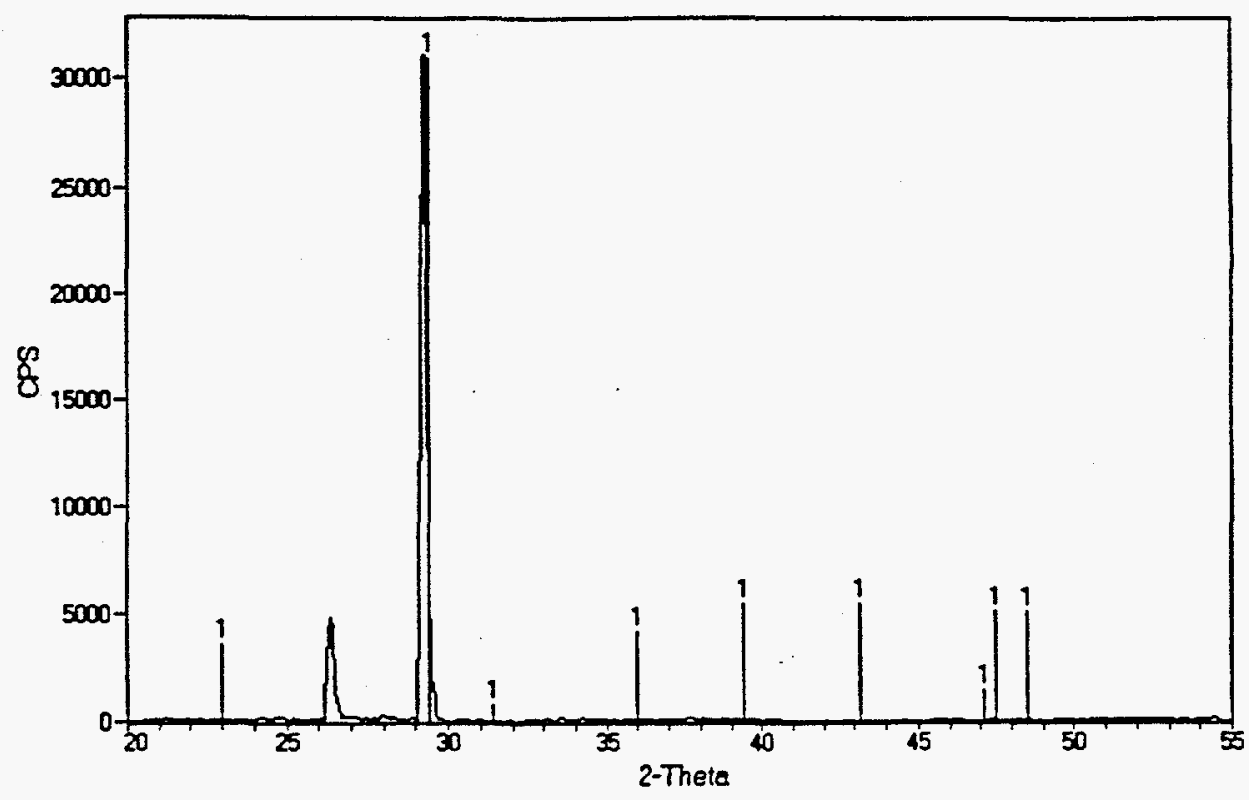

1) 05-0586: Calcite, syn

Figure 3

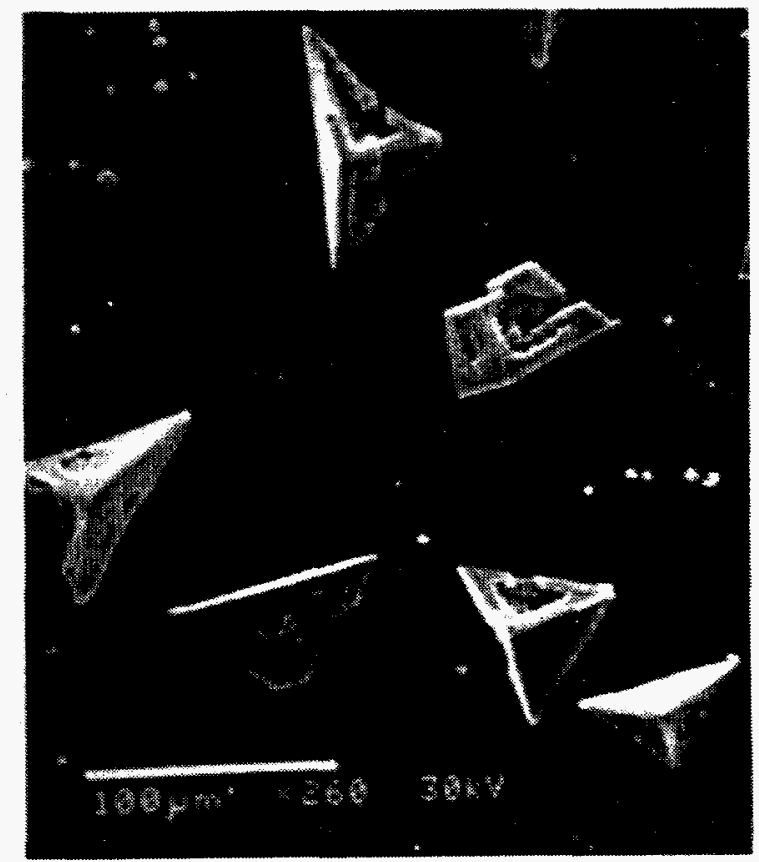

Figure 4 


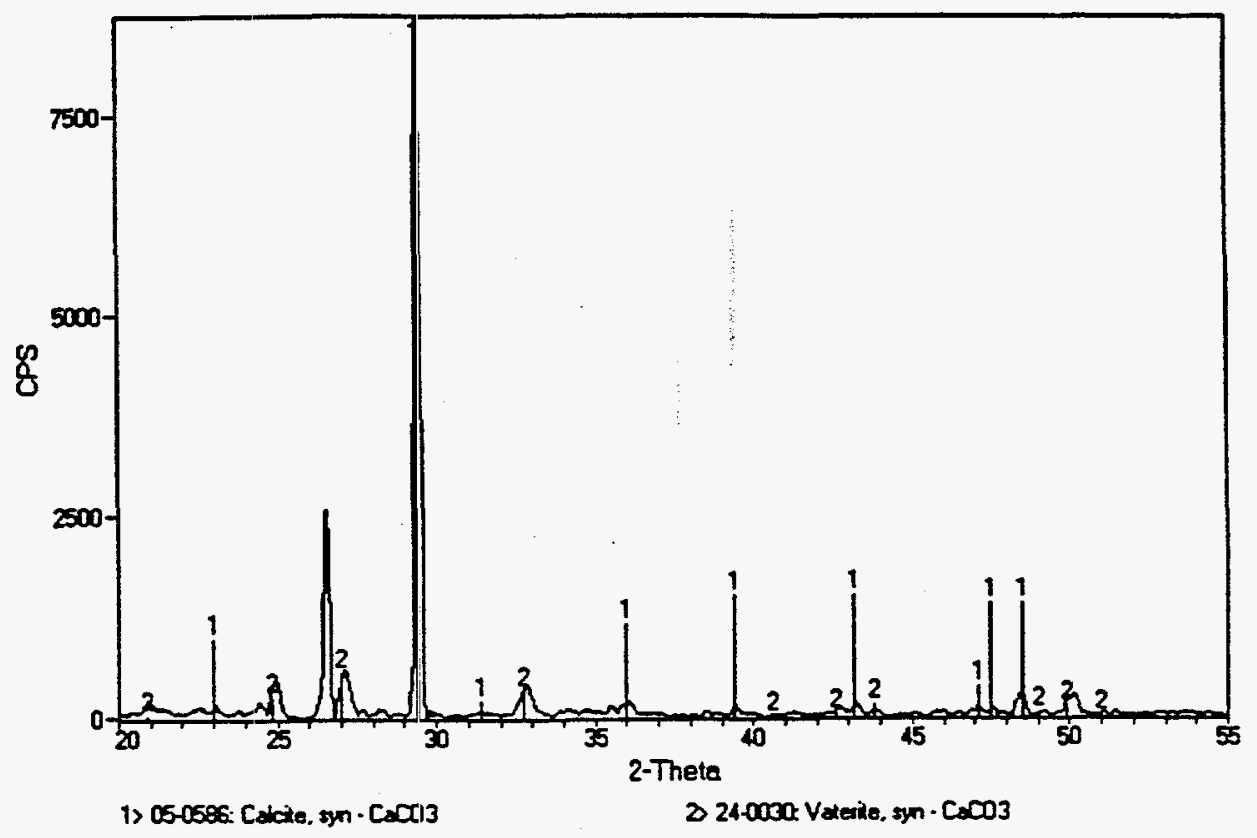

Figure 5

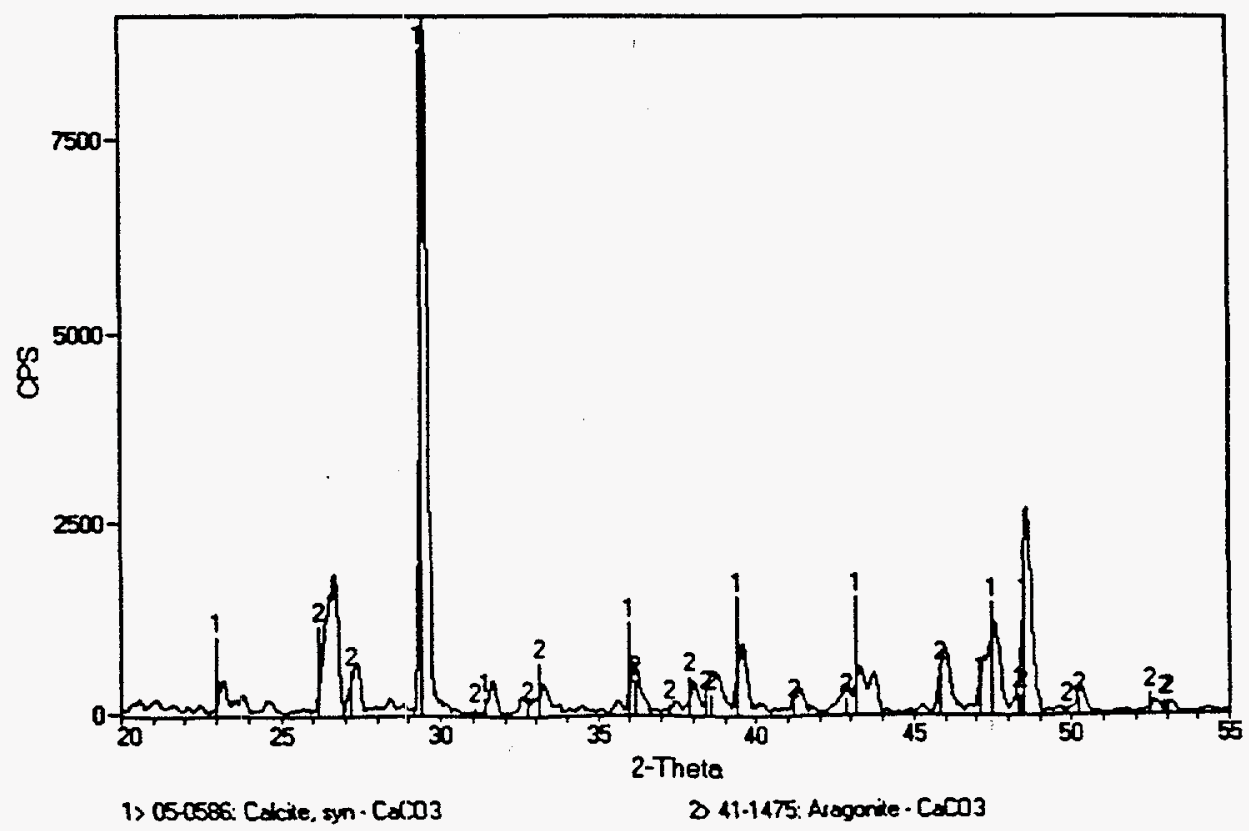

Figure 6 


\section{DISTRIBUTION:}

5 MS-1349 J. Cesarano

1 MS-0710 J. Shelnutt

1 MS-0333 A. Hurd

2 Gillian Bond

Materials and Metallurgical Engineering

New Mexico Tech

Socorro, NM 87801

$2 \quad$ Lev Feigin

Institute of Crystallography

Russian Academy of Sciences

Leninsky Prospekt, 59

117333 Moscow

Russia

1 MS- 9018 Central Technical Files, 8940-2

5 MS-0899 Technical Library, 4916

2 MS-0619 Review \& Approval Desk, 12690

For DOE/OSTI

1 MS-0161 Patent and Licensing Office, 11500 